\title{
Creative Resistance Tactics in the Work of English-Canadian Screenwriters
}

\author{
McArthur, Kerry
}

McArthur, K. (2017). Creative Resistance Tactics in the Work of English-Canadian

Screenwriters (Unpublished doctoral thesis). University of Calgary, Calgary, AB. doi:10.11575/PRISM/25484

http://hdl.handle.net/11023/3982

Downloaded from PRISM Repository, University of Calgary 


\title{
UNIVERSITY OF CALGARY
}

\author{
Creative Resistance Tactics in the Work \\ of English-Canadian Screenwriters
}

by

Kerry McArthur

\begin{abstract}
A THESIS
SUBMITTED TO THE FACULTY OF GRADUATE STUDIES

IN PARTIAL FULFILMENT OF THE REQUIREMENTS FOR THE DEGREE OF DOCTOR OF PHILOSOPHY
\end{abstract}

GRADUATE PROGRAM IN COMMUNICATION, MEDIA AND FILM

CALGARY, ALBERTA

JULY, 2017

C) Kerry McArthur 2017 


\begin{abstract}
This dissertation analyzes how eight successful English-Canadian screenwriters negotiate various systems of filmmaking practice, in particular the criteria for screenwriting structure, character development and closure as imposed by Hollywood normative practice, Canadian film producers and national funding organizations. The writers discuss their tactics for conciliating the interests of funders and producers while honouring their own interpretations of what they consider essential narrative elements in screenplay projects. Analysis of interview transcripts reveals that many of these writers take their inspiration from works of literature and theatre as much as from influential films; further textual analysis of films written by these same screenwriters shows that not one follows the exact dictates of classical Hollywood narrative, although all deploy various elements and permutations of the form for their own purposes.
\end{abstract}

As per French sociologist Michel de Certeau's position that society's powerless both consciously and unconsciously adopt stealth tactics to make their way in the world, these screenwriters reveal the many ways they resist overt control of their writing, alternately by neglecting/ignoring rewriting strictures (provided through reader's reports and/or producer's notes), by instinctively taking up anomalous narrative structures provided by alternate genres, and/or by adopting new roles in the process via which they may better exert control over the filmmaking project.

Finally, while many of the interviewees reveal a working knowledge of Canadian cinema and related national identity questions, few seem to consider it a relevant issue in their own work as screenwriters. The focus for most English-Canadian professionals instead is upon telling their own versions of contract story ideas in original ways, rather than devising a national 'voice' to communicate a cultural identity. 


\section{Acknowledgements}

This project began 27 years ago, when I was introduced to the art of screenwriting at the Television and Film Institute (TFI) for Screenwriting of Edmonton, where Scott McPherson provided instruction on the crafting of the classical Hollywood screen narrative. In the early 1990s, I met Los-Angeles-based James Schmerer and Jack B. Sowards, who patiently coached me in the rewriting of a screenplay. Days spent with Jack and Jim under the lemon trees of North Hollywood taught me the Socratic Screenwriting Dialogue - an exchange invaluable for its practical erudition, its expletives and its belly laughs.

I owe an enormous debt of gratitude to my instructors at the University of Calgary: Professor Doug Brent, whose professionalism and erudition cannot be matched; Professor David Mitchell, who can ferret out irony in even the most austere theory; Professor Barbara Schneider, who clarified once and for all the great advantages of qualitative methodologies; and to Professor George Melnyk, whose encyclopedic knowledge of Canadian cinema is simply beyond compare.

My greater debt however is to Professors Melnyk and William Beard as this project's co-supervisors. I shared many memorable discussions, lunches, coffees and latenight telephone conversations with these two wonderful scholars. I am profoundly grateful to them both.

This project would not exist without the co-operation of eight brilliant EnglishCanadian screenwriters, who cannot be named but whose contributions comprise the core of this project.

And of course I wish to thank my family: Megan, who offered insightful literary observations throughout my progress; Kathryn, who shared with me the transformative experience of intellectual thought; and Miranda, whose preternatural understanding of education and family lifted me through some dark times. Finally, there's Mark, who walked me through every step of the project with enthusiasm, insight and understanding, and whose intellectual generosity still astonishes me. 
To my father and stepmother, who provided the essential support to complete this project;

To my mother, who saw me off on this journey with delight and tears,

But would not see me finish it;

To my daughters, who heard me out at every stage;

To my husband, who stood by me and taught me the argot of scholarship --

To him I owe everything. 


\section{Table of Contents}

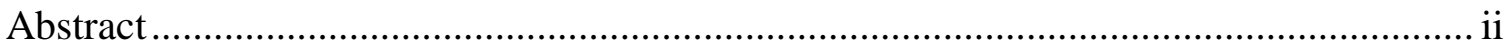

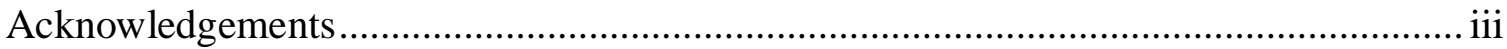

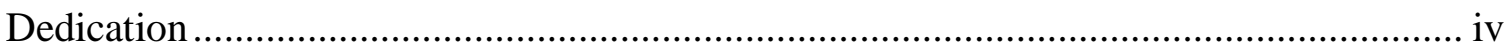

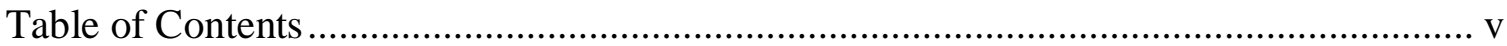

List of Figures and Illustrations ............................................................................. viii

Chapter 1: The Construction of the Screenwriter .............................................................. 1

1.1 The Construction of the Screenwriter ............................................................ 1

Chapter 2: Review of Literatures in the Screenwriting Field..................................... 12

2.1 Review of Literatures in the Screenwriting Field ............................................ 12

2.2 Prescriptive Literature: Best-selling Screenwriting Textbooks ......................... 13

2.3 Prescriptive Literature: The Character Arc ....................................................... 20

2.4 Prescriptive Literature: After Field and McKee............................................... 24

2.5 Philosophical and Literary Precedents in Screenwriting ................................. 26

2.6 Revelatory Literature: Insider Notes on Filmmaking Inequities........................ 30

2.7 Scholarly Literature: Current Pedagogies of Screenwriting ............................... 37

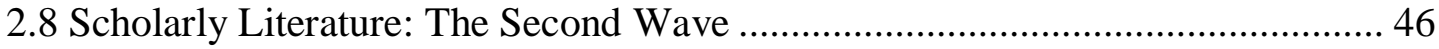

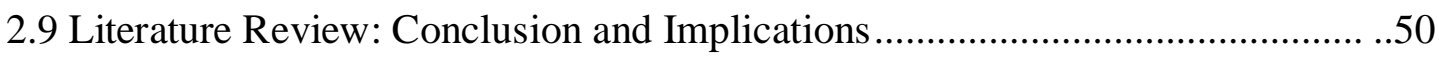

Chapter 3: Methodology: Textual Analysis and the Interview .................................. 54

3.1 Methodology: Textual Analysis and the Interview …...................................... 54

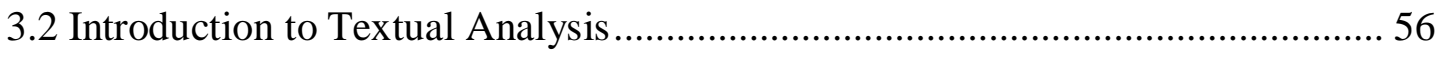

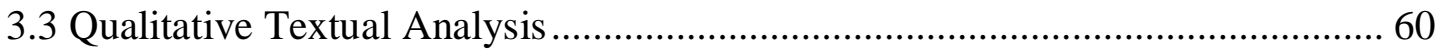

3.4 The Interview and its Evolution in Social Sciences Research ........................... 61

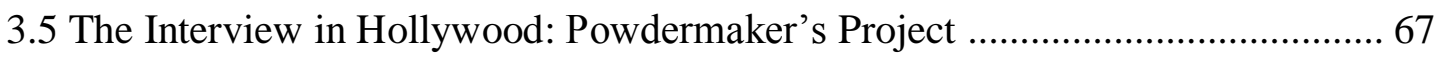

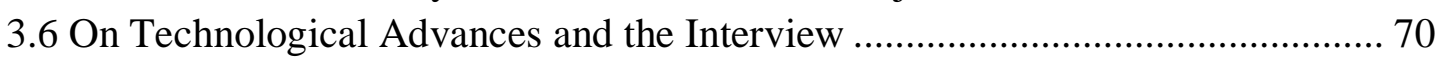

3.7 Interview Research Methods for this Project ................................................... 71

Chapter 4: Theory Influences: Luhmann and Certeau....................................... 76

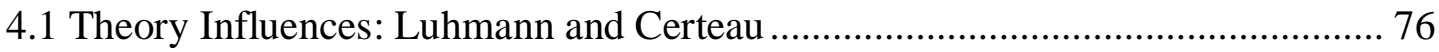

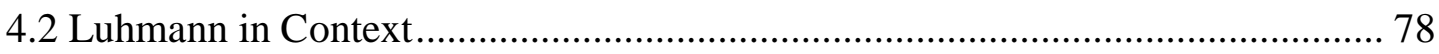

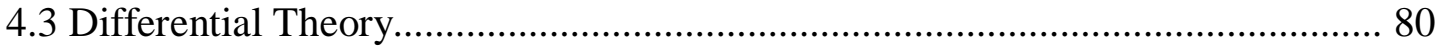

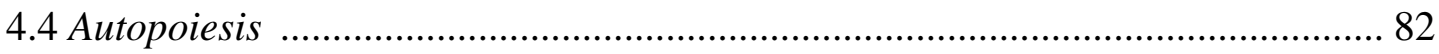

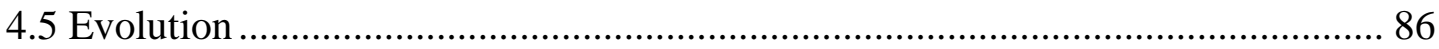

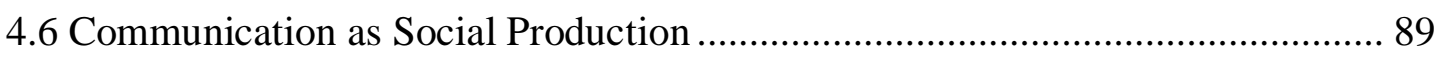

4.7 Michel de Certeau: An Introduction .............................................................. 91 


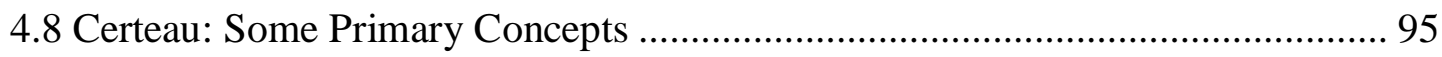

4.9 Anti-Discipline and Certeau's Contemporaries .................................................... 99

Chapter 5: Identity and Film Policy in English-Canadian Screenwriting ............... 105

5.1 Identity and Film Policy in English-Canadian Screenwriting............................ 105

5.2 National Identity and English-Canadian Film Policy ........................................ 106

5.3 Canadian National Thematics in Literary Studies .............................................. 109

5.4 Overview of English-Canadian Cinema and Cinematic Narratives.................... 113

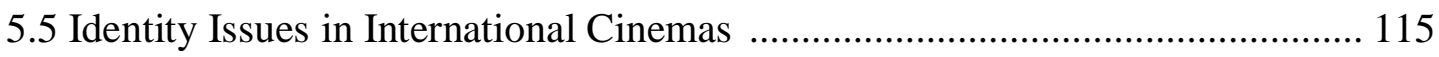

5.6 Polarization in English-Canadian Film Theory............................................... 120

5.7 Overview of Canadian Film Policy, 1998-2005 ................................................ 123

5.8 Review of From Script to Screen Initiative, 2005 .......................................... 126

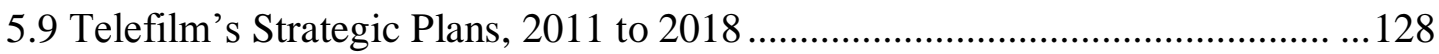

5.10 Canadian Film Policy as Identity/Canadian Identity as Film Policy ............... 135

Chapter 6: Analysis of Representative Screenplays ........................................................ 139

6.1 Analysis of Representative Screenplays …………………………………........ 139

6.2 Film A: Melodrama With Dual Protagonists ………………………………..... 140

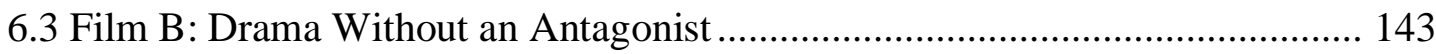

6.4 Film C: Romantic Comedy Without a Character Arc ……………………...... 148

6.5 Film D: Melodrama With "Inner Conflict"........................................................ 151

6.6 Film E: Ensemble Drama With Thematic Focus .............................................. 155

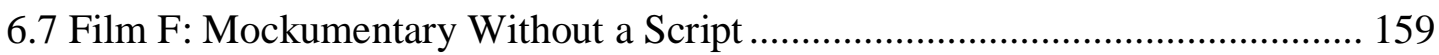

6.8 Film G: Romantic Comedy With Anomalous Structure.................................... 162

6.9 Film H: Road Movie With Surprise Ending ................................................... 165

Chapter 7: Analysis of Research Data .................................................................................... 171

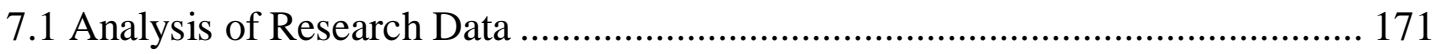

7.2 Forms of Screenwriting Education............................................................... 174

7.3 Rating the Work of Screenwriting Gurus......................................................... 179

7.4 The "Rules" Of The Game: Structure in Screenwriting ……………................. 186

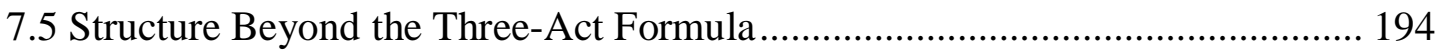

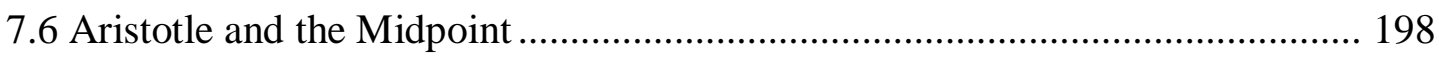

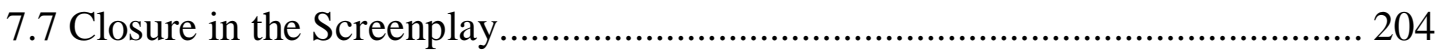

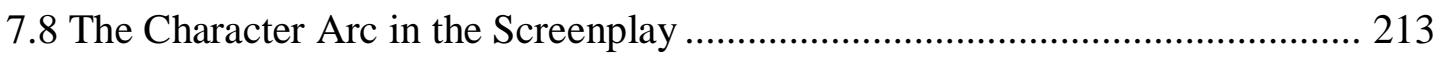

7.9 On the Reader's Report in the Funding Process ............................................... 221

7.9.1 Summation: On Power and the Screenwriting Process in Canada.................. 230 
Chapter 8: Concluding Observations and Implications of the Study

8.1 Concluding Observations and Implications of the Study................................ 240

8.2 Review of Methodological and Theoretical Approaches ................................. 242

8.3 Findings on Screenwriting Practice for English-Canadian Screenwriters ......... 244

8.4 Findings and Implications for Policymakers................................................. 249

8.4 Critical Observations of Funding Criteria and Practice ................................... 251

8.5 Findings and Implications for Post-Secondary Education in Screenwriting ..... 255

8.6 Considerations for Further Research in English-Canadian Screenwriting ........ 258

8.7 Limitations of the Project......................................................................... 262

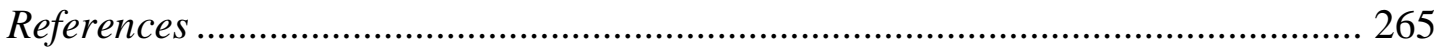

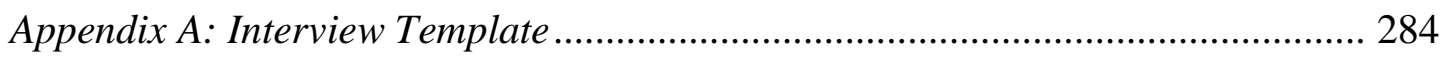




\section{List of Figures and Illustrations}

Figure 2.1: Field's screenplay paradigm, described in Screenplay, 2005; p. 200......17

Figure 7.1: Field's screenplay paradigm, described in Screenplay, 2005; p. 200.....201

Figure 7.2: Freytag's 'pyramid' paradigm, described in Die Technik des Dramas (1863, The Technique of the Drama, trans. 1900); p. 115.........................202 


\section{Chapter 1: The Construction of the Screenwriter}

\subsection{The Construction of the Screenwriter}

English-Canadian screenwriters face various professional challenges over the course of their careers. One complaint common of the North American industry is that while they may create scripts for multi-million-dollar projects, screenwriters have little power or influence within the filmmaking world (Froug, 1972; Lucey, 1996; Macdonald, 2010; Maras, 2011; Miyamoto, 2015). Contemporary screenwriter Max Landis speaks for many of his fellow writers when he notes that a filmmaking system "driven by metrics and development" has no regard for the guiding genius of the writer: "As a screenwriter, you are at the bottom of the totem pole, with no control over anything, and yet you are the one blamed in the reviews" (Fleming, 2016).

Although the industry includes the screenwriter in the project's "above the line" (aka creative development) team, the writer is primarily a contract worker assigned to deliver first drafts and rewrites of a screenplay with direction from the team's producer (the film project's chief business co-ordinator and the screenwriter's employer) and its director (the

film's visual creator). Within the trio, the director and producer are considered the most important elements in ensuring the film's success. Canadian feature producer Peter O'Brian explains:

The screenwriter has a seat at the table with the director and the producer, but usually as the lesser of equals. The reason for this is that theatrical films are capitalized at huge cost. The producer and the director must bring the product into being and deliver it to commercial interests. They are empowered and obligated to do so. (O'Brian, 1996, p. 198) 
A related concern of most screenwriters is that while they typically strive to write original work with compelling characters and plots, they are required by industry expectations and their own creative teams to write to formulaic standards. These formulae have been in place at least since the so-called Golden Age of Hollywood (approximately 1920 to 1960), but were codified as late as 1972 by the American screenwriting instructor Syd Field in Screenplay: The Foundations of Screenwriting. An iteration produced in 1997 by another screenwriting guru, Robert McKee, further cemented the structural and motivational tenets of feature film screenplays in Story: Substance, Structure, Style and the Principles of Screenwriting. These two works were soon accompanied by a flood of other how-to textbooks (i.e., Michael Hauge's Writing Screenplays That Sell (1988); Viki King's How to Write a Movie in 21 Days (1988); Wells Root's Writing the Script (1979); William Miller's Screenwriting for Narrative Film and Television (1980); Dwight Swain's Film Scriptwriting: A Practical Manual (1988); and many others).

One cannot overstate the influence these books had upon the North American filmmaking community. Although each text presented a version of the model in a slightly different manner, the basic model for the manuals was the same: viz., "a story built around an active protagonist who struggles against primarily external forces of antagonism to pursue his or her desire, through continuous time, within a consistent and causally connected fictional reality, to a closed ending of absolute, irreversible change" (McKee, 1997, p. 45). This tabulated version of Joseph Campbell's Hero's Journey eventually became the standard against which all scripts in development were measured, both in Hollywood and many other English-speaking countries. Film scholar Steven Maras notes that while "writing by recipe" is an everyday complaint amongst above-the-line teams, "these conventions are at the same time held to embody time-honoured dramatic principles 
that are often restated to justify the format- or template-driven nature of the work" (Maras, 2009, p. 66).

Until recently, the subject of screenwriting has received little scholarly attention. One of the earliest studies of screenwriting was included in the American anthropologist Hortense Powdermaker's Hollywood: The Dream Factory (1951); this ethnography personifies the average screenwriter as a well-paid but disgruntled contractor whose true life goal is to write novels or plays. Then in the early ' 70 s, the American screenwriting professor and social activist William Froug began a series of texts ${ }^{1}$ featuring interviews with celebrated screenwriters such as I.A.L. Diamond (The Apartment), Nunnally Johnson (Grapes of Wrath), Buck Henry (The Graduate), Walter B. Newman (Great Escape), amongst others. These non-academic books reveal screenwriters' idiosyncratic approaches to their writing, many of them dismissing formulaic strategies and advocating for greater knowledge of film and theatre narratives. In 2009, Australian film scholar Steven Maras examined American screenwriting practice from the perspective of screenwriting manuals from the 1910s and '20s in his Screenwriting: History, Theory and Practice; a year later, British scholar Steven Price published The Screenplay: Authorship, Theory and Criticism, which scrutinizes individual screenplays to devise a theoretical approach to the form. Finally, the Journal of Screenwriting, launched in 2010, is a forum for scholarship on the subject, examining the history of the form, the relationship of production and the script, and the cultural significance of the screenplay.

The topic of screenwriting in English-speaking Canada receives even less consideration. With the exception of a number of scholarly articles in the Journal of Screenwriting and brief mentions of screenplays (and their writers) in monographs on individual directors, the English-Canadian screenplay as a written form is rarely studied. 
This paucity of scholarship contributes to the general sense in this country that our cinematic narratives have in some general way failed to meet industry standards, in particular those posed by our neighbours to the south. This is not to say, of course, that Canadian film scholarship does not have its practitioners: the film scholars and historians George Melnyk and William Beard ${ }^{2}$ are just two of the writers whose works have added immensely to our store of knowledge on English-Canadian cinema, its history and its directors. However, these scholars normally examine the work of auteur directors, who write their own screenplays, rather than screenwriters, who do not direct. This study deals with the latter.

Given the idiosyncratic nature of English-Canadian film narratives, especially those in the canon, it is surprising this form of writing draws so little focused scrutiny. For example, the episodic natures of François Girard/Don McKellar screenplays for Thirty-Two Short Films about Glenn Gould (1993) and their The Red Violin (1998), the nested stories of Guy Maddin/Evan Johnson's The Forbidden Room (2015), the ten networked narratives of Jeremy Podeswa's The Five Senses (1999), the unusual four-act structure of the M. Charles Cohen/Don Haldane script for Drylanders (1962), the ironic undermining of the heroine in Sandy Wilson's My American Cousin (1985), and the picaresque qualities of Donald Shebib/William Fruet's Goin' Down the Road (1970) pose not simply anomalous story structures, but unique narrative goals that share little in common with the hero's-journey approach favoured by Hollywood. Indeed, these stories are so universally distinctive, they suggest their writers have purposely taken an alternate approach to screenplay writing.

This speculation and associated observations around screenwriting in English Canada thus led me to ask a two-fold question about the nature of the discipline, namely: 
How do English-Canadian screenplay narratives differ from

American screenplay stories? and

How do English-Canadian screenwriters distinguish their scripts

from their American counterparts as part of the exercise to

define an English-Canadian national identity?

To help address these questions, I interviewed eight English-Canadian screenwriters who are successful practitioners of the form: the hour-long telephone interviews with each of these anonymous sources posed questions to discover how these writers perceive the classical Hollywood narrative. Although the goal of the project was to detect how they distinguish their work from American paradigms, there was no direct probing of this angle: the writers were simply invited to speak about the influence of the normative form and how they perceive it.

Over the course of the interviews, the focus of the project began to change, largely because most writers did not offer observations about the differences between American and Canadian writing. Instead of discussing nationalist or regionalist aspects of screenwriting, these English-Canadian practitioners for the most part cited their positive writing predecessors as international literary and theatrical works, rather than screenplays of any particular genre or country. Instead of distinguishing their work as discrete from the goals of Hollywood narrative forms, they expressed their desire to write in original and meaningful ways - that is, to write from an instinctive space where their own carefully curated influences provide them with inspiration. Because the direction of the project began to pull so strongly in this new direction, the research questions evolved to explore the writers' personal goals and artistic learnings, with emphasis upon narrative control and influence in the development and funding process: 


\section{How do English-Canadian screenwriters defy normative}

narrative models as they write? and

How do they retain artistic integrity and control over the work as their screenplays' progress through the development process?

The dissertation comprises eight chapters, including this introductory section. Chapter 2 is a literature review that surveys both scholarly and practitioner writing from the late 1970s to current day. I have categorized this body of literature into three sections: the prescriptive (generally written to proselytize the Hollywood model of the screenplay); the revelatory (comprising interviews with screenwriters in which practitioners are invited to speak about and explain motivations, writing techniques, etc. behind their work); and the scholarly (in which film and writing academics explore a variety of approaches to screenwriting matters). Normative expectations of the screenplay, including structural paradigms (in this case, the three-act screenplay structure) and attendant requirements for the successful execution of the character arc, internal story logic and story closure are discussed. The revelatory text section indicates that Hollywood screenwriters are well apprised of normative screenwriting expectations (as per prescriptive texts), but that most dismiss it as aimed at beginner screenwriters. The chapter reviews major works by late$20^{\text {th }}$-century German, Australian and British academics who sparked a strong wave of scholarly writing on the topic in recent decades. Much of the writing in the revelatory and scholarly categories focuses upon practitioner/scholar rejection of normative screenplay models and celebrates collaborative strategies that supersede normative models.

Chapter 3 examines the dissertation's qualitative methodology, which incorporates interviews and textual analysis as its two primary methodological tools. While briefly discussing the quantitative researcher's bias for reliability, validity and generalizability, the dissertation opts for the qualitative approach, which emphasizes truth value, applicability, 
consistency and neutrality. Further, the project actively regards the research interview as a socially constructed document: viz., understanding that any form of qualitative data occurs within certain socially prescribed arenas, with the relationship between interviewer and interviewee a major factor in the outcome of research-based knowledge. The scholarship of anthropologist Hortense Powdermaker and sociologists Clive Seale and Aaron Cicourel completes this chapter with additional discussions of power and influence in the interview process.

Chapter 4 comprises the dissertation's theory section, integrating the resistance theory of Michel de Certeau with the systems theory of Niklas Luhmann. Although the two bodies of thought may appear antithetical, I suggest Luhmann's approach is simply the first step in a full description of the field of English-Canadian cinema: while critically disengaged, his theory is nonetheless essential in outlining the various bureaucracies engaged in Canadian film policy. Luhmann's explanation of the autopoietic nature of these structures -- that is, the ability of English-Canadian film systems to reproduce themselves in a self-contained manner -- is of interest here, as is his sub-theory of difference, which aims to clarify how distinctions define and support the self-reproduction of specific systems. Certeau's contribution by comparison examines how subaltern citizens negotiate rigid structures to their own ends, appropriating what they value and ignoring (or unconscious of) dominant powers as they proceed. The French theorist interprets the powerful and the powerless as strategists and tacticians accordingly: the former assumes the role of property-owner whose role is to defend that property, while the tactician is a freelancer who lacks a secure stronghold and must gather what she/he can in transit. These theory sets are later deployed to interpret the relationship of English-Canadian screenwriters to both their creative teams and to the funding agencies that support their projects. 
The dissertation's policy section, Chapter 5, examines the political economy of English-Canada's film policy, specifically its subordinate role to the Hollywood film industry. The works of Ted Magder, Manjunath Pendakur and Michael Dorland introduce us to English-Canada's historic approach to feature film production. Policy documents in this chapter outline Canada's feature film policy documents and various scholarly studies of the industry since it was introduced in the early 20th century. The chapter concludes with a review of Canadian Heritage and Telefilm Canada policy changes over the past 20 years.

Chapter 6 contains a textual analysis of eight original English-Canadian feature film narratives by each of the writers interviewed for the dissertation. The task was to examine these anonymous texts against the classical Hollywood screenplay with its three-act structure, absolute closure, character arc and contiguous internal logic. In each case, the Canadian screen narratives prove themselves anomalous in at least one major writing approach: i.e., some texts avoid complete and satisfying endings, several others work against form by shaping their stories in four- or ten-act structures, while still others complicate the usual 'hero's journey' by incorporating multiple primary protagonists or denying the protagonist's character arc, etc.

In Chapter 7, I conduct a review and analysis of the data produced by the interviews with these eight screenwriters. Here, the focus is upon summarizing and analyzing answers to questions about how these writers use/perceive the three-act structure, the notion of the character arc, the importance of closure in the screenplay, as well as the function of the reader's report and producer notes in shaping the screenplay. Summaries of the interviews reveal few strong commonalities between the writers, although the quest to discover fresh ways of writing the screenplay and to glean original insights into the screenwriting process is universally valued. A general plea for greater/better education for those holding policy or funding organization positions completes the section. 
Chapter 8 contains a review of the primary findings of the research and makes a number of critical observations of both screenwriting policy in English Canada and of related education practices.

The reader of this dissertation needs to be reminded that interviewee anonymity is a requirement of the University of Calgary's Conjoint Faculties Research Ethics Board and of any conscientious researcher committed to protecting her/his sources' identity. This requirement becomes critical when the sources' community is small and there is an accompanying danger of deductive disclosure (also known as internal confidentiality). Participants in the research had to be assured they could not be identified by fellow industry professionals or by funding organization executives, as the general belief in industry is that even the mildest criticism of funding bodies like Telefilm Canada may jeopardize a filmmaker's chance for financial support. For this reason, the project took care to disguise interviewees by withholding information on their current working locations, the cities in which they were educated, as well as the identities of production companies, fellow filmmakers or earlier films on which they may have worked. As per ethics requirements, sources chose their own pseudonyms. In the case of this paper, the only factual information communicated about each interviewee was her/his gender and her/his age.

While anonymity is obviously of paramount importance, it also means reading this dissertation may be a challenge, particularly the chapters on analysis of scripts and research data, as visualizing the films discussed may be difficult. Readers dealing with this added layer of abstraction should be assured that it is not meant to complicate the project's findings but to ensure its anonymous screenwriters and filmmakers remain anonymous.

It is important to recognize that in any creative system in which money changes hands, there will be those who work to uphold that system and those who work to revise it. The 
strategists and tacticians of Michel de Certeau's universe are both represented in this dissertation, although the former are conspicuous by their (relative) absence: future research in English-Canadian feature film policy would do well to thoroughly explore the policy-maker's complex environment. My intention here was not to weigh both factors of our film system equally, but to better understand how successful English-Canadian screenwriters find their way through normative systems and writing structures to help create distinctive and memorable films. In the following chapters, I examine their tactics and offer their insights as a window into the screenwriter's unique writing process. 


\section{Notes}

1. The first of these was The Screenwriter Looks at the Screenwriter (1972), followed by The New Screenwriter looks at the New Screenwriter (1992), Zen and the Art of Screenwriting: Insights \& Interviews (1996). Froug published a number of other texts on screenwriting, including Screenwriting Tricks of the Trade (1992) and his autobiography, How I Escaped from Gilligan's Island... and Other Misadventures of a Hollywood Writer-Producer (2005).

2. That these two academics are also this project's co-supervisors will not escape the careful reader's attention. 


\section{Chapter 2: Review of Literatures in the Screenwriting Field}

\subsection{Review of Literatures in the Screenwriting Field}

Literature supporting the subject of cinematic screenwriting generally falls into three categories: the prescriptive, the revelatory and the scholarly. ${ }^{1}$ Of these categories, the first is the most populated: its ranks include the many hundreds of screenwriting manuals published since American script advisor Syd Field published his influential Screenplay: The Foundations of Screenwriting in 1979. Prescriptive textbooks are almost always written according to American film industry norms, and virtually all elevate this Hollywood screenplay operating within recognized film genres as most successful in obtaining audiences. The revelatory category represents a curious set of volumes, not inconsiderable in its own right: these texts comprise a series of directly transcribed interviews with screenwriters, in which these individuals are invited to speak directly about their writing and their scripts, and to comment upon working conditions affecting them. Finally, scholarly literature addressing screenwriting arises from an emerging scholarly community: to date, its proponents are few in number, but its ranks are growing. These volumes are generally published by film academics specializing in narrative studies; foci may range from a purely illuminative approach (in which the writer describes current screenwriting practices in Hollywood and/or in national cinemas) to a more analytical address (in which the writer scrutinizes the underlying systems controlling screenwriting direction and output).

Examining screenwriting texts within these categories allows the observer to more readily map historic currents in filmmaking pedagogy and to trace North American abovethe-line film policy and industry developments decade over decade. While writers in at least two of these categories insist that screenwriting follows universal and timeless fictive 
laws, evidence suggests this notion has lost currency during the early 21 st century; changing models of distribution and viewership have made significant inroads into an increasing diversity of screen-based narrative forms, although these have not yet been thoroughly analyzed and identified.

\subsection{Prescriptive Literature: Best-Selling Screenwriting Textbooks}

Screenwriting manuals serve a uniquely utilitarian purpose for those aspiring to write not the 20th-century Great American Novel but the 21st-century's Great American Screenplay: in short, these texts contain clear instruction on the most efficient way to create a successful and profitable movie scenario. While the era of the highly publicized screenplay appears to have peaked in the mid '90s with Hollywood writer Shane Black's record-breaking The Long Kiss Goodnight (purchased for $\$ 4 \mathrm{M}$ ), screenwriting pedagogy continues to attract hopeful writers, spawning new flights of prescriptive bestsellers: i.e., David Trottier's The Screenwriter's Bible: A Complete Guide to Writing, Formatting, and Selling Your Script (2010); John Truby's The Anatomy of Story: 22 Steps to Becoming a Master Storyteller (2007); and Joseph McBride's Writing in Pictures: Screenwriting Made (Mostly) Painless (2012), amongst others. ${ }^{2}$ This new generation of manuals continues to support the dreams of many otherwise untutored screenwriters in the English-speaking world.

While the stream of screenwriting texts emerging from North American publishers has stemmed somewhat in recent years, the aggregate number of how-to manuals available to acolytes is nonetheless extraordinary. Some of these works were written to accompany their authors on screenwriting workshops; of these, script expert Robert McKee's Story:

Substance, Structure, Style and the Principles of Screenwriting (1999) and Syd Field's 
Screenplay: The Foundations of Screenwriting (1982) are by far the best known. A number of other texts appeal to fledgling writers who have completed a first draft of a screenplay and are contemplating a re-write (i.e., Linda Seger's Making a Good Script Great (2010)), while others specialize in helping the writer prepare to market the screenplay (Field's Selling a Screenplay: The Screenwriter's Guide to Hollywood (1989); Cynthia Witcomb's Selling Your Screenplay (1988); Carl Sautter's How to Sell Your Screenplay: The Real Rules of Film and Television (1992), amongst others). Written from the late 1970s to the late 1990s by a variety of experts (some of whom, like McKee, teach within the university system as well as on the lecture circuit, while others are independent of a post-secondary affiliation), the manuals discussed here have at least two functions in common: all emphasize the primacy in Hollywood film of the three-act structure, and all comment in some way upon the role of evolutionary change in accomplishing the screenplay's mandate. There are a considerable number of other commonalities between these books, many of which will be discussed directly.

Given his status as a screenplay manual pioneer (film scholar Steven Price calls him a "screenwriting guru" (Price, 2010, p. 33) and Steven Maras echoes Sue Castrique, who calls him a "script guru" (Maras, 2009, p. 10)), University of Southern California-based instructor Syd Field represents the usual entry point for those wishing to try their hand at screenwriting. Credited with the identification of the three-act screenplay structure and with the naming of its various parts and functions, this Hollywood-based instructor and his numerous manuals and workbooks are a recognized introduction to scenario writing in film production circles, although subsequent texts by other authors rarely mention or credit his work with the contribution (hardly a surprise, given the competitiveness of the how-to book publishing sector). Field introduces his most popular screenwriting manuals (Screenplay 
(1979), The Screenwriter's Workbook (1984) and Screenplay: The Foundations of

Screenwriting (2005)) with the notion of a universal dramatic construct containing a fixed tri-part structure - his patented screenplay paradigm. When scientists describe the atom, he writes, they build a model; when they receive satellite data, they build a planetary model (Field, 1984, p. 27). When writers create screenplays, they too use an archetype: "The paradigm is a model, an example, a conceptual scheme of what a screenplay looks like. It is a whole, comprising parts" (Field, 1984, p. 27). Further, the necessary relationship of the model to the final product can be compared to that of fire ("a fire and its heat" (Field, 1984, p. 139)) or ice: he describes the latter metaphor in his 2005 Screenplay: The Foundations of Screenwriting in phrasing and terminology similar to 1984's The Screenwriter's Workbook. Good structure in a script, he says, "is like an ice cube and water":

An ice cube has a definite crystalline structure, separate and different from water. But when an ice cube melts, it becomes indistinguishable from whence it came. It is the same, but different. It should be so integral to your story...you can't see it. (Field, 1984, p. 17)

Field similarly positions his story sections in both Screenplay and Screenplay: The Foundations of Screenwriting in Issac Newton's third law of motion, which he recommends as a general guideline for all writers. The law ...states that for every action, "there is an equal and opposite reaction." Which means, basically, that everything is related. ...In a screenplay, the same principle holds true: Everything is related. (Field, 2005, p. 106)

In essence, he locates the activity of screenplay writing within the province of immutable natural order. By this logic, screenplays resist technological and/or socially motivated 
forces: they are instead highly codified enduring structures rooted a priori in scientific law. We may recognize these notions of course as not natural law but simply metaphors for the writing process; for acolytes, however, if these laws provide guidance and solidity for a notoriously difficult writing exercise, then such figurative language is potentially useful. Like most modernists, Field conceives of structure as an enduring model with essentialist qualities (unlike post-modernist narrative theorists who would view his approach as replicating Hollywood's industrial practices.)

He continues the description of the screenplay paradigm, noting that it is expressed in three parts: "(A) beginning, middle and end. The beginning corresponds to Act I, the middle to Act II, and the end to Act III" (Field, 1984, p. 27). As vague as this passage may appear, it signals an industry attachment to the teachings of Aristotle, in particular his Poetics: indeed, British scholar Steven Price calls it one of screenwriting's "holiest books" (Price, 2010, viii). And while Field does not at this point in his text directly attribute his paradigm to Aristotle (he does so later, when he refers to "the three-act structure first laid down by Aristotle" (Field, 1984, p. 30), we may recognize the lineaments of this tri-part notion from The Poetics' discussion of plot in tragedy: "(A) whole is that which has beginning, middle and end" (Aristotle, 1920, I:7). Aristotle himself does not at this point elaborate beyond this description except to note:

A beginning is that which does not itself follow anything by causal necessity, but after which something naturally is or comes to be. An end, on the contrary, is that which itself naturally follows some other thing, either by necessity, or as a rule, but has nothing following it. A middle is that which follows something as some other thing follows it. (Aristotle, Poetics, 1:7) 
Field completes this section by delineating of the components of a plot's beginning, middle and end; further, each of these points is named and signposted so as to provide absolute clarity to the acolyte. He provides us first with a visual depiction of his model so we may better understand his conception of this "whole, comprising parts":

His next task is

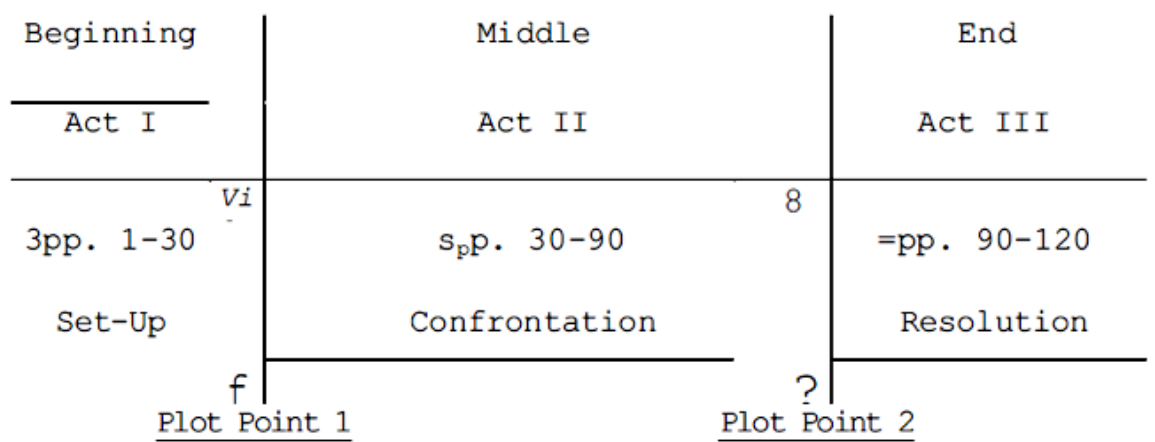

to describe the model's parts: the screenplay's beginning is its Act I, its middle, Act II, Figure 2.1: Field's screenplay paradigm, described in Screenplay, 2005; p. 200 and its end as Act

III. The first act works as the story's "set-up"; the second as its "confrontation" and the third as its "resolution" (Field, 1984, p. 27). Further, within each of the acts are one to two key story points, each with its own function: for example, in Act I, Plot Point arrives somewhere between pages 25 and 27.

A plot point is an incident, episode, or event that "hooks" into the action and spins it around in another direction, "direction" being a "line of development." (Field, 1984, p. 30)

Similarly, within Act II, Plot Point II must arrive at page 88 of the script; it too must spin the story into "another direction" (Field, 1984, p. 143) To support this point, Field refers to Hollywood films that best perform the plot-point spins: Body Heat (Kasdan, 1981) reveals Plot Point I when the two illicit lovers first come together, and Plot Point II when the protagonist learns an unknown individual is framing him for the murder of his lover's 
husband. In An Unmarried Woman (Mazursky, 1978), the first plot point arrives when the protagonist's husband reveals he is having an affair and wants a divorce, the second when she spends the night with a new lover. Plot points, says Field, are "geared by both the emotional and physical forces working on the character: the outside events affect the interior, emotional life of the character and move the script to its next level of action" (Field, 2005, p. 147). Finally, Act III does not contain a plot point but is in itself and over the course of 30 pages the resolution to the filmic plot. The key to writing Act III is not to "think too much about it, just do it":

If you try to figure out the "correct," the "right" ending, you'll never do it. Choose an ending that works, that fits your story. As you write it, you'll find out whether it's effective or not. (Field, 1984, p. 180) This lack of direction from an otherwise firm-handed instructor is curious. How is it that a film's final scenes -- typically the subject of film focus groups, usually to test a "sad" versus a "happy" ending -- should be left so entirely to the authority of the fledgling screenwriter? In his Screenwriter's Workbook, Field admits that current market prefers an "up" ending (p. 179), but defers ultimately to the Greek tragedy, which "enriches" the human condition:

In the eternal conflict between good and evil, does evil ever win?

Never. That's just the way it is. In the long run, good always triumphs over evil. (Field, 1984, p. 179)

Although Field's most significant draw upon Aristotle is borne out in his (Field's) structural paradigm, this is not the only reference to the ancient Greek's universal advice. He notes for example that Aristotle "talked about the three unities of dramatic action: time, place, and action" (Field, 1984, p. 22): without enquiring as to the significance of any of these three unities in Greek theatre, Field extrapolates the factors directly to contemporary 
feature film. His discussion of time, for example (which follows immediately after the quote directly above) poses the length of the Hollywood film as a constant, albeit one of that has developed over a series of decades:

The normal Hollywood film is approximately two hours long, or 120 minutes; foreign films tend to be a little shorter, though that's changing as we bridge the language of international film... Why?

Because it's an economic decision that has evolved over the years. (Field, 1984, p. 22)

Field notes here that films are two hours long because a) any longer, and they would be more expensive, and b) such a length is advantageous to theatre owners "simply because you can get in more viewings of the movie per day" (p. 22). The question of shorter films (viz., one hour to 1.5-hour-long features) is not addressed, nor is the evolution of film from its earliest beginnings as minute-long loops in Kinetoscopes at the turn of the last century, nor the 30- to 60-minute comic narratives emerging in the 1920s in the films of Buster Keaton and Charlie Chaplin, to name a few early film forms.

The constancy for Syd Field of physics and Greek theatre is thus less a scholarly precept than a series of prescriptive metaphors offered to novice writers struggling to grasp conventions of this writing genre, although as we have seen, even a small unpacking of these strategies will prompt queries from a careful reader. This appeal to tradition is a constant throughout Field's textbooks, but he is far from the only writer to invoke it. While it is no doubt true that this screenwriting expert makes such assertions because positivist pedagogical statements are supposedly easier for beginner writers to grasp and accept, it is also possible that such normative models may become irrelevant as filmmaking and its uses and gratifications evolve. 


\subsection{Prescriptive Literature: The Character Arc}

Screenplay manual writers comment not only upon the need for ordained structure in the script but the requirement in a successful screenplay for character arc: namely, transfiguration of the protagonist through external conflict (prompted by the scenario's antagonist(s)) and internal turmoil, resulting in permanent change to the protagonist's character. While Field is exacting in his explication of screenplay structure, he is less concerned with character arc, devoting only two pages to the subject in his Workbook. For example, in discussing Ordinary People (Redford, 1980), he suggests the film's main and supporting male characters (its son and father, respectively) evolve through crisis to better understand the death of a family member; the filmic family's mother figure is on the other hand incapable of change "and the family splinters apart":

In the last scene, father and son are sitting on the porch after the mother has left. Her leaving brings father and son closer together.

(Field, 1984, p. 59)

Twenty-one years later as Field rewrites Screenplay: The Foundations of Screenwriting, a new disinclination to emphasize character arc is evident. At this stage, Field considers character change a good-to-have but not a must-have: "Having a character change during the course of the screenplay is not a requirement if it doesn't suit your character. But transformation, change, seems to be an essential part of our character, especially at this time in our culture" (Field, 2005, p. 69).

Where Field is increasingly diffident on the subject of character change, Robert McKee is absolute: "The finest writing not only reveals true characters, but arcs or changes that inner natures, for better or worse, over the course of the telling" (McKee, 1997, p. 104). Described on the book jacket of his famous Story: Substance, Structure, Style and The 
Principles of Screenwriting as a $\mathrm{PhD}$ in cinema arts (not quite true: McKee did not complete his doctoral dissertation on narrative design, according to at least one biographer $^{3}$ ) and a former Fulbright scholar," McKee has gained considerable notoriety as a screenwriting expert, particularly since the release of the feature film Adaptation (Jonze, 2002), in which he was lampooned as a bombastic lecturer and theoretician of screenwriting practice. Although McKee does not spend an inordinate number of pages describing the filmic protagonist's character arc, he does choose to illustrate this section with a description of one of theatre's most renowned tragic heroes, Hamlet. By the end of the play, he notes, the young prince's choices "have profoundly changed the humanity of the character... He reaches a peaceful maturity as his lovely intelligence ripens into wisdom: 'The rest is silence'" (McKee, p. 105). Adamant that irreversible change is an essential element in describing the protagonist's character, McKee extends the analogy to The Verdict (Lumet, 1982), tracing how the film's alcoholic protagonist seeks personal salvation through a case for a wronged client: "With victory comes resurrection. The legal battle changes (Frank Galvin) into a sober, ethical and excellent attorney -- the kind of man he once was before he lost his will to love" (McKee, p. 104).

Further, while Field spends the majority of his screenwriting manuals illustrating his points on screenplay structure, McKee addresses the subject in one chapter on act design. However, where the former attempts to simplify his structural theory throughout his texts, explaining his ideas in short sentences and colloquial language, McKee moves into more complex explanations, adding three new subplots to the plot schemata of a typical screenplay and complicating it with his own identified design features. For example, where Field identifies plot elements as plot points, McKee names the first such point as the "inciting incident" and the second as the "mid-act climax" (McKee, p. 181 and p. 220); 
given that not just the plot but each subplot contains its own inciting incidents and midpoint climaxes, the organizational complexity of McKee's screenplay equation is neatly quadrupled against Syd Field's streamlined plot structure. Indeed, every section of McKee's text calls upon the author's knowledge of narrative structure: rather than reducing elements of story to simple cause-and-effect actions and reactions, he poses each against other narrative factors. In the second part of his text, for instance, McKee combines the idea of story structure with, consecutively, setting, character and meaning; each of these discussions produces central definitions that are engaged at other sections in the text (i.e.: "LEVEL OF CONFLICT is the story's position on the hierarchy of human struggles" (McKee, p. 69), or "A STORY must obey its own internal laws of probability" (p. 70)). The reader's impression in studying McKee's text is that screenwriting is a complicated but quantifiable exercise that can be guaranteed success if the writer will only apply these complex rules to his/her advantage.

A summary correlation of these two writers can be made at this point. First, while McKee espouses law-like narrative features that arise from his own observation of emotionally satisfying and economically successful films/scripts, Field grounds his screenwriting theory more loosely within the bounds of natural law, using scientific paradigms as metaphors for the writing process. Given their discrepant market approaches (Field's target audience appears to be the inexperienced, even uneducated novice while McKee's book reads more like a textbook addressing senior undergraduate writers), it may seem ironic that Field encourages greater interpretation of his recommendations by the fledgling writer, trusting the novice's instincts more fully and allowing for interpretation and extrapolation from the writer's experiences. Indeed, Field is entirely more holistic in 
his approach, insisting only upon adherence to his Aristotelean three-act structure, whereas McKee requires considerably more adherence to his complex principles of screenwriting.

Second, neither writer extensively addresses the issue of the diversity of film genre as a potential structural or character factor in contemporary screenplays. In fact, both Field and McKee deal almost exclusively with the prestige drama, viz., high-production-value scenarios addressing serious, contemporary social and/or psychological issues (also considered in film circles the usual candidates for Oscar Best Picture nominations). This is not to suggest that neither expert refers to the subject in their texts: McKee outlines the categories of film genres and subgenres early in Story (McKee, pp. 80-86); he makes good on this short discussion in the section "Structure and Genre" (pp. 79-99) by elaborating very briefly upon the conventions of the crime drama, the comedy, the Western, the love story, etc. These conventions - namely, expectations both producers and audience have of any particular genre — are limited to certain story elements (i.e., the notion that the detective film must exemplify the "cop's POV (point of view" (p. 82), or the rule that comedies differ by "the focus of comic attack" (p. 82)). Field on the other hand addresses genre more conversationally and in passing (Field, p. 187, viz., "The action genre is a significant staple of our film fare..."). However, neither writer considers in their texts the possibility that genre itself may play an important role in the structure of the screenplay, or how it is that distinct genres may recreate the 'character arc' of the protagonist in different ways. In other words, the stability of the three-act structure for both Field and McKee, and the inviolable requirement for character arc for McKee, are not questioned. 


\subsection{Prescriptive Literature: After Field and McKee}

Following Syd Field and Robert McKee are a variety of textbook writers, most of them highly placed in Hollywood or New York (the centres of filmmaking culture in North America) as instructors, script doctors or successful screenwriters. Many of these advisors have also enjoyed considerable industry acclaim; all approach the ideas of structure and character arc from disparate angles, supporting the basic models promulgated by Field and McKee but distinguishing and rebranding their theories by insisting upon variations of the structural and character arc themes.

One of these experts is Professor Richard Walter, former Screenwriting Faculty Chairman in the Department of Film and Television at the University of California at Los Angeles (UCLA). His self-deprecating Screenwriting: The Art, Craft and Business of Film and Television Writing (1988) preserves the Aristotelean construct of the story with a beginning, middle and an end, and anticipates McKee in his requirement that a screenplay's characters "grow and develop throughout the tale" (Walter, 1988, p. 69). Consider for example his caveat regarding character development and change: "Must a character change?

Not necessarily. Patton is still Patton at the end of Patton - every bit the possessed warrior he always was. But in the course of the movie his character has been challenged, articulated and rearticulated in such a manner as to provide a glimpse into why he is who he is. And even if we don't exactly like him, we are fascinated. (Walter, 1988, p. 71)

ULCA instructor and television/film writer and executive Lew Hunter takes an approach similar to Walter's in his 1994 Screenwriting 434; another entertaining read on the complex business of Hollywood screenwriting, it likewise maps the three-act structure 
as essential for proper screenplay form. Hunter creates his own nomenclature for particular points in script structure: rather than Field's plot points or McKee's inciting incidents, he offers "scene pinnacles" (Hunter, p. 176). As to the issue of character development, he notes the use of "touches" (p. 177), which he describes as visual descriptions, often without dialogue, added to a script to indicate character psychology and inner turmoil: "Such moments of dialogue or business are rarely essential to plot but always essential to good character" (p. 178). Rather than personally elaborating upon the importance of character arcs, however, he recommends reading the work of Hungarian-American playwright and creative writing coach Lajos Egri (specifically The Art of Dramatic Writing (1942)).

Two years after Hunter's text, American screenwriter and UCLA and USC instructor Paul Lucey weighs in with Story Sense: Writing Story and Script for Feature Films and Television (1996). Equipped with a formidable bibliography (that includes in its screenwriting section the texts of Lew Hunter and Richard Walters but not Syd Field), Lucey's work is objective, even scholarly: rather than promoting a particular patented approach to a three-act screenplay, for example, he notes the pros and cons of adhering to such normative structures:

Although many new writers find inspiration in such films (as Pulp Fiction), it is not easy to invent new story forms that will attract audiences. This is why most movies continue to organize around the traditional three-act structure and why professional screenwriters work intensely to create such scripts. (Lucey, 1996, p. 41).

Further, he notes, there are "variations within story traditions" that some writers may use to stage a more innovative approach to their scripts, but even these are to be used with caution. Although the three-act structure is "fussy" and not always easy to grasp, it works, 
and "production companies expect to find (it) in scripts considered for purchase. Scripts that are judged to be out of the mainstream make buyers uneasy (this is true even though everyone realizes that art should cause uneasiness)" (p. 41).

\subsection{Philosophical and Literary Precedents in Screenwriting}

The preceding review glosses the work of several prominent scriptwriting gurus, providing this study with an overview of screenwriting instruction from the late 1970s to the mid-1990s: a few observations may be made at this point. First, these experts generally ground their writing theory in both successful (by which I mean economically successful) and contemporary screenplays/films. Beyond the occasional note, few of these writers acknowledge classic works either in theatre, or in historic or art/foreign film canons (although Hunter briefly acknowledges the Greek classics and Shakespeare (Medea, Oedipus Rex, Hamlet, King Lear) and the plays of Tennessee Williams (Streetcar Named Desire, Cat on a Hot Tin Roof) in the opening pages of his text (pp. 22-23)). Given the primacy of Aristotle in many of these texts, the decision to exclude references to the important dramatic works of ancient Greece is revealing. If contemporary screenwriting gurus consider Aristotle's advice relevant, why would the works of Homer, Sophocles, Euripides, Aristophanes or any of the other ancient Greek playwrights not figure as exemplars in the same textbooks? Readers of Aristotle's Poetics cannot help but notice repeated references to the tales of Oedipus, Medea, Orestes, Odysseus, Sisyphus, etc. would not explication of these stories in a contemporary context prove constructive for screenwriting students?

Further, it is important to note that while Aristotle (as per Syd Field) posits every story must have a "beginning, middle and an end" (Aristotle, trans. 1920, I:7), this suggestion 
does not necessarily correlate to a three-act structure. Indeed, in his explication of tragedy, Aristotle advocates a four-part structure containing prologue, episode, exodos and chorus (with chorus divided into parodos and stasimon) as the "formative elements" of theatrical narrative (Aristotle, trans. 1920, I:12). This point is particularly relevant, as so many screenwriting texts conflate Aristotle's holistic advice regarding organic form with directive advice on narrative structure. Indeed, the philosopher compares in his section on the beginning, middle and end of stories the beauty of a "well-constructed plot" with that of a "living creature," noting that "to be beautiful, a living creature, and every whole made up of parts, must not only present a certain order in its arrangement of parts, but also be of a certain definite magnitude" (Aristotle, trans. 1920, 1:10). The vagaries of this first passage are deliberate and are meant to describe the larger qualities of narrative beauty, not to direct students as to structures and their parts, as does his second passage.

Further, if Aristotle's Poetics is so universal a precedent, how do these screenwriting instructors account for the work of the Roman poet Horace, who advocated with Aristotle a rational linear plot development but who departed from his predecessor by insisting that a five-act structure is best for dramatic structure (Ferriss-Hill, 2015, p.196)? Which of these two experts should be trusted to describe the one 'true' narrative structure — the philosopher-scientist or the poet-storyteller? The point here is that adoption of an ancient narrative structure is not helpful unless the adopter has a holistic understanding of the environment in which this structure bears fruit; extrapolating holus bolus classical narrative structure to a 21st-century North American setting requires either extensive knowledge of both ancient Greek and contemporary western cultures, and/or a tremendous leap of faith that the conditions of one culture map neatly onto those of the other. Unfortunately, the writers invoking Aristotle make the assumption that narrative structures are created $a$ 
priori, like mathematical equations or formal logic — that there can be in such structures no accommodation for a social/historical construction of writing or for that matter artistic license.

Second, there is promulgated throughout these textbooks the position that "new story forms" are difficult if not impossible to create (viz., Lucey, p. 41), and that there is little beyond the three-act structure that operates successfully as a storytelling narrative. It would seem few of these writers consider theatrical or folktale narrative structures as relevant models, or they might have recognized that there are in these forms a multitude of different constructions for such purposes. Vladimir Propp's (1895-1970) Morphology of the Folktale (1928) for example explicates the structure and narrative elements of Russian folk tales: Propp does not break these stories into acts, but notes instead the presence of 31 separate functions in the folktale that generally follow in sequence. Study of such linear structure is known to semioticians as syntagmatic structural analysis; conversely, paradigmatic story analysis regards the story's theme as latent within the structure and expressed in binary oppositions (i.e.: country/city, past/future, parent/child, East/West, etc.), as per Claude Lévi-Strauss’s (1908-2009) structuralist approach (Dundes, 1968).

Another point: few if any of these writers include reference to theatrical narrative structure, which, as Ted Nannicelli notes, has informed screenwriting practices since the early 20th century ${ }^{4}$, he points out that established models of one-, two-, four-, five- and eight-act play structures have long had a pronounced influence upon many early screenwriters. The work of German playwright and novelist Gustav Freytag (1816-1895), in particular the Freytag's Pyramid, is informative in this regard; like his predecessor Horace, Freytag argued that the writing structure exemplified in ancient Greek (and in addition Shakespearean) drama comprises five sections: exposition, rising action, climax, 
falling action, and dénouement (Freytag, 1900, pp. 114-115). In this case, the play’s climax — viz., the turning point that decides the protagonist's fate — arrives at the halfway mark: "it is almost always the crowning point of a great, amplified scene, enclosed by the smaller connecting scenes of the rising, and of the falling action" (p. 128). Finally, very few of the aforementioned writers address the narrative pattern promulgated through American mythologist Joseph Campbell (1904-1987) and his 'monomyth,' namely, the circular narrative pattern in 17 (or fewer) stages, which describes the departure, initiation and return from the unknown of the narrative's hero:

A hero ventures forth from the world of common day into a region of supernatural wonder; fabulous forces are there encountered and a decisive victory is won; the hero comes back from this mysterious adventure with the power to bestow boons on his fellow man. (Campbell, p. 23).

The point here is not to insist upon new narrative schema but to inquire as to why the McKees, the Fields and the Luceys have not considered examining or even briefly discussing alternative screenplay approaches before espousing the primacy of the three-act structure. Surely even a short discussion would encourage screenwriting students to consider the significance of earlier structural models in literary and dramatic history against the relevance of the three-act structure in the 20th and 21 st centuries. The absence of such a discussion suggests either a lack of knowledge of alternate structures by these writers or their outright dismissal. Either way, the arguments made by many of these screenwriting textbooks reveal a strong trending to inductive reasoning, exhibiting in particular confirmation bias (in which presenters submit evidence that confirms a position while ignoring other data that may contradict it). The result is a narrowed view of narrative 
construction that created the conditions for a mechanistic approach to screenwriting, and has discouraged significant innovation in some sectors of the filmmaking industry, particularly in the Hollywood context.

\subsection{Revelatory Literature: Insider Notes on Filmmaking Inequities}

Like many books in the prescriptive category, the revelatory text probes to discover the 'secrets' of successful screenwriting, in this case by consulting the source of successful screenplays - generally, the writers themselves. As often as not, however, this form moves past first-person revelations into heated discussions of inequities experienced by individuals in this highly paid craft. Depending largely upon the direction provided by the interviewer, these texts begin with entertaining and gossipy information on the trade of writing in Hollywood, then move into discussions on the pernicious qualities of auteur theory, the misguided qualities of studio notes, the insatiable desire of directors and producers to dictate screenwriter output, and so on. Generally, if the prescriptive form of screenplay literature describes industry 'best practices' -- in this case, an intense focus upon structural conformity and how this craft may best be exercised for maximum return -- then the revelatory volume relocates screenwriting in a political arena, where power and ego are currency, and instruction a secondary preoccupation.

Emmy-winning University of California Los Angeles professor William Froug (19222013) himself produced numerous versions of the revelatory text: The Screenwriter Looks at the Screenwriter (1972) features screenwriter interviews with Nunnally Johnson, I.A.L.

Diamond, Buck Henry and Ring Lardner Jr. on the hegemonic practices of various Hollywood directors and producers. His follow-up volumes, Zen and the Art of Screenwriting: Insights and Interviews (1996) and Zen and the Art of Screenwriting 2 
(2000) pose the same questions to a later generation — namely, screenwriters Callie Khouri, Frank Darabont, Bo Goldman and Larry Gelbart, amongst others. Tutelage proffered in Froug's revelatory texts generally comes in the form of cautionary career advice (viz., writers should for their own benefits join their local writers' union, obtain the services of a reputable agent and an industry-savvy lawyer, etc.). In essence, these books are less about screenplay craft than the polity of the filmmaking world's "above-the-line" creative teams.

If prescriptive works deal with the art involved in screenwriting, the works of both Froug and most other writers in the revelatory mode recommend the acolyte to the business of screenwriting, typically via a directly transcribed question-and-answer dialogue between the knowledgeable interviewer and the successful screenwriter. What is revealing in this choice (that is, the tendency to favour the Q\&A versus the usual expository journalistic profile) is the unspoken assumption that a word-for-word transcription accurately imparts the 'truth' of a case than does a purely descriptive account; truth, or at least transcription accuracy, is of particular importance, since much of the information imparted in these interviews lays blame for screenwriting position inequities upon particular parties (usually producers) in the creative process. Despite the fact that Q\&As are as likely to communicate false or libelous information as any other written form, the producers of revelatory texts clearly prefer this form, shaping their transcripts with short, often leading questions (i.e.: "Since we're working in a collaborative medium....are screenwriters overly sensitive?" (Froug, 1972/1991, p. 77), followed by the writer's often lengthy contextualization/ explanation. To that point: when Froug interviews screenwriter Walter Brown Newman (The Great Escape (1963)) on the subject of collaboration, Newman says he "jibs" at the word: 
I don't quite know what it (the word collaborative) means. When Frank Lloyd Wright designed a building and then Herman Goltz, the building contractor, came in and hired a lot of very hard working structural workers, masons, carpenters, etc., was that all a collaborative effort?... (W)hen I have written a screenplay because I've been hired by the studio and written one of my own, and nobody has seen this thing until I have written FADE OUT at the end of it, I don't think I've collaborated with anybody at all. I feel I've given somebody a blueprint. I hope it's followed. (Froug, 1972/1991, p. 77)

The collaboration problem implied here concerns the matter of authorship and control in screenplay interpretation, as well as the industry's practice of shared screenwriting credits, often between writer (identified in the analogy here as Frank Lloyd Wright) and producer (as Herman Goltz, the Lloyd project's contractor). Curiously, Newman does not account for standard industry practice, which is for the film's producer and/or its producer and director to hire a screenwriter to either produce or revise a given screenplay property. More importantly, however, his analogy animates a long-held grievance in the profession of screenwriting, whereby writers receive neither recognition nor remuneration for the film's foundation.

Such responses are not unusual in the revelatory textbook. Renowned screenwriter Nunnally Johnson (The Grapes of Wrath (1939)) proceeds from discussing producer functions in the screenwriting process to more pointed comments on the directorial function, specifically in regard to Hollywood director John Ford:

I think John Ford almost dies because he can't write. It just runs him nuts, that he has thoughts and ideas and has never trained himself to 
put them down on paper. And I've found this true of so many directors. They're just thwarted. That's why they often try to pretend that the writer didn't exist. That this stuff on the paper came on there through some chemical action of the director's eyes, as they ran down a blank sheet. (Froug, 1972/1999, p. 255).

Johnson moves beyond castigating film directors to criticize the film review business (at that time conducted by newspaper columnists), suggesting that review writers were envious of the proportionately larger sums paid to screenwriters for what appeared to be a similar writing assignment: "I think that was one of the reasons why the newspaper reviewers celebrated the director. Not the writer. I think it was jealousy" (Froug, p. 256).

Froug's later revelatory texts dwell less upon power struggles within small above-theline teams and more upon various other concerns, including: "the proliferating business of hiring rewriter after rewriter after rewriter" in the screenwriting process (Froug, 1996, p. 96, 169); problems around the Writers Guild of America's controversial credit-arbitration system during the mid-1990s (p. 56); narrative intention and the difficulties of collaboration in expanding creative teams (particularly those in which actors, cinematographers, screenwriter teams as well as directors and producers are invited to collaborate on the script (p. 43)); writer "burnout" during lengthy development processes, (p. 169); and issues around adaptation of literary material (p. 214). One of the more interesting turns in Froug's later books is his focus upon screenwriting pedagogy, particularly that exercised via prescriptive texts. In one introduction, he notes that pedagogical screenwriting rules are meant to be broken, and that "no professional screenwriter writes with 'steps' in his or her head" (Froug, 1996, p. 197; italicization his). In his interview with Thelma and Louise 
(1991) screenwriter Callie Khouri, the question of the three-act structure arises, with Khouri admitting that she doesn't "really pay any attention to it":

One of the things (fellow writer) Jim Rogers did for me (in a rewriting process) was tell me that I had a five-act structure, and that's why I was getting confused about the three acts. He told me to forget about it. And so I did. It's really helpful not to have to think like that about a movie. I try not to weigh myself down with any rules. (Froug, 1996, p. 101)

This direction in the revelatory text is taken up by American filmmaker/film journalist Kevin Conroy Scott in his Screenwriters' Masterclass: Screenwriters Talk About Their Greatest Movies (2005). His interview with Requiem for a Dream (2000) filmmaker Darren Aronofsky reveals a similar distaste for screenwriting pedagogy (in discussing his early writing, the alternative filmmaker notes he "was aware enough to know that those Syd Field books were evil"' (p. 133)), although he also admits he developed his own process to “identify a three-act structure, which I do believe in" (p. 133). Similarly, in his interview with British filmmaker Alex Garland (28 Days Later... (2002)), Scott asks how the filmmaker prepared for writing his first screenplay: “Did you take Robert McKee’s cause or read Syd Field books?” Garland responds, “No, I always felt distrustful of that. Maybe that McKee guy is terrific, I don't know. And actually, I do write in a three-act structure sort of way" (Scott, 2005, p. 173). Scottish filmmaker Paul Laverty (Sweet Sixteen (2002)) answers the same question by observing that without a rigidly structured outline, screenwriter characters "surprise you and take you in a way you never expected"; otherwise, "if you've got it all worked out beforehand, I think maybe you'll wind up with a tight structure but somehow it tends to lack energy and life" (Scott, p. 287). Amores Perres 
(2000) writer/director Guillermo Arriaga echoes this observation, noting there are two types of writers - "those who don't need any kind of internal way to order things inside themselves, so they need structure, page thirty, page sixty, and so on" versus his own writing, which in his film 21 Grams (2003) "goes back and forth all the time, and I had a perfect understanding of where it was going. I never got lost or thought that I needed a plot point here, or for something to happen in the second act” (Scott, p. 384).

Other relevant volumes in the revelatory mode include entertainment journalist Joel Engel's Screenwriters on Screenwriting: The Best in the Business Discuss Their Craft (1995), which takes an approach similar to Froug's later revelatory texts, querying Ernest Lehman, Robert Towne, Michael Mann, Ted Tally and others on their approach to screenwriting and asking these writers about their arguments with directors, film reviewers, producers, actors. American screenwriter Susan Billington Katz's Conversations with Screenwriters (2000) begins her compressed text with a telling anecdote:

"Someone once said that a critic is a person who comes onto the battlefield after the war and shoots all the wounded. The person who said that was a writer. Writers know all about wounds.” (Katz, 2000, p. vii)

Her compilation airs many of Froug's grievances, although Katz focuses as well on the mechanics of writing, asking her interviewees to describe their "writing day," how they choose subjects for spec screenplays, the problems of script adaptations from novels, and so on. Story and Character: Interviews with British Screenwriters (editor Alistair Owen; 2002) keeps its interview questions neutral, but the interviewed complain of the same issues: viz., the problems with screenwriting pedagogy, vanity credits claimed by directors, continuous rewrites. Finally, the American film scholar Patrick McGilligan's Backstory 1: 
Interviews with Screenwriters of Hollywood's Golden Age (1988) and four subsequent texts (Backstory 2 (1991), Backstory 3 (1997), Backstory 4 (2006) and Backstory 5 (2009)) invest in questions of film genre and their impact upon screenwriting, matters of writing 'best practices' (i.e.: how to introduce conflict, how to bring characters into a room, etc.), gossip about famous directors (Rear Window's John Michael Hayes on Alfred Hitchcock, Woman of the Year's Ring Lardner Jr. on Fritz Lang, 52 Pick-Up's Elmore Leonard on John Frankenheimer), the effect of world events on filmmaking (viz., American and world reaction to the war in Vietnam), casting decisions, relationships with actors, and so on. Many of McGilligan's interviews touch upon writing dynamics in screenplays: Lawrence Kasdan, for example, notes that the three-act structure is inherent in his work, even the "loose" Grand Canyon (1991). Paul Mazursky discusses Blume in Love (1973), saying it was "unmapped" and that all he knew was "I wanted it to end with Tristan and Isolde, and them coming together" (McGilligan, 2006, p. 235); later in the interview, Mazursky responds to a question about screenwriting rules by insisting that the "people who write all the books about screenwriting" are ill-informed:

They don't know. They don't know. I'll get killed for this, but I'm against a lot of those books. There are no rules! Structure? For every movie you show me, I'll show you one that defies everyone one of those rules and yet is a great movie. (McGilligan, 2006, p. 259).

Revelatory texts thus provide a number of pedagogical functions for those desiring to learn the screenwriting craft: while they deign to dictate writing rules, texts in this mode strive to impart the various screenwriting and filmmaking-business experiences of practicing screenwriters. As a general mode of screenwriting literature, the revelatory text poses a counterbalance to the prescriptive mode by advising readers against adhering to preset rules 
on writing for the screen (although this as we have seen is not always the case, as some writers claim to have profited to some degree from these books). Another common refrain amongst the revelatory texts is undoubtedly that of expertise and power, and the filmmaking industry's apparent conspiracy to relieve the screenwriter of the latter at every turn. Writers in this craft chafe not only at the desire of producers and directors to 'meddle' in their work, but at the apparently endless proliferation of screenwriting textbooks designed to dictate every move of the writing process.

But the most telling finding here is that screenwriters come to their notions of filmic narrative structure in idiosyncratic ways, and that prescriptive texts often play a very limited role in the shaping of professional screenwriters. Would this conclusion stem the steady tide of prescriptive screenwriting texts amongst publishers, if they were privy to it? This author suspects not: the "how-to" manual is after all designed to introduce neophytes to the craft of screenwriting and to the possibility of earning large sums of money if (and only if) its instructions are closely followed. No doubt the prescriptive text is more profitable for its publisher than it is for either the filmmaking industry or the erstwhile screenwriter.

\subsection{Scholarly Literature: Current Pedagogies of Screenwriting}

Although academic articles discussing screenwriting have appeared since the 1970s in such journals as Film Comment, the Journal of Film and Video and Film History, it was not until the late 1990s that a significant critical/theoretical monograph was published on the subject. Claudia Sternberg's Written for the Screen: The American Motion-Picture Screenplay as Text (translated from her German-language $\mathrm{PhD}$ dissertation in 1997) acknowledges first that Hollywood is a challenging environment for any screenwriter: 
given the American industry's tendency to regard the director as a film's primary auteur and its corresponding relegation of the screenwriter to rank-and-file (and eminently replaceable) employee, working conditions in this enterprise are taxing, to say the least. Despite this acknowledgement, the German scholar admits she delayed her dissertation in favour of contracting her services to a Hollywood studio as a script reader and to writing her own screenplay, Suspended Mourning, in 1989; whether or not her screenplay was successfully produced or even optioned is not discussed (Sternberg, 2014, p. 202). As a linguist and narratologist, Sternberg approaches the subject of screenwriting as a form of socially constructed discourse, and the screenplay itself as a site of semiotic activity: As a prestructuring interface of word, sound and image, the screenplay reveals the narrative and dramatic potential of the medium's form and content through the use of verbal signs. (Sternberg, 1997, p. 64)

A text constructed and encoded by industry, the screenplay must display certain markers of 'professionalism,' including the exclusive use of the Courier typeface, capitalization and abbreviation of key directives (i.e.: INT. to indicate "interior," VO to indicate "voiceover,"), prescribed indentation and other formatting standards, etc. To operate outside the bounds of these conventions is to risk being dismissed as an amateur - a neophyte hoping for entry but unworthy of membership. Sternberg thus positions the screenplay as an hermetic text designed for a small and exclusive readership: it is in essence a blueprint to be read by a privileged and competent contractor, not a text for interpretation by a rank-and-file reader.

Despite these apparent constraints upon the screenwriter, Sternberg suggests that a screenplay is little different than a play written for the theatre: both texts require translation by a producer: "The screenplay and dramatic text precede a performance and require 
readers at all reading stages to actualize the implication of the text's performance potential" (Sternberg, 1997, p. 58). While she acknowledges that a screenplay generally indicates a single performance versus a written play, which may generate numerous interpretations of its text at different times and by different producers, the two written forms are, she asserts, literature in their own rights, each with plots, characters, and the unique contribution of their writers: "It is...the individualism of the author...that becomes manifest in the relationship between dialogue and scene text, and the design of the modes of report, description and comment" (1997, p. 84). Further, the screenwriter shares with the playwright the ability to shape the text through written dialogue, which allows a particular artfulness that is not to be discredited. Indeed, Sternberg suggests that contrary to expectation, scriptwriters have considerable power to influence the shape and delivery of screenplay to screen:

Dialogue and scene text, in which film technique and narrative are combined, demand a certain degree of cinematic-technical imagination from their readers. If these combinations are very complex, the directorial input can be anticipated to a large degree. The screenwriter therefore becomes a hidden director. (Sternberg, 1997, p. 231)

Twelve years after the publication of Sternberg's translated dissertation, Australian media and communications scholar Steven Maras released his Screenwriting: History, Theory and Practice (Wallflower, 2009). This acclaimed text emerged just one year before the launch of Intellect's Journal of Screenwriting (first published in 2010) and Steven Price's influential The Screenplay: Authorship, Theory and Criticism (2010). Like Sternberg, Maras positions screenwriting as a key discursive element in the filmmaking industry, tracing it through movie history in a variety of what he calls frames (in sociologist 
Erving Goffman's pioneering use of the term, this is the packaging of rhetorical terms in such a way as to communicate key elements of an issue to recipients). Foremost amongst screenwriting frames is the structure/story approach discussed earlier in this chapter, in addition to business, practitioner and "anti-screenwriting" frames (the latter is "suspicious of the literary dimension of filmmaking and tends to 'beat down' the writer" (Maras, p. 11)). The missing element in this list, he suggests, is a relevant academic frame. "The fact (is) that in many academic institutions screenwriting is separated from film studies, or even other production disciplines... [W] hat has become apparent is that film studies does not always know what to do with screenwriting" (Maras, p. 5, 7). Part of the issue is that this form of writing is ill defined, both by industry practitioners and scholars:

Is the 'object' of screenwriting on the page or the screen? Does the script or its realization exist independently from the film? Is the 'script' the final product of the screenwriting process, or just one aspect of (it)? Are we dealing with two objects (the script as read and the film as distributed) or one?...These questions are not easily answered. (Maras, p. 11)

Exacerbating this lack of definition is a largely misunderstood or misinterpreted history of screenwriting. Maras deigns to track down the 'first screenplay' (an approach that takes scholarship "dangerously close to a focus on origins and 'firsts' that has proven unhelpful in film and photography studies" (p. 29)), suggesting instead that attention refocus to the form as it shifted first from the scenario of the pre-sound era, then to the 'administrative' continuity-focused screenplay as it was written in the latter half of the 20th century (p. 36), and finally to the recent 'layering' approach to writing and production, in which new digital processes may prefigure or run parallel to the writing stage (p. 22). Recounting this 
evolution of the screenplay allows Maras to identify key turns in Hollywood filmmaking (i.e., shifts from silent to sound cinema, from film to digital moviemaking, etc.) and to reveal policy and management changes as technical innovations revolutionize the industry.

As for the enduring debate as to whether or not a screenplay may be considered literature (and all the torturous comparisons of the forms that come with that discussion), Maras cites Pier Paolo Pasolini, who argues that screenplays are not autonomous literary texts if for no other reason than each is a "structure that wants to be another structure" (Maras, p. 50). American screenwriter Dudley Nichols, writing in 1943, points out that the screenplay represents a stage of evolution of a narrative work, with the produced film the completed product; as such, the screenplay cannot be considered a consummated work of literature. Nichols's screenwriting partner John Gassner counters this completion notion, asserting that if "the drama intended for the stage can be called a form of literature, so can a screenplay" (p. 59). Maras himself repositions the screenplay-as-literature argument by asking how it is we read these texts: does the reader hear and see a film "on the screen of the mind's eye" (Maras, p. 71)? Does the screenplay ever qualify as a poetic form that might "evoke" for a director, for instance, a particular type of lighting or dialogue delivery (p. 73)? Or does the screenplay act instead as a pluralized entity, "in which the context of meaning is constantly shifting" (p. 78)?

These questions lead the writer to his primary thesis, namely that the screenplay "is a site for discursive struggle in which written compositions are framed and argued for in different ways" and that changes in related terminology (viz., "scenario" to "script" to "screenplay") provide significant clues to important historical changes in the filmmaking industry (Maras, p. 80). Again, most of these changes are driven by the evolution of industry practice. For example, the 'scenario script' of the early 1910s, considered a 
"blueprint of a film rather than a written work" (p. 88), has become known today as the 'treatment,' usually a five-page document outlining the narrative's three acts and its main conflicts; this change alone reflects the burgeoning industrialization of filmmaking in North America and the requirement to satisfy the film's stakeholders that risks have been managed and profits maximized through identification of success indicators (viz., the compliant adoption of the three-act structure).

Further, given the proliferation of nomenclature in screenwriting over the industry's life (viz., scenario, script, screenplay, outline, treatment, one-page, two-page, etc.), tracing changes in naming conventions is difficult to unravel - and, the author suggests, a nonstarter. Maras does not attempt to find a linear through-line in this development, but notes that filmmakers have adopted what they see as relevant metaphors to describe ideal screenwriting: "The screen writing literature of the 1930s is littered with references to the story as a primary material or 'raw ore' that is processed, and the need for more, or the right kind, of stories" (p. 94). This idea of valuable but malleable material evolves in the latter half of the 20th century when screenplays widely came to be known as narrative blueprints (p. 96). That both metaphors reflect elements in construction gives considerable weight to the larger and by now well-worn paradigm of filmmaking as industrial process: the blueprint now becomes the "management tool" establishing lines of authority and providing fixed guidelines for assembly (p. 123). From this mechanistic process springs a demand for uniformity and compliance to the rules of the screenwriting game. Where Claudia Sternberg may have seen the screenplay-blueprint as an enabler of screenwriterly ambition, Maras suggests it is a site of constant struggle, where writers more often than not submit to a hierarchical system. 
Despite his cynical take on the subject, Maras concludes that a pluralistic approach to screenwriting, "one that recognizes different styles of scripting" (p. 170) and seeks to move beyond the usual three-act structure paradigm, is still possible in today's high-stakes movie industry. In fact, such pluralism can be seen practiced by such luminaries as British filmmaker Mike Leigh (whose screenplays spring from actor improvisation and rehearsal rather than from a single writer), Australian writer-director Kriv Stenders (who uses the word "scriptment" to describe his loose, improvisational approach to screenwriting) and the aforementioned George Lucas, whose layered productions no longer rely solely upon the prescribed 120-page screenplay model. And although the requirements of large-scale filmmaking will continue to call for written screenplays, Maras suggests the 'blueprint' model of screenwriting will inevitably be challenged:

What has, and will, come under greater scrutiny is the idea of a sovereign script arising, presiding over the production process - the product of a single feature of conception or pre-planning. (Maras, $\mathrm{p}$. 179)

Steven Price's Screenplay: Authorship, Theory and Criticism (2010) continues the Sternberg/Maras discussion of the screenplay as blueprint, but where Maras directs his inquiries primarily to archival and art cinema literature, this British scholar like Sternberg refers primarily to Hollywood industry practices. Exploration of key case studies (including a chapter-long analysis of Hitchcock's collaboration with The Birds' screenwriters Evan Hunter and Jay Presson Allen) provides Price an historical perspective engaged in classical Hollywood cinema and later with contemporary industrial practices. The result is a blended grounded-theoretical approach (Glaser and Strauss, 1967) to the subject of screenwriting as a socially constructed practice. 
Price, who is a scholar of British and American theatre and an expert on the screenplays of David Mamet, points out that while screenwriters may consider themselves prime architects of narrative, films scripts in reality are rarely if ever the result of a singular talent:

[T]he screenplay is not so much a blueprint as an enabling document, necessary for the production but transformed by directors, actors, vagaries of the weather, and a multitude of other factors that occasion the rewrites that are the bane of the screenwriter's craft. (Price, p. xi)

That screenwriting is and has always been an intensely collaborative activity challenges the Romantic notion of "the text as an act of personal expression" (p. 9), but there are also practical reasons for collaboration: "Much more than with other forms of creative writing, notions of authorship in relation to screenwriting tend to be displaced by legal and contractual relationships" (p. 9):

'Inspiration' is subject to modification to only by the writer but, more importantly, by the studio system to which s/he is subject, while the text itself is caught up in a related system" (Price, p. 9)

This notion of the screenwriter as reluctant but complicit employee thus becomes central within Price's text, which explains perhaps his pragmatic approach throughout the rest of his book. His explication of screenwriting-related matters including writer credits, Writers Guild of America (WGA) definitions and principles, writers' drafts and stages of screenplay development places his work within Sternberg's world of the script as industry artifact. Unlike Maras, he does not take a critical approach to his subject, but like Maras works to locate the screenplay within an historic range of narrative forms. 
In particular, Price enters into comparisons between literatures, for example in the relationship of film scenarios to theatrical plays and the effect of distinct linguistic functions of each form, and in the comparison of literature to screenplays and attendant issues of adaptation. Following Roland Barthes' description of the text as a "methodological field" in constant flux (vs. the "work", which is a static artifact, like a published volume in a library (p. 38)), the screenplay shares with the text an amorphous, unauthored, pluralized quality that accommodates rewriting, an essential function in the collaborative work of filmmaking. While it has some qualities it shares with the work (i.e.: a formalized format, a drive for plot closure), the screenplay's lack of authorial style makes it "literally impossible to read conventionally" (Price. p. 41).

Finally, he notes that that any screenplay-as-literature argument must face the usual curious obsession with structure displayed by filmmakers and screenwriters - to such an extent that onlookers dismiss the comparison outright. Especially in regard to adaptations, the screenplay becomes not a work of literature but "little more than a mediating device" that follows the dots to completed narrative work (p. 56):

The extreme emphasis on structure in screenplay-specific discourses such as writing manuals and the credit system, and the concomitant devaluation of enunciation (which, as far as the cinematic spectator is concerned, essentially means dialogue) therefore contributes materially to the perception of the screenplay as non-literature. (Price, p. 56)

In an environment pitting literary aficionados and business-minded filmmakers against the individual screenwriter, script development is an uncontrolled and often hostile process, one in which the absence of any definitive final draft coupled with the inevitable struggle of collaboration render the writing of the screenplay "a chaotic affair that removes any sense 
of authorial control and structure" (Price, p. 63). It is significant that Price's epilogue comprises a short tribute to Sunset Boulevard (Wilder, 1950), in which a murdered screenwriter relates the story of his disappointing career from beyond the grave.

Screenwriting is in this and almost every instance a story of "ghost writing" that denies the writer the respect and credit s/he has earned and deserves (p. 170).

\subsection{Scholarly Literature: The Second Wave}

The Sternberg/Maras/Price triumvirate provides an initial set of theories for other scholars entering the field; articles in the recently launched Journal of Screenwriting (JoS) and related journals cite all three writers routinely. Citation analysis reveals a half-dozen most-cited entries published in JoS that bear some scrutiny here: of these, K. Millard's "After the Typewriter: the Screenplay in a Digital Era" (2010) has been most highly cited.

The Australian essayist, who is both professor and filmmaker, draws upon her own experience to examine artefacts of screenplay 'professionalism' — namely, industry’s insistence upon the use of Courier 12-point typeface, three-ring drilled holes and brass brads for binding scripts, etc. "One cannot help but wonder if the enforcement of this equation does not nudge the screenplay towards a production and budgeting document, rather than a creative record of a screen idea," she notes (Millard, 2010, p. 17). This enforcement leeches more significantly into matters of screenplay development, specifically the "restructuring" and "pruning" of Millard's own script for her feature Travelling Light (2003) by Australian film-funding bureaucrats:

My experience with Travelling Light, and my background as a script reader and assessor for various funding bodies, leads me to the conclusion that many scripts are over- rather than under-developed. 
The handful of screenplays and film projects chosen for development through government programmes all too often lose momentum and energy as a consequence of this selection. (Millard, 2010, p. 12)

Citing Canadian filmmakers Atom Egoyan and Guy Maddin, who observe similar forms of bureaucratic meddling in their screenplay development, she concludes that the blueprint model of the 20th century is in flux and about to be transfigured by the fluidity of amateur filmmaking and digital cinema: "So much of the current era, with its proliferation of digital technologies, returns us to the beginnings of cinema and creates spaces to investigate the paths that were not followed...the byways of cinema, as Guy Maddin describes them" (Millard, p. 22).

In the same $J o S$ issue, British film scholar Bridget Conor uses the Foucauldian model of governmentality to examine screenwriting as a form of "industrialized writing" (Conor, 2010, p. 36); much like Millard, she observes that current filmmaking policy "acts as a set of coercive tools and sets standards and expectations within the industry" (p. 38). However, Conor's "Everybody's a Writer: Theorizing screenwriting as creative labour" extends the argument to suggest that collaboration is not simply a necessary evil in the script development process, but a device to undermine the screenwriter's expertise, mainly through competition within the above-the-line team. Indeed, screenwriting work "only becomes productive, useful and thus meaningful when it is subject to development, notes, and input from other film-makers" (p. 37). Despite these dour observations, Conor notes that in her survey of published screenwriter memoirs and testimonials, many screenwriters relish the flexibility and opportunity offered by their career; they are "able to exercise creative autonomy and freedom not possible for many other film production workers; 
they...may be rewarded with both high remuneration and also critical rewards and recognition" (p. 39).

J.J. Murphy’s “No Room for the Fun Stuff: the Question of the Screenplay in American Indie Cinema" examines alternative screenplay forms in independent cinema, specifically within the subgenre of mumblecore (viz., low-budget film that uses improvised dialogue to depict the joys and woes of young Americans). Exploring films like Ron Rice's The Flower Thief (1960), Kent Mackenzie's The Exiles (1961), and Andy Warhol's The Chelsea Girls (1966) to the more contemporary The Pool (Chris Smith; 2007), Ronald Bronstein's Frownland (2008) and Gus van Sant's Elephant (2003), Murphy finds that virtually all contain improvised dialogue and minimal exposition. The 'screenplays' for these films most often comprise 25- to 30-page outlines, with resultant scenarios characterrather than plot-based, and with dramatic arcs "flattened":

In striving to differentiate their works from mainstream films, independent film-makers often employ realism or naturalism as a foil to the staged contrivance of Hollywood....Improvisation often can lead to deeper complexity of characterization. (Murphy, 2010, p. 192)

Another frequently cited article in $J o S$ makes a foray into the screenplays of European art cinema, this one focusing upon the work of Italian poet and screenwriter Tonio Guerra, in particular his work for Andrei Tarkovsky and Michelangelo Antonioni. Finnish scholar/screenwriter Riikka Pelo describes the working methods of both filmmakers and their shared "denominator," pointing out that structuring and writing of screenplays for New Wave filmmakers was intensely and generously collaborative: much of the time (especially in Tarkovsky's case), the auteur rewrote the poet's screenplay as a whole. This activity is in keeping with auteur practice, notes Pelo, which considers the director the 
authentic author of the screenplay, "the one who has dreamed up or invented the original fictional world, its themes and characters" (Pelo, 2010, p. 120). In these cases, the screenwriter is seen as a combined confessor/psychoanalyst, responsible for helping to reveal the auteur's hidden visions to him/herself. In these cases, authorship is "considered not in terms of a personal signature":

...but more according to the mathematics of the child and the madman as they appear in Guerra's oeuvre; as one plus one equals one, so Guerra and Tarkovsky's work constitutes a whole in which one is inseparable from the other. (Pelo, p. 127)

Addressing the problems of screenwriter ego and power, I.W. Macdonald's ““...So it's not surprising I'm neurotic': The screenwriter and the Screen Idea Work Group" suggests a new paradigm for the screenwriting process: the Screen Idea Work Group (SIWG), which embraces the idea of feature-film screenplay collaboration on a larger scale and considerably earlier in the writing process. Macdonald's model extends group work on the screen idea (vs. the screen play) to a relatively large number of participants, including "the writer, the script reader, the script editor (a TV term) or development executive (a film term), the producer and/or the commissioning editor or department head, and the director" (Macdonald, p. 50). Phase two of the screen idea development process includes below-theline workers, including location scouts, actors, art directors, even the "friend in the bar who offers his own ending to the story" (p. 50).

The scholar takes his model to a group of seven diverse industry workers for feedback. Not surprisingly, the group's two screenwriters relive their own experiences in industry so far, talking "of being 'constantly rejected' (Writer B 2003) and 'being locked out of decisions' (Writer A 2003) and of being led into directions they were not inclined to go 
down" (Macdonald, p. 51); direct comments from other workers in the group are not offered. The upshot here is that "opposition of power and control versus collaboration and trust (is) a balance important to all interviewees" (p. 51) and if practiced correctly, the SIWG relieves the screenwriter in particular of the burden of 'genius' — viz., the expectation that $\mathrm{s} / \mathrm{he}$ will produce a flawless script that will please every member of the above-the-line team. All seven participants in Macdonald's survey agreed in conclusion that an admirable screenplay:

...appears to aim particularly at four specific goals associated with industrial practicability: realizability; an appropriate structure; a clear thesis, and some aspect of originality (or perhaps novelty).

(Macdonald, p. 53)

Macdonald concludes that the SIWG is a working idea only, and not one to replace "the idea of individual authorship" (p. 56); it is however an attempt to upset the "orthodox discourse" of power at the screenwriting stage, and in this regard contributes to a more equitable balance of screen ideas at the preliminary screenwriting stage.

Attribution of, or credit for, creative ideas is not the purpose of this way of studying screen idea development. It is instead intended as a way of understanding what actually happens when a moving image narrative is conceived, developed and produced. (Macdonald, p. 56)

\subsection{Literature Review: Conclusions and Implications}

Scholarship examining screenwriting and screenwriters is in, if not its infancy, then at least its early childhood: the diversity of approach exemplified by the small number of texts reviewed here suggests the literature has enormous potential to grow in scope and depth. 
One potential area for productive growth, I suggest, would be more direct observational research in the field. With the exception of the Macdonald article noted above, the studies mentioned here drew almost exclusively upon texts and historical records for their observations and conclusions: while credible enough in its own way, this methodology has left a number of its writers vulnerable to factual error and omissions. For example, Steven Maras' formidable theory misses the mark when it fails to acknowledge and deal with the all-important matter of collaboration in the screenwriting process. As we have already seen, filmmakers understand well that screenwriting is never as Maras suggests "the product of a single feature of conception or pre-planning" (Maras, p. 179), but rather an intensely collaborative process involving producer, director, primary actors and screenwriter that sees the screenplay continuously modified throughout the pre-production and production stages. Even a preliminary foray into the filmmaking field would have revealed just how much teamwork is involved in the conception and writing of any screenplay, whether a Hollywood or even an auteur script. The same argument can be made of Macdonald's worthy study: if the scholar had investigated writing processes amongst television writers, for example, he might have discovered his model has existed within that field for decades. The "writers' room," in which a half-dozen or so contract television writers gather first to collaboratively plan an episode, then reconvene at a later stage to discuss resulting scripts and to select the best dialogue, gags and plot turns from same, is a standard practice Macdonald might have referenced for his own model, if he had known of it. More importantly, ethnographic/observational research can, in combination with textual analysis, reveal new ways forward for a field of inquiry. If for example Maras had interviewed any of George Lucas' writing collaborators, he might have revealed considerably more about 
the American filmmaker's comments regarding "layered production," and how that new approach to screenwriting will no doubt transfigure industry writing in the years ahead.

But these are minor quibbles, to be sure, for a literature that is still finding its feet. What is most to be celebrated in this category are the scholars who insist that auteurdominated notions of the visual in film are not the only ideas for academic consideration, that definitions of the screenplay form are far from resolved, that matters of structure and format have more to do with industry compliance than with any empirical or deductive approach to the subject. At the same time, it is American and British academics who currently dominate the field of screenplay scholarship; the intention behind this dissertation is to add a Canadian perspective to that mix. 


\section{Notes}

1. An argument may be made to include here a grouping entitled the descriptive text on screenwriting, which incorporates a U.S.-dominated opus of published screenplays, many but not all of which are printed in their penultimate pre-production form. If there is a commentary included in these texts, it usually comes in the form of an introduction, sometimes written by the screenwriter her/himself, sometimes by the film's producer or distributor, or as often as not by a film scholar. Hollywood-produced screenplays are routinely published in their penultimate pre-production formats by theatrical publishers like New York's Samuel French, Inc. and U.K.-based Faber and Faber; in Canada, there is at least one textbook in this category: Best Canadian Screen Plays (1992; editors Douglas Bowie and Tom Shoebridge). While there are no doubt many insights to be gained by explicative readings of these commentaries, it is also the case that same are often dominated by production notes and/or personal recollections around shoots, the reception of the film, etc. My decision to not include this category in this paper does not mean it is without merit, only that it might be better scrutinized in a more holistic filmmaking context.

2. The screenwriting manuals now available to eager students number in the hundreds, with new volumes and updated editions appearing each year through a variety of American and British publishing houses. Many of these texts were designed to deliver Hollywoodtested instruction to acolytes residing both on and off a seminar circuit: consider Michael Hauge's Writing Screenplays That Sell (1988); Viki King's How to Write a Movie in 21 Days (1988); Wells Root's Writing the Script (1979); William Miller's Screenwriting for Narrative Film and Television (1980); Dwight Swain's Film Scriptwriting: A Practical Manual (1988); Eugene Vale's The Technique of Screen and Television Writing (1982); J. Michael Straczynski's The Complete Book of Scriptwriting (1982); Edward Dmytryk's On Screen Writing (1985); Irwin Blacker's The Elements of Screenwriting (1986); Robert Berman's Fade In: The Screenwriting Process (1988); Margaret Mehring's The Screenplay: A Blend of Film Form and Content (1990); Alan Armer's Writing the Screenplay (1988); Denny Flynn's How Not to Write a Screenplay: 101 Common Mistakes Most Screenwriters Make (1999); F.A. Rockwell's How to Write Plots that Sell (1975); and many more. A few of these books appeal to initiate writers who have completed at least a first draft of a screenplay and are contemplating a re-write (viz., Linda Seger's Making a Good Script Great (1987)), while others specialize in helping the writer prepare to market the screenplay (Field's Selling a Screenplay: The Screenwriter's Guide to Hollywood (1989); Cynthia Witcomb's Selling Your Screenplay (1988); Carl Sautter's How to Sell Your Screenplay: The Real Rules of Film and Television (1988), amongst numerous others).

3. Ian Parker, "Robert McKee, Lessons of a Screenwriting Guru," http://www.jewishtheatre.com/visitor/article_display.aspx?articleID=305. August 1, 2013. 


\section{Chapter 3: Methodology: Textual Analysis and the Interview}

\section{1: Methodology: Textual Analysis and the Interview}

There was never a point during this dissertation's planning stages that a qualitative research program was not the favoured approach. Given the ultimate goal to discover how English-Canadian screenwriters negotiate the normalized expectations of producers, directors and policymakers in writing their screenplays, acquiring such information through a quantitative approach (for example by survey, which requires large sample sizes to ensure reliability and validity) could potentially lead to consensus but not necessarily to insights on strategies deployed to negotiate funding and production directives. Further, the qualitative project as carried out through interviews provides a unique opportunity to understand in depth important professional/industry issues; ${ }^{1}$ these include not only the problems of negotiating funding requirements, producers' notes, directors' preferences and other above-the-line issues, but matters of film and literature scholarship, economic conditions of the screenwriting industry, etc., that may not be obvious to the academic researcher.

This dissertation deploys two major forms of qualitative research methodology: the first is that of textual analysis, which in this case will focus upon interpretive readings of eight full-length film scenarios (specifically in Chapter 6: Script Analysis), explication of a multitude of scholarly and trade textbooks promulgating various forms of screenplay models (in Chapter 2: Literature Review), analysis of numerous government and filmrelated policy documents (in Chapter 5: English-Canadian Feature Film Policy), and coding/analysis of interviews with eight English-Canadian screenwriters (in Chapter 7:Coding and Analysis). Understanding these texts in terms of both their inherent narrative 
structures as well as their larger cultural contexts is a major focus for this dissertation: close examination of these structures will reveal at least some of the major discrepancies and discontinuities between English-Canadian screenwriting policy and Hollywood practices. Textual analysis involves the close reading of texts to discern thematic clusters and thereby to reveal latent insights into issues around English-Canadian screenwriting.

The second qualitative research mode used in this study is the person-to-person interview: it is this form that provides this paper with its primary data for analysis and conclusions. Because the interview methodology deployed in this paper revealed significantly complex issues around matters of interviewee reliability, power relationships between interviewee and interviewer, and irony/ambiguity in the interview process, focus on this research approach forms the bulk of this chapter.

One note on interviews and ethics procedures: the University of Calgary's Conjoint Faculties Research Ethics Board (CFREB) requires that all university-affiliated research involving humans beings is a) kept confidential (i.e., by ensuring the identity of the participant is not revealed in any way), b) securely stored in locked files/filing cabinets and c) authorized by the participant with a written consent form requiring a signature and specifying the conditions of disclosed information. Interviewees for this project were also emailed the transcription of their interview (for approval and changes) as well as a consent form; this allowed them to choose their own pseudonym and sign off on the revised interview transcript. This additional approval stage not only allowed participants to correct certain specifics (viz., exact dates, places, etc.), but provided the researcher additional confidence in the accuracy of her interview materials.

Confidentiality of interview information is of particular importance. As significant but ultimately deferential contributors to any film project, screenwriters are particularly 
vulnerable to retribution (including dismissal or blacklisting) via any number of industry professionals, namely producers, directors, and the funding bodies that support their projects. Generally speaking, English-Canadian screenwriters are well-paid professionals whose contract positions have usually been won after long years of networking and confidence-building amongst those in the business; any suspicion that they are biting the hand that feeds them could potentially ruin or severely curtail their career in this highly competitive industry. Indeed, because much of the collected data exposed policy inconsistencies and/or ideological proclivities of these same players, the vast majority of the writers interviewed were openly worried about their anonymity; one writer later assured this writer that he/she had not provided any 'controversial' responses as a way to further protect his/her anonymity in the marketplace.

\subsection{Introduction to Textual Analysis}

Textual analysis (TA) is generally recognized as a qualitative method, but increasingly, scholars consider it a hybrid form, employing elements of both qualitative and quantitative inquiry. To review: quantitative TA (often known as content analysis) aims to identify commonalities and differences in large amounts of data through mathematical modelling or statistical estimation (explaining in essence the who and what factors of posed research), while qualitative TA (also known as interpretive textual analysis) seeks to understand the feelings, ideas and opinions of individuals and the social context of such information, typically through much smaller amounts of data (explaining the why and how of the research). As German sociologist and film theorist Siegfried Kracauer points out, qualitative textual analysis differs from its elder sister in that "it achieves its breakdowns without special regard for frequencies," focusing "not so much on the content of a 
communication as rather on its underlying intentions or its presumable effects on the audience" (Kracauer, 1952-53, pp. 637-38).

There are a series of paradoxes inherent in qualitative textual analysis: the first is the unavoidable act of quantification that occurs during the coding process, even when data sets are relatively small. As stated in American communication scholar Klaus Krippendorf's introduction to the subject,

(e)ven qualitative content analysts who avoid counting and measuring cannot bypass issues of unitization -- for example, when sampling textual matter for inclusion in a study, selecting relevant features of text for attention, or coding and sorting pieces of text into interpretable categories. (Krippendorf and Bock, 2009, p. 43).

There is as well an almost irresistible impulse when "sorting pieces of text into interpretable categories" to weigh categories with greater frequency counts against those with smaller counts, and thereby to grant larger data sets greater primacy during the final stages of analysis. This impulse no doubt arises from the prevalence of 20th-century quantitative research models, which de facto seek to measure and compare data sets based upon numbers and size versus meaning and idiosyncrasy.

On a related note, the British sociologist David Silverman points out that because coding schemes in both qualitative and quantitative research "are based upon a given set of categories, they furnish a 'powerful conceptual grid' from which is it difficult to escape;" further, this powerful grid may inevitably "deflect attention away from uncategorized activities" (Silverman, 2001, p. 123) and thereby miss important findings. In this case, the threat comes not so much from the numerousness of shared instances within a category as from the grip of certain ideas upon the researcher's imagination; for example, important 
diversity of evidence may be ignored for a more engrossing interpretation. Closely related to this issue for Silverman is the danger of creating too few categories during the coding process (p. 123), which again may not allow for sufficient diversity in the data to emerge, and which often results from coding in undue haste (p. 124).

Quantitative TA by comparison aims to prove its analysis by increasing its reliability, validity and generalizability. The first of these categories refers to consistency of measurement in research, specifically to the repeatability of research findings when replicated in a second or third course of research. Error is a key concern for researchers considering reliability, although it is understood that error is to be expected in testing and recording of research data, "whether the recording is accomplished by a machine or a human" (Drew \& Hardman, 1987, p. 115). Validity refers to the extent to which a work of research measures what it claims to measure, specifically by demonstrating the relationship between the experiment/tested behaviour and the experiment/test itself. Understanding the potential discrepancy between the two basic concepts — that is, that which a test should measure and that which it actually does measure — is essential for scholars concerned about quantitative research validity (Wiley, 1991, p. 84). Validity is for some quantitative researchers the most critical element in this duo, as it "answers the question, 'Did in fact the experiment... make a difference in this specific experimental instance?"” (Mason \& Bramble, 1989, p. 95). Generalizability (also known as external validity in some quantitative research circles) refers to the extent to which research findings can be validated or "generalized" from one test setting to another, or from a study to a population (Neuman, p. 131). This form "speaks to the issue of how much is the research setting like the world about which the investigator wishes to say something... How well do the results of a given investigation represent...the population being studied and the environment in which this 
population resides?" (Drew \& Hardman, pp. 120-121). The construct allows researchers to make predictions based upon these recurring instances, such that a premise may be generalized to a similar occurrence. However, the enterprise of generalizability is based upon the notion of probability, itself a problematic idea in science and one that cannot be regarded as conclusive (Mason \& Bramble, p. 196).

In the world of qualitative textual analysis (QTA), this "holy trinity" of validity, reliability, and generalizability often receive disdainful treatment. Norwegian research psychologist Steinar Kvale (1995) insists that all three constructs are laden with historical baggage, but at the same time admits it is a mistake to dismiss them out of hand. Balking at the traditional definition of validity and its preoccupation with measurement and numbers, Kvale calls for deeper questions in research: against for example quantitative methods of testing intelligence and future career success in schoolchildren, he asks instead, "what should be the criteria of success: job position, income, contributions to the community?" (Kvale, p. 22). He calls for a return to craftsmanship, communication and pragmatism in research - craftsmanship in that the researcher must pride herself on a continuous checking and questioning of findings, communication in that she must test her claims to valid knowledge in ongoing dialogue within a disciplinary community, and pragmatism in that research must not proceed without equal commitment to action or treatment.

British researcher Clive Seale picks up on Kvale's theme, replacing notions of quantitative validity and reliability with terms that better reflect a qualitative research project's "trustworthiness": these are truth value (viz., how can one find confidence in the 'truth' of these findings?), applicability (viz., how can one apply these findings to other studies and contexts?), consistency (viz., are the findings repeatable in other contexts?) and neutrality (viz., how can one ensure the biases and motivations of the researcher are not 
reflected in the data?) In place of reliability, there is "dependability," a reflexive exercise in auditing requiring the researcher to provide a "methodologically self-critical account of how the research was done" (Seale, p. 104). At the heart of this approach is the conviction that truth is not a single implacable reality but multiple "constructed realities" (p. 104) that appear plausible to a reader, are accompanied by strong evidence to support claims, and supported by research that is "value-relevant but not...value-laden" (p. 107).

\subsection{Qualitative Textual Analysis}

Textual analysis of the qualitative research conducted here was carried out in a (roughly) two-stage approach. First, a close reading of all relevant texts (viz., scholarly literature, films, interviews, policy documentation, etc.) was undertaken to identify their particular commonalities and meanings; these commonalities were segmented into a series of distinguishable categories, each category coded with a word or short phrase that describes it (i.e.: in this paper's coding and analysis section, the category of Outsider Status constitutes a significant segment of the research). When required, larger categories were broken down into discrete segments to allow greater comparison of data sets (i.e.: Outsider Status is broken down into Outsider as Woman, Outsider Language, Outsider Education, and so on). These category labels were created in response to repetitive cues from the data.

Stage Two then required active comparison of coded segments between various sources to discover differences and similarities in the data, and to draw inferences and conclusions about these coded findings. In performing this phase of the research, conscious effort was put in to discern themes through inductive rather than deductive reasoning that is, I sought premises that might provide evidence for the truth of an assertion rather than impose premises upon the material to be proven through evidence. 
As for Seale's qualitative measures of truth value, applicability, consistency and neutrality, these research aims are not so easy to measure in one's own work. However, throughout the stages of my textual analysis, I actively worked to keep normative responses at bay by demarcating and thoroughly examining less frequently coded segments and by keeping the highest aims of qualitative research front of mind at all times. This latter case manifested itself as a continuous questioning of my methods as I proceeded through the coding and analysis stages: Am I working to discover the latent implications of the text here? Have I neglected to treat any apparently off-hand comments or oral clues (i.e.: sighs, laughter, silences) that may support or contradict my working theories? Could the results of this work be applied to other industries, or to other professions within the filmmaking profession? Am I appropriately unbiased in my treatment of all texts — particularly given my own experience with screenwriting? Am I sufficiently sensitive to irony and sarcasm in all texts, particularly in the screenwriter interviews? or on the other hand, am I over-reading what appears to be irony/sarcasm in the text? In the absence of visual clues from interviewees, this latter question can be difficult to answer, but the spirit of the exercise remains. In all cases, the researcher's task is analyze and code texts in the spirit of early 21 st-century research: that is, sufficiently aware of personal bias, misreadings and miscalculations, but devoted to continuing on in the spirit of academic curiosity.

\subsection{The Interview and its Evolution in Social Sciences Research}

David Silverman's claim that we live in “" an interview society,' in which interviews seem central to making sense of our lives" (Silverman, 1997, p. 248), strikes a chord in many fellow sociologists. One agrees that the interview now "produces our contemporary 
cultural experiences and knowledges of authentic, personal, private selves" (Rapley, 2004, p. 15), while others note the interview is today "a worldwide form of cultural production": The interview is part and parcel of society, not simply a mode of inquiry into and about society. If it is part of, not just a conduit to, our personal lives, then we might as well entertain the possibility that the interview's ubiquity serves to...ramify the very culture it ostensibly only enquires about. (Gubrium and Holstein, 2002, p. 30)

Clive Seale (2004) similarly lauds the interview as producing a great diversity of research techniques and principles, from the positivist survey instruments of the 1940s and '50s, to the romantic, emotion-saturated experiments of the 1960 s, and finally the constructionist epistemologies of the 1990s and beyond. His historical perspective clarifies the quantitative-to-qualitative progress made since the early 20th century, when sociologists using the interview as a research technique first conceived of it in positivist terms, an ideal tool with which to mine the mind of the interview subject. Holstein and Gubrium dub this the "vessel of answers" approach in which the active scientific researcher plumbed the "repositories of facts and the related details of experience" within the passive subject (Holstein \& Gubrium, 1995, p. 7). Because the authenticity of the subject's knowledge is easily contaminated by non-scientific methods (i.e.: a directional or biased interview process, a distracting interview setting), the researcher is directed to follow the best practices of interview methodology: viz., ask "neutral" questions that "acknowledge alternate sides of an issue," suppress all personal opinions, "shake off selfconsciousness... and avoid stereotyping the respondent” (1995, pp. 9-11).

Jennifer Platt's history of the interview discovers this vessel-of-answers approach in an early guide to interviewing techniques: H. Odum and K. Jocher's 1929 Introduction to 
Social Research. In this text, the subject is not simply a neutral and passive interviewee but an informant probed for "data" that may "corroborate evidence got from other sources" (Platt, 2002, p. 36). She may also be of "status superior to the interviewer," which means the researcher must proceed with an "unstructured (interview) approach" that will not antagonize or unduly upset the respondent (p. 36). In this case, the control position usually assumed by the interviewer is not a fait accompli, but a stance that may be threatened by a senior and potentially antagonistic interviewee. In 1939, American social worker Pauline Young published Scientific Social Surveys and Research, which signaled a departure from the approach of the pre-WWII Odum \& Jocher manual, the author recognizing that the researcher's goal of establishing herself as a neutral party in the exchange is neither productive nor realistic:

The fieldworker needs to know in a general way why he is interviewing this particular person or group and what he intends asking... The interview proper does not begin until a considerable degree of rapport has been established... The most important touchstone is probably the mutual discovery of common experiences. (qtd. in Platt, pp. 36-37)

Instead of describing the controlled environment and question set that would most efficiently extract answers from a potentially volatile informant, Young advises the researcher to sit back and let the respondent speak: "When people are least interrupted, when they can tell their stories in their own way, they can react naturally and freely and express themselves fully" (Platt, p. 37).

In his discussions of research evaluation, Clive Seale points to a holistic turn in post-WWII research methods: "Before the 1940s," he notes, "people just interviewed" 
(Seale, 2004, p. 103) without distinguishing between quantitative and qualitative approaches. Post-war changes were prompted by new marketing techniques in the form of "structured" interviews, also known as surveys: now, instead of interviewing an expert witness or informant (whom Seale notes often acted as a "gatekeeper" of information), the researcher approached "a member of a sample representing some population" with a largescale survey (p. 103). These larger survey instruments sought standardized information and were usually conducted by contracted interviewers who had not been involved in the design aspects of interview questions, which meant they could not query respondents in a 'qualitative' manner.

In 1964, American sociologist Aaron Cicourel published Method and Measurement in Sociology, which took an interest in the topic of the interview itself - the 'how' of the instrument - rather than in its results - its 'what.'

Method and Measurement took sociology away from the Durkheimian notion that the social world exists independent of human action... and toward a vision in which social reality is created, structured, and sustained through social interaction. Moreover, social interaction was shown to be possible only by, and through, the intersubjective meanings and resources that are provided by language and other communicative practices. (Davies and Mehan, 2007, p. 596)

Two points for consideration here: first is that research for Cicourel is not conducted in a black box that renders neat answers from neatly formulated questions. The process of the interview is considerably messier: it must take into account a vast range of differences between interviewer and interviewee, including personal beliefs, cultures, memory and even comprehension. Writing later in his life, Cicourel noted that one of the (relatively) 
unaddressed issues of sociological research involved a "lack of theory of comprehension and communication that can provide a foundation for the way that question-answer systems function, and the way respondents understand them" (Cicourel, 1982, p. 11).

The implications of this gap for Cicourel were troubling, particularly as he observed these effects in his own research in organizational communication: namely, that when there is a lack of theory to organize and interpret large, ambiguous communications between for example patients and doctors, or supervisors and employees, the power route will always emerge as the dominant choice. This route brings about a "'historical reconstruction' of everyday discourse...with considerable consequences" for the people involved (generally, the people lower down the bureaucratic scale) in the exchange (Davies and Mehan, 2007, p. 600). Indeed, Cicourel insists that "structures of dominancy profoundly influence every aspect of social action":

Domination, as a special case of power, is closely linked in modern societies to the possession and use of knowledge. This view of power in especially evident in the professional-client relationship, particularly the case of doctor-patient exchanges, where knowledge as power also translated into economic rewards. (Cicourel, 1985, p. 170)

The second important point in this discussion is one deeply entwined in all aspects of social interaction: language and literacy. Revisiting his concern about knowledge and power in the medical setting, Cicourel considers the referral interview as a particularly revealing scenario: he describes how in a typical referral setting, an oral or written note about the patient's concern is passed from a nurse to a physician, how that physician "poses indirect, direct, leading or probe-like questions" to the patient, and how these responses are translated into hypotheses about a "differential diagnosis." It is this "historicized, 
interpretive, summarization process that can subsequently result in the production of a crisp and factually oriented oral or written account of the patient's medical history" (Cicourel, 1985, p. 174). This "crisp" analysis however ignores the ambiguous and confusing torrent of information that may emerge from the patient during the first meeting with the physician, which is often based upon the patient's own messy, unsuccessful series of meetings with other physicians - and as a result, it risks trivializing the knowledge the patient herself has of her symptoms and medical history.

Researchers take these same risks when they deploy the tools of the interview and its analysis. Cicourel points out that scholars seldom allow their readers to "see the limitations in our own knowledge base and how such limitations can influence our inferences and claims about those studied" (1985, p. 182): in essence, he accuses researchers of making laymens' mistakes when incumbent writing and literacy practices prevent them from transparency in their dealings with interviewees. Much of the problem here comes from the research community's own bureaucratic literacy and the opacity of its writing practices, despite the scholarly desire to seek "objective, context-free textual knowledge" (1985, p. 183).

Methodological discrepancies are most obvious when researchers leave their academic confines for alien arenas where not just language and interpretation but values and systems are foreign currency, and where, against standard procedure, interviewees are of greater social status than the interviewer and have the upper hand in the interview process (also known in early '70s research circles as the "elite" interview (Dexter, 1970)). This is the general scenario described by American anthropologist Hortense Powdermaker in her celebrated 1950 study, Hollywood, the Dream Factory: An Anthropologist Looks at the Movie-Makers. A comparison between her methods and the qualitative work done in 
this paper will reveal various similarities in approaches but, more productively, a number of key differences that reveal evolutionary changes in the qualitative interview in a filmmaking setting.

\subsection{The Interview in Hollywood: Powdermaker's Project}

Powdermaker describes her 13-month project (July 1946 to August 1947) to study the nature of American film via systems theory:

My hypothesis was that the social system in which (movies) are made significantly influences their content and meaning. A social system is a complex co-ordinated network of mutually adapted patterns and ideas which control or influence the activities of its members.

(Powdermaker, 1950, p. 3)

As a working anthropologist with experience studying Aboriginal people in the South Seas, Powdermaker saw little difference between the inhabitants of Hollywood or Polynesia, except for the fact that the former spoke English (which meant that she as researcher did not have to "learn a new language or work through an interpreter" (p. 4)) and the latter lived in a self-contained village (unlike Hollywood citizens, who were dispersed by profession and income throughout the many boroughs of Los Angeles). This last point also meant that finding a representative sample of 300 individuals distributed across the functions of producer, director, writer, actor and so forth was time-consuming ("Taking every nth name in a directory would simply not have worked" (p. 4)). However, with a few letters of introduction and recommendations from contacts, she was eventually able to complete 900 interviews over her research period. Some people she saw once, others a halfdozen times; interviews were conducted in homes, studios and restaurants. 
Powdermaker describes her role in the data collection process as that of participantobserver, as much of her initial field work was done by watching directors, actors and producers on set or at guild meetings, where she learned of their complaints and issues. She refrained from taking notes while interviewing her subjects: “(I) have found that when I want fairly intimate data, I get more by not writing during the interview, even at the risk of forgetting some details" (Powdermaker, 1950, p. 6). Once the interview was complete, she would drive her car around a corner and write down as much of the conversation as she could remember.

While her process is in contemporary terms true to qualitative research - if for no other reason than it employs a series of in-person interviews - there are a number of anomalies in Powdermaker's methodology that would not be considered necessary or even desirable in current research circles. The first is her goal to discover norms in the data revealing filmmaking patterns in Hollywood, "and the way they work":

While I tried to get the norm for each of the major patterns (of mores), I was equally interested in the exceptions which often clarify the norms. In a changing situation, the exceptions may also represent new trends. (Powdermaker, 1950, p. 7).

This idea of gathering large quantities of information with the goal to identify key characteristics (and their exceptions) across numerous groups suggests a textbook approach to quantitative survey work - it is in essence the aim to identify patterns in discrete groups that would allow the researcher to compare groups and make claims about their attributes. Further, Powdermaker's large sample size of 900 interviews supports the quantitative research goal, which prompts generalizations across broader populations and lends itself to numerical/statistical information. At the same time, her goal to capture "intimate" data 
without a standardized set of interview questions, coupled with her complete immersion in the world of her subjects, suggests a strong commitment to qualitative research goals as they are defined in current scholarship.

Powdermaker makes good on the integrated nature of her research by grouping her interviewed screenwriters by their characteristics ${ }^{2}$ : these groups are identified with adjectives, viz., "Mr. Hopeful," "Miss Sanguine," "Mr. Pretention," "Mr. Modest," "Mr. Cynic," "Mr. Acquiesce," etc. Each of these neatly inscribed categories provides her with a place to note the general backgrounds, the salaries, the hopes and values of the grouped screenwriters. At the same time, her appreciation for qualitative information reveals itself when the otherwise conglomerated "Mr. Cynic" becomes an individual through a meaningful quote:

(H)e opened a conversation with the statement, "I am a hack writer," in a rather bitter tone, and then mentioned that he had no respect for anything that he had written in Hollywood. (Powdermaker, 1950, p.

The idiosyncratic tone of this quote — the ineffable quality that makes it the heartfelt words of an individual rather than the amalgamated intentions of a group — is the condition of the qualitative exercise, one that seeks a kaleidoscopic view of human work rather than an authoritative, "scientific" pronouncement of truth regarding screenwriters in post-WWII Hollywood. Although, like Powdermaker, I too find commonalities between the writers I have interviewed, idiosyncratic quotes play a more significant role because I find they provide insights about the highly individualistic nature of screenwriting in 21stcentury English-speaking Canada. It's also important to note that unlike Powdermaker's 
strategy to meet in person with her interviewees, I approached my subjects first by email (to set up an appointed time for the interview), then interviewed all by telephone.

\subsection{On Technological Advances and the Interview}

Since 2000, scholars have noted steady growth in the use of various technologies (i.e.: telephone, email, internet, Facebook, etc.) in conducting research; much of their writing focuses upon methodological challenges, including increased concerns about potential loss of confidentiality and privacy, possible misunderstandings due to the lack of a face-to-face encounter, "losing the thread" of communication during an extensive online interview, etc. James and Busher (2006) posit that lack of personal contact in even the most active technology-enabled interviews is an "adverse" outcome, one that tends to "deprive participants of the sense of engagement in a human conversation and a sense of knowing...who a researcher is socially" (James and Busher, 2006, pp. 411-412). Further, they suggest democratization of the interview agenda through the "equal ground" of technology-enabled discussion is undermined by the fact that the researchers set the interview agenda and terms, and monitor reply frequencies. Nevertheless, the telephone interview may also produce a thoughtful set of responses, such that narratives developed between both interviewer and interviewee become more "naturalistic" and "rich," with participants exerting a comfortable modicum of control during the interview process (James and Busher, p. 415).

While telephone interviews hardly seem technologically advanced, many researchers are still reluctant to rely upon them for anything more than short exchanges, fearing a lack of visual clues and the mechanical nature of the exchange may weaken data quality (Sturges and Hanrahan, 2004, p. 108). These same researchers later discovered however 
that telephone interviews also provide participants with a heightened sense of anonymity and the convenience of teleconferencing from home. The interviewer similarly benefits from the telephone interview, particularly when it comes to costs, and/or when the research setting presents "some potential danger" to her/him (i.e.: when the researcher is female, the participant male, and the research location isolated or closeted; Sturges and Hanrahan, p. 110). On balance, the qualitative interview can be successfully conducted by telephone, they posit, if a) initial recruitment of participants is done in a face-to-face encounter, and b) the research agenda does not rely upon visual cues as a major component in its data. Indeed, these researchers insist that close comparison of telephone interview and face-toface interview transcripts "reveals no significant differences in the interviews" (Sturges and Hanrahan, p. 107).

\subsection{Interview Research Methods for this Project}

Because rapport (which can be difficult to secure in a single email interview) is a major component in conducting conversations with other writers, real-time interviews appeared the best possible tool with which to provoke desired insights. Further, because time and travel expense were factors in this equation (the writers live in four different cities, including Vancouver, Montreal, Toronto and Los Angeles), I opted to interview my subjects by telephone at their homes during times when they were unencumbered by work or parenting concerns. After obtaining permission from each interviewee, I both recorded the telephone session and made typed notes on my computer as the participants spoke; this strategy provided me a back-up if one of these recording strategies failed, and allowed me the chance to highlight in my typed notes the most enlightening points made during the interview. 
I obtained access to these screenwriters via the Writers Guild of Canada (WGC), whose administrators I approached for help in early September 2013. The WGC office relayed my research parameters to its membership by email; within two days, I was approached via email by three different screenwriters, and subsequently interviewed all three. A film studies professor at the University of Alberta kindly approached a number of her screenwriting friends for their help in my research; a total of five more writers then agreed to participate in the study. As per my agreement with the research ethics authority associated with the University of Calgary, all eight screenwriters were promised anonymity (each choosing their own pseudonym), and all were granted the opportunity to view and change any misinterpreted words or phrases in their transcripts, and to sign off on their contribution to the project.

In sum, I conducted a total of eight English-language telephone interviews with eight different English-Canadian screenwriters over a period of three months - September to November 2013 - with each interview lasting on average one hour. Some interviews ran a little longer, particularly those in which interviewees opted to contribute final insights about their experiences in the discipline; in these cases, some of the 'last-minute' contributions continued another half-hour or longer. In total, the interviews generated 145 pages (approximately 36,250 words) of double-spaced text. Because clarification of tone, pauses, emphases and inflection in the dialogue is important in the interpretation of this data, I opted to transcribe the interviews myself.

I began the interview with a set series of questions, but often deviated from these if the interviewee expressed impatience with the query or suggested a better line of inquiry (this happened more often than expected). In all interviews, I sought to discover the context of the screenwriter's approach to his/her work (by asking questions about the individual's 
education, his/her background (i.e., reading habits as a child, occupation of parents, etc.)), and the ideological/rhetorical stances that may have informed each individual's approach to screenwriting (viz., by probing on compliance to dominant Hollywood screenplay models, by asking for information about "bad" experiences with producers in both Canada and the U.S., etc.)

As per the guidance of interview scholarship (reviewed above), I reflected from time to time during my telephone interviews upon the importance of social status in research gathering. As per Lewis Dexter's advice on interviewing elite informants, I entered into each interview seeking to establish neutrality but also adopting, as far as was possible, "the interviewee's orientation (and) sympathetic understanding so that the interviewer (could) without strain talk the informant's language" (Dexter, p. 26). Platt's advice to consider the researcher's social status vs. that of his/her informant was also top of mind; in this case, however, the possible issue of domination by the researcher was not relevant. Most successful screenwriters seem to consider themselves elite personalities — or at any rate, more elite than $\mathrm{PhD}$ candidates - and certainly as adept in language skills and nuances as any graduate student. I found my interviews curtailed more by time and interest constraints imposed by the writers than by any limitations at my end. As per instruction from Young and Dexter to encourage interviewees to elaborate without interruption upon certain sensitive or irritating topics, I was careful to let informants talk at will upon whatever subjects they found appropriate, including many that did not directly answer my questions. In some cases, these answers took the form of autobiographical information, long anecdotes about colleagues in the business, philosophical asides about the industry, etc. Finally, as per Cicourel's notes, I kept in mind during all proceedings that the interview is itself a field of social reality - an arena where truth is co-created, not excavated as from a mine. 
Preliminary analysis of the data was launched immediately after the final interview. Coding of the eight interviews was completed with the assistance of MAXQDA software; a catalogue of codes, consisting of 55 topics (i.e., "Anomalous Structure," "Insider Language," "Power: Readers," etc.) provided the foundation for the project's analysis. After completing the coding, this writer swept the data several more times to ascertain anomalies of tone (i.e.: sarcasm, irritation, humour) and to find instances where the screenwriters paused or interrupted. Such instances afforded the analysis greater depth of interpretation, particularly when it came to appreciating subtle differences in agreement (between interviewer and interviewee) or camouflaged changes in the direction of discussion (usually precipitated by the interviewee).

At the time of the interviews (late 2013), the purpose of my study was to describe what I considered a uniquely English-Canadian approach to the writing of feature-length film screenplays; as the interviews progressed, however, this goal became less a project to outline one definitive approach and more an opportunity to describe the innumerable ways in which these writers assess, negotiate and elude in their own unique ways the normative structures of feature film screenwriting in English-speaking North America. All eight screenwriters were introduced to my initial research goal at the beginning of our telephone interviews: few shared interest in this goal, but all proceeded to explain to me their personal aims in writing their scripts. As noted, these aims changed the general direction of my research in what I now consider a more productive and enlightening direction. 


\section{Notes}

1. Given the recent explosion of scholarly literature on the subject, a complete and unbiased description of the "proper" goals of qualitative research is a very large task. While my depiction of qualitative research here does not acknowledge the strides made by numerous academic stars, it nonetheless depicts the bare essentials of the field in a way that provides this chapter with a context.

2. Although I focus here upon Powdermaker's treatment of screenwriters in her study of Hollywood, it is important to note that she did not neglect equal treatment of other above-the-line players in filmmaking, viz., producers, distributors, directors, actors and stars. 


\section{Chapter 4: Theory Influences: Luhmann and Certeau}

\subsection{Theory Influences: Luhmann and Certeau}

Twentieth-century cultural theorists Niklas Luhmann and Michel de Certeau could not be more polarized: one was a systems theorist who described society as an innumerable set of organizations that establish themselves through communication, and the other an antisystems exponent who observed that many (if not most) members of society live in the cracks between systems and automatically take advantage of those breaches whenever possible. Luhmann believed humanity follows a normalized but not essentially humane order, with individuals responding in systems-level ways to stresses and opportunities;

Certeau celebrated humanity as a resilient race whose ability to consciously but mostly unconsciously defy systems preserves its place in the world. It is not clear whether these two contemporaries, one an embedded scholar in Germany and the other a Jesuit instructor living between France, South America and the United States, knew of one another's work; if they did, it seems unlikely that either was particularly compelled by the other's theory.

How could two such antithetical writers properly inform a project like this one? First, it's important to note that both Luhmann and Certeau consider 'the System' a reality of contemporary society, with each theorist (albeit one more cold-bloodedly than the other) describing ways individuals are created and constrained by their own organizations. Because this dissertation addresses Canadian cultural policy and the ways in which applicants deal with its often monolithic regulatory conditions, a theoretical perspective upon 1) how a system functions and 2) how it is negotiated, is, in my opinion, essential.

Second, it's possible to regard the two theories as a form of yin and yang, whose interdependency is complementary rather than purely oppositional. Luhmann continuously 
asserts the conditions of the system in an opus of scholarly writing that itself can be likened to a grand system; Certeau comments lyrically, passively, anecdotally upon the details that support his sometimes opaque observations. In both style and substance, Luhmann's theory provides a productive set-up for Certeau's revolutionary thesis: where the first writer envisions an impermeable system free of human choice and volition, the second observes the same system occupied by relentlessly marching individuals (ants swarming over and through a concrete wall) — not because these individuals desire to tear down the system (or the concrete wall), but simply because the system must be negotiated/climbed over.

Third, to my knowledge, no single writer within the discipline of sociology neatly encapsulates the theoretical focus of this dissertation. One candidate earlier in the process of developing this paper was Michel Foucault, who positions the system in political terms as an amalgam of power and knowledge, wielded to control subordinates. Pierre Bourdieu was another considered contestant: his sociological work on how educational institutions shape cultural tastes and thus perpetuate the class system might have provided a lens through which to consider the problems of Canadian film policy. Both Foucault and Bourdieu belong (in varying degrees) to what the communications community would consider an activist school of scholarship: while their writing does not prescribe revolutionary change, it describes conditions in such a way that no active reader could fail to recognize the call for social and policy change.

Neither Luhmann nor Certeau would be considered strong activist theorists, although the latter is anything but a conservative thinker. It is this aspect of their writing (viz., an observational and at least semi-detached approach to the subject of social justice) that makes them valuable to this project, as it is in my opinion important not to prescribe solutions to malfunctioning policy bureaucracy in the process of empirical research, but to 
observe and describe the field first, then to recognize appropriate implications of the research for bureaucratic change from those working in the field. Without this relatively hands-off approach from the scholarly community, there is little hope for true change; activism should begin within the discipline, not with an outsider, no matter how well informed he/she may be.

\subsection{Luhmann in Context}

Surprisingly little has been written, or at least translated, about the life of the German sociologist Niklas Luhmann (1927-1998). What is known is that Luhmann was born to a brewer and his Swiss wife in Lüneberg in northern Germany, and that as a child he attended a National Socialist Gymnasium. The family “cultivated its distance towards the (school's) regime" by spending as much of their free time as possible in Switzerland with in-laws; this distancing also allowed the boy to indulge his "forbidding reading mania" (Stichweh, 2011, p. 287). By 1943, however, the 15-year-old was drafted to help load anti-aircraft guns at the local airport; a year later, he was provided with a brief course of military training and deployed as a regular soldier in the German army. In 1945, he was captured by American troops and sent to a prisoner-of-war labour camp in the south of France, where he was beaten and otherwise harshly treated. Biographer and sociologist Jakob Arnoldi suggests Luhmann's treatment at the hands of the Americans led him to pursue a career in law, "which he saw as instrumental in restoring order to the chaotic postwar society" (Arnoldi, 2001a, p. 249). After completing his law degree at Freiburg in 1949, the young man returned to Lüneberg and began a dissertation that was never completed. In 1960, he accepted a scholarship to Harvard where he worked for a year under the cyberneticist Talcott Parsons, whose writing and mentorship had a noticeable impact upon the young 
Luhmann, at least during the first part of his academic career. By 1966, he was granted a chair at Münster and, three years later, accepted a tenure position as a sociologist at the new university in Bielefeld. During the course of his career, Luhmann wrote no fewer than 50 books and more than 300 scholarly articles; when asked in later life to describe his research, he replied, "A theory of society. Duration: 30 years. Costs: none" (Arnoldi, 2001b, p. 1).

While German sociologists have been significantly influenced by Luhmann's theory, on this continent he is still best known as the unofficial loser in an early- ' 70 s debate with countryman Jürgen Habermas; this heated skirmish was later recollected in a joint collection of essays on the qualities of systems theory, the Theorie der Gesellschaft oder Sozialtechnologie (1968). While both authors worked within what C. Wright Mills described as the grand theory approach to sociology, it was Habermas' critical approach that met with general approval on this side of the Atlantic. With apologies to Habermas, his argument may be distilled as an historical model defining an idealized public sphere as a democratic culture in which any citizen may speak openly, and where "arguments are not distorted by fear or political or social power" (Gestrich, 2006, p. 415). Luhmann on the other hand argues that society is too complex to be reduced to holistic notions of nations, norms and lifeworlds: society is in fact a numberless series of distinct but comparable subsystems (or codified arrangements of conduct) that define themselves, evolve and reproduce via the act of communication. Indeed, according to Luhmann, "society is communication" (Lee, 2000, p. 320)).

This theory of communication requires considerable unpacking. First, Luhmann's systems are defined not by their size or number of members (they may be as small as a family, an individual or a body part, or as substantial as an transnational institution (i.e., the 
legal system, the institution of education, etc.)) but by their core elements, which include their ability to distinguish themselves from other organizations (differential theory), their capability to recreate themselves (autopoiesis), to evolve, plus their raison d'etre, which is to communicate. Luhmann notes that complex and arbitrary structures that may seem to comprise logical 'systems' - nations, as one example — are in fact conglomerates of many subsystems (i.e., educational, economic, scientific, etc.); nations in particular are too multifaceted to be considered systems in themselves. Subsystems by his definition are arrangements that exist within highly complex systems to reduce complexity and provide a form of interpretation/meaning for the larger system (in that they reduce confusion due to inordinate system-wide complication and in doing so provide opportunities for action and decision-making).

Before proceeding however into more discussion of Lehmann's approach to systems, it is essential to examine his first doctrine: differential theory.

\subsection{Differential Theory}

In a 1991 lecture delivered to his colleagues at the University of Bielefeld, Niklas Luhmann discussed a concept he considered the most foundational of his social systems theory: the differential theoretical approach (Luhmann, 2006c). This conception of difference, with reference to Jacques Derrida, the French sociologist Gabriel Tarde, Lehmann's teacher Talcott Parsons, mathematician Louis Kauffman and others, begins with British anthropologist Gregory Bateson's assertion that information is "a difference that makes a difference” (Bateson, 1972, quoted in Luhmann, 2006c, p. 40). Here, difference is posed in a temporal mode: information is information only after it has arrived and created a change in a particular system. It is not information until that point in time, 
and it is not information a second time (that is, information loses its value as information when it is no longer new).

He follows this line of thinking with a description of difference, depicted in this case as an arrow. The arrow is a straight line with an arrowhead at its end and bent into a circle "so that it points to itself" (Luhmann, 2006a, p. 42). In this form, the arrow describes not one idea but two: reference and reference to self. For Kauffman, this elemental sign represents the recognition that there is no difference between self-reference and observation, "for he who observes something must distinguish himself from that which he observes" (p. 43).

Luhmann expands this notion of difference with reference to the work of British mathematician George Spencer-Brown, specifically his calculus of distinctions. For Spencer-Brown, distinction begins with the drawing of a line - or what he calls a cross that represents a difference between a space that is observed and a space that is not observed; the crook at the bottom of the cross indicates the area included in observation. With the drawing of the crook, the space takes on an asymmetry: the marked or included side now receives the entirety of the observer's attention while the unmarked side receives none. What is significant about distinction is that while the observer observes the marked side, he/she does not 'see' what has been excluded and therefore does not consider the possibilities of other marked sides or other unmarked sides. The distinction in this case is purely arbitrary and carries with it the potential for more focused scrutiny, namely: why has the observer chosen to regard the marked side and to exclude the unmarked? SpencerBrown observes in this regard that a boundary that draws a distinction is a "form" - a thing with two sides, system and environment. Luhmann suggests a system may be called a form if and only if it invokes the difference between system and environment. Such a seemingly simple idea is nonetheless "not intuitive," and Luhmann suggests the reader "simply must 
keep it in mind" (Luhmann, 2006a, p. 44). Indeed, as he makes his next point (that systems comprise a plurality of terms (unit, boundary, process, structure, etc.), a veritable "andness" of elements), he asks us to imagine that such a united chain of operations occurs within a particular environment. If this chain of elements continues and the operation in question is "capable of connectivity," a system emerges and "creates itself as a chain of operations" (p. 46)). Nothing more occurs at this stage: the system continues to create itself in a series of operations, and the system's environment — Spencer-Brown's unmarked side — remains outside and unobserved.

Much farther past these descriptions of difference, Luhmann claims he dares not venture: the important point for him is this simple idea of distinction - but not just any distinction. "The theoretician must use the pointer or indication in such a way that it indicates the system and not the environment," writes Luhmann. "The environment remains outside. The system is on one side, the environment on the other" (Luhmann, 2006c, p. 44). In other words, the system is structured in such a way that it not only distinguishes itself from its environment, but shuts off the complexity of the environment; in this way, the system may continue to thrive (relatively) independently and within the activities of its own chain of operations.

But specifically how does this chain of operations continue within the system? Here, Luhmann enters into a second major component of his systems theory: autopoiesis.

\subsection{Autopoiesis}

Autopoiesis, or the ability of the system to repeatedly reproduce itself, depends upon a variety of linked functions. Luhmann invokes the Chilean biologist Humberto Maturana and his icon of the circle to describe (in brief) how systems first began to self-produce: 
At some point in time, such a circular mode of operation was set in motion for reasons that can no longer be known with any precision and that one can state as a living being only if one is already alive. For evolutionary reasons, this process multiplied and then there were worms, snakes, human beings and all forms that are possible on the basis of an orientational type that, in principle, always has the same chemical composition. (Luhmann, 2006c, p. 46)

In this naturalist schema, the circular form of self-reproduction "multiplies" to create additional inventions ("such as bisexuality, the central nervous system and so forth," p. 46), but in every case, these inventions presuppose an initial system with "the same chemical composition." As per Luhmann's differential theory, the system continues to be distinct from its environment, with this difference in the act of autopoiesis "produced and reproduced by the operations of the system itself" (Luhmann quoted in Seidel and Becker, 2006, p. 14). But where Maturana's theory deals with biology and is committed to describing actual operations of living systems, Luhmann takes the concept to a more esoteric level: autopoietic movement for him is not simply a reproducible biological event but an abstract concept that may be applied across scientific disciplines. "If we abstract from life and define autopoiesis as a general form of system-building using self-referential closure," he posits, "we would have to admit that there are non-living autopoietic systems, different modes of autopoietic reproduction, and general principles of autopoietic organization which materialize as life" (Luhmann, 2006a, p. 64).

Having released autopoiesis from its ties to living systems, Luhmann is free to apply the process to non-living systems, including the organization and society — and at a sufficiently abstract level, autopoiesis also becomes a process dislocated from temporality 
(if not history). Luhmann sees autopoiesis in a sociological context as exempt from normal contingencies, such as duration: while reproduction in a biological setting requires sufficient time and energy to see cells develop and mature, the autopoietic knowledge system shifts within the space of an utterance. "Events have no duration but vanish as soon as they come into being; they are "momentary and immediately pass away"' (Luhmann quoted in Seidl \& Becker, 2006, p. 16).

A self-reproducing system is subject to a number of other constraints/requirements: the most important of these is the necessity of the system to regard itself. Unlike most acts of self-observation, however, these perceptions occur not as a result of observation of the system's environment, but of its own programs in lieu of the environment (recall Luhmann's differential theory in which an observer can observe only the 'marked side,' which in this case is the system's own operations). "(T)here is no difference between selfreference and observations," notes Luhmann, "for he who observes something must distinguish himself from that which he observes" (Luhmann, 2006c, p. 43).

A second major characteristic of the autopoietic system is its operative closure. Operations performed by a system occur internally, not from the system's environment: like a living organism that produces its own blood cells, sugars and lipids, the system must reproduce its functions through continuous internal renewal of processes. Luhmann again turns to the biologists Maturana and Francisco Varela to describe operative closure, making specific reference to Varela's case of a cell:

(I)t is a network of reactions which produce molecules such that (i) through their interaction they generate and participate recursively in the same network of reaction which produced them, and (ii) realize the cell as a material unity. (Varela et al, quoted in Seidl, 2004, p. 2) 
Operative closure does not rule out the need for exchange with the system's environment; closure in this case means that operations are not free to leave the system, nor are new operations free to enter it. Like all living creatures, systems depend upon their environment for survival - an "exchange of energy and matter without which they could not exist" (Seidl, 2004, p. 3). However, this exchange with the environment is governed by systems in that the system itself determines which sources of matter and energy will enter; this cooperative arrangement Luhmann calls interactional openness.

Further, as Maturana and Varela insist, “(o)perative closure is a precondition for interactional openness" (Seidl, 2004, p. 3). Rather than the environment invading or entering the system in the process of interactional openness, Luhmann suggests the environment sparks perturbations (or what he calls irritations) in the system, which cause changes, either small or profound, within its internal structure. It is important to note that these irritants do not directly effect change within the system: they "take effect as if read or interpreted by the organism through its own internal language" (Lourenco, 2010, p. 2). The productive relationship between system and environment allows both system and environment to co-evolve; Luhmann dubs this new dynamic structural coupling. A system is structurally coupled to its environment if its structure is "in some way or other 'adjusted' to the structures of the environment" or if the system reacts positively (that is to say, not in a self-destructive way) to important environmental occurrences (Seidl, 2004, p. 4).

Luhmann poses Varela's anecdote of the cell to discuss the mechanics of autopoiesis in nature; in a social systems-based approach, he offers the metaphor of the psychic mind to explain the process. Like the cell, the mind is operatively closed:

...(N)o thought can enter the psychic system from outside — for example, the thought in the mind of one person cannot enter into the 
mind of another person - nor can any thought produced by the psychic system get out of the system and enter into the environment. (Seidl \& Becker, 2006, p. 17).

In a fashion analogous to the psychic system, social systems use communication to perpetuate their own form of autopoietic reproduction. In this case, however, the main components of autopoiesis are communications "which are recursively produced and reproduced by a network of communications and which cannot exist outside of such a network" (Luhmann quoted in Seidl \& Becker, p. 18). Communication is thus revealed as the significant generative factor in autopoiesis.

\subsection{Evolution}

While the social system reproduces itself via autopoiesis, it can transfigure itself only through the act of evolution; such change occurs when a system finds itself challenged by operating within a highly complex environment. In this case, the system evolves by increasing its inner complexity to match the condition of its environment (Knodt, 1995, p. xxxv). Although Luhmann points to the codependency of system and environment during the act of evolution, he does not observe exact correspondence between the two. It is however the case that environment and system will evolve together when conditions are optimal namely, when "a sufficient complexity of system-environments exists... (I)n this sense, evolution is the co-evolution of systems and environments" (Luhmann, 1995, p. 27).

Further, Luhmann notes that a system may evolve only when its operations diverge from their usual reproductive functions; such deviations from regular operations may or 
may not be accidental. Evolution can never be planned, as social systems generally act, unlike individuals, without self-consciousness. Indeed, the system "operates without a goal and without foresight":

(Evolution) may bring about systems of higher complexity; it may in the long run transform improbable events into probable ones, and an observer may see this as "progress.” (Luhmann, 1982, n.p.)

This observation of progress is anecdotal, as there is no way to plot the introduction or course of evolution; regardless, anomalous and highly complex self-conscious systems may attempt to execute said plotting in an effort to accelerate their own evolution. But despite possible intentions to evolve as a safeguard against extinction, evolution in systems does not "guarantee survival: as a matter of fact, most species in life... have vanished or about to vanish," he notes.

We are not dealing with essences, whether secured by nature or by a cosmos of essences. But evolution remains problematic, and so does the question of how such a proliferation of species is possible to begin with. (Luhmann, 2000, p. 231)

Evolution within the art system, however, poses a new series of issues for the observer, notes Luhmann, as this system as a whole is disconnected from society and social systems. Much of this separation is due to the art world's unusually accurate understanding of its own evolution, which it traces through a self-written history of art; however, the more important factor here is that the art system sees little to no commonality between itself and systems of "religion, politics, the economy, education, and so on," (2000, p. 231); and although he does not note it here, one of these essential "so ons" is, to Luhmann's mind, science. This drive to differentiate arises in part because the art world is constantly seeking 
to define its purpose in subjective/aesthetic terms, no more poignantly than when the system is renewing its decisions regarding beauty, specifically "what fits (is beautiful) or does not fit (is ugly)" (2000, p. 220). He describes for example the transition from Renaissance classicism to the Mannerist movement of the High Renaissance, the latter rejecting the harmonious and balanced ideals of the earlier movement for "capricious and fantastic trends that explode the limits of proportion" (2000, p. 220). The art world flaunts science's obsessive reverence for classical precedents by turning to Mannerism (and Mannerism-inspired approaches) with its tendency to turn "deviance into a program. One used one's knowledge of perspective for the deformation of forms" (p. 256).

It is worth reminding ourselves here that such strong reversals of artistic standards occur only when a system is self-aware and independent enough to separate itself from its environment and other systems -- and it is important to point out how completely the art system pulls away from otherwise analogous social systems. Lehmann observes that because beauty for the art system could never be "subsumed under rules or laws," ...it could claim a domain of its own. It participated in social communication because it was different. Like the sovereignty of the king and of love, the sovereignty of art displayed an inexplicability that was nonetheless not to be understood as arbitrary. (Luhmann, 2000, p. 238)

The evolutionary genius of art, then, is its systemic self-driven "capacity for dissolution and recombination," even as adjacent systems respond to the demands of evolution reactively and/or without control (Luhmann, 1987, p. 108). This distinctive characteristic of the art world may help explain why so many artists (including screenwriters) instinctively resist 'classical' narrative strictures in favour of their system's 
propensity to dissolve and recombine storytelling structures and techniques to its own inventive ends.

\subsection{Communication as Social Production: Luhmann}

Luhmann posits a social system emerges fully when it becomes a communicationsfocused entity, at which point "communication develops from communication" (2006c, p. 47). For him, communication is a manifold package, a synthesis of "information, utterance and understanding... Communication is the structural equivalent of biochemical statements by means of proteins and other chemical substances. (It) exists because of the same basic occurrence: namely communication" (p. 47). Because, according to systems theory, individual communicators do not control the mechanisms of information, utterance and understanding, Luhmann observes that communication occurs only at a systemic level:

While the concept of action is intimately bound up with the concept of actor, agent or subject as "producer of the action, the concept of communication is free of reference to any underlying subject. In this sense, the communication can be said to be produced by the communication system rather than by individual actors. (Seidl \& Becker, 2006, p. 19)

Further, unlike the traditional Shannon/Weaver 'hypodermic' model of communication (in which information is 'injected' from the speaker into the listener), communication for Luhmann is a conglomerate incident generated within the system that uses the system's distinctive patterns to create meaning for its members. 'Meaning' here takes on historical and evolutionary significance in that a system uses its unique reduction of complexity (a 
kind of adaptive shorthand) both to communicate amongst its members, and to evolve, both internally and against its environment, through first- and second-order observation.

In his Modernity as Contemporary Society (1998), Luhmann writes that "[o]bservation is any kind of operation that makes a distinction so as to designate one (but not the other) side. Such a definition is itself contingent, since what is defined would have another meaning given another distinction" (Luhmann, cited in Rabinow, 2008, p. 64). First-order observations are generally the empirical or "realist" attempts to understand an issue: as such, they use difference by recognizing distinctions between themselves, their point of observation, their environment and their focus of study. By contrast, second-order observations observe not only first-order observations/observers but themselves as well and indeed, more than one context or environment. Luhmann in a metaphoric sense thus regards human beings as observers, and sociologists as observers of observers: the sociological project in this light for example is not to respond to the news that fish are dying in untold numbers in the Rhine (as Luhmann notes in his text Ecological Communication), but that the German economy, its press and many of its schoolchildren are communicating this news and discussing its consequences. These are the interesting facts for the sociologist, he claims - "not the fact that the fish are dying" (Luhmann, 2006c, p. 56). Relieving the observer of the burden of ideology (i.e., the fact that the fish are dying) allows him or her to occupy a "distanced position" that is free to refer to historic structures and to the current state of society.

Assigning roles of observer and observer-of-observer does not mean however that Luhmann regards the process of communication as a subject-based activity. Both first- and second-order observation are roles performed by human beings who act as cogs in the system's machinery: 
Humans cannot communicate; not even their brains can communicate; not even their conscious ends can communicate. Only communications can communicate. (Luhmann quoted in Seidl, 2004, p. 20)

By now, it is obvious that Luhmann's understand of communications requires a profound shift in conception - from a classical view of society, which "consists of subjects of action whose fundamental unity is based on sharing a common understanding" (Bechmann and Stehr, 2002, p. 70) to a world that "temporalizes, differentiates and decentralizes all identities" (Bechmann and Stehr, p. 71). From this subject-decentred theory we turn to de Certeau's understanding of communication within a social system as a series of subversive activities, as unconscious of subjectivity as is Luhmann's systemsenslaved human race.

\subsection{Michel de Certeau: An Introduction}

Scrutiny of the early life of cultural theorist and historian Michel de Certeau reveals an academic devoted to pursuit of theological knowledge. Born in 1925 in Chambery, France, he earned degrees in philosophy and classics at the universities of Lyon, Paris and Grenoble, and entered the Jesuit order at the age of 25. In 1960, he completed his PhD in theology at the Sorbonne, focusing upon the writings of the French exorcist and mystic Jean-Joseph Surin. Various scholars comment upon the academic sophistication of this early work: Ian Buchanan notes Certeau had a lifelong interest in Surin, and that he returned to studying the mystic's work "several times after both the dissertation and the enormously laborious scholarly editions of Surin's work he prepared...were published" (Buchanan, 2000, p. 1). In a similar tone, the editors of Diacritics suggest his writing on Nicholas of Cusa is "the most resolutely erudite essay ever to appear in this journal," and 
that it "testifies to the depth of our respect for Michel de Certeau's monumental learning, his scholarly originality, and his powers of insight and argument” (Certeau/Porter, 1987, p. 2).

By 1965, Certeau had become a frequently cited scholar in the field of religious studies and a contributor to a variety of Catholic journals, Etudes and Christus in particular (Ahearne, 1995, p. 2); at about the same time, he joined Jacques Lacan's École Freudienne, a psychoanalytic society in Paris. Hoping to tour China but dissuaded by the outbreak of the Chinese revolution, he taught and conducted ethnographic studies instead in South America (Argentina, Chile and Brazil) where at the same time he began in earnest his exploration of alterity, a journey his biographer Luce Giard explains as a kind of quest for transcendence:

He had had from childhood an intense desire, in his own words, to "not belong, "to free himself," to overcome the limits of family, of milieu, of a province and a culture, and to encounter the Other in order to be, at the same time, again in his own words, "transformed" and "wounded." (Giard, 1991, p. 216)

This need to meet the "Other" in unfamiliar territory reflects Certeau's uncommon humanity, which stemmed from a deep-seated conviction that heterology (as he deemed it) was a natural state of being for all creatures, and that losing oneself in a crowd of strangers far from home was akin to a state of godliness: “(f)or de Certeau, the Christian call is to wander, to journey with no security apart from a story of Christ that is to be 'practiced' rather than objectively stated" (Sheldrake, 2001, p. 44). Understanding this unseated loss of self is integral to appreciating his writings: it reveals the extent to which the historian considered himself not a privileged academic but an ordinary human being, another face in 
the crowd. His biographer recalls that Certeau believed that as a Jesuit and an intellectual, he was no better suited to speak the "truth" than any other speaker:

To claim to do so would have meant that he believed himself "authorized" to do so, but by what authority? The logic of the position he adopted denies all identification with a determined place chosen as the center of power from which the law is announced and from which the ownership of property is organized. (Giard, 1991, p. 218)

Upon his return to the continent and in May 1968, Certeau found himself caught up in the worker and student protests in Paris; he immediately wrote a number of essays for Études about his intense reaction to the season's demonstrations. Six of those essays comprised the larger part of La prise de parole (The Capture of Speech) which, when published in October 1968, represented his debut into a larger arena of sociology studies. Cultural policy scholar Jeremy Ahearne considers the text a "watershed” for Certeau: “(h)is writings were now clearly situated in relation to a range of contemporary problematics, and cut across issues in psychoanalysis, historiography, epistemology, semiotics and the social sciences" (Ahearne, 1995, p. 2). At the heart of these new writings was Certeau's conviction that the May ' 68 protests reflected a revolution not so much in social equity but in speech. He recounts at one point an overheard exchange:

A young elevator operator from the Samaritane department store who was being interviewed by a journalist stated: "I really don't know what to say, I don't have any education." A friend who was on strike interrupted him: "Don’t say that! Knowledge is finished. Today, education, well, it's all in what we say!" (italics his; Certeau, 1997, p. 
The voice of the Other — the socially alienated, marginalized — was at last clearly heard, and society's theatre transformed, its spectators "changed into actors" (Certeau, p. 7). For Certeau, this moment was of revolutionary importance: it indicated what Ahearne calls a "founding rupture," at which point the 43-year-old broke definitively away from his focus upon theological studies and entered into a new and "more common life" (Ahearne, 1995, p. 5)

Amongst cultural scholars and aficionados, France's Ministry of Culture took particular notice of La prise de parole, commissioning Certeau in 1970 to oversee a series of cultural policy projects; these consultative programs would occupy much of the historian's time until 1985 (Highmore, 2006, pp. 153-154). While accounts of this period suggest that the Ministry's intentions were honourable and its departments appropriately staffed to support Certeau's investigations, his findings and recommendations were so outré as to create general consternation amongst high-ranking Ministry officials. In short, Certeau's approach departed significantly from that of his predecessors by focusing not upon the usual elite definitions of mass culture (viz., expeditions to the opera, theatre, museums, fine dining, or what he considered a "culture of consumption"), but upon a populist approach shaped by everyday activities, namely, "reading, amateur artistic activity, cinema, gardening, local associations, etc." (Ahearne, 2004, p. 82). This alternative "culture of development" redirected policymaker attention from the conception of mass culture as defined by class structures (Bourdieu) to a focus upon the individual as a prime civilizing force: "Cultural action presupposes that we give credit to each individual, considering them as capable of autonomy and destined to participate in the elaboration of a common language" (quoted in Ahearne, p.82). 


\subsection{Certeau: Some Primary Concepts}

But Certeau's approach was hardly the stuff of classic policy doctrine, and his recommendations were uneasily accepted by a majority of the Ministry's bureaucrats (Ahearne, 2004, p. 97). Despite - or perhaps because of — this uneven success within French policy circles, Certeau began in the early ' 70 s to write what many North American cultural scholars consider his defining work, The Practice of Everyday Life (1974). This series of essays introduces a number of interrelated concepts for which Certeau has become widely known, particularly in cultural circles: viz., emphasis upon practices vs. texts as the necessary focus of cultural studies; the idea of tactics vs. strategies in social interactions; la perruque or 'the wig,' which suggests the myriad ways employees pilfer time from their employers; poaching or 'everyday resistance,' which describes how citizens use activities like walking, reading, sewing and cooking to wrest control from the power-holding "apparatus" (Certeau, 1988, p. xiv); and "anti-discipline" (p. xv), which depicts the ways in which "the weak must continually turn to their own ends forces alien to them" (p. xix). In each case, he begins with an appreciation of the individual as a creative force who makes his/her own way, sometimes consciously but as often not, within a highly structured social system.

Of these concepts, Certeau's identification of tactics and strategies is the most easily summarized and accordingly most often incurred when his writing is discussed. A strategy occurs, he notes, when an entity assumes both a role and a physical space that "serves as the basis for generating relations with an exterior distinct from it (competitors, adversaries, 'clienteles,' 'targets' or 'objects' of research)” (Certeau, 1988, p. xix). Strategy is associated with aggressive maneuvers of power: an entity uses strategies when it has ownership of property, and intends to defend it or offend on its behalf. A tactic on the other 
hand belongs to the Other, the subaltern who has no physical base from which to operate; this individual lacks a strategic stronghold where s/he "can capitalize on its advantages, prepare its expansions and secure independence" (p. xix). Because tacticians are without a physical place, they must constantly be on their guard to defend themselves against strategists and to consume/use what they acquire on the fly. Further, whatever the Other "wins, it does not keep" (p. xix); the problems of powerlessness and baselessness that characterize the tactician also predicate his/her inability to retain property, if for no other reason than there is no stronghold in which to keep it. Certeau finds in the housewife a metaphor for the tactician: in making decisions about what she will serve at the evening meal, this (otherwise) disenfranchised individual draws from a range of "heterogenous and mobile" sources (i.e., the products she has at home in her kitchen, the food she may choose from in the supermarket, her knowledge of the preferences of those she is feeding, etc.; $\mathrm{p}$. xix) to create sustenance for her family. If particular vegetables are not available to her, she uses substitutes; if the barbecue is out of propane, she uses her oven broiler. The creativity of the tactician is boundless, arising from her need to produce something (a meal) from nothing (her imagination, her tools and a variety of ingredients); she does not 'keep' that which she has produced, for the simple reason that it is consumed by others.

While the strategy-tactic dichotomy has been presented here as a simple polarity of the powerful vs. the powerless, Certeau in his next breath insists it is anything but. Not only are the weak constantly in the process of undermining the powerful with "clever tricks, knowing how to get away with things, 'hunter's cunning,' maneuvers," etc., but they disguise these activities with what he describes as biologically adaptive traits, "the intelligence displayed in the tricks and imitating of plants and fishes" (Certeau, 1988, p. $\mathrm{xx}$ ). This latter point is important, as Certeau stresses that trickery does not necessarily 
represent the conscious, organized rebellion of individual workers or groups of workers: it is instead an inherent, adaptive capability, like the ability of an insect to disguise itself as a twig or an orchid that has evolved to resemble a female bee. What is important to remember here is that whatever system of oppression presents itself to the tactician, that individual adopts automatically a series of subversion ploys to undercut said power. In practice, the subaltern seems unaware much of the time of any discrepancy in power and influence, but simply goes about her/his business, cutting corners, saving time, seeking small advantages here and there.

This theme of meagre ploys is introduced in two discrete concepts: la perruque ("the wig) and poaching. Certeau describes the first as a universal phenomenon, "proliferating in governmental and commercial offices as well as in factories" (Certeau, 1988, 26), and common wherever there are employees and employers:

La perruque is the worker's own work disguised as work for his employer. It differs from pilfering in that nothing of material value is stolen. It differs from absenteeism in that the worker is officially on the job. La perruque may be as simple a matter as a secretary's writing a love letter on "company time" or as complex as a cabinetmaker's "borrowing" a lathe to make a piece of furniture for his living room. (p. 25).

This worker's tactic is not deliberately subversive, suggests Certeau, but merely a compensation in a market economy that relegates the individual to a working unit. Citing the French ethnologist Marcel Mauss, Certeau suggests the employee's concession is a sort of potlatch, a competitive gift-giving festivity, in which the individual exchanges the gift of her/his skills and dedication for a salary, but also expects benefits in return. That many 
employers turn a blind eye to employee diversions means that la perruque is, if not encouraged, at least allowed to quietly thrive; it is a phenomenon that has implanted itself into the history and traditions of many contemporary organizations, and furthermore provides workers with a cheerful sense of justice having been done. "Melancholy is not enough" to undermine hierarchy and dominance, says Certeau (p. 27): workers will turn to trickery and sly tactics to obtain what they consider rightfully theirs. At the same time, employees also know they must comfortably maintain a civil relationship with employers; there are rules to the degree to which la perruque may disrupt the work setting or draw upon the employer's abundant but not infinite resources.

Less a colloquialism than a personal metaphor, Certeau's notion of poaching extends the motivations for la perruque to other everyday activities conducted by society's powerless; this is famously evident in his description of reading as an act of poaching. In this case, the reader does not 'own' the written text in the act of reading, but simply uses it for her/his own purposes. "(T)he viewer reads the landscape of his childhood in the evening news":

A different world (the reader's) slips into the author's place. This mutation makes the text habitable, like a rented apartment. It transforms another person's property into a place borrowed for a moment by a transient. (Certeau, 1988, p. 28)

'Consumption' of the written or any other text means for Certeau that the reader takes what s/he wants from the work, ignoring the writer's intentions and adding her/his own daydreams, logic and other interpretation to the text, with a sort of bricolage result. "Far from viewing consumption as imposing meanings upon the public," says American media theorist Henry Jenkins, "consumption involves reclaiming textual material, 'making it 
one's own,' appropriating or reappropriating it" (Jenkins, 1988, p. 471). As la perruque may produce pleasure (in that workers are generally fully aware they are 'borrowing' company time or products to their own advantage), so may poaching: "readers are travelers; they move across fields they did to write, despoiling the wealth of Egypt to enjoy it themselves" (Certeau, 1988, p. 174).

\subsection{Anti-Discipline and Certeau's Contemporaries}

This brings us to the stated subject of Certeau's Practice of Everyday Life — viz., the notion of anti-discipline. The concept immediately invokes the argument the historian had with two of his contemporaries, Michel Foucault (1926-1984) and Pierre Bourdieu (19302002). 'Discipline' conjures for most critical theorists Foucault's Discipline and Punish: The Birth of the Prison (1975), which explores how 18th-century European bourgeoisie developed the prison system to create docile, disciplined 'bodies' under the constant, watchful eye of the state. Certeau questions the closed logic of Foucault's claims, asking a) the theorist to explain exactly how the "panoptic apparatuses" of the prison system came to be so privileged (a question an historian like Certeau would ask), and b) why the "immense reserve" of those with "silent itineraries" are ignored in Foucault's writing (Certeau, 1988, pp. 47-48). In short, what is the status of those who resist the positivist order of Foucault's immutable system — where are the tactics of those subordinated but not conquered by a dominant power?

Certeau takes similar issue with Bourdieu's use of habitus (roughly, an omnibus concept describing the way society imposes "durable, transposable dispositions, structured structures predisposed to function as structuring structures" in such a way that individuals unconsciously produce and reproduce them (Bourdieu, 1990, p. 53)). While praising 
Bourdieu's historical acuity (specifically in the latter's ethnographic study of the Kabyle people of Algeria) with a respectful summation of the strategies used by this ethnicity to maintain its systems, Certeau simultaneously asserts his colleague's failure to recognize the conscious tactics of the subordinated Kabyles. Worse, he accuses Bourdieu of adopting a "foreign and superior" approach (p. 56) that reduces the history of Algerians to "a mystical reality, the habitus, which is to bring them under the law of reproduction":

The subtle descriptions of Bearnian or Kabylian tactics suddenly give way to violently imposed truths, as if the complexity so lucidly examined required the brutal counterpoint of a dogmatic reason... The blanket Bourdieu's theory throws over tactics as if to put out their fire by certifying their amenability to socioeconomic rationality or as if mourn their death by declaring them unconscious should teach us something about their relationship with any theory. (Certeau, 1988, p. 59)

The suggestion here is that a structured, organized theory of any description, be it Luhmann's, Foucault's, Bourdieu's or that of any other theorist, is automatically at odds with the notion of anti-discipline. Consider that theory imposes a certain logic, a 'discipline' its subjects must follow if the theory is to be considered valid, reliable, reproducible; such a concept is directly at odds with Certeau's observation of the haphazard, improvised, everyday practices of ordinary people. Thus the anti-doctrinaire state of anti-discipline lends itself to the fluidity of everyday life: practice, in particular the practice of poaching and of la perruque, implies a methodology that emerges in its doing, that evolves as naturally as do history or speech or walking in the city, the latter another of Certeau's famous metaphors. Theory on the other hand is dictated by a theorist, frozen into 
a text, interpreted cautiously and rigorously debated by its advocates; it belongs not to ordinary people but to one 'extraordinary' individual who must be consulted and obeyed if the theory is to be properly elucidated. That Certeau disdains the power that comes with theory-creation should by now be evident.

What may not be as evident is how Certeau supports this apparent distaste for theory when he is a cultural commentator himself. This irony would have been keenly felt by the historian, whose writing in The Practice of Everyday Life has literally nothing of the doctrinaire about it. Consider for example a few of the opening sentences of his most famous essay, "Walking in the City":

To be lifted to the summit of the World Trade Center is to be lifted out of the city's grasp. ...An Icarus flying above these waters, he can ignore the devices of Daedalus in mobile and endless labyrinths far below. His elevation transfigures him into a voyeur. It puts him at a distance. ...It allows one to read it, to be a solar Eye, looking down like a god. (Certeau, 1988, p. 92)

Certeau here uses the godlike gaze of the voyeur to describe how the dominant regard the planning and execution of city design, how their "lust" for knowledge situates them far above the streets and how that lust sets them up them for an "Icarian fall" (p. 92). Contrast this section with his description of the "ordinary practitioners of the city,"

(who) live "down below," below the thresholds at which visibility begins. They walk - an elementary form of this experience of the city; they are walkers, Wandersmänner... The networks of these moving, intersecting writings compose a manifold story that has neither author nor spectator, shaped out of fragments of trajectories 
and alterations of spaces; in relation to representations, it remains daily and indefinitely other. (Certeau, 1988, p. 93)

Certeau writes here and elsewhere in his cultural books less like an empiricist than a poet. This approach follows his own description of the wandering, sensitive and easily distracted soul: the chapters are launched without proper introductions and leave off without conclusions, they meander and break off in mid-thought. It is a conscious approach, of course - for if the organization of his writing was deliberate and systematized, the historian would be as guilty of paternalistic theorizing as any of his Icarian colleagues. Even more significant in Certeau is his refusal to call for the end of inequalities and injustice: it is the historian's role to observe and comment upon revolution that occurs in situ and entirely without the intellectual's intervention. Although the approach does not begin in the same place as does Luhmann's abstract and more purely analytic theory of social systems, it is to my mind curiously similar, in that both writers trust their subject and reader first, to fully appreciate the magnitude of the system and second, to trust that human beings will not be subsumed by it.

It should be noted here that Michel de Certeau's theory does not always map perfectly to the experiences of the English-Canadian screenwriters interviewed for this project -although in fairness, it is unlikely that any theoretical schema, however finely tuned, is a precise fit to any set of qualitative research data. As we will see later, the writers interviewed here are rarely in an entirely subordinate position in the filmmaking team, as many combine their role as writer with the more powerful positions of director and producer (or both), while others consider their work as screenwriters sufficient to their purpose and not without a certain amount of prestige in the larger world of English- 
Canadian culture. Power is, as Michel Foucault often noted, promiscuous and, as Certeau himself might have added, generally in the eyes of the beholder.

This chapter has examined numerous concepts within the systems theory of Niklas Luhmann and the related (although antipodal) work of Michel de Certeau; in the former, foundational systems theory ideas around differentiation, autopoiesis and communication have been investigated (albeit passingly), while in the latter, notions on tactics and strategies, la perruque and poaching have been similarly glossed. I have already suggested that the work of these two writers represents two sides of the same coin, in that both concern themselves with the workings of social systems and both understand that this larger system drives and decides our organizational meanings. While Certeau presents an alternative to Luhmann's apparent enslavery to the system (namely, his oppositional stance to contemporary systems theory), it must also be noted that Certeau and Luhmann share the conviction that systems/anti-systems activities are not subject-based, but comprised of larger depersonalized forces. Luhmann considers the social system a self-generating engine of communication for which individual human beings are (largely) irrelevant; Certeau considers the tactician/working 'class' (for lack of a better word) similarly systems-bound in that it unconsciously responds to certain forms of activity (shows of authority, for instance) in subversive ways. No one demagogue has taught the housewife to poach ideas for supper from recipe books, childhood memory or grocery sales; no one agitator has taught the carpenter to poach company time and the use of tools to complete a cradle for his newborn grandchild. Ideas like la perruque are communicated through a compensatory system that does for its constituents everything that Luhmann's system does for its members: it provides for the continuation of successful practices and the reproduction of 
similar tactics as the anti-system evolves. This idea will be discussed again in the coming chapters. 


\section{Chapter 5: Identity and Film Policy in English-Canadian Screenwriting}

\subsection{Identity and Film Policy in English-Canadian Screenwriting}

"What is Canadian cinema?" asks Canadian film scholar Christine Ramsay in concluding her survey of the subject (Ramsay, 2002a, p. xxxv). Alternately despairing and optimistic as she outlines major developments in the country's film history (viz., the development of the National Film Board, the emergence of distinctive French- and EnglishCanadian film markets, the 'new wave' of Canadian film in the 1960s and '70s, etc.), her answer closes with a sprawling definition:

(Canadian cinema is) realistic and fantastic, big budget and small-time, crude and polished. It's conventional and bizarre, generic and hermetically personal, plot-driven and character-oriented. It's male and female, gay and straight, chaste and pornographic. It's about interior states and exterior worlds. (Ramsay, p. xxxv)

Ramsay's assessment is above all things equitable in its assessment of the extraordinary range of Canadian film's markets, its goals and methods, but does it move us any closer to a more holistic understanding of English-Canadian cinema? Is it possible to hold such an all-encompassing description against other national and regional definitions of cinema, and understand it as a comprehensive assessment of a localized cultural product? The answer to this query may legitimately be No, but legions of English-Canadian film scholars, policymakers and audiences continue to ask it, many of them seemingly weary of the discussion but continuing to pursue it if for no other reason than even a refreshed answer may provide new theoretical traction for those observing, practicing, administering to, writing and/or teaching on the subject. After all, the entire concept of national cinemas and their discrete characteristics rests on the assumption that there are distinct national 
cultures based on differing histories, languages, economies, etc., and that these cultures are expressed in film along with other art forms. The seminal film identity work of Canadian cinema scholars and filmmakers Charles Acland (2003), William Beard (2002), Liz Czach (2004), Zoë Druick (2007), Bruce Elder (1985/1988), Seth Feldman (1984), Jennifer L. Gauthier (2005), Christopher E. Gittings (2002), Peter Harcourt (1977), Brenda Longfellow (2006), George Melnyk (2004), Peter Morris (1978), Joyce Nelson (1988), Peter Urquhart (2004), Darrell Varga (2008) and Jerry White (2002), amongst others, has wrestled with the question, many writers offering theories, others preferring to leave the question open to interpretation.

Whatever that interpretation might be, the issue of identity in English-Canadian film and, specific to the aims of this dissertation, the issue of identity in English-Canadian film as formulated by the Canadian state's film policy — remains a major question for most anyone involved in this country's film community. Analysis of this issue requires a brief survey of relevant Canadian/national identity theory and Canadian film policy since the late 1990s, during which time a significant transformation in the latter issue has (arguably) occurred. The goal of this chapter is to signal points at which English-Canadian film identity radically shifted its focus, with particular attention paid to Telefilm Canada's strategic plans.

\subsection{National Identity and English-Canadian Film Policy}

As any 21 st-century sociologist will confirm, the very concept of national identity presents a conundrum. At the root of the problem, notes British theorist Stuart Hall, is that while identity on one level suggests a unified, common construction of meaning shared by a singular entity, this 'unified construction' has inevitably been formulated by a dominant 
party that advances the image in its own likeness and, further, posits it as a homogenous, uncontested entity (Hall, 1991). Second, cultural scholars increasingly recognize that identity is not a static representation but a diverse and constantly shifting image that defines itself as much by the idea of distinction as by unity:

Identities are always relational and incomplete, in process. Any identity relies upon its difference from, its negation of, some other term, even as the identity of the latter term depends upon its difference from, its negation of, the former. (Grossberg, 1996, p. 89)

Given these positions as set forward in contemporary cultural theory, the argument for national identity in film becomes a murky proposition. If identity of any description is, as suggested above, a matter of shifting, diverse representations, how can any country present itself as a unified entity? And how does film fit into this situation — how might this 'product' represent a nation if even the concept of unified identity is so fraught?

The problem is especially charged when a country seeks not only to create an identity in part through its film, but to shape its film policy around issues of national identity: such is the case (I will argue) for English-speaking Canada. Cultural policymakers at all levels of government and industry have expressed for decades their desire to "tell Canadian stories as varied as our landscape" (From Script to Screen, 2000), "tell Canadian stories with wide audience appeal” (Telefilm, 2002), “tell Canadian stories to moviegoers” (WGC, 2005, p. 1), “tell Canadian stories to the world" (Writers' Guild, 2010), to "[r]einvest in cultural institutions to tell Canadian stories" (ACTRA, 2016). Although these same policymakers assume (to their credit and counter to traditional identity norms) that the filmic tales told by English-Canadian filmmakers will be as diverse and "varied as our landscape" (Telefilm, 2007, p. 5) the suggestion here is that in telling its stories, Canada succeeds finally in 
representing itself, both within and to an international audience, and that these stories as a collection promote some form of positive, integral national portrait. Rarely if ever in this panoply of film policy documentation do the writers posit that cinema's first duty in both national and international capacities is to entertain while telling these stories; somewhat less rarely do these documents state the goal for a national film to recover its costs and/or achieve profitability... while telling its stories.

A second trend in Canadian cinema policy is an escalating tendency to market Canada's below-the-line film services and locations. The underlying goal here celebrates "Canadian vision, Canadian values" through championing of the national audiovisual industry and its transparency, its responsible delivery of services, its respectful work environment and sustainability (Telefilm, 2007, p. 5). The language in this case reflects not the ideological focus of telling Canadian stories to the world but a laundry list of 21 stcentury corporate values: the audience for this subset of values is not the Canadian consumer but the international/American film production team exploring co-production funding and/or alternative locations for shoots.

Championing an industry and promoting a nation are two different matters, which brings us back to the original question. How does a nation assume some form of identity, a representation that is recognizable to the world? And more importantly, is such a representation ethical, relevant or even possible? The problem has long been debated in Canadian literary scholarship, which is where many national cinema studies in this country begin. 


\subsection{Canadian National Thematics in Literary Studies}

Of the works that have informed English-Canadian national (and by extension, film) identity since the mid-20th century, a few texts are seminal: one is CanLit scholar Northrop Frye's The Bush Garden (1971). Invoked as the grandfather of Canadian national identity, the scholar and his work conjure a particularly northern scenario, in which inhabitants are "mentally garrisoned against a terrifying nature, frostbitten by a colonial history (and) a vision that still has the power to provoke" (Hutcheon, 1995, pp. viii-ix). Frye begins his siting of the garrison in the Canadian wilderness, where we have inherited from our forefathers the voyageurs the tendency to "probe into the distance (and) fix the eyes on the skyline" (Frye, 1971, p. 224). In a vast country through which one is constantly traveling (as does the voyageur), this seeing deep into a landscape is essential to successfully navigating it.

Further, in such a vast expanse, communication is essential to survival (and here Frye calls forth countrymen Harold Innis and Marshall McLuhan): in both its verbal and nonverbal forms, communication invokes continuity, not simply between Self and Other, but between spaces and in time. The reflexive and "relentless cultural stock-taking and selfinventory" of Canada's observers is a continuum of this far-sightedness, although Frye is not particularly complementary in his assessment of it (Frye, p. 226). One example: he notes that in moving from exploration to civilization of Canada, settlers established their cities and villages in geometric patterns, "dividing up the farm lands into chessboards of square-mile sections" and ignoring the natural contours of the land in favour of an "arrogant abstraction, the conquest of nature by an intelligence that does not love it" (p. 226). This abstraction, this lack of love, arises out of fear of a frozen and indifferent 
landscape, a nature "red in tooth and claw," but also from the anxiety of the voyageur's "self-inventory":

It is not a terror of the dangers or discomforts or even the mysteries of nature, but a terror of the soul at something that these things manifest. The human mind has nothing but human and moral values to cling to if it is to preserve its integrity or even its sanity, yet the vast unconsciousness of nature in front of it seems an unanswerable denial of those values. (Frye, p. 227)

The only recourse for these terrified settlers is community — an ironic development, given these rough-hewn communities are separated by great distances from their British brethren and American neighbours, not to mention from each other. Confronted by an unthinking, unfeeling landscape and isolated by distance, human roles become polarized, with no intermediate positions available: "one is either a fighter or a deserter" (p. 228). Worse, however, the settler finds s/he is no longer comfortable unless completely ensconced within the garrison:

The real terror comes when the individual feels himself becoming an individual, pulling away from the group, losing the sense of driving power that the group gives him, aware of a conflict within himself that is far subtler than the struggle of morality against evil. (Frye, p. 228) Resisting the terrifying prospect of looking not across plains but into the abyss, the Canadian settler settles for assimilation, "getting along" without risking introspection, observing and communicating with internal and external worlds with extreme care, striving to confront neither the forces of Nature nor to upset the balance of community, both in- and outside the garrison. 
A student from Frye's University of Toronto classroom later adapts his garrison metaphor and spins it to new theoretical advantage. Margaret Atwood reconceptualizes his work in her Survival (1972), drilling down as he did to specificities in Canadian poetry, but in addition shifting her focus to a comparative aspect of 'CanLit':

The study of Canadian literature ought to be comparative, as should the study of any literature; it is by contrast that distinctive patterns show up most strongly. To know ourselves, we must know our own literature; to know ourselves accurately, we need to know it as part of literature as a whole. (Atwood, 1972, p. 17)

This new agenda gives Atwood space to compare the literatures of Britain and Ireland (Austen, Browning, Dickens, Doyle, Joyce, Kipling, Shakespeare, Tennyson) and America (Emerson, Hawthorne, Hemingway, Mailer, Melville, Thoreau) to the French and English works of Canada. This repositioning with its expanded sightlines initially depresses, then exhilarates, because as she notes, it liberates the Canadian artist from his/her previously circular victimhood. Analyzing two contemporary Canadian stories, Ray Smith's "Cape Breton is the Thought-Control Centre of Canada" (1969) and David Godfrey's "The HardHeaded Collector" (1977), she finds both to be about victimization and failure; instead of attaching this failure to fate or moral weakness, she posits the causes are political. These writers blame not nature but "the United States as an imperial master" (Atwood, p. 241). Close examination of Dennis Lee's Civil Elegies (1968) gives her greater hope: for this writer, "[n]ature is no longer a monster but a potential home" and his protest of the "attitude towards the land that results in its exploitation" is the embedded fury of the Canadian towards outsiders. Better yet, this negativity turns itself in a positive direction when our writers "urge us to control our own space, physical as well as cultural": 
But that space must be controlled with love or it will be the control typical of a tyranny: there will not be that much difference between Canadian ownership and the absentee-landlord draining of the land we already live under. ...[T]here is more chance of destructive choices being made by outsiders than by people who will have to endure the effects of these choices because they actually inhabit the country. (Atwood, p. 244)

In short, Atwood's agenda for Canadian artists accepts the bleakness of CanLit as long as the writer can mobilize within it. To Frye's question, "Where is here?", she suggest the query is no longer relevant, as "having bleak ground under your feet is better than having no ground at all. Any map is better than no map as long as it is accurate... A tradition doesn't necessarily exist to bury you: it can also be used as material for new departures" (Atwood, p. 246).

Frye himself does not rule out new departures:

As the centre of Canadian life move from the fortress to the metropolis, the garrison mentality changes accordingly. ...But though it changes from a defence of to an attack on what society accepts as conventional standards, the literature it produces, at every stage, tends to be rhetorical... [This literature helps] to unify the mind of the writer by externalizing his enemy, the enemy being the anti-creative elements in life as he sees life. (Frye, 1971, p. 233)

In other words, as Canadian artists leave the confines of the garrison and can fend for themselves in a larger metropolitan/globalized world, they adopt what Australian film historian Stephen Crofts categorizes as the "critical" approach to encroaching cultures 
(Crofts, p. 55). While the "enemy" goes unnamed in Frye's essay, Canadian film scholars like Margaret Atwood are not so coy, nor are the many international academics who examine and produce national film and related identity documents.

Before turning to comparative identity issues in international film, however, it may be helpful to contextualize the screenplay in English-Canadian cinema, as such a discussion may throw new light on screenwriting issues in this forum.

\subsection{Overview of English-Canadian Cinema and Cinematic Narratives}

Film in English-speaking Canada was formally launched in 1897, when Manitoba farmer James Freer made and exhibited a series of industrial/scenic films depicting agricultural life on the Canadian prairies. The Canadian Pacific Railway, which had sponsored Freer's films, immediately commissioned their own cinematic enterprise entitled Living Canada, a picturesque series of 35 short films designed to entice British immigrants to Canada. By the mid 1910s, American filmmakers began to recognize in these films the spectacular settings and cultural anomalies of Canada and accordingly to create a new subgenre, the "Northwoods Melodrama," incorporating Mounties, lumberjacks, prospectors and nature-loving heroines (Magder, 1993, p. 21). Already, the objectification of Canada -a nation to be observed rather than a nation telling its own stories -- had been initiated. Following the success of Canada's first domestic feature by Canadian Bioscope Company, Evangeline (1913), Ernest Shipman produced Back to God's Country (1919) starring his wife, Nell; the picture was a smash hit that launched a series of on-location films based on

Canadian novels. By the mid 1920s, however, this encouraging uptick in domestic film had vanished and Canada's fledgling film industry had practically evaporated, with the exception of a few lone features: Carry On, Sergeant! (1927) and The Viking (1931). 
Canadian film historian George Melnyk notes such films were essentially docudramas that carried on an earlier tradition of objectification: "Canada had been 'defined' in a similar way by numerous foreign travel writers of the nineteenth and early twentieth centuries who wanted to explore the exotic and the wild" (Melnyk, 2004, p. 52).

While it was a breakthrough for Canadian filmmaking in documentary forms, the creation of the National Film Board (NFB) in 1939 did not substantially further the cause of feature filmmakers in this country -- nor did the Canadian Co-operation Project (19481957), which was introduced to address the American-Canadian imbalance of payments issue following World War II. In the early 1960s, however, the NFB experimentally produced two feature films, Drylanders (1963) and Nobody Waved Goodbye (1964), which seemed to breathe new life into English-Canadian cinema; by 1967, with the creation of the Canadian Film Development Corporation (later, Telefilm Canada), the industry began to flourish with such tragi-comic sketches as Wedding in White (Fruet, 1972), The Rowdyman (Carter, 1972), Paperback Hero (Pearson, 1973) and Madeleine Is... (Spring, 1971). The arrival of Canada's "tax-shelter era" introduced David Cronenberg's early body-horror films (Shivers, 1975; Rabid, 1977; The Brood, 1979; and Scanners, 1981) as well as a variety of more mainstream genre pictures including The Silent Partner (Duke, 1978), Meatballs (Reitman, 1979), Prom Night (Lynch, 1980), and Porky's (Clark, 1981). At the same time, a number of pictures depicting uniquely Canadian points of view received critical acclaim: Why Shoot the Teacher? (Narizzano, 1977), Who Has Seen the Wind (King, 1977), and The Grey Fox (Borsos, 1982).

Many of the best English-Canadian films of the 1980s and '90s were made by women: My American Cousin (Wilson, 1985), I've Heard the Mermaids Singing (Rozema, 1987), Double Happiness (Shum, 1994), Kissed (Stopkewich, 1996), and Bye Bye Blues (Wheeler, 
1989). At around the same time, the Toronto New Wave (including Atom Egoyan, Bruce McDonald, Jeremy Podeswa and Don McKellar) introduced distinctly English-Canadian sensibilities to their feature films, while in Winnipeg, Guy Maddin and his screenwriter George Toles launched a series of surrealistic features that received their highest acclaim in overseas markets.

Unpredictably, the first decade-and-a-half of the 21 st century has been a critical success for French-Canadian filmmakers, but something of a dud for their EnglishCanadian counterparts. With the exception of David Cronenberg, whose A History of Violence (2005) and Eastern Promises (2007) have been financial and critical triumphs, filmmakers in English Canada seem to have settled back into a role they played to some extent earlier in the 20th century -- viz., supplier of resources (in the form of below-the-line talent) and cost-effective shooting locations to American contractors. English-Canadian identity in film has slipped backwards, it seems, from the heady experimental narratives of the 1970s and '80s to a contemporary business model that employs crews and suppliers, but leaves the Canadian perspective out of the picture. Additional perspective on possible policy-related causes of this retraction will be offered later in this chapter.

\subsection{Identity Issues in International Cinemas}

A seminal collection of essays delineating the cinemas of various nations (including amongst others India, Russia, Ireland, Britain, Japan, Palestine and Taiwan; Canada receives only passing mention), Theorising National Cinema (2006) problematizes the issue in the opening sentence of its introduction by asking why scholars persist in "clustering" films around the notion of national cinema: "Why has this relationship between the nation and film become so widely and uncritically accepted?" (Vitali \& 
Willemen, 2006, p. 1). The editors point out that as an industrial process created first through technological breakthroughs, filmmaking was not in its beginnings a nationalized product; it was only when French film manufacturers established subsidiary offices in New York in the first decade of the 20th century that American competitors sought to define their "national" film works against "intrusive foreign" products. The situation intensified as policy was created in various international locations to recognize distribution jurisdictions, specifically "the rights to derive profits within a particular geographical region" (Vitali \& Willemen, p. 1). Much as a nation might consider its lumber or oil exports as commodities to be reckoned and distributed through an international marketplace, early film producers saw their efforts as highly individualized, competitive and entrepreneurial although not, at least in the early stages, as cultural strategies asserting nationhood.

Drawing upon the works of British theorist Paul Rotha and French counterparts Georges Sadoul and Georges Charenol, Vitali \& Willemen trace the growth of the Hollywood-influenced film narrative from this industrialization: it is a metaphor that endows the American economy and by extension its film industry with a "myth-like 'natural' past":

One of the models used to narratavise the nation and its culture as a given is the Bildungsroman - a rhetoric that recounts the birth and maturation of some cultural practices (from literature to cinema) as if self-evidently imbued with the more intangible aspects of an assumed 'national' cultural essence. (These models) were, in effect, biographies of an industrial sector. (Vitali \& Willemen, p. 2)

Industrialization thus imposes its coming-of-age story (e.g.: a humble beginning, pursuit of an ambitious goal, struggle and conflict to achieve the goal, and finally, victory and maturation) upon the impressionable film industry, imprinting the rise of capitalism in 
industrialized nations' most ubiquitous cultural product. The editors observe that, despite objections emanating from the Frankfurt School, the two countries that adopted this model with the greatest alacrity were the United States and Germany; significantly, it was German film historian Siegfried Kracauer who recognized the industrial (and other) patterns of the Bildungsroman in his ground-breaking From Caligari to Hitler (1947).

Stephen Crofts integrates this notion of national cinema into the larger context of world cinema: in his important "Reconceptualizing national cinema/s" (1993), he notes how the Bildungsroman, now successfully adopted by American filmmakers as their paradigm of film narrative, is observed and countered by seven varieties of alternate national cinema, of which Asian cinemas are perhaps the best entrenched. Briefly, this taxonomy comprises: 1) cinemas that target a specialist market and thereby do not compete directly with Hollywood (viz., European art cinema); 2) those that do not compete but actively critique Hollywood (viz., the "third cinema" of Latin America, Africa and Asia); 3) European and other entertainment cinemas that pit themselves fruitlessly against Hollywood (viz., Third World and European commercial cinema working in the thriller, comedy and soft-core pornography genres); 4) those that ignore Hollywood (viz., the Bollywood cinema of India and the "culturally specific" cinema of Hong Kong and Taiwan (pp. 55-56)); 5) cinemas that "try to beat Hollywood at its own game" (Crofts, 1993, p. 50; this category includes much of the cinema of Canada, Britain and Australia, all of them predominantly Anglophone countries); 6) cinemas supported by their states (viz., the totalitarian cinemas of fascist Germany and Italy, and Chinese cinema between 1949 and the mid-1980s); and 7) those whose culture/language is different from the nations in which they reside (viz., the minority cinemas of Quebec, Wales, Chicano and Afro-American cinema).

Crofts attributes the English-Canadian, British and Australian imitative models to their Anglophony: English as a common language means for these national filmmakers that they 
are already immersed (and thereby semi-equipped to compete with Hollywood) in an homogenous market. It is a game, says Crofts, that these national film industries, "weakened (by) substantial inroads made into domestic distribution and exhibition by Hollywood interests," cannot win: "For each success story like A Fish Called Wanda and Crocodile Dundee which have drawn on some local cultural values, there have been hundreds of films made in these lesser-player countries which, in trying to second-guess the desires of the US market, have produced pallid imitations" (Crofts, p. 56). As for Quebec, it produces the world's "best-known regional cinema," with major directors like Denys Arcand deservedly catapulted to global fame (p. 57).

Two anomalies introduce themselves in Crofts' analysis, the first and most puzzling being the single category in which English-Canadian film finds itself. Many scholars in this country would no doubt argue for inclusion of Canadian film artists in Vitali \& Willemen's first category - that is, as "cinemas that target a specialist market and thereby do not compete directly with Hollywood." Given the diasporic status of several of Canada's most prominent filmmakers — including Deepa Mehta and Atom Egoyan, whose work is developed as much for (respectively) Indian and Eastern European audiences as it is for Canadians - there should be little debate on this matter (Egoyan has been known at times to flatly tell his students, "I don't make films for North American audiences" (Perlmutter, 1989, p. 14)). The second and more important gap is Croft's failure to acknowledge the canonic films produced by filmmakers in Canada's English-speaking regions. Consider for example seven English-Canadian films named in Walz's Canada's Best Features: Goin' Down the Road (1970), The Apprenticeship of Duddy Kravitz (1974), The Grey Fox (1982), Videodrome (1983), I've Heard the Mermaids Singing (1987), Careful (1992), and Exotica (1994). Admittedly, none of these films constitutes break-out pictures in the category of $A$ Fish Called Wanda or Crocodile Dundee in that few have reached a large international 
audience and not one has been recognized with an Academy Award (with the partial exception of Duddy Kravitz, 1974 Best Adapted Screenplay nominee). But to consider these films "pallid imitations" of Hollywood narrative film would be to overlook narrative and aesthetic qualities in them that have resonated with local audiences, critics and scholars, not to mention to ignore the idiosyncratic ways these narratives depart from normative narrative models.

Examined in Walz's collected essays, these qualities, some of which may legitimately be challenged as stereotypical rather than archetypal, include: a desire for a constructed sexuality which is, like national identity, constructed, open to historical change, unstable and insecure (this against: "stark, if not 'depressing' social realism); documentary flavour; eccentric and off-beat characterizations; contemplative treatment of the landscape" that formerly constituted the recognized attributes of English-Canadian cinema (Ramsay, 2002b, p. 5)); reflexive examinations of society and cinema that position American ideological narrative structures against Canadian national uncertainty (the author calls this an American/Canadian-situated "anxiety of influence," following Harold Bloom's famous study of precursor and contemporary poets) (McSorley, 2002, p. 53); a seemingly Hollywood-modeled western narrative trajectory that inexorably moves "from the material to the mythic" (Allan, 2002, p. 137); a critical and reflexive representation of a world "beyond simulacrum," in which media fantasies are paid for with real blood and pain (Young, 2002, p. 169); introversion, amorality, gender-ambiguity and goofy charm (AustinSmith, 2002); reflexive evocation of an idiosyncratic film genre (in this case, the Bavarian mountain film) against an anticipated (in this case, English-Canadian) cinema as a form of "radical alienation" (Straw, 2002, p. 312); and finally, reflexive and hyper-ironic emotional distancing that seeks to "understand rather than to either criticize or exploit...the dynamics of narrative pleasure and scopophilic desire" (Russell, 2002, p. 338). 
A few tentative conclusions may be made about 20th-century English-Canadian film at this stage. First, many of our canonic films display reflexive tendencies: they are inwardlooking and hyper-aware of artifice. Further and as a result of this self-observational tendency, these films are also Hollywood-comparative: everything about them asks Northrop Frye’s famous literary question, “Where is here?” (Frye, 1995, p. 222), responding with, "Across the pond from our father, but right next door to our big brother." Second, even our cinematically realistic (i.e.: narratively and aesthetically conventional) films escape into anti-causal realms at key stages of their development; evocations of the landscape become charged with meaning, requiring semiotic analysis rather than merely “contemplative" musing (Ramsay, 2002b, p. 5). Third, our movies epitomize the notion of alterity: they are quirky, eccentric, unpredictable, 'queer.' English-Canadian films often represent a familiar Other, stubbornly and methodically resistant to dominant discourses, expressing its alterity with fantastical musings and sly rhetorical devices including irony and understatement. Everything about this film seeks to define our covert, concealed identity -- we may not be of a discernible nationality, to ourselves or to outsiders, but we know one thing, which is that we are not American. As for Crofts' categories, it might be helpful to add an eighth section to his listing, one that plays upon his second category (viz.: "those that do not compete but actively critique Hollywood (viz., the "third cinema" of Latin America, Africa and Asia)" (Crofts, p. 50)) with a single word change: "8) those (films) that do not compete but covertly critique Hollywood (viz., the canonic films of English-speaking Canada).”

\subsection{Polarization in English-Canadian Film Theory}

Canadian film scholars are not generally shy to identify Hollywood, the sheer embodiment of cultural hegemony, as the Goliath to be conquered by alternate national 
cinemas. Consider for example Toronto-based R. Bruce Elder who, during the mid 1980s, took direct aim not so much at the moviemaking behemoth as at traitors to the national cause, accusing film festival co-ordinators and policy regulators at the federal level of playing into American hands by adhering to imperial (viz., non-Canadian) systems of technology and narrative. His "The Cinema We Need" attacked the "realist" cinema promulgated by Canadian film scholar Peter Harcourt and festival co-ordinator Piers Handling, accusing it of naïveté and a refusal to "deal with the here and now" (Elder, 1985/1988, p. 264). This refusal translates for Elder as a slavish attachment to the chronological tyranny of narrative - a "reminiscence" when what is needed is resistance: Any cinema that wishes to deal with the experience of the moment must not offer description: rather, it must reveal how events come to be in experience, that is, the dynamic by which events are brought into presentness in experience. (Elder, 1985/1988, p. 264)

His formal choice for the new Canadian cinema is a non-narrative avant-garde cinema that proffers a uniquely reflexive, local and "profoundly rhythmic" experience typified by the best experimental film: “[I]t will be a cinema of immediacy, multiplicity; will use noncausal, non-teleological forms of instruction and will not attempt to arrest time" (Elder, p. 272). This declaration calls to mind the work of Canadian avant-garde filmmaker Michael Snow (viz., Wavelength (1967) and La Region Centrale (1971)), but also Elder's own experimental films.

Elder's manifesto was greeted with the resounding sound of film scholars scratching their collective heads. Bart Testa's "So, what did Elder say?" (1985/1988) first situates the manifesto in Canadian philosopher George Grant's Lament for a Nation (1965) and his Technology and Empire (1969), which critiques the flaws of western society and predicts 
its premature demise. In Testa's opinion, Elder's more original contribution is his attack upon the "New Narrative," which appears to conflate the aims of experimental film with more conventional cinema products. However, even Testa seems unclear as to the success of this argument: "on the side of film criticism, no topic has been so vexed in the past 15 years as the articulation of just what the big problem is with narrative" (Testa, 1985/1988, p. 278). Canadian film critic and educator Piers Handling enters the fray at this stage, situating Elder against the Canadian documentary film tradition of John Grierson and the National Film Board, and clarifying for Testa the troublesome issue of narrative and the New Narrative: "Narrative in Elder's world is a falsification of experience that conceals more than it reveals, that essentially closes off the world and suggests that experience is ordered, rational, explainable" (Handling, 1985/1988, p. 287). Peter Harcourt responds, redefining Elder's cinema "realism" as "naturalism," and defending its qualities as rhetorical strategy:" [a]ny form of suasion must be cast in the language that the people with the power to effect change will be able to understand" (Harcourt, 1985/1988, p. 296). That is, if Canadian filmmakers were to give up conventional narrative practice, they would also relinquish the right "to tell our own stories about ourselves in our own way": in essence, this means such filmmakers would forfeit their right to tap into public funds and thereby commit "an act of suicide" (Harcourt, pp. 296-297).

In concluding their rebuttals, both Handling and Harcourt come back to a more inclusive stance, arguing for multiple forms of Canadian cinema - experimental at one end of the continuum and conventional narrative films at the other (Harcourt does get in one final shot, however, when he accuses Elder of "justify[ing] his own filmmaking activity" via the manifesto, "making it seem monocratic and self-serving" (Harcourt, 1985/1988, p. 299). Like Christine Ramsay, Handling and Harcourt move past what Will 
Straw defines as the old "essentialist position" of Canada's filmic identity (Straw, 2002, p. 103) to a holistic embrace of our film's multiple narrative forms. Exasperated with the project of nailing down a clearly defined identity in an evolving national cinema, they appear to give up — for, after all, if our nation is fully multinational, should our cinema not identify itself in the same way?

This argument and its denouement are essential reading in the literature of EnglishCanadian screenwriting, if for no other reason than they encapsulate the enduring issue of Canadian identity in its national cinema. State funders of this nation's film have long attempted to formulate policy structured upon an essentialist notion of Canadian narrative; as I will point out in coming chapters, this administration has led to the rejection of many well-deserving screenplays and their associated projects.

\subsection{Overview of Canadian Film Policy, 1998-2005}

Canadian and international scholars have produced a number of book-length studies of the origins of film policy in 20th-century Canada: Manjunath Pendakur's Canadian Dreams and American Control: The Political Economy of the Canadian Film Industry (1990) is a political economist text tracing the film industry's policy formation during the early 20th century to the era of "free trade anxieties" of the mid 1980s (Pendakur, 1990, p. 251). Published a few years later, Ted Magder's Canada's Hollywood: The Canadian State and Feature Films (1993) examines Canada's film policies from the beginning of the industry to the early 1990s, exploring "the relationship among culture, Canadian nationalism, the film industry, and government policy, with an emphasis on the latter" (Coates, 1995, p. 308). Michael Dorland's Foucauldian So Close to the State/s (1998), an insightful work chronicling the discursive role of the National Film Board (NFB) and the 
Canadian Film Development Corporation (CFDC, now Telefilm Canada) in forming

Canadian national identity through its cinema, provides an important update upon this initial historical perspective in 1998. Semiotic readings and critical scholarship on the role of Canadian policymakers are included in the work of Christopher Gittings (2002), Debra Henderson (2011), Brenda Longfellow (2006) and Dal Yong Jin (2011); related investigations in English-Canadian genre formations in Aaron Taylor's work (2003) as well as the ongoing historical and textual analysis work of Peter Harcourt (2004) and Peter Urquhart (2006), provide meaningful updates. Although it would be an exaggeration to declare homogeneity in this scholarship, there is a marked tendency to critique government decisions in Canada's film and media arena, from either a feminist or queer theory perspective, a postcolonial/imperialism standpoint, or an historical/international relations prospect.

At the policy level, documentation predicting cultural trends and explaining government decisions is equally bountiful, especially during the period from the late 1990s into the 21st century. ${ }^{1}$ In 1998, the Department of Canadian Heritage (PCH) examined the feature-film sector in this country in its Review of Canadian Feature Film Policy: A Discussion Paper; over a year later, it addressed the findings of that review. This combined strategy — From Script to Screen (FSTS) — concluded that the filmmaking industry in Canada is mature but lacks an audience:

Now that the Canadian industry has come of age and the building blocks of a vibrant industry are in place, it is time to focus on securing a larger share of our own market. The Canadian Feature Film Policy therefore concentrates on filling cinemas with enthusiastic audiences for Canadian feature films... The challenge is clear. Having built an 
industry, it is now time to build audiences. (Department, From Script, 2000, p. 5)

The policy's objectives were fourfold: over a six-year period, it would 1) develop a complete development package with training for Canadian producers and screenwriters; 2) increase support programs as "reward" for successful Canadian producers (aka the allusive 'performance envelope' program (Seguin, 2004, p. 10)); 3) boost marketing efforts in both domestic and foreign markets; and 4) increase efforts to archive and distribute films in the Canadian canon. Finally, the federal government declared its intention to "capture 5\% of the domestic box office in five years (2005-06), and to increase audiences for Canadian feature films abroad" (Department, From Script, 2000, p. 5). These objectives Heritage would carry out through the auspices of its primary film-funding instrument, Telefilm Canada.

PCH's evaluation of the 2000 strategy came five years later: the findings revealed FSTS had had mixed results. Reorganization of the English-Canadian support programs to reward successful producers was not particularly helpful, as "box office successes were not high enough to generate sufficient 'rewards' through the performance envelope" (Department, From Script, 2000, p. 52). The policy's priority to build larger audiences at home and abroad for Canadian feature films met with similarly uneven results: although Canadian features had more than doubled their share of domestic box office "from $2.0 \%$ in 2001 to $4.6 \%$ in 2004" (Summative Evaluation, p. 53), French-language films that year had absorbed $21.2 \%$ of the total box office share while English-language films captured only 1.6 per cent of the market. As for the goal to "preserve and disseminate our collection of Canadian films for audiences today and tomorrow," while PCH had acquired over 250 titles and preserved over 235 legacy feature films, the non-profit Audio-Visual Preservation 
Trust of Canada organization, whose work it had been to promote and preserve Canadian film masterworks, was in 2008 cancelled by Harper's Conservative government.

As for the first objective of the From Script to Screen report, viz., "to develop and retain talented creators by investing in screenwriting and professional development for filmmakers" (Department, From Script, 2000, p. 5), while no specific performance goals were identified in the earlier strategy, success in this case appeared to hang upon the possibility that Canadian producers would access a significant bank of screenplays generated through the agency's new Screenwriter Assistance Program (SAP). As of March 2005, SAP had generated/funded 366 new scripts; however, producers optioned only 16.7 per cent or 61 screenplays, and of this total, " 29 scripts (7.9\%) ultimately received development funding (and) only 6 projects (1.6\%) received Canadian Feature Film Fund (CFFF) production funding” (Department, From Script, 2000, pp. 2-3). The evaluators concluded that in "English Canada, there is evidence to suggest that producers have generally not used the (SAP-generated) scripts," although no speculations were offered to suggest why producers did not take advantage of these funding-supported screenplays (Department, From Script, 2000, pp. 2-3). A discussion of the likely reasons for the disappointing performance of the government's From Script to Screen project follows at the end of this chapter.

\subsection{Review of From Script to Screen Initiative, 2005}

Nine months after publication of the PCH's evaluative survey came a Canadian Heritage standing committee report — Scripts, Screens and Audiences (SSA) — with findings generated through quantitative and qualitative methodologies with 180 industry workers and another 43 industry stakeholders on the holistic creation-to-exhibition state of 
the Canadian filmmaking project. The committee employed Decima Research to also survey audiences of Canadian film to determine their awareness of indigenous film, their purchases (specifically of DVDs and CDs of or related to Canadian film) and their attendance of Canadian film at movie theatres. The results: 84 per cent of participants agreed with the statement, "I think it is important that Canadian movies can be seen in movie theatres in Canada"; 68 per cent with the statement, "Over the last couple of years, I think that the Canadian movie industry has begun to make better films"; 62 per cent agreed that "The acting, directing and production quality of Canadian movies is as good as movies made in other countries"; and 28 per cent with the statement "The stories in Canadian films relate to me." In its conclusion, Scripts, Screens and Audiences is openly critical of the FSTS policy direction:

[T]here has been virtually no improvement in audiences for Englishlanguage Canadian films since the introduction of From Script to Screen. Indeed, as seen in Chapter 2, most of this improvement is explained by an increase in audiences for treaty co-productions made with other countries. (Heritage, $S S A$, n.p.).

Further, the committee finds the work of Telefilm Canada wanting, observing that the funder predicates its decisions upon an outdated Hollywood studio model, in which a centralized decision-making group selects the projects it decides best deserve investment; this model is ineffective in producing the "desired effects in (Canada's) English-language market" (Department, Scripts, n.p.):

A number of changes need to be made to the internal workings of Telefilm. The Committee wants the selection of projects to be done by those qualified to select them and wants this selection process to be 
similar to that used by other cultural agencies (e.g., the Canada

Council for the Arts). In a word, officials should not be deciding what projects to support. They should decide the type of projects eligible for support, but the choice of individual projects should be made by peers and experts from outside Telefilm. (Heritage, SSA, n.p.)

The standing committee recommends that Telefilm revamp its bureaucratized approach for a more egalitarian model, one similar to the loosely affiliated working artists consulting to the Canada Council for the Arts: this new paradigm would invite working producers, directors, screenwriters, and other members of the Canadian filmmaking community to participate in a peer review system to select worthy film projects (Heritage, $S S A$, n.p.).

\subsection{Telefilm's Strategic Plans, 2011 to 2018}

Without admitting the outright failure of FSTS, Telefilm's later strategic plan, Fostering Cultural Success: Telefilm Canada's Corporate Plan, 2011-2012/2014-2015, tacitly acknowledges where the former document's goals might have been misguided. Following consultation in 2009-2010, the corporation's board conducted another analysis of the film industry: this time, five per cent solutions and other measurable goals are not mentioned. Indeed, because gross revenues for feature films at this point include factors such as DVD sales and video-on-demand services, recognition at festivals and critical acclaim, box office figures "simply don't tell the entire story":

In this context, the higher priority Telefilm will place on stimulating audience demand now requires a broader measure of success - a measure that will also include the commercial, cultural and industry value that a project can deliver. For this reason, Telefilm will pursue 
discussions with the industry and Canadian Heritage to create a new

framework for measuring the industry's important contribution.

(Telefilm, Fostering, n.d., p. 7)

Accordingly, another set of four new priorities are outlined by Telefilm's board of directors for the foreseeable future: these include: 1) stimulating demand for Canada's films through promotion; 2) generating "innovative ideas" and market intelligence for producers approaching markets; 3 ) helping producers find new financing sources as well as providing funding through traditional programs; 4) being "a strong leader in the industry" (Telefilm, Fostering, p. 8).

Unpacking these new priorities, the first — "Develop our role as promoter" — is veiled in language that bears resemblance to the corporatese of an organization in the throes of downsizing. Telefilm will "help" industry to promote their films "in innovative ways" (although no hints as to the nature of these innovations is provided); it will leverage existing channels like websites and speaking opportunities to further Canada's film products; it will maintain its offices across Canada and at film festivals to build its "international brand"; and it will promote its minority and Aboriginal filmmakers — all politically sound offerings. However,

[o]n an operational level, Telefilm believes its funding decisions should require producers to demonstrate clear and innovative approaches for reaching audiences, and maximizing the appeal of the finished production. (Telefilm, Fostering, p. 12)

This last general comment suggests that Telefilm will a) leave the enormously expensive prospect of marketing to film producers (ergo, "maximizing the appeal of the finished production"), and b) that it will hold them accountable for the success or failure of these 
marketing efforts in future (viz., if these essential marketing activities are not properly coordinated or financed, this failure may impact the producer's performance envelope).

The same tone of fiscal conservatism emerges in the document's third objective: this point acknowledges openly that Telefilm is currently in a period of "economic restraint and limited resources" (Telefilm, Fostering, p. 11). On that note, the corporation encourages producers to take on more financial risk and to diversify their funding sources: this suggests in essence that the corporation is asking filmmakers to source private funding for a (here unspecified) percentage of its production. For this initiative, Telefilm will ensure its new recoupment prototype reflects a more sophisticated business model; the $\$ 1$-million performance envelope that became an Achilles' heel for so many producers in the mid2000s will be revisited and its ambitious goals downsized to fit market realities. Besides promising to streamline its complex funding applications, the corporation also pledges to more forcefully pursue international co-productions (viz., film production in which two or more film production companies pool their talents and funds to create film products), which provides producers access to foreign governments' incentives and subsidies, and opens doors to the partners' own and other third-country markets. Indeed, with the inception of the Canada Feature Film Fund (CFFF) in 2001, co-productions "have been responsible for approximately $47 \%$ of (the Funds') total production budget” (Telefilm, Fostering, p. 11).

Fostering Cultural Success's final two objectives (viz., sharing industry intelligence and reinforcing Telefilm's "organizational excellence") echo the financial focus of the previous objective. Although the funder professes to keep its administrative costs to a minimum, the Harper administration nonetheless cut Telefilm's budget by 10 per cent in its 2012 budget (Government of Canada, n.p.). This threat may have been looming as Telefilm prepared its new corporate plan, hence the report's defensive language (i.e., "Telefilm has 
been recognized by independent sources as a model of organizational excellence," "Administrative costs are kept to a minimum," "Becoming a flexible and agile administrator is an important priority for Telefilm”, etc. (Telefilm, Fostering, p. 14)).

Telefilm's most recent strategic plan, Inspired by Talent. Viewed Everywhere (20152018), opens with a curious celebration of Canada's 50-year-old Expo '67, comparing without specific evidence the fair's creative innovations to current transmedia and Internet 2.0 successes ("Canada has a history of success in taking on the future" (Inspired, p. 3.)) It is an inauspicious start. After declaring again its commitment to Canadian stories ("Where a Canadian story can be shown, let's take it there," Inspired, p. 5), Telefilm sets out six new goals: 1) promoting Canadian content (“Industry Recognition"); 2) supporting innovation in marketing ("Marketing Practices"); 3) conducting market research ("Market Intelligence”); 4) revamping funding models (“Industry Funding”); 5) working successfully in co-production teams ("Ecosystem of Companies") and 6) delivering profitability (“Organizational Excellence") (Inspired, p. 6).

The aim to promote Canadian film as a "brand," as the document repeatedly refers to it, is something of a departure from a similar goal in Telefilm's preceding strategic plan, Fostering Cultural Success. Where the earlier document was relatively clear in assigning roles and expectations, Inspired is vague but expansive:

By leveraging strategic partnerships and industry-wide resolve, Telefilm aims to markedly increase awareness levels of our great writers, directors, producers, craftspeople and screen performers wherever they live and work. (Inspired, p. 7).

There is no commitment here to promote Canadian film through particular offices, film festivals or websites (as was noted in the Fostering document) — only the promise to 
"conduct effective promotion of the industry and its success directly to customers" (Inspired, p. 7). Inspired's second goal, "Encouraging innovations to reach audiences," is similarly obscure. The section hints at although does not name the phenomenon of transmedia (viz., the technique of telling a filmic story and exploring its related 'storyworld' through numerous media platforms). At the same time, it assigns the expensive responsibility for transmedial products to the producer: "Canadian filmmaking teams must apply their creative skills off the screen too in new ways, experimenting for example with multi-platform roll-outs that take a film everywhere its fans want to see it" (Inspired, p. 8).

The subject of market intelligence comprises in the Inspired document its own goal, a departure from the previous strategic plan, although it is suggested that Telefilm has been conducting market research for some time:

Telefilm will continue its precisely-targeted market intelligence activities, scanning and distilling the reams of relevant data, finding the patterns — sometimes surprising, always changing — and fulfilling the industry's need for a more global and strategic approach to its work. (Inspired, p. 9)

While this section does not clarify a commitment to either quantitative or qualitative research, or to when and where this measurement is scheduled, this goal is somewhat better defined than the previous two. At the same time, the implication here is that metrics will predict audience preferences and thereby guide Telefilm's funding choices, despite the promise that "no set of metrics can take the place of creative decisions made by writers, directors and producers" (Inspired, p. 9). 
Goal \#4 expresses the commitment to find new funding partners through "experimentation with alternative financing strategies," one of which is Telefilm's own The Talent Fund (Inspired, p. 10). In a separate release, the corporation reveals that the fund, launched in 2013, was formed to accept private donations; the Fund's two partners are Bell Media and Corus Entertainment, with a variety of charitable foundations and private donors providing additional support. The Talent Fund development appears a marked departure from one of the Fostering plan's key goals, which was to encourage producers to source their own private funding; at the same time, it seems a more realistic approach, given the difficulty Canadian filmmakers have raising funds in this country's staples-biased economy. The section also concludes with a note that Telefilm will experiment "with alternative financing strategies to ensure Canadian filmmaking reaches new heights" said alternative financing strategies likely to include such concept-testing strategies as crowdfunding and/or crowdsourcing.

Following these two refreshingly candid goals, Inspired's fifth objective reverts again to corporatese: Telefilm will "develop and support an ecosystem of companies...effective at delivering against expectations" (Inspired, p. 11). The goal is a worthy one to be sure, but it is difficult to know here how Telefilm plans to take a role in developing said ecosystem of guilds, associations and unions, given its admittance that this robust system already exists (" $[t]$ he result (of the past five decades) is the emergence of a complex, competitive and mature ecosystem of production and distribution entities" (Inspired, p. 11)). Finally, Telefilm promises via its sixth goal that it will continue to conduct itself as "one of Canada's most effective and efficient publicly-managed organizations," operating in an efficient and low-net-cost environment and "sustaining its productivity and client- 
focused approach" (Inspired, p. 12): it is an aim very similar to the sixth goal of Telefilm's previous strategic plan, but less forthcoming with details than the earlier promise.

One final and crucial note on Inspired by Talent. Viewed Everywhere: in a list of bullet points early in the document is a note stating that "[i]ndependent films occupy less screentime and fewer screens in mainstream cinemas" (Inspired, p. 4). The statement raises questions, especially given the fact that independent film does not appear to be addressed in the document. Does it signal that Telefilm considers independent film a losing battle, and is increasingly unwilling to fund it? That its main interest is now in the relative safety of studio-made or co-productions that will help share the cost and risk of filmmaking? This is an important question, if for no other reason that in recent years Canada's highest-budget and most successful feature film co-productions have been those whose above-the-line teams are from other countries. From a listing of Canadian co-productions completed in 2015, consider for example: the award-winning Brooklyn, written by British novelist Nick Hornby and directed by Irishman John Crowley; Every Thing Will Be Fine, written by the Norwegian dramatist Bjørn Olaf Johannessen and directed by German auteur Wim Wenders; Life, written by Australian novelist Luke Davies and directed by the Dutchman Anton Corbijn; The Witch, written and directed by the American Robert Eggers. One exception here is the Oscar-nominated Room (budget \$13M), whose director, Lenny Abrahamson, is Irish, and whose writer, Emma Donoghue, is Irish-Canadian. Many of these worthy films are shot in Canada, which (generally) means they employ below-the-line Canadian tradespeople and workers, but where in this list are Telefilm's much-vaunted Canadian stories, their directors and writers $?^{2}$ 


\subsection{Canadian Film Policy as Identity/Canadian Identity as Film Policy}

The past 20 years has produced a number of ambitious initiatives in Canada's feature film policy, the From Scripts to Screens program and in particular the Script Assistance Program $(S A P)$ the most prominent misfires. In hindsight, these initiatives appear to be an attempt to bring the Canadian story to the fore - a worthy strategy, given the desire of Canadian audiences to hear stories they can "relate to" (Heritage, SSA, n.p.), but inevitably an expensive misstep. To appreciate this failure, it is important to know something of the way in which screenplays in North America are commissioned. ${ }^{3}$ Generally, the process is a fluid one: a screenwriter approaches a producer or director with what is called a "spec" (speculative") script; if the writer is canny, he/she has produced this script based upon close observation/perception of the producer/director's previous film successes and thematic preferences. In other words, the spec script is a marketing device, designed to showcase the screenwriter's skill as a narrative storyteller, and to introduce his/her talents to the producer/director. If the latter finds the spec script promising, generally this opens the door to a first meeting, often the most difficult step in the process of breaking into a fortress-like business. However - and this is the most important point here — the spec script is rarely if ever on the table as a genuine commodity. The producer or director in almost every case uses the script as a point of entry for discussion of his/her own screenplay ideas: here, the talk centres upon a new script, one to be co-developed by the producer/director and screenwriter. The move is calculated: if the producer or director is to receive industry credits as the co-creator of the project, he/she must have a hand in the initial conception of the script. The other significant consideration here is the very steep hierarchy embodied in the North American filmmaking business. Within the film's creative team — traditionally a trio including producer (the project's chief business co-ordinator), director (the film's 
visual creator) and screenwriter — the director and producer are considered the most important factors in ensuring the film's success. As Canadian producer Peter O'Brian reminds us, "( $\mathrm{t}$ )he screenwriter has a seat at the table with the director and the producer, but usually as the lesser of equals" (O'Brian, 1996, p. 198). The proposition here is that the screenwriter is paid (usually very well) to collaborate willingly with those in more powerful and risk-burdened positions.

The Canadian government's Screenwriters Assistance Program appears not to acknowledge any of these homely realities. The notion that the aptly named SAP would help "ensure that today's aspiring creators and quiet achievers become tomorrow's celebrated film personalities" (Department, From Script, 2000, p. 6) is incorrect on two counts: it first assumes against common industry knowledge that producers are committed to producing speculative scripts (as per information above that SAP supported the creation of 366 of these, of which only six were produced as feature films (Department, Scripts, n.p.)); it further assumes, rather frivolously, that the "quiet achievers" who are screenwriters will be empowered to vault the rigid hierarchies of the North American filmmaking world to become "tomorrow's celebrated film personalities." Very few professionals working within the screenwriting business harbour the illusion that they are to become film personalities: how many average filmgoers can recall the name of a film's screenwriter, even the most celebrated (i.e.: Buck Henry, the writer of The Graduate (1967) and Catch 22 (1969), or Ring Lardner, Jr. (not American humorist/satirist Ring Lardner, Sr.), the writer of $\left.\mathrm{M}^{*} \mathrm{~A} * \mathrm{~S} * \mathrm{H}^{*}(1970)\right)$ ? The misfires of FSTS and SAP suggest that Telefilm is to some extent disconnected from the homely realities of the industry it represents: the corporation is in all likelihood staffed with scholars or bureaucrats with little 
hands-on experience in filmmaking, and/or its upper-level management may be making strategic decisions without the support of evidence or experience. ${ }^{4}$

Regardless, a sharp reversal of policy in the early 2010s suggests Telefilm has settled for a largely conservative approach, one that accepts English-Canada's place in the international film marketplace as primarily a service and location provider, one that willingly participates in prestigious co-productions as a shared profit centre. National identity for these 21 st-century policymakers seems to have little to do with filmmaking; that dated notion falls away before the business strategy of a sound return on the investment dollar, a respectful, safe and ethical workplace, and a contingent of not-unhappy shareholders (namely, the Canadian public), goals that are important for any corporation. In the vein of Northrop Frye and Margaret Atwood, then, it appears the English-Canadian filmmaker in the 21 st century has not mobilized against an anti-creative and/or American master, but willingly adopted a subordinate role as a respectful and efficient supplier to foreign-owned big business. And while there is a nod to Canada's multinational, multidimensional identity in the fact that Telefilm-supported films range over a diverse field of subjects, ethnicities and nations (so diverse, in fact, that there is little to no commonality amongst them), there seems little beyond that heterogeneity to represent this country's cultural values at this stage in its filmmaking history. 


\section{Notes}

1. For the purposes of brevity and because a study of contemporary film policy in Canada would properly fill a dissertation by itself, I focus here upon Telefilm's strategic plans, rather than its annual reports, press releases, white papers and other corporate documentation.

2. I have noted several successful and generally high-budget co-productions here; to be fair, Telefilm also supported a number of English-Canada-led co-productions and productions through its 2015 programs, including Robert Budreau's Born to be Blue (about American jazz musician Chet Baker), Stephen Dunn's Closet Monster (about a sexually frustrated teenager), Patricia Rozema's Into the Forest (a science-fiction about two isolated women), Alexander Carson's $O$, Brazen Age (a compilation film), and numerous other films for which no other information is readily available. Most of the films in this category seem to have been less than successful, and it is unlikely that all obtained distribution, as titles do not appear to have a marketing presence (i.e., trailers, websites, etc.)

3. I rely on my own experience as a screenwriter here, as I can find nothing in scholarly material and only a few mentions in Canadian film industry literature to support this information (the world of screenwriting is still a hermetic realm, which is in part why the so-called screenwriting 'doctors' and educators continue to make a decent living through perennial production of how-to texts and weekend screenwriting seminars).

4. The elephant in this dissertation, and in many contemporary discussions of Canada's film policy, is this country's participation in free-trade agreements with the United States.

Korean policy scholar Dal Yong Jin focuses upon the contemporary plight of the Canadian domestic film market in an American-dominated distribution system in his formidable "A Critical Analysis of US Cultural Policy in the Global Film Market: Nation-States and FTAs" (2011). The research outlines how the US and Hollywood have "hampered cultural diversity and sovereignty in other countries...through the use of FTA (Free Trade Agreements) in the midst of neoliberal organization" (Jin, p. 651). The author describes two FTAs between the US and Canada, the first of which was signed in 1989; the second, the North American Free Trade Agreement (NAFTA), was signed in 1994. In the first of these FTAs, Canada excluded its cultural industries sector via Article 2005; unfortunately, this exclusion was later disemboweled by means of Article 2005:2, which provides the US the right to retaliate against Canada if the latter "unfairly subsidiz[es] an industry, including culture" (Jin, p. 663). Although not all of Canada's dismal performance can be blamed upon either of these FTAs, the numbers tell a grim story: for example, in 2007, Canada's domestic share of its total domestic box office was 3.2 per cent against Australia's total of 4.0 per cent, Mexico's at 12 per cent, and Korea's at 50.8 per cent. Counties like France, India, Japan and China that did not sign FTAs with the U.S. have experienced in recent years rapid development in their film industries, with Japan's domestic film numbers increasing from 278 in 1996 to 417 in 2006, and India's from 649 in 1996 to 1091 in 2006. Jin concludes his assessment with the assertion that the "Canadian film industry particularly in production holds a relatively weak position in its own domestic market"; further, "the FTA has prevented the Canadian film industry from reviving, and it is the US government making sure that its northern neighbour's cinema remains weak" (Jin, p. 663). 


\section{Chapter 6: Analysis of Representative Screenplays}

\subsection{Analysis of Representative Screenplays}

The following chapter analyzes the structural trajectory of eight feature-film narratives by the eight English-Canadian screenwriters interviewed for this project. Selection of these texts was made by the author asking each writer to name a film based on one of her/his screenplays considered "typical"/representative of her/his work; these films were then studied and interpreted, with the resulting analysis providing the bulk of this chapter. The selection is not therefore a random but a biased sample based upon the screenwriter's individual recommendation. Given the anonymity of the eight films studied here, however, it is difficult if not impossible to prove to readers that such analysis is accurate (or at least insightful). To address this issue, the author has added to each section of this chapter supplementary analysis of named English-Canadian films exhibiting similar anomalies in their structures, characterization, closure, character arcs, etc. The goal here is to exhibit that divergent qualities in the anonymous films is shared to a large extent by other EnglishCanadian pictures; this addition should also help to make the sample wider and, if not entirely 'valid' (as such a term belongs to the field of quantitative research), then at least more consistent and applicable.

All eight of the 'anonymous' films (referenced here as "Film A," "Film B," etc.) as well as the named films were analyzed by viewing the films as texts rather than scrutinizing their screenplays. Narrative reception suggests that not only screenwriters but movie-going audience members are similarly capable of parsing such schema (Branigan, 1984, 1992; Bordwell, 1985). Further, names and key details (viz., actors, shooting locations, etc.) of these films are undisclosed so as not to reveal the identities of the screenwriters. 
It is also important to note that while above-the-line players generally have considerable input into the various drafts of any particular screenplay, I have chosen to attribute the authorship of the film narrative to the lone screenwriter named on each project. This decision was made understanding that while various creative participants may provide verbal or written suggestions (known in the business as "notes") to guide the writing process, ultimately the business of incorporating and making sense of notes falls to the screenwriter. Given the often combative nature of this work, producing a working draft of a screenplay is a difficult task for which the screenwriter deserves ultimate authorship.

\subsection{Film A: Melodrama with Dual Protagonists}

The first film to be analyzed may be described as a family melodrama, which situates it within a not uncommon contemporary film genre. Ninety-four minutes in length, Film A features six lead characters, three of them male, three female; not one of the actors playing these roles would be considered stars of American or English-Canadian cinema. However, unlike most feature-length motion pictures, Film A does not follow the protagonist to whom the audience is first introduced through the full length of the narrative, but disposes of him by the end of the film's first act. Further, the script's focus shifts between all five remaining lead characters in such a way that it is difficult to discern a replacement protagonist. However, by the halfway mark of the scenario, a second male lead recovers the protagonist's position, and it is his story we follow through to the end of the film. This curious splitting of the narrative is reinforced with the film's intertitle cards, the first of which announces "End of Part One," and the second, which reads, "Part Two." There are no further title cards to introduce a third part to Film A, which suggests the screenplay comprises a two-act structure. 
Without revealing too much of Film A's plot, it may be enough to note that it explores a variety of subjects, incest and murder primary amongst them, but in addition thwarted love, sibling rivalry, extreme social repression and psychological torment. The movie's initial protagonist is so confused by his desires that he is overwhelmed and ultimately destroyed by them; the second protagonist attempts to redeem the first by falling in love with his (the first character's) partner, then stymies another character's anticipated marriage by murdering a third party. A suicide and two premeditated (although hapless) deaths follow, succeeded by the second protagonist's comparatively bloodless demise.

At a glance, the structure of Film A resembles nothing so much as a Shakespearean comedy in its plot convolutions and love triangles. Moreover, McKee's notion of the classical design and the character arc — viz., "a story built around an active protagonist who struggles against primarily external forces of antagonism to pursue his or her desire, through continuous time, within a consistent and causally connected fictional reality, to a closed ending of absolute, irreversible change" (McKee, 1997, p. 45) — is disrupted early in the course of the story. The protagonist in Film A is active and he struggles, but his story is not causally connected in ways that make sense to contemporary film audiences accustomed to Hollywood continuity, nor is his story followed to the film's end. In much the same way Hitchcock played with audience expectations in Psycho (1960), disposing of his first heroine within the first half of the film, so the screenwriter of Film A similarly removes his/her first protagonist. This characteristic alone takes Film A out of the realm of typical Hollywood fare, which typically strives to align its protagonists' goals and desires with those of its audience. The process of identification in entertainment is however a complex one that, according to one communications scholar, "is partly achieved by offering an illusion of reality," 
... a semblance of how people behave and act in real life, and a consistency of character that resonates with audience members. Another factor that increases involvement and enjoyment is the relevance of the issues and events in the text and the degree to which they resonate with viewers' lives. (Cohen, 2006, p. 185)

Here is a subject - the psychology of identification, with the contemporary preoccupation with 'realism' and relevance — that the screenwriting texts mention only in passing.

An equally disruptive entry in the subgenre of the two-act family melodrama is Sarah Polley's Away From Her (2006). Based on a short story by Canadian writer Alice Munro, the screenplay makes a profound alteration at its halfway mark when it shifts its point of view from the protagonist to its second protagonist. The story of an aging couple quietly haunted by the husband's earlier infidelities, Away From Her first grants its primary point of view and the audience's sympathies to Fiona Anderson, wife to Grant Anderson, a retired professor. Fiona is struggling from the film's opening with early symptoms of Alzheimer's Disease: the first act reveals to the audience her disorientation (as she puts a saucepan into the refrigerator, then becomes lost while cross-country skiing just outside her home), then her quiet revelation to her husband that she had been aware for years of his dalliances with his students (this on the way to the nursing home where she is ostensibly to live out the rest of her life). When Fiona disappears into the nursing home at the end of the first half, her role in providing the film's point of view is relinquished -- and passed to her husband Grant. At the start of the film's second half, Grant realizes that during the month he has been away from Fiona, she has become attached to another patient in the home and seems to have forgotten her marriage. The narrative's central thematic question -- viz., has Fiona truly forgotten Grant, or is her new attachment to Aubrey an act of quiet vengeance? -- belongs 
to Grant, as does the film's point of view. The audience accordingly shifts its sense of identification from Fiona to Grant, and despairs (as he does) as Fiona's illness progresses. And as per Film A's rejection of the 'quest' narrative, Away From Her's dual protagonists do not appear to want anything beyond a chance to address old grievances and make amends.

Film A and Away From Her clearly violate many of the precepts of classic filmic dramatic structure and plot: both refute the three-act form and work directly against the idea of the single protagonist pursuit of her/his desire. Although Away From Her is otherwise a 'conventional' family melodrama, Film A centrally questions McKee's dictate that a film scenario refer to a consistent and causally connected fictional reality. It should also be noted here that Film A is a canonic English-Canadian film that represents an extreme 'arthouse' case on the arthouse-film-to-mainstream-movie continuum: it will prove instructive against the other more traditional screenplays to be examined below.

\subsection{Film B: Drama Without an Antagonist}

Film B is a 96-minute family drama performed by what is commonly known as an ensemble cast; the drama revolves around a major traumatic event that directly involves three families. One Hollywood star (born and raised in western Canada) is cast in the film; the other cast members work and live in western and central Canada. Twelve different characters appear in the film, with 10 given roughly equivalent amounts of onscreen appearance time during the first half hour; that distribution changes significantly as the film progresses. In the film's opening scenes, no fewer than five of the 10 characters vie for the role of the scenario's protagonist: as the story progresses, however, three major figures emerge as central to the story's throughline. Unlike other films that begin with large casts 
and quickly narrow down their focus to one main figure, the distribution of screen time and equalized characterization amongst these individuals is sustained until approximately 65 minutes into Film B, with the movie's conclusion bringing the three characters together into shared states of acceptance, redemption and/or rejection.

The screenwriter's choice to incorporate an ensemble cast in Film B suggests a democratization of the story, an apparent desire to showcase the various forms of despair and disengagement that plague this scattered group of characters. According to Canadian film scholar Ernest Mathijs, the decision (either by screenwriter, producer or director) to tell a film story through a large ensemble cast reflects "a sense of collectivity and community at odds with the structure of protagonist that otherwise characterizes Hollywood cinema" (Mathijs, 2011, p. 89). ${ }^{1}$ This collectivity/community is held in abeyance in Film B until the final 15 minutes of the movie, when three of the five major characters confront one another and receive either forgiveness or rejection for their role in the trauma. Until that time, the narrative places all 12 characters in situations of increasing conflict, through which the events of the trauma are eventually revealed; this disclosure, known to screenwriters as exposition, is drawn out slowly through the film until its final act, allowing the audience to participate in the gradual unveiling of the trauma's mysterious (but not unrealistic) circumstances.

Although the presence of an ensemble cast may suggest that Film B will contain a variety of narrative motifs, the narrative has in fact only one strong theme - viz., grief and the way men and women in different relationships with the victim deal with it. The film can best be described as bleak and almost entirely without humour: it begins with a flashback conveying the information that a character has been killed and explores from that point the ways in which the ensemble resorts to alcohol, promiscuity, despair, blame and bitterness. 
At the film's midpoint, the screenwriter deploys a ubiquitous item to contrast the emotions of all three protagonists: this item is alternately examined (with reverence), discarded, and taken out of a forgotten hiding place to be examined again. While the item acts for the audience as a visual update on the three characters' contrasting degrees of remorse and grief for the deceased character, it also broadcasts the quantity and quality of redemption each will receive at film end. Indeed, during the last ten minutes of Film B, one protagonist comes to preliminary closure with the trauma, a second is beaten and blamed as the guilty party for his role in the accident, and the third escapes the situation by leaving town with a new love.

It should be noted that although two of the three major characters in Film B bears some degree of blame and guilt, one character accepts the lion's share of responsibility for the trauma. In most classic screenplays, such a character would be considered an antagonist viz., an individual who works against the protagonist to achieve an opposing goal. In McKee's schemata, antagonism usually activates some form of conflict or action that precipitates further activity on the protagonist's part:

A story that progresses to the limit of human experience in depth and breadth of conflict must move through a pattern that includes the Contrary, the Contradictory, and the Negation of the Negation. (McKee, 1997, p. 321) However, while Film B's guilty character must accept responsibility for the trauma, the film establishes early on that this individual was doubly compromised at the time of the accident: not only was he in the grip of illness, but he was attempting at the same time to aid a stricken family member. Because the trauma was an accident, there is nothing in the film narrative here that suggests deliberate "Contrary" or "Contradictory" activities by this 
character; his activities occurred through mishap, not through a deliberate desire to oppose any of the film's other characters. Film B lacks an antagonist, and the pattern of "negation" required by McKee is replaced by discrete patterns of personal torment and grieving as each character works through his or her individual burden of responsibility for the trauma. In short, if there are three protagonists for this film, there are an equal number of antagonists: the characters must struggle against their own forces of passivity, despair and anger to come to a resolution.

Not surprisingly, the structure of Film B exists quite outside the regular classic narrative. Rather than a story told in three acts with specifically timed plot turns, the scenario is designed as a series of alternating scenes that shift between the three protagonists and their various family members. Information that in a classic film inevitably sparks an inciting incident in this case simply provides exposition: there is generally no direct action taken by the characters during the first two-thirds of the film to suggest that new decisions have been made to further any of the protagonists' goals. In fact, there are no apparent goals — stated or otherwise - for these characters during this stage of the narrative: their activities reveal only their desires to ignore, deny or hide their emotions around the event. Further, analysis of Film B's 96 separate scenes reveals that no two contiguous scenes contain the same characters: the story not only switches its focus from scene to scene, but divides its time as equally as possible between its protagonists another aspect of its collectivist/communal nature. In fact, the general shape of Film B may be described not so much a projected line with a terminus point (as per Field and McKee) but a spiral that begins in a broad and rather undefined way then begins to accelerate and tighten as the film progresses. In fact, as the film moves into its final ten minutes, the length of each scene is significantly reduced, with some scenes lasting only 30 to 45 
seconds; the effect here is to heighten the tension of this last stretch of the film and to validate a final outburst of violence.

Although it could hardly be described as an ensemble drama, Don Shebib's Goin' Down the Road (1970; screenwriter William Fruet) displays many of the anomalies of Film B (including a spiral-shaped narrative); in particular, it lacks a definitive antagonist. This canonic English-Canadian film opens its first act in high spirits, with Cape Breton pals Pete and Joey leaving home for Toronto, where they believe they will find better jobs and a happier life. Both do in fact find jobs and girlfriends, but before long, they're laid off from their positions in a bottling factory and must take much lower-paying jobs. When Joey's new wife Betty becomes pregnant and cannot work, pressure mounts. The film's penultimate sequence reveals the two men in a grocery store, where they attempt to steal a cartload of food: when a store clerk tries to stop them, they attack him in the store parking lot and leave him badly beaten. At home, they discover their furniture out on the street and Betty nowhere to be found: Pete persuades Joey they must once again leave town and head west.

While Goin' Down the Road contains scenes of intense conflict and distress for both protagonists, at no point does the film clearly identify an antagonist or for that matter any outward manifestation of opposition. In a literary context, the conflict of this narrative could be described as that of Man Against Self, in which the protagonist must face and overcome personal evils that stand in as antagonistic forces (viz., addiction, ennui, mental illness) in order to evolve fully as a character. However, even this trope is inadequate to describe the adversaries of Goin' Down the Road, which are in Pete's case, envy and restlessness, and in Joey's, a sluggish mind and the desire to simply get along. If Pete and Joey are truly engaged in a battle of Man Against Self, neither of them seem to know or 
acknowledge it -- they are characters without the ability to reflect in a meaningful way upon their circumstances, and so are doomed to repeat their failures forever or at least until they're caught.

Both Goin' Down the Road and Film B opt for anomalous structural shapes and a refusal to follow filmmaking norms of protagonism and antagonism. Not unlike many English-Canadian movies, the films comprise a generic hair shirt, with overtones throughout of sadness and a certain hopelessness. It remains to be seen as to whether this austerity is typical in the scenarios of our remaining films.

\subsection{Film C: Comedy without a Character Arc}

At 108 minutes, Film $\mathrm{C}$ is a romantic/teen comedy with a single protagonist and a Who's-Who list of English- and French-Canadian screen actors in supporting roles. The film follows closely the goals of the young male protagonist, which, although comedic, are telegraphed through the screenplay as worthy and socially just: no doubt because his character's aspirations are complex and require considerable exposition and action throughout the scenario, there are very few scenes in Film $\mathrm{C}$ in which he does not appear. The actor playing the protagonist was a rising English-Canadian star when the film was released; he has in the meantime become one of Hollywood's most promising young actors and an emerging screenwriter and director in his own right.

The issue of social justice during a time of relative wealth and citizen apathy is the central theme of Film C, specifically the question of whether today's youth believe they have a stake in fighting for equitable treatment. Although the movie does not touch directly upon issues of religious and cultural diversity, these sub-themes are represented throughout with visual references to Canada's bilingual and bi-cultural legacy; matters of gender 
diversity are also briefly suggested. As a rather gentle comedy, Film C does not overexploit references to these themes, but plays for the most part upon historical references and physical resemblances for its laughs; these references require knowledge of the period from which they are drawn. It is probably not unfair to suggest that in American hands, Film $\mathrm{C}$ would be a considerably broader comedy playing more forcefully upon social disconnections and amplifying the various battles pitched through the movie.

At the same time, Film C is not without scenes of heated conflict. The movie's protagonist is so fractious a figure that he creates confrontations wherever he goes: this conflict is for him an ideological necessity and his very reason for being. In this way, Film C very much falls in line with Robert McKee's "Law of Conflict," viz., "Nothing moves forward in a story except through conflict" (McKee, 1997, p. 210). In his typical blunt form, Syd Field also notes that:

All drama is conflict. Without conflict you have no action; without action, you have no character; without character, you have no story; and without story, you have no screenplay (Field, 1989, p. 25).

If conflict alone was the driving force of Film C, this movie would be a poster child for these prescriptive screenwriting texts. But there is, as noted earlier, something idiosyncratic about this portrayal of conflict, as it is conveyed entirely without physical violence or even raised voices. For example, at the height of the movie's most dramatic scene, one character is bound to a chair and a loose cloth bag is thrown over his head; the protagonist soon lifts the bag from the bound man's head to allay the prisoner's minor discomfort. A little later, the prisoner is released and exacts his revenge upon the protagonist by laying a hand upon his arm and pulling him towards him through a window; the scene, which anticipates some form of slapstick comedy, is muted in its delivery in that the antagonist is controlled, even 
compassionate in pulling the young man through the window. At the same time, this short scene still manages to convey intense ideological conflict. Another sequence centres upon the protagonist's disappointed love affair and his conviction that his loved one is nonetheless the right woman for him; the girl, who has just broken off her relationship with him, apologizes to him and he responds by saying he no longer trusts her. A few scenes later, he phones the girl to tell her that he still loves her. The point here is that Film $\mathrm{C}$ presents an unusually subdued but nonetheless deeply felt series of conflicts; indeed, the insider comedy of the movie for many Canadian viewers will no doubt dwell upon the perceived courtesy and mannerliness of this country's culture of debate as communicated through these scenes. Further, the film's primary action sequences are precipitated entirely by the protagonist and his knowledge of an historical precedent that guides every activity in the narrative. This lends the film an unusually serene air: although the hero declares himself without friends or love at certain junctures, he also knows it is ordained his friends and his love will be returned to him, and that he will emerge triumphant (at least, in this first stage of his life). Nothing about the scenario's activities surprise the protagonist because he has recreated them; even when he seems to be in real danger, the jeopardy is muted because the character is able to consult precedent and work his way successfully through the worst conflict. In short, our hero lacks what Robert McKee calls "inner conflict," a state that otherwise propels film protagonists to examine their lives and move forward — that is, to change in accordance with the lessons taught to them through the course of the film.

This same aura of cheerful unflappability permeates the buddy picture Strange Brew (1983), an English-Canadian comedy written and directed by Second City TV actors Dave Thomas and Rick Moranis. The film, which might best be described as a farce based loosely on the story of Hamlet but with the addition of beer, hockey and various English- 
Canadian in jokes, poses the two brothers against the wicked Brewmeister Smith (Max von Sydow) who has tainted his beer with a mind-controlling drug that prompts its victims to attack innocent bystanders. Despite its themes of violence and murder, the film is positively cartoonish in its amateurish staged fight sequences and death scene (in which von Sydow is electrocuted on an illuminated map of the world): one fight sequence is so self-conscious that its blows (with hockey sticks) rarely if ever meet their marks. As per the collisions of Film C, conflict in this movie is not a central concern, but a convenient formality upon which to structure the narrative.

As we have seen, change as exemplified through the character arc is the ground zero principle of the classic narrative film. It may be obvious by this time that neither Strange Brew nor Film C contain clear character arcs: the protagonists are entirely unmoved by their adventures. The protagonist of Film $\mathrm{C}$ meets his disgrace at movie end with positive stoicism, moving into his certain future with the same confidence and self-assuredness he displayed at the beginning of the film; the brothers of Strange Brew similarly continue on their hapless ways (in this case, stealing a beer truck at the movie's end). In this way, both films bear resemblance to a parodic fable like Jerzy Kosiński’s Being There (1979), in which a mentally challenged protagonist sets off a flurry of self-questioning behaviour and subsequent enlightenment amongst everyone he meets. ${ }^{2}$ The character arc in these films is not deployed in the normative sense; more importantly, this absence hinders neither the movies' narratives, nor their box-office success. ${ }^{3}$

\subsection{Film D: Melodrama With "Inner Conflict"}

Film D is a 93-minute family melodrama with a core cast of three primary characters; the central conflict is predicated upon the extreme and serialized sexual misconduct of one 
central characters, and the resulting suffering of the two other characters in the trio. For the most part, the film splits its protagonist designation between two female characters, with the male lead in the role of antagonist (a fourth male character takes a pivotal but less prominent role). The film was a significant success in western Canada at the time of its release: its casting included two rising stars (one of whom had not yet appeared in film) and a male actor who later took on numerous lead performances in Canada and several character roles in Hollywood.

As per Christine Gledhill's definition, melodrama as expressed in Film D ...organizes an imaginative world constructed on the principle of terminal conflict between polarized moral forces that run through the social fabric and are expressed in personal and familial terms extending beyond the biological family into all areas of social life. ...Melodrama (seeks) to prove (by making visible) the presence of ethical forces at work in everyday life, and thereby to endow the behavior of ordinary persons with dramatic and ethical consequence. (Gledhill, 1992, p. 107)

Accordingly, Film D positions two forces — men and women in diasporic and indigenous social settings — in oppositional and interactive capacities.

As per McKee, Field and most other screenwriting gurus noted in this paper, conflict is generally the driving force within produced screenplays. Hollywood script doctor Linda Seger posits five forms of conflict found in stories: inner, relational, social, situational and cosmic. Inner conflict, she notes, is most often found within novels but is problematic in film narratives as it is less easily understood in visual terms; however, this issue can be solved if the writer "project(s inner conflict) outward onto a person or object" to force the 
conflict into relational terms (McKee, 1987, p. 128). Relational conflict, then, focuses upon the "mutually exclusive goals of the protagonist and antagonist" (p. 129), societal conflict upon an individual and a group (p. 131), situational conflicts upon disastrous occurrences (as per The Poseidon Adventure (Nearne, 1972), The Towering Inferno (Guillermin, 1974), Earthquake (Robson, 1974), etc.; p. 134), and cosmic conflicts upon the argument between the protagonist and God or Satan (consider for example Shakespeare's King Lear or the scenario for Amadeus (Forman, 1984); p. 135). McKee insists that the writer focus upon one of these conflict forms for the centre of the film narrative, using "smaller conflicts throughout each scene...to give your story interest, punch, and dimensionality" (p. 140). Against Seger's advice, Film D's writer/director deploys inner, relational and social conflict to propel his/her story through its melodramatic paces. The film opens upon an obscured scene of physical violence, one in which the exact nature of the conflict is unclear: a hooded figure (whose identity is likewise not revealed) witnesses this act with alarm (as per an extreme close-up upon the hooded character's widened eyes). The shameful mystery of this conflict haunts its family, which relocates to another country to avoid further confrontation and begin with a fresh start. The mystery continues to torment this primary couple and in particular its female protagonist, then emerges as an issue within a larger social context (as the relocated family fails as a group to adapt to its new environment), and finally is visited in one final violent act upon the second couple's family. Societal and relational conflict is highlighted in the friendship between the two female protagonists, who act together in the film's final scenes to convict the male antagonist.

Further, rather than offering exposition/set-up information in its first act, Film D's narrative opens with the scene of a mystery, then continues to tease its audience with heavily veiled clues (i.e., scenes of fights in which the issue is not clear, refusals to provide 
requested information, etc.) The narrative at the 25 - and 40-minute junctures offers covert signals and clues regarding the female protagonists' twinned dilemma, including a scene of the antagonist's discomfort when a common friend is mentioned in conversation, a protagonist's overt unhappiness regarding the absence of her eldest child, her unexplained anger when the second protagonist's family arrives at the former's home, and her subsequent refusal to sleep with her husband in their marital bed. None of these narrative clues provide the momentum of either the inciting incident or Plot Point \#1; rather, they contribute to a general mood of restlessness, dysfunction and unhappiness. It is only during Film D's final few scenes that a final violent act reveals the mystery, one of the protagonists attacks and disables the antagonist, and justice (in the denouement) is served. Further, it is at this final stage that the oscillating friendship of the two female protagonists is resolved, their misunderstandings solved and the criminal in their midst brought to justice.

Written by Irish-Canadian novelist and screenwriter Emma Donoghue, the Oscarwinning co-production Room (2015) similarly explores the various natures of inner conflict — ironically so, given the narrative's theme of forced captivity and sexual slavery. The story is, for a filmic narrative, unusually bathetic: its first half depicts the captivity of fiveyear-old Jack and his mother Joy, as the young woman struggles to teach her son to adjust to the confines of their room (an enclosed shed) and to "Old Nick," Jack's biological father and Joy's rapist. Conflict in these first scenes is muted, with the female character placating her dangerous assailant and striving constantly to keep her child both mentally and physically healthy; however, the general tone of these scenes is marked by palpable melancholy and rage. Like the first female protagonist of Film D, Joy must disguise her distress if she is to thwart her male tormentor. The end of the second act sees the two 
protagonists released from the shed - another unusual turn, given most conventional scenarios would aim to release the prisoners at the end of the film in a natural 'big finish.' The second act of Room then considers the mother and son as they readjust/adjust to the reality of freedom, and it is here that the screenwriter introduces conflict with a vengeance: Joy fights with her mother, who has remarried since her abduction; she is distressed at her father's open rejection of Jack; she struggles with her son as he adjusts to a new reality outside the shed; and finally she attempts to take her own life after a television interview in which the host queries her motivation for keeping Jack with her during the length of her abduction. Room's literary inner conflict — and its explosive second act - are not confined to Donoghue's novel but visited upon the film in evocative and unsettling terms. Like Film $\mathrm{D}$, this narrative refuses to deliver conflict on demand, but contains and then releases it at unique turns in the filmic plot.

\subsection{Film E: Ensemble Drama With Thematic Focus}

Clearly influenced by but considerably more explicit than Max Ophüls’1950 La Ronde (a veritable roundelay of relationships that sees each new character engaging in an illicit affair with a character from the film's previous scene), the 92-minute Film E adopts an ensemble cast to play out a series of sexual encounters during a significant natural occurrence. The film belongs to no recognizable genre, although in the broadest terms, it is most certainly an adult drama: the narrative focuses entirely upon the nature of fleeting sexual encounters between consenting adults, both straight and gay. Of the motion pictures examined in this chapter, Film E immediately took on cult status and eventually led its writer/director to considerable success in English-Canadian cinema and, later, American quality television. 
Critiqued for its somewhat overenthusiastic adherence to its guiding metaphor (which is blurred here to protect the identity of the screenwriter), Film E indicate its dismissal of classic writing norms by referencing this motif at every turn. Described on one level as the notion that unusual circumstances beget unusual, apathetic and often destructive couplings, the metaphor is restated during interstitials by a narrating character who comments upon the plot's overarching natural disturbance and by extension upon the licentiousness and alienation of individuals during periods of relative wealth and social complacency. ${ }^{4}$ Indeed, to suggest that theme is a central preoccupation in Film E is an understatement of the largest order: the movie takes its fixation to agitprop heights, although never without an undercurrent of irony.

The topic of theme in screenwriting's prescriptive manuals rarely emerges; however, when it does, the discussion is generally held in pragmatic terms. UCLA instructor Paul Lucey defines the idea of theme in the opening chapters of his textbook, describing it as "the writerly perspective on the significance of the story" (Lucey, 1996, p. 57), but warns immediately thereafter that writers may overplay this writing element to their peril: Screenwriters have issues they believe in, often passionately, and these topics... often provide the thematic content that enriches our stories. Unfortunately, when a script sizzles with one of these issues, the movie studios may back away, fearing such material will alienate audiences. The studios argue that audiences do not buy tickets to be lectured on ethics, politics, reforming the world, vegetarianism or anything else. (Lucey, p. 57)

Studio man Samuel Goldwyn put the advice to his screenwriters more succinctly and considerably more famously: "If you've got a message, send a telegram." 
Is Film E's overstated theme a deliberate strategy, however, or is it the failure of a relatively inexperienced writer/director to follow industry norms? Lucey's advice to "weave invisibly, so the thematic content is felt rather than noticed outright" (p. 57) is so blatantly ignored here that the former alternative seems the more likely. The writer/director underscores his theme via a mysterious small item that is passed from one actor to another (although not amongst all): the item's suggested decadence and uselessness is further accentuated by its easy transfer between the film's most 'disreputable' characters. It should also be noted that Film E was this writer/director's eighth film (albeit his/her first feature film), and that it was funded by Telefilm and other federal/provincial funding bodies: the auteur could hardly claim ignorance of screenwriting norms, and his/her highly unusual structure suggests knowledge of filmic precedents and a deliberate flouting of filmic narrative guidelines.

Structure in the film is similarly anomalous. Film E contains not three major acts but ten contiguous and interrelated scenes that link one character to another in a seamless daisy-chain. Each scene consumes about as much time as the one before it; no one scene provides any greater characterization or emphasis upon actions than the one after it. The film launches directly into a relationship, one of whose participants solicits sex from the other; once the act is completed, the film moves on to the next sexual encounter. Further, Film E identifies no one character in the film as either protagonist or antagonist: one character seems to come close to the villain's role (by dint of his wealth and his exploitation of a younger person), but as he makes only two short appearances in the movie, this threat of villainy is sketchy. The most accurate statement to be made about the film's characters is that they are the definition of diversity: they are as noted of differing ethnicities, work in a variety of different professions, are upper-, middle- and lower-class 
citizens, and express a variety of sexual orientations. Film E's expression of this diversity is, however, critical, as its narrative does not see any of the ten characters connect in any meaningful or long-term way: their differences are acknowledged, but this acknowledgement creates neither cohesion nor social justice, only further alienation. The natural occurrence anticipated throughout the narrative is showcased at the film's end, and it is a cathartic event (several individuals are seen to be in tears, others appear joyful), yet these ten characters are shown in isolation, as though their attempts at relationship throughout this brief period have been in vain.

A film sharing Film E's structural anomaly and focus upon theme is François Girard's The Red Violin (1998), written by Toronto New Wave screenwriter Don McKellar. The story of a structurally perfect violin that is passed from hand to hand over three centuries and five countries, The Red Violin draws upon a similar host of diverse characters with differing motivations: in Vienna, the violin prodigy Kasper Weiss hopes to win a place in the court of Prince Mannsfeld; at Oxford, the renowned violinist Frederick Pope uses the instrument as a means of seduction (and ultimately relinquishes his happiness as a result); in Shanghai, the music teacher Zhou Yuan maintains the violin as a link to his beloved western music; and in Montreal, Charles Morritz hopes to shield the violin's identity by passing off another instrument in its stead and taking the famous violin home as a gift to his daughter. Thematically, the film dwells upon the idea of material beauty as an instigator of human desire and suffering: Roger Ebert states the movie's theme as "the idea that humans in all times and places are powerfully moved, or threatened, by the possibility that with our hands and minds we can create something that is perfect" (Ebert, 1999). As is the case for Film E, the players in The Red Violin are not subject to powerful character arcs or dramatic scenes of self-revelation: they are instead at the mercy of an object with remarkable 
talismanic qualities. Humanity's inconstancy and degeneration in both films is offered against the purity of the inanimate instrument, which plays as much upon the (temporary) owner as the owner plays upon it.

\subsection{Film F: Mockumentary Without a Script}

This 75-minute mockumentary tells a story of two male friends and a male outlier who is not able or willing to properly enter the world shared by the film's protagonists. The narrative moves through two major crises, one ending in the death of one character and the other in a rejuvenation of a protagonist and a return to status quo. Unlike the other narratives examined here, Film F was shot without a script and with the goals of each scene described by the writer-director, then improvised by the three main characters. What's interesting in this case is that the resulting movie aligns itself more faithfully to the Field/McKee narrative model than do any of the other films examined in this chapter: the inciting incident, mid-act and second act climaxes and denouement all arrive precisely at the Field/McKee designated moments.

Thematically, the film seems at first to lack substance, following as it does a 'documentary' approach to the lives of two male characters: there is little reason for the film's being as it portrays an uneventful, even ordinary way of life. This lack of theme soon reveals itself as the outlier's lack of vision, as the character (who plays the role of a filmmaker) is portrayed not only as without authenticity but also raw filmmaking ability: the movie continuously upbraids its 'unreliable author' by displaying boom mikes that intrude into shots, out-of-focus long takes, repetitive and tiresome footage of the two protagonists indulging in childish behaviour, etc. As is the case for all mockumentaries, Film F must at some point reveal that it is not a real journalistic investigation: this reflexive 
moment no doubt occurs at different stages for viewers, depending upon their sophistication and/or experience with the genre, but all doubts are allayed at the climax of the second act, when the fictional filmmaker is forcibly removed from his project and the movie continues without him. At this point, the theme emerges with more clarity, as the hackneyed practice of the 'artiste' is held up against the authentic (albeit infantile) life of the film's subjects: in short, without true friendship and a strong sense of integrity, life offers its benefactors nothing.

The film's slow approach to its theme is integrally linked to its apparently indifferent regard for its antagonist. In truly idiosyncratic fashion, this character does not oppose the two protagonists in any immediately discernible manner; indeed, on one level, the character appears to support the protagonists' project in every sense. Further, rather than confront the main characters at any point, this 'villain' accidentally does away with himself in a scene so downplayed it may appear humorous to inattentive audiences. Literally every element in the characterization of this figure works against McKee's Principle of Antagonism: "A protagonist and his story can only be as intellectually fascinating and emotionally compelling as the forces of antagonism make them" (McKee, 1997, p. 317). The dialectic McKee proposes is virtually absent in Film F: rather than spur the protagonists to new heights of action and opposition, these two forces proceed on adjacent trajectories, with one path abruptly terminated and the others proceeding apace, seemingly without significant disturbance or change. As noted, a 'strong' theme in narrative does not emerge clearly without a sense of the story's goal and competition for that goal. In the case of Film F, the theme dawns mildly upon the viewer, and most likely in hindsight.

As might be expected, aligning with this shadowy theme and weak oppositional force is a non-existent character arc. Film F concedes major change to nary a one of its 
characters: in fact, when the film's two protagonists are faced with what seems certain death, they insist upon exercising the right to live in their usual fashion. When the film ends, with disaster narrowly averted, neither protagonist has mended his ways/learned a lesson/become a better person. In this way, the film is cynical about the possibility of change for any of its figures, particularly for its antagonist who (as noted) passively dies rather than become 'educated' in the protagonists' more authentic way of being.

Written, directed and produced by Canadian auteur Don Owen, Nobody Waved Goodbye is a 1964 National Film Board of Canada feature originally designed as a halfhour documentary on young offenders and their probation officers. Like Film F, it is a faux documentary (although it is most certainly not a comedy, nor is it an ironic comment upon the documentary genre), and like Film F, it was made without a screenplay. The story is loosely told of an 18-year-old who rejects the materialist values of his parents but lacks the wherewithal to strike out on his own; frustrated, he steals his father's car and is caught for driving without a license. Peter moves out of his parents' home, finds a menial job at a car park, and begins to meet with his probation officer. A final confrontation with his father prompts Peter to steal money and another car so he and his girlfriend Julie can leave the city; she tells him she is pregnant and that she cannot trust him to help raise the baby. The film's final scene depicts the young man driving into the night, weeping.

Similar to Film F, Nobody Waved Goodbye lacks a clearly defined antagonist: the various adults who oppose Peter are kind in their own ways (at least at first) and are after all only doing their jobs. As per the approach of Shebib's Goin' Down the Road and Film F, Peter's worst enemy is himself: at every turn, he makes the incorrect decision, despite his desire to lead an ethical and well-examined life. And while Peter has more intellectual wherewithal than any of the characters of Film F, he is similarly young and apt to act 
foolishly. His ability to change and eventually effect Hollywood's character arc is unclear: Peter's tears could be those or remorse, or simply frustration, in which case he is apt to repeat his previous offences. Both filmmakers leave the confines of Hollywood storytelling here for more thoughtful explorations of a literary theme; that both also take a 'documentary' approach is an intriguing coincidence.

Despite the discrepancy in the films' genres (Film F is a comedy with dark inflections, while Nobody Waves Goodbye is a family drama), both narratives are remarkably similar in their goal, which is to examine from a documentary-like distance the foibles of unreflective male youth. Shooting a film without a script is a daunting prospect, but the writers/directors both discussed the scenes beforehand with their actors and crew, trusting all to interpret the unfolding narrative in ways that would feel spontaneous and new. Nobody Waves Goodbye belongs rightfully to the canon of Canadian feature films, where Film $\mathrm{F}$ is an EnglishCanadian favourite, effortlessly subverting the American myth of progress to revel in the unaltered lives of its protagonists.

\subsection{Film G: Romantic Comedy With Anomalous Structure}

The 89-minute Film $\mathrm{G}$ is a romantic comedy featuring a number of rising stars and one A-list actor. Of the films examined in this chapter, it is the most widely distributed, in many ways the most successful (at this early stage of its release) and amongst the most conventional. Opening with what Austrian-American director Billy Wilder trademarked as the "Meet Cute" moment, the story follows a male protagonist and his conflicted attraction to a friend's close relative; the female lead nurses a similarly tormented interest in the male lead but thwarts her feelings for a variety of semi-legitimate reasons. Film $\mathrm{G}$ follows these characters and a variety of their close friends and relatives, including a parallel romantic 
couple, through a prolonged period, during which time the two main characters are separated, then regroup. The film's final scenes depict the protagonists' wedding.

Like most romantic comedies, Film G adheres to prescribed genre conventions, leaning heavily upon a revolving narrative-door of attraction, misunderstanding, spats and reconciliation: as per Brian Henderson's analysis, the film story “implies a process of perpetual displacement, of euphemism and hiding laid over what is constantly present but denied, unspoken, unshown" (Henderson, 1978, p. 22). The narrative depicts a love triangle in which the heroine must choose between a long-term boyfriend and the protagonist for whom she feels an immediate attraction. As is the case in classic precedents Design For Living (Lubitsch, 1933), The Awful Truth (McCarey, 1937), The Philadelphia Story (Cukor, 1940), The More The Merrier (Stevens, 1943), the movie subjects both its protagonists to periods of prolonged yearning and enforced abstinence, with the aim to release character and audience tension with the (offscreen) promise of sexual and romantic fulfillment. With some revision, this formula has been remarkably successful in previous incarnations, and it finds equivalent profits in the comedy of Film G.

Film G pursues a similarly normative line of the character arc, with "irreversible change" transforming both characters (although one character is transfigured in minimal ways). As noted earlier in this chapter, the romantic comedy genre may bestow its character arc upon not one but two main figures: in such a case, the transformation will be doubled, with both characters learning important lessons and becoming better people in the process. Film scholar Steve Neale refers to this doubled character arc as the "learning process," a process in which the members of the couple come to know themselves as they come to know one another, and in which, in doing 
so, they come to develop and acknowledge compatibility and mutual love. (Neale, 1992, pp. 292-293)

In line with conceptions of romantic education as a gradual process, Film G takes its amorous transfigurations slowly; indeed, if there is any aspect of this picture that does not follow conventional Hollywood standards, it is its tendency to repudiate the usual rules of "inciting incidents" and other key turning points of the classic narrative. Rather than introducing at the 15- to 20-minute mark what McKee calls a "dynamic, fully developed event...that radically upsets the balance of forces in the protagonist's life" (McKee, 1997, p. 189), Film $\mathrm{G}$ instead offers a series of minor revelations that build to a revelatory scene almost exactly at the halfway mark (at minute 47 , during which the male protagonist hints during a public event that he is in love with the female protagonist). Relationship setbacks caused by comic misunderstandings occur routinely throughout the second half of the film, although there are so many of these that they too fail to qualify as McKee's dynamic events that upset the protagonist's balance of forces, etc.

Written and directed by British Columbian Sandy Wilson, the 1985 faux-romantic comedy My American Cousin shares many of Film G's anomalies, including a structure that moves sporadically and seemingly without larger motivation. Twelve-year-old Sandy Wilcox expresses unrelenting boredom with her life on her father's cherry orchard in the idyllic Okanagan until her cousin Butch arrives from California in a red Cadillac convertible. Suddenly fixated upon this prime specimen of blond American manhood, Sandy and her friends trail Butch around Penticton, even as he pursues the pretty Shirley, who in turn avoids her boyfriend. This roundelay of pursuit and rejection is paced in rapid succession, without discernible plot points or strong character motivation: the teenagers and pre-teens tumble after one another like puppies, merely exercising what will no doubt be 
more serious romantic moves in future. This romantic comedy is in the end without an actual romance, or even a coming-of-age motif, as not one of the central characters appears to grow or learn anything through the course of the film — indeed, Butch's parents arrive from Los Angeles at the end of the narrative to take their rebellious child home. At the same time, My American Cousin hints (offscreen) at Sandy's genuine sexual awakening: in the movie's penultimate scene, Kitty tells her sulky daughter that "As you get older, you'll see, boys are like buses. If you miss one, there'll be another one along before you know it." The girl snaps back, "I doubt it," but Sandy's final voiceover also reveals her "mom was right about the boys." While growth through romance is still somewhere in the future, Wilson slyly reveals the all-important arc eventually does come to be - just not within the bounds of this picture.

The "learning processes" of both Film G and My American Cousin are both thwarted by delays, procrastination and immaturity: while the more conventional of the two films eventually fulfills this Hollywood requirement, Wilson's picture happily subverts it.

\subsection{Film H: Road Movie With Surprise Ending}

Film $\mathrm{H}$ is a 73-minute black comedy that initially positions itself as a thriller: after seven minutes of pratfalls and other acts of physical comedy, the narrative's erstwhile antagonist informs the protagonist that he is about to murder him as recompense for his (the protagonist's) criminal activities. This set-up, which in other hands might have played out as a chase narrative or a cat-and-mouse thriller, becomes instead a dialogue-intensive character-driven set piece with a surprise finale.

The film's thematic concern — that of gratefulness for the privileges and relative comforts of contemporary western life — is revealed gradually through a series of Inferno- 
like encounters with residents of a small city in central Canada, the antagonist playing Virgil to the protagonist's Dante. The narrative takes both characters through confrontations with a prostitute, a former employer and a relative, with the film's hero resolving grievances or making final apologies to each character before facing his fate. With the exception of the scheduled arrival of Film H's inciting incident at the sevenminute mark, the narrative structure of the film is almost entirely anomalous: there is no discernible break at the end of either the first or second act, no clear midpoint and no obvious sense of steadily "rising" action throughout the narrative (McKee, 1997, p. 301). Instead, the film follows a sort of journey of revelations, with encounters sparking either arguments between the two lead characters or tiny, almost unnoticeable moments of epiphany — all of which are followed swiftly by absurd disagreements or acts of physical comedy, each perpetuated by the antagonist upon the protagonist. In one scene, the film's hero demands from a former employer justice for an abused worker; moments later, the antagonist sharply rebukes the hero for his hypocrisy. In a later scene, the protagonist makes a heartfelt apology to a relative; in a sequence immediately following, the antagonist inflicts upon the young hero a superficial wound for being otherwise so heartless towards this family member. Each of these rebukes is played for laughs (in that not one is particularly serious), and each succeeds in diverting audience attention from what otherwise might have been an emotional high point. In this case, the notion of revelation becomes an exhausted narrative trope dismembered by the screenwriter with considerable glee.

Revelation, considered by many script gurus to be the most powerful of narrative devices, occurs not only when the protagonist reveals a key point related to the narrative, but also when a key point (usually the revealing of a detrimental or self-destructive character trait, or a psychological block) is revealed to the protagonist. In many ways 
similar to Joyce's conception of epiphany (although without associated Platonic implications), the idea of revelation in screenwriting is designed to display the progress of the protagonist's vaunted character arc:

TRUE CHARACTER is revealed in the choices a human being makes under pressure - the greater the pressure, the deeper the revelation, the truer the choice to the character's essential nature. (McKee, p. 101)

Revelation is similarly withheld in an earlier English-Canadian film, Hard Core Logo (McDonald, 1996), a punk-rock road faux documentary that hints at but will not fully unveil its queer heart. Band lead singer Joe Dick and guitarist Billy Tallent reunite with their band to tour the western Canadian provinces and provide support to punk rock legend Bucky Haight, who has apparently been shot. When Bucky reveals that Joe concocted the shooting incident to force the band's reunification, Billy bolts for a more prestigious gig and Joe, apparently in despair, shoots himself in the head. The gradual unravelling of the relationship between the two musicians is echoed in the disintegration of the band as a whole: one member loses his medication and becomes unhinged, shows in various cities are cancelled or undersold, prostitutes steal the band's cash, and the band drops acid together in one penultimate act of self-destruction. Where Joe's true feelings for Billy might be revealed gradually during these periods of intense pressure (as would be recommended by most screenwriting gurus), McDonald chooses to disguise his film's centre and force his audience to rethink the protagonist's motivation, even as the end credits are beginning to roll. The character arc that should be so prominent (for those who know where to look) is literally non-existent -- until the viewer returns once again to the film to search for clues. 
The refusal of Hard Core Logo and Film H to allow revelation to evolve simply and without refutation defies normative storytelling standards: the films deny their protagonists and by extension their audiences the emotional satisfaction of seeing the character develop throughout the course of the narrative. Even in the face of Film H's last revelation - the 'surprise ending' that offends many of the film's critics — the success of the protagonist's character arc is not assured; in the case of Hard Core Logo's hero, however, ambiguity lingers but the fate of the protagonist does not.

It is entirely possible that if a script analysis similar to this one was conducted with a cross section of Hollywood scripts, the same observations might be made — namely, that very few if any produced screenplays exactly follow normative scriptwriting laws as dictated by the ruling script doctors and gurus. This chapter's analysis does however pose successful counters to the model promulgated by McKee and Field in particular, an observation that should have implications for pedagogical and film policy-based practices. These implications will be discussed in the analysis and recommendations sections.

Of the many conclusions that might be made following the analysis of these narrative, one is certain: viz., that there are many different ways to successfully contravene the normative screenplay model. In examining the differences between these eight scripts and the standard screenplay models, no common thread or guiding principle is readily apparent, beyond the observation that each narrative creates and follows its own structural laws according to the writer's personal proclivities or unstudied inclinations. Second, despite their tendency to ignore normative screenwriting laws, the screenplays examined here are not totally 'arthouse' fare: at least five of them appeal directly to what might be considered a conventional market, with the goal to entertain audiences and make a profit. Indeed, even 
the projects at the indie/arthouse end of the continuum have been cast with Canadian stars or American B-list actors, which suggests their producers are aiming to make a profit and doing their best to follow recognized industry norms for success. The anomalies represented by these narratives suggest that screenwriting rules are malleable.

Third, none of these films with their transgressive screenplays could be considered unsuccessful: box office numbers for each are not readily available, but all succeeded in obtaining theatrical distribution, and all have achieved second-run distribution on premium/specialty television channels like Bell Media's The Movie Network, Corus Entertainment's Movie Central, Allarco's Super Channel, Netflix, etc. Several have become cult favorites, while other newer releases are still finding audiences. Indeed, every one of the screenwriters involved with these projects continues to work in his/her chosen field which, given the competitive nature of the North American film industry, is in itself a marker of success.

Despite my initial hesitancy to label English-Canadian screenplays as deliberately contraventional, even subversive in their aims and structures, it is nonetheless clear that these narrative works skirt normative models in central rather than marginal ways. Why these works are anomalous is unclear at this point, but data arising from screenwriter interviews may clarify some of these questions. 


\section{Notes}

1. Unfortunately, Mathijs does not pursue this promising premise, opting to write his article on the significant of ensemble casting for cult films and the ramifications upon cult-film actors when they are cast in such movies.

2. The comparison between Film $\mathrm{C}$ and Being There ends here, however, as the latter film parodies not only the social and cultural flabbiness of late '70s America, but plays upon Chauncey Gardiner's naïveté/simplemindedness to skewer a multitude of American homilies. Where Being There uses cynicism and sarcasm to create its comedy, Film C relies more upon its audience's faith in the protagonist and knowledge of his namesake's fate to propel the narrative.

3. Strange Brew made $\$ 8.4$ million against its budget of $\$ 4$ million, making it one of the rare English-Canadian films to not only not lose money, but to garner a fairly significant profit.

4. In this regard, Film E also takes a strong cue from Alain Resnais' Mon oncle d'Amérique (1979), in which a scientist/philosopher illustrates social problems of the day. 


\section{Chapter 7: Analysis of Research Data}

\subsection{Analysis of Research Data}

The screenwriters selected for this chapter's interviews were contacted in a variety of ways. Three responded to a call distributed through the Writers' Guild of Canada that requested a confidential one-hour interview on the subject of screenwriting and film policy in Canada. The remaining five were contacted personally by an Edmonton-based film scholar with deep knowledge of the Toronto-based film market; these interviewees agreed to participate in a confidential one-hour session. All interviews were conducted by telephone; all were taped, transcribed and distributed back to interviewees to ensure accuracy of quotes and data.

Although the individuals interviewed for this project would not strictly speaking comprise a widely diverse set, there are key differences between them that should be acknowledged. Six of the eight currently act as filmmaking auteurs: that is, all six write and direct their own screenplays, with most acting as their projects' producers most of the time. One interviewee is female; the remainder are male. Seven of the people interviewed are what might best be described as white; one is a Moroccan-Canadian. Two interviewees are Jewish, one is a self-described lapsed Catholic, another a lapsed Protestant and the remainder of no named religious affiliation. One individual is in her/his 70s, one in her/his 60 s, one in her/his 50 s, one in her/his 30 s, and the rest in their 40s. One interviewee is openly gay; the others did not declare their sexual identity to me. The diversity of this research set suggests something of a counter to the norms of contemporary Hollywood (i.e.: at the age of 40 , screenwriters are widely considered too old to be viable in a marketplace catering to 18- to 35-year-olds), although the Anglo-Saxon/Jewish mix here is not unlike that of the American screenwriting majority. 
It is important to note at the outset that these interviewees are what most film scholars would consider successful filmmakers: that is, all make a living (generally a handsome living) from their work in the screenwriting/filmmaking trade. Data on the annual incomes of these individuals was not collected; however, one glance at their IMDB pages suggests that all eight (with the possible exception of several older participants, whose screenwriting/filmmaking productivity has slowed slightly in recent years) enjoy considerable momentum in their careers. A snapshot: one interviewee is currently directing episodes of quality American television series like Game of Thrones and The Walking Dead; another is producing/directing mainstream Hollywood film with A-list actors; another writes and acts in a cult-comedy television series that enjoyed the biggest debut of any series on a streaming television service; yet another has been a partner/collaborator with one of this country's most renowned filmmaking artists. All freely and cheerfully volunteered their time, both for the interview itself and for the sometimes lengthy process of reviewing the resulting individual transcription.

One other interview deserves mention here. In June 2013, I made a trip to Toronto to interview a senior Telefilm executive involved in assessing and revising screenplays. Following University of Calgary ethics requirements, I telephoned this executive first to schedule an interview, then during the course of this introductory phone conversation read a notification that outlined the terms of our upcoming interview (viz., that the interview would be recorded, that the interviewee would be provided with information on the confidentiality and ethical parameters of the interview, then asked to sign off on the proceedings, etc.) None of these requests appeared to cause concern. However, when I arrived at Telefilm's offices, I was greeted with a marked lack of enthusiasm: I was told that the interview would not be recorded on tape and that even note-taking would be 
problematic, and that the interview was strictly for background information purposes without attribution. My questions regarding structure, character arc and other norms of screenwriting were greeted with firm answers: in every response, the executive used language from Robert McKee's book. It was clear to me that for this individual, at least, McKee's Story was an essential text in determining screenplay quality.

The renowned anthropologist Hortense Powdermaker introduces her chapter on Hollywood studio" "front offices" in her formidable Hollywood: Dream Factory with a telling quote from the English poet Lord Byron:

Like other businessmen, front office executives are concerned with attaining large profits, but the profit motive is not always primary, and rarely the only one. For many executives, power is even more important; and Lord Byron's description of the political boss fits many Hollywood executives. He writes: "The aim of a Boss is not so much fame as power, and power not so much over the conduct of affairs as over persons.” (Powdermaker, 1951, pp. 66-67)

Although Telefilm Canada is hardly a Hollywood studio front office, its position in Canadian filmmaking circles is to some degree analogous: Telefilm uses many of the same criteria deployed by yesterday's studios and today's independent producers to bestow and distribute capital. Regrettably, the encounter was a failure by the standards of the other interviews. Probing into the decision-making of a funding agency turned into a challenge to an established power structure, and even with all the safeguards in regard to anonymity, the research appeared to be viewed as a threat. The failed interview, however, did highlight the distance that exists between the information offered by the creative mind of the 
screenwriter and information provided by a funding agency.

\subsection{Forms of Screenwriting Education}

As might be expected, the question "How did you educate yourself in the ways of screenwriting?" was met with a variety of answers, many of them leading to a broader although brief discussion of the writer's personal post-secondary education journey. For the most part, interviewees identified their screenwriting education as: a) conventional, which for participants generally meant they had attended film school (at a 'technical' institution like Ryerson University, the Canadian Film Centre or either Toronto or Vancouver Film Schools) or had entered a film program at university; or b) unconventional, which meant interviewees had taught themselves the craft by reading screenplays or books on screenwriting and/or playwriting, or had simply thrown themselves into the practice by writing screenplays, i.e., 'learning by doing.' Many writers considered themselves to have taken a hybrid route in which (for example) they began at film school, then dropped out to pursue screenwriting on their own. Others who regard themselves as filmmakers (that is, directors or producers) or who were educated to teach in the general field of filmmaking/film studies, make it clear that screenwriting was not their primary educational pursuit; these individuals often direct the interviewer back to their original fields of study to contextualize their screenwriting as a secondary educational pursuit.

Of those who entered and completed the conventional film school educational route, writer/director/producer Benjamin Philip, 54, considers himself "very typical": he recalls the influence of his father, who had been a "big film buff," as well as the fact he (Benjamin) had conducted his own film studies at an early age ("I was always reading about movies and watching movies") (B. Philip, personal communication, January 12, 
2012). Forty-year-old Matt Sparks, who identifies primarily as a filmmaker, went to film school at Concordia University, "and so did my three or four years there, did my short films and whatnot" (M. Sparks, personal communication, September 27, 2013); writer/producer Joseph Freiman, 42, studied at Queen's University “because they had a really good film program” (J. Freiman, personal communication, January 21, 2012). Forty-year-old screenwriter Richard Bruce started a film degree at the University of British Columbia, but found it too generalized ("all I wanted to do was write screenplays"), so transferred to a part-time certificate program at Capilano College; still later, he completed a six-month television writing program at the Canadian Film Centre ${ }^{1}$. The interruption to his studies at university came not as a result of distaste for his studies, he notes, but because he had already begun to work within industry:

(W)hat happened with me was that I sort of had some success very early, which prevented me going back and doing what I really wanted to do, which was to get my degree in film, either theory or production, from UBC. But because I'd had, you know, a screenplay optioned and TV stuff going it, it felt like the train was moving so I'd better get on, rather than wait at the station to finish something else. (R. Bruce, personal communication, September 26, 2013)

Those who took a less conventional route often came to screenwriting equipped with tangential or unrelated degrees: 70-year-old film director and screenwriter Jane Parsons launched her career with a BSc in Mathematics as well as a Bachelors in Education, then began to work towards an MA in Music. With experience in teaching, performance and conducting orchestras and choruses, she segued into filmmaking and screenwriting upon finding employment at the National Film Board of Canada. Writer/director/producer Henry 
Talbot, 43, majored in Communications at a Canadian university, "(b)ut I did as much film stuff as I could, and when there was an option to make a movie rather than write a paper, I would always make a movie" (H. Talbot, personal communication, September 20, 2013). William Chopin, 69, is a film scholar and screenwriter, amongst other things (he completed a $\mathrm{PhD}$ in English at an American university before writing screenplays); his education in the form came from reading plays as a young man, "and then gradually, gradually learning to ascertain the differences between what I'd understood to be playwriting and playwriting structure, and screenwriting" (W. Chopin, personal communication, October 25, 2013). At the other educational extreme, Ron Booth, 37, bypassed the university/college route altogether; he is both a writer and director, and now has production credits for a feature and a television series. As a child actor, he spent a great deal of time reading screenplays. Writing in this form seemed to him a natural transition:

I have no formal education in terms of particular scriptwriting: I am a high school graduate but I didn't go to college. I was just always the kind of kid that wrote - I wrote plays, I wrote stories, I wrote everything, and so it was kind of probably inevitable that I would write scripts because they were what I read the most. (R. Booth, personal communication, November 6, 2013)

Most conventionally trained interviewees indicate that screenwriting was not a focal point in their respective programs. Sparks suggests the form was introduced at Concordia, but that it was a relatively minor offering:

I can say that some of the initial ideas were taught there. It's probably been just more doing it that has caused me how to figure how to do a 120-page screenplay... (At the Canadian Film Centre), I learned a few 
more things and since then I've been learning by making films and writing various scripts. (M. Sparks, personal communication, September 27, 2013)

Joseph Freiman also notes he did not study screenwriting per se: "the only actual formal screenwriting class I ever took was a six-week summer course at Queen's, where we would write short screenplays, basically, short films" (J. Freiman, personal communication, January 21, 2012). Benjamin Philip is somewhat more critical about this same lack of screenwriting focus:

(T)here's very little academic training specifically in screenwriting. I did have a course I think at one time in screenwriting but it was pretty cursory - it was very, very academic bare bones. And then it was really about applying myself, finding my own way through it and reading about screenwriting — and then just doing it. You know: learning by doing. (B. Philip, personal communication, January 12, 2012)

Only one of the eight writers interviewed identifies a key instructor of the screenwriting process. Jane Parsons cites filmmaker Tom Daly of the National Film Board (NFB) as the "guru who came into everybody's editing room or at the beginning of films" to examine their scripts:

He was a student of (George) Gurdjieff and he had a very philosophical spiritual meditative presence. He taught us all to experience each step of the process as a meditation, I guess you could say... At any rate, he was one of my first and only teachers, because I 
never went to film school. (J. Parsons, personal communication, September 24, 2013)

Except for this vivid description of an influential teacher, the interviews as a whole are dispassionate, and at times somewhat critical, on the subject of screenwriting education and/or screenplay perusal. In recounting his education in screenwriting, William Chopin flatly describes his dislike of the form:

I hate reading them. I hate reading my own, I hate reading anyone else's. Occasionally, there are exceptions, but it's a form I recoil from. I guess what I've learned is I hate wasting really good language on action, description, and things that are not going to be in the movie, so sometimes I please myself if I'm in a fanciful mood, it's often just a break from the demands of a particular structure or I've got to entertain the director somehow because I haven't really solved a scene problem yet. (W. Chopin, personal communication, October 25, 2013)

No other interviewed screenwriter or filmmaker is as dour in his/her description of the form, but it is also the case that no other interviewee describes the process, either of education or of screenwriting itself, as particularly enjoyable or fulfilling. Henry Talbot describes the "insurmountable" quality of learning to write screenplays, and how "(y)ou start writing and it's probably going to be awful, but you keep going." At the same time, he clearly advises the best way to approach screenwriting education:

(A) lot of the cliches are correct, in terms of writers. If you want to be a writer, start writing. Start reading: read a lot of scripts. That was the best way for me to learn. I don't think I ever took a quote-unquote 
screenwriting course. (H. Talbot, personal communication, September

20, 2013)

Given the heterogeneity of ages, backgrounds and aims of these eight writerfilmmakers, it is not surprising that they share little commonality in their experience of screenwriting education. They are significantly more united, however, when it comes to discussing the significance of contemporary Hollywood screenwriting doctrine, particularly that promulgated by Robert McKee and Syd Field.

\subsection{Rating the Work of Screenwriting Gurus}

The reaction of interviewees to the names of these two screenwriting experts and/or titles of books written by same was not positive ${ }^{2}$ this feedback comprised a continuum, with comments ranging from dismissal to disgust. As might be expected, some writers invoked either McKee or Field following a question on three-act structure; others responded to prompts on related subjects. For example, Matt Sparks, who offered the mildest commentary on these instructors, responded to the query "What is the importance of the three-act structure in your work?" in this way:

I'm certainly aware of it. I mean, that's probably the first thing they make you aware of, at least back in my Concordia days. When Syd Field was the only game in town... (M. Sparks, personal communication, September 27, 2013)

Another temperate reaction came from Richard Bruce, who had responded to a question about screenwriting education that he had read "every (screenwriting) book (he) could get (his) hands on." When queried about McKee's work, he said he had not attended any of this instructor's seminars, but he had read Story and had "mixed feelings" about it: 
And you know, it's been a while since I read it although I think he is full of a lot of BS, I think he is a blowhard but he does make some good points. As with all of them: they all make some good points, but at the end of the day, the only way to really learn is to do it -- read actual scripts and continue to write. And figure it out for yourself. (R. Bruce, personal communication, September 26, 2013)

This note - that many of the screenwriting texts make good points, albeit that they must be tempered by the screenwriter's own experience and understanding of the form - is echoed by Benjamin Philip, who recalls being "exposed" to the books of Field and McKee "at some point":

I actually took a Robert McKee program -- he came to Toronto for a three-day writing workshop thing -- and that was actually useful in a certain way... It didn't appeal to me as a way of writing but it appealed to me as a way of thinking -- just to understand the underpinning of classical screenwriting... (B. Philip, personal communication, January 12, 2012)

While these responses reflect what I would consider a good-humoured distaste for the instruction of Field and McKee, they also reflect a positive turn, in particular, that of a move away from the systems-level property of Hollywood instruction to that of reliance upon an individual understanding of screenwriting form. In these cases, the complaint against the Field/McKee pedagogical proposition is that it is not original: Philip in particular makes this suggestion when he notes that he (Philip) has "never been a person who creates by pattern": 
(McKee's) approach is really rigorous... I never really wanted to approach my own writing in that way, but it did give me something to reference and cherry pick from, in an unconscious way, I guess... I remember at the time being a bit impressed with the whole approach that he took, but in the end realizing that I had to pretty much dismiss it almost entirely in order for me to create anything that was even remotely original. (B. Philip, personal communication, January 12, 2012)

Not all interviewees were as diplomatic in their responses to this question. Henry Talbot is openly critical of McKee's teaching, calling it "predatory":

I think he sort of preys on a lot of dreams. His rules aren't wrong, but there's no golden thing that he does. Although I think if people want a bit of guidance, it's a good thing to go and do, if you're looking for some education, for sure. But I think what you can learn from Bob McKee you can learn from anywhere. (H. Talbot, personal communication, September 20, 2013)

Talbot's comment on McKee's position as a tutor arises in all likelihood from a common perception in the screenwriting community — namely that he (McKee) has profited enormously from a circumscribed life of instruction. This perception is deserved, according to a New Yorker feature:

McKee has houses in Bel Air and Arizona, and a handsome black Jaguar, and membership in a country club just north of the Getty Museum, but these are mostly the benefits of a rather uncinematic life of repetition: McKee has given the same screenplay course for twenty 
years - the same three-day, thirty-hour performance during which he assumes, variously, the roles of after-dinner raconteur, gloomy controversialist, and freewheeling, cross-disciplinary university lecturer. (Parker, New Yorker, October 20, 2003, n.p.)

Other writers are more perfunctory: in answer to a question about narrative closure (which invokes one of McKee's prime directives on the proper way to end a screenplay), Ron Booth replies, "Bullshit." Later in the interview, he makes a sophisticated reference to the film Adaptation (Jonze, 2002), in which the famously bombastic McKee (portrayed by actor Brian Cox) leads a seminar on screenwriting for an auditorium of students, including Charlie Kaufman, the writer of Adaptation (portrayed in the film by actor Nicolas Cage). Booth notes that while he knows of the "big" texts in screenwriting,

I've actually never read any of them. The closest I have come to reading any of them would be watching Adaptation, I think. I felt that I'd read enough, then. It was like, "I get it, I get it." (R. Booth, personal communication, November 6, 2013)

William Chopin similarly makes a reference to Adaptation, although is less economical in his allusion: where Booth is content to simply allude to the film and allow comic shorthand to communicate his distaste for the Field/McKee books, Chopin adopts the Kaufman persona to better portray his dislike for this directorial form of instruction:

I try to avoid that feeling that I'm following in a mechanical way the Syd Fields or Robert what's-his-face from Adaptation. It's just those pagecounters, beancounters. I hate all the words, in fact, like the character playing Charlie Kaufman -- I hate the word arc, I hate the 
word redemption, I hate the phrase dark night of the soul in the third act, I mean, all the terminology makes me puke. (W. Chopin, personal communication, October 25, 2013)

For her part, Jane Parsons responds to a query on the usefulness of Robert McKee's advice on closure with one phrase, pronounced in a sarcastic tone: "Final cadence," she says, before pausing and changing the subject. (J. Parsons, personal communication, September 24, 2013)

We can surmise here that screenwriters have at least two major objections to the Field/McKee methods of instruction: the first settles upon the jargon associated with such teaching. This insiders' language — arc, redemption, dark night of the soul, final cadence, beat, etc. - creates a visceral reaction, although not necessarily because it inaccurately describes factors of the screenwriting process. Indeed, as Philip notes, there are useful aspects to many of these textbook approaches to classic Hollywood screenwriting, even if they provide only an introduction to the craft. So why do writers object so strenuously to seemingly innocuous lingo?

It may be helpful at this point to again consider Niklas Luhmann's systems theory, which situates the topic of insider language within a general arena of communication. For Luhmann, a "language community" is one in which "members introduce new terms by explicitly or implicitly agreeing on terms (observable by correct actions following on statements)" (Rosenkranz on Luhmann, 2011, p. 571). Such agreement on terms inevitably creates a shared vocabulary for members of a system: we understand this vocabulary in a colloquial sense as jargon, lingo. Luhmann notes that within an organization, shared terms/language (situated within the act of communication) is a major driver of the system — in fact, it constitutes the act of autopoiesis itself. 
(Shared language) has to be recreated from situation to situation by referring to previous communications and to possibilities of further communications which are to be restricted by the actual event... Information, utterances and understandings are aspects which for the system cannot exist independently of the system; they are co-created within the process of communication. (Luhmann, 2006, p. 67)

Systems theory is far from the only scholarly discipline to address the issue of insider language. Organizational communications scholars including Eric Eisenberg regard jargon as a self-perpetuating "restricted code to which only certain individuals are privy"; this "privileged interpretation" acts to include organization members as members and to exclude those who do not belong to the knowledgeable in-group:

To those outside of the language community, the discourse is strange, technical, or purposefully ambiguous; to those inside, it acts as a kind of incantation, an implicit expression of loyalty to the group or organization. (Broms \& Gahmberg, 1983; Edelman 1977) (Eisenberg, 1984, n.p.)

Eisenberg further situates his discussion of jargon (and related issues of ambiguity) within the exercise of power inside organizations: in essence, the use of insider language serves to protect the system's knowledge owners from both a) treacherous insiders who seek to rise too quickly within the organization, and b) infiltration by outsiders from competing organizations. When jargon is creatively designed and skillfully deployed, practitioners may use it as a smokescreen to hide intentions or deceptions; when practitioners need to assert authority, they may augment or re-interpret aspects of shared language to defend their stronghold. So again: if insider language truly acts to include and protect group 
members who might otherwise feel marginalized within the confines of a system or organization, why would the screenwriters interviewed for this project so vigorously reject it and the insider status such language conveys? Would not the protection afforded by jargon and its privileges not overrule or at least balance at least one of the objections that several of these writers have, viz., that insider status precludes original thought and writing?

It's important to remember that the writers interviewed for this project are highly successful on their own terms, whether as directors, producers, screenwriters, scholars or combinations of same. It may be in this case they resent the suggestion they may have sought help from screenwriting pedagogues and textbooks — which tend to be perceived within industry as guides for neophytes hoping to make a fortune (or at least a living) writing Hollywood screenplays. In this case, being part of an "in crowd" reduces their work to that of the rank amateur; jargon thus becomes a sort of meaningless membership in a club of anxious postulants. For those who think deeply about screenwriting and spend much of their lives in its practice, knowledge of screenwriting structure and technique is often a form of intellectual property — hard won property, in many cases.

I should also point out, however, that most of the individuals interviewed for this project have been compelled to take an independent, usually entrepreneurial approach to their careers (generally the norm in Canada, which does not enjoy direct benefits of the studio system). Belonging to an organization that protects its members and offers them insider language is not a viable option for these individuals ${ }^{3}$ : it is generally the case that English-Canadian screenwriters find themselves working as outsiders both by virtue of their profession (which is as we have seen is regarded as one of the lower rungs of the above-the-line hierarchy) and by dint of their nationality (that is, as foreigners working 
within an international industry consolidated in America). Further, in this country, the profession is established in such a way that ambitious writers inevitably consider working in other roles, viz., as producers and/or directors, if for no other reason than they may retain creative control over their narratives. In such capacities, they act as independent businesspeople who must cope with the creative and technical aspects of a notoriously difficult and unstable industry. Significant insider language for most of these people resides more within the industry's financial activities (i.e., "negative pick-up guarantee," "production negative costs," "output deals," etc.) than in beats, character arcs and final cadences. Again, this would suggest interviewees' impatience with screenwriting lingo reflects the contempt of the seasoned pro for the eager amateur ${ }^{4}$ : when there is limited time or resources to devote to any industry concern, the business of filmmaking naturally assumes centre stage.

\subsection{The "Rules" of the Game: Structure in Screenwriting}

As discussed earlier in this dissertation, the idea of structure in screenwriting practice is roughly equivalent to what narrative analysts would consider the construct of plot: that is, structure is a holistic notion that describes a (generally) linear fiction driven forward at key junctures by revelations, story reversals, action, etc. In North America, structure in screenwriting is almost always understood as three-act structure, a classic screenplay form that continues to be linked to the teachings of Aristotle's Poetics. Recognizing the primacy of this concept, then, I ensured a question in my interviews probed writers on the significance of the three-act structure, then upon the place of closure, the midpoint and the character arc in their screenwriting. 
Given the generally disparaging feeling toward the most prominent analysts of the three-act structure (Field and McKee) and to its highly touted universality, one might speculate that interviewees would comment in a similarly negative way upon the form: this, however, was not the case. All eight interviewees consider three-act structure a foundational design in classic and contemporary screenplay design and, in relation to their own writing, a latent form that should not be overanalyzed but allowed to express itself within the script as the script evolves. Writers spoke of the three-act structure in terms like "instinctive" (Booth), "innate" (Sparks), "loose and intuitive" (Chopin), "organic" (Parsons), "golden" (Talbot), and "unconscious" (Philip). Joseph Freiman said simply, "I don't think about it too much":

I think that movies have a beginning, middle and an end. I think the structure can be used to - I think people get too caught up in that sort of structure, like it's math or something. (J. Freiman, personal communication, January 21, 2012)

Given the apparent study required to master the three-act structure, why would an intuitive approach make sense? A screenwriter in my own circle once suggested to me that mastering the form was analogous to perfecting a golf swing: awkward and artificial at first, but increasingly natural as the practitioner exercises the craft. When I suggest the analogy to Ron Booth, he exclaims, "That's totally it!”:

It feels so alien and weird off the top, like "What do you mean, 'act,' what are you talking about?" Especially to writers that come from writing from another art that is less structured, and you feel like, "Well, I just want to intuit here, I want to create..." (R. Booth, personal communication, November 6, 2013) 
The reference here is to artistic freedom, a concept suggested earlier here in discussions of screenwriting gurus and their texts: that is, writers who come to screenwriting may chafe at the constraints of the form and consider it too restrictive. Booth is clearly acquainted with the concern, but explains it by way of another analogy — viz., iambic pentameter which he admits, for actors like himself, may at first feel "imposed":

(A)nd you feel, Uch, this feels so foreign and controlled and, yeah, imposed. But then once you learn it, you're like, oh no, this is actually a way to make (writing) easier... It's the opposite of what it seems. It seems like it's all about rules and limiting your freedom, when really it frees you to explore way more. (R. Booth, personal communication, November 6, 2013)

This writer notes, however, that his embrace of the form is a fairly new development: in his early 20s, he "toyed" with unconventional structure (“(c)all it being the Pulp Fiction generation"), but eventually learned to use the three-act construct as an enabling design. At this stage of his career, the most important factor for understanding his screen narratives involves what he calls "dreaming": "I have to dream my way through the beginning of the script up until the second act.” For Booth, screenplays must be internalized and slowly reckoned as holistic narratives over an extended period of time - "years, like usually at least a year and a half, two years before I ever sit down to write" — with structure consciously addressed only in the first stages of writing.

...I know from experience if I only have a first act in my head, I will just stop writing after the first act and not know where I'm going. So I have to be able to get past that, to know what happens in the beginning and middle of the movie, and then I have to know how the movie ends. 
And then usually I can start the last tennish pages or so. And if I know all that and I can kind of start writing, I know the middle will come to me... (R. Booth, personal communication, November 6, 2013)

Other writers take a more mechanistic approach to structuring their narratives. Henry Talbot extrapolates from his background in feature filmmaking to describe his experience of the three-act structure: "I started as an editor so really that structure is built in the edit suite,"

....and it's something you follow even more to a $\mathrm{T}$ in the edit, where anything superfluous ends up on the floor. So I also approach writing from an editing background, where you're hyper-aware of anything superfluous and how it will end up on the floor so there's no point shooting it. So I always try to keep everyone on story and hang everything off of an A plot or a B plot. (H. Talbot, personal communication, September 20, 2013)

For this filmmaker, the three-act structure is golden, but not sacrosanct. "(Y)ou have to understand it to move away from it... and then if you want to buck it, you have to understand what the three-act structure is doing so you can replace it with something else." Education - generally the self-education involved in making (as well as, in Talbot's case, editing) the film — leads the filmmaker to alternate structures: what these might be, he does not say. But when asked if he could work, for example, within the boundaries of a 12act structure, Talbot is dubious ("I dunno if that works for a feature.") (H. Talbot, personal communication, September 20, 2013)

Matt Sparks shares to some extent Talbot's sense of the programmatic screenplay structure (“(S)ometimes when you consider a new idea, it's like, Okay, I can see a first act, 
is there enough of a middle?") This director/writer similarly makes reference to the selfeducation of the practitioner, but in relatively clipped language suggests this training is largely based on repetition. He notes the tendency to write screenplays in three acts is "innate":

It usually ends up being there (the three-act structure), although I try not to think about it too much, but you kind of arrive there regardless, because you've watched a thousand - or in my case, ten thousand movies, and I think it's just innate. (M. Sparks, personal communication, September 27, 2013)

Sparks' light-handed approach is perhaps not so much instinctive/a priori (as he suggests) as engrained through his experience in writing screenplays and in watching film. The comment is akin to Ron Booth's response to the golf-swing analogy: it suggests that constancy in dealing with (if not actively thinking about) structural narrative issues and problems is the most important factor in this form of writing. As per journalist/cultural studies writer Malcolm Gladwell's 10,000-Hour Rule, which posits that 10,000 hours of deliberate practice are required before a practitioner may attain mastery in a field, the idea of devotion to a craft and knowledge of its outcomes (viz., films themselves) is evident in Sparks' comment. His assertion is echoed in Benjamin Philip's response, although the latter offers a somewhat cryptic response to the question of the importance of the three-act structure: "I think it's something that you're conscious of on an unconscious level": (Y)ou don't really think about it when you're writing. But when you get back into rewriting after you've done a first or second draft, you think about those things, not so much because you want to conform to a structure but because you find parts of the script less satisfying or 
more satisfying organically. (B. Philip, personal communication, January 12, 2012)

Philip's use of the word organically is telling. Not only does he use the word twice within one short response, but he poses it against the more rigid term, "structure," in a form of offhand counterpoint. Note how in this second instance he a) invokes the erstwhile Aristotelean golden rule, and b) again uses both "structure" and "organically" in opposition: "Organically, those things (namely, first, second and third acts) do emerge; inevitably, every movie has a beginning, middle and an end, no matter how it's structured."

Although later in his The Practice of Everyday Life, Michel de Certeau takes some glee in knocking Michel Foucault from his Cultural Studies throne (viz., in his 'Chapter IV: Foucault and Bourdieu'), he first borrows from his contemporary's theory to define the concept of discipline, namely: "'miniscule' technical procedures acting on and with details, redistributing a discursive space in order to make it the means of a generalized 'discipline"' (Certeau, 1988, p. xiv). Acknowledging that Foucault has cleared the way for sociologists and cultural studies practitioners to recognize the "grid" of discipline and how it has become ever more extensive as a form of education, Certeau also insists that it is "all the more urgent" to recognize "how an entire society resists being reduced to it," (and) what popular procedures (also "minuscule" and quotidian) manipulate the mechanisms of discipline and conform to them only in order to evade them... (Certeau, 1988, p. xiv)

Certeau not only examines but celebrates the "consumption" of disciplinary texts/practices by ordinary citizens; his concept of anti-discipline celebrates the creativity of the subaltern in their manipulation and evasion of discipline. In light of this passage, the unstudied remarks of Benjamin Philip on the notion of the three-act structure should be 
considered: the filmmaker not only willingly produces the terms of the discipline (viz., "structure," "beginning, middle and end") but redirects them, reposits them as behaving "organically" and thus denies having to scrutinize them. Indeed, even as Philip appears to conform to the discipline of screenwriting, he evades it: he insists that he will not go into writing "thinking, Okay, this is the first act, that's the second act, and that's the third act," but that "organically," structure will emerge. There's also this curious phrase: "inevitably, every movie has a beginning, middle and an end, no matter how it's structured": that is, it is "inevitable" (or out of the writer's hands) that screenplays will have three acts, no matter how deliberately the practitioner plots the course of the narrative. Screenplay structure thus belongs to the form, not to the theorist or even the practitioner: the casual act of antidiscipline brings this point to the fore.

Not all interviewees take an anti-disciplinarian approach. Jane Parsons points out that different types of screenwriting take practical discrete forms. She begins her answer in universalistic tones, speaking the "beginning, middle and end" of conventional narratives, and in particular the holism of the oral tradition:

My grandparents were pioneers, and I spent many, many evenings listening to stories. So stories fall naturally into (the three-act structure) -- it wasn't something I learned from a book. If you were going to catch your listeners, you had to pull them in like a fish, get them on the hook (laughs), which is the end of the first act. Then you can play with them for a while, either reel them in or let them go, you know. (J. Parsons, personal communication, September 24, 2013) Like Philip, she uses the word "organic" as a key descriptor of the writing process: (“(I)t's a very organic structure, those three acts... a story well told just ends up rolling out in that 
structure.") In the next breath, however, she notes that because so many of her colleagues are now working in television ("because we can't get to the screens with all these $\$ 200$ million movies making so much money for their exhibitors that you can't possibly compete"), the structure of writing "completely changes." In answer to the interviewer's note that much television is written in five acts, she notes, "Well, sometimes it's even seven":

They'll let you know -- depending on what your primary network is, they'll tell you. And you'll write it that way, but I've never ever had it end up in the editing where you thought the acts were going to be. Because in the editing, you end up restructuring, and scenes become longer or shorter than you thought they were going to be. There's also all these rules that the first act can be no shorter than 20 minutes, every other act can't be anything over eight, except for the last which should be around 15. (J. Parsons, personal communication, September 24, 2013)

Such structures accommodate a new player into the narrative arena: the advertiser-sponsor. As Parsons indicates here, act breaks occur at specific junctures in a traditional television screenplay to allow for a set number of commercials (although with the onset of contemporary "quality" television, this practice has given way to experimentation in product placement and other unique marketing promotions (Kmet, 2013, n.p.)) The 'beginning, middle and end' of these narratives obviously do not fall into such neatly demarcated boxes as set by the filmic three-act structure. This does not mean that television narratives lack filmic cohesion and wholeness. Parsons does not elaborate upon this comment except to say that writing for television is a complicated matter ("I just finished (a 
script) for Hallmark and we ended up completely restructuring it in the editing. None of the thought and time that was in into the act endings stayed put") (J. Parsons, personal communication, September 24, 2013).

Inevitably and despite her accommodation to television form, Parsons is not happy with the idea of the regulation-based teleplay, noting that the act of imposing multiple acts upon a television narrative "controls how we tell our stories":

For the record I hate it, and feel like it compromises the scripts, making us repeat and review what has already happened. But it comes down to a choice of working or not working in television. A director is not going to win any battles fought to eliminate commercial breaks. (J. Parsons, personal communication, February 4, 2017)

At the same time, she notes creative compromise is not limited to the arenas of film and television. Citing a genetics conference at which she spoke some years ago, she realized during that event that "science and art are under the same constraints":

Geneticists can't really initiate research projects unless there's a product at the end that is sellable. It's so market-driven now that it bends the whole art form into another structure. (J. Parsons, personal communication, September 24, 2013)

\subsection{Structure Beyond the Three-Act Formula: The Case of William Chopin}

Not every interviewee regards the subject of screenplay structure as intuitive or organic. William Chopin, a film scholar, alternative-screenplay writer, actor and veteran director of theatrical plays, hesitates when asked about the three-act structure. He notes he "has a rough idea of what it is," but seems reluctant to subject that idea to further scrutiny: 
"I try to avoid that feeling that I'm following in a mechanical way the Syd Fields or Robert what's-his-name from Adaptation." At the same time, Chopin mentions the concept of "classical structure," suggesting that despite the ubiquity of screenwriting pedagogy, most contemporary writers still have not mastered the form:

I think that most mainstream movies now have if anything the worst of both worlds: they don't have classical structure nor do they take advantage of genuinely creative rethinking of structure. What you have is a mess that is gesturing vaguely toward classical structure. It's full of clichés but they're not well-structured clichés, and it's just about zapping the spectator with noise and speed. I'll take classical structure any day over that. (W. Chopin, personal communication, October 25, 2013)

"Classical structure" for Chopin and most film scholars is shorthand for the studiocommandeered filmmaking and screenwriting executed during the classic Hollywood era (approximately late 1920s to early 1960s). American film scholar David Bordwell notes that it comprises a) a narrative with a linear plot; b) a protagonist motivated by psychological causes who has a defined goal/desire and is subject to change; c) a logical set of cause-effect events, and d) a complete sense of closure constitutes classical narrative (Bordwell, 2010, pp. 102-103). We will assume this definition supports Chopin's approach to the form.

The writer/scholar contrasts his definition of classic structure with the narrative of Robert Altman's Nashville, which he calls by comparison, "fast and loose": What the hell kind of structure does that film have in the absolute sense? He (Altman) had close to 30 characters in a limited time frame, he decided that there had to be something decisive at the end which he 
felt should be an assassination that was both about entertainment and politics, and he brought those things together. (W. Chopin, personal communication, October 25, 2013)

While the Nashville narrative appears at first to constitute a three-act screenplay, Chopin suggests it soon turns into another form (although he does not specify what form that is):

And it does feel like a three-act structure, but once you identify

Barbara Jean as the main character, you could say, well, let's start with her and track it through. You make the three-act leap, but it doesn't match up with your experience of the movie as you're watching it. (W. Chopin, personal communication, October 25, 2013)

The character of Anna in Michelangelo Antonioni's L'Avventura performs a function similar to Nashville's Barbara Jean, he suggests, in that both are "lost" characters who cannot be considered protagonists and therefore have a limited role within the narrative:

You can organize a narrative in your analysis so that everything is doing some sort of mirroring of other things within the structure but you have to remember what a gigantic devastating lacuna is the disappearance of that character (Anna) and the inability of the other characters to find her or account for her missingness. That is the core of the movie and you don't want to turn that into something that is structurally tidy. (W. Chopin, personal communication, October 25, 2013)

He segues here between notions of classical structure, failed classical structure, and structure that is outside the norms of Hollywood altogether. "Structural tidiness" has its advantages, he says, as does the sprawling narrative nature of Nashville or L'Avventura 
(what he posits is "genuinely creative rethinking of structure"), but most screenwriting today is bereft of either quality. "I think in terms of telling a story, what I worry about mainly in a draft is securing and holding my own interest in the story," he concludes.

Chopin brings an unusual perspective to the question of the three-act structure: he is in the unique position of acting as both scholar and practitioner of the screenplay form, and as such has scrutinized the form in ways other interviewees have not. Of the interviewees, he is also the least insistent (certainly, the least positivistic) on the primacy of Hollywood narrative: he neither lobbies for one particular structure, nor does he suggest there is anything "organic" about the act of writing screenplays. What Chopin does primarily is to relate screenwriting to his personal circumstances ('I'm doing little bits of poetry, little bits of narrative filigree, I'm doing a little of this and a little of that") and associated interests, one of which is the relationship of the actor(s) and director to the screenplay. Discussing Sidney Lumet's Twelve Angry Men, he notes the screenplay adaptation by Reginald Rose (with Lumet) presents a "spectacular" example of opening up a play to cinematic possibilities:

(S)omebody or both of them were thinking, well, yeah, there's a ton of language here and a ton of specificity for the 12 jurors, but in fact what makes the movie work is the faces and how the viewers will read those faces in relation to the language: what we see beyond what we hear...Solving the movie is thinking about the reactions and the withholding and all that stuff, which I think is aligned with my training as an actor and a director of plays. (W. Chopin, personal communication, October 25, 2013) 
Here, Chopin relates the act of screenwriting to another major stage in filmmaking, namely the interpretive work done by both director and actors in staging and shooting the narrative. In Certeau's terms, Chopin's sideways writing is a tactical act that allows him to escape the bounds of normalized classic structure in an idiosyncratic manner; this point will be discussed in more detail at the end of this chapter.

\subsection{Aristotle and the Midpoint}

It may be worthwhile at this point to reference the work of Aristotle, in particular the surviving books of The Poetics, because these texts hold a primary place in the practice and imagination of numerous screenwriting educators. In particular, the construct of the threeact structure (which does not appear to have been exercised in any significant way, if at all, in the realm of ancient Greek theatre) is associated in contemporary filmmaking circles with Aristotle's recommendation/observation that every fictional story has a "beginning, middle and an end" (Aristotle, Poetics, Book VII). This latter passage is more frequently quoted in screenwriting pedagogy than Aristotle's arguably more significant observations of successfully constructed dramatic scenarios, including: that tragedy represents a complex scenario and comprises a mix of pity and fear (Aristotle, Poetics, Book IV); that dramatic poetics express a distinct form of "imitation of an action that is serious, complete, and of a certain magnitude" (Aristotle, Poetics, Book VI); that tragedy ends in a sense of "wonder" (an idea interpreted by some classic scholars as the moment of catharsis (Aristotle, Poetics, Book XXIV)); that tragic plots should best follow a predestined sequence of cause and effect (Poetics, Book IX):

Plays which fail to exhibit the sequence of cause and effect are condemned (1) because they lack the unity which befits tragedy, (2) 
because they miss that supreme effect of fear or pity produced by incidents which, though unexpected, are seen to be no mere accident but the inevitable result of what has gone before. (Aristotle, Poetics, $[1452 \mathrm{a}, 1]$

Three of the screenwriters interviewed for this study invoked Aristotle by name while speaking of their own screenwriting; it should be noted that these were passing references (in two cases to the Poetics and in one to Aristotle's place in history as Alexander the Great's philosophy instructor). Given the importance of Aristotle in the most influential of screenwriting textbooks, this paucity of references is notable. More interesting, however, is not that two interviewees invoked Aristotle when asked how they deployed the three-act structure in their writing, but that in discussing this structure, spoke instead about the importance of the "midpoint" or the halfway mark in the script. For example, Richard Bruce considers the midpoint in his writing "really important to me":

I mean, this goes back to Aristotle and Poetics, but for me, the way I look at it, I think the most important...the most important beat of a script, if you're going to look at that template, for me is the midpoint. That is kind of the tent pole that everything hangs on. And this might sound weird, but I almost picture it like a circus tent: so you've got your sides, that first side is your Act 1, that first slope up to your very middle? That's Act 2, and then it slopes down, and then there's another side. (R. Bruce, personal communication, September 26, 2013) Here, Bruce describes in highly visual terms a story structure that seems of his own design (that is, no other screenwriting educator that I have yet encountered describes screenplay story structure in such terms). More importantly, however, he describes without 
acknowledging as much a four-act structure (if the second "side" if the circus tent mirrors the first side.)

Interviewee Matt Sparks invokes Aristotle when referring to the requirements of the coming-of-age genre: he suggests a key element of this form is closure, but with a difference. "(I)f you're telling, as in the case of (one of his own films), a more humanistic coming-of-age comedy, the demands of the genre call for that. But when I say trick, I mean surprise - surprising but inevitable as Aristotle would say." A few minutes later, he makes an observation similar to that made by Richard Bruce: viz., that the midpoint of the screenplay represents a critical juncture; that it should be conceived beforehand if the story idea is to be a successful one; and that the second act must be sufficiently populated with "some subplots and character complexity" to carry the writer through the screenplay. If the writer has no idea "how to get through the middle of a story...you realize as you're writing it that it's not an idea." (M. Sparks, personal communication, September 27, 2013)

One other writer refers to the screenplay midpoint, although his discussion of it is not prompted by Aristotle but by the interview question on three-act structure. Joseph Freiman insists that the idea of structure is too limiting, but that the idea of the midpoint is "one thing I actually do think about":

The idea - what happens in the exact middle of your movie? I think that's an interesting thing. And so what I find is when I'm actually putting the movie together, that midpoint scene, that point that actually turns out to be the middle of the movie, is usually exactly where it needs to be. So I think about that: I think, What's the exact centre of my film? Because I find that's a really good guideline. (J. Freiman, personal communication, January 21, 2012) 
As is the case with both Matt Sparks and Robert Bruce, the idea of the midpoint for Freiman seems to arrive from nowhere: there is no reference made here to Aristotle, Field or McKee, nor is there a reference to his screenwriting education. Because the interview is at this stage in its final stages, the interviewee does not offer additional comment on the midpoint, nor does the interviewer prompt him to explain why the midpoint is so important to him.

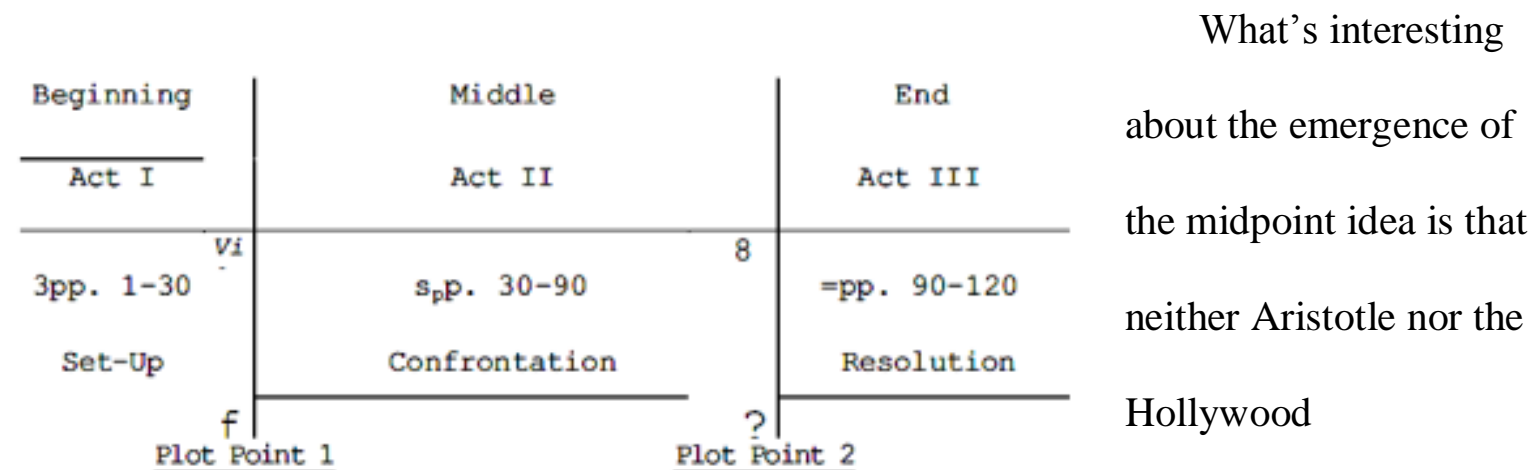

Figure 7.1: Field's screenplay paradigm, described in Screenplay, 2005; p. 200

screenwriting discipline makes a concerted

reference to the halfway mark of a story structure. Field, who is somewhat more prescriptive than McKee in his notes on the three-act structure, writes extensively about the two plot points that come at the end of Acts I and II, but does not discuss this concept of the midpoint; McKee mentions the "Mid-Act Climax" but notes very briefly that this point of "reversal" takes the screenplay out of its conventional domain:

(It means) a major reversal in the middle of Act Two, expanding in the design from three acts to an Ibsen-like rhythm of four acts, accelerating the mid-film pace. (McKee, p. 220) 
It's worth noting at this point that the story authority who does in fact discuss the notion of the midpoint is Gustav Freytag who, as noted earlier in this dissertation's literature review, identified what he considered the guiding structure of ancient Greek and

Shakespearean drama. As we have earlier noted, Freytag argues for a five-part structure in which the play's "climax" arrives at the halfway point: further, the climax comprises what he calls "one chief scene" (Freytag, 1900, p. 115) in which the results of the previous acts arrive in a "strong and decisive" way:

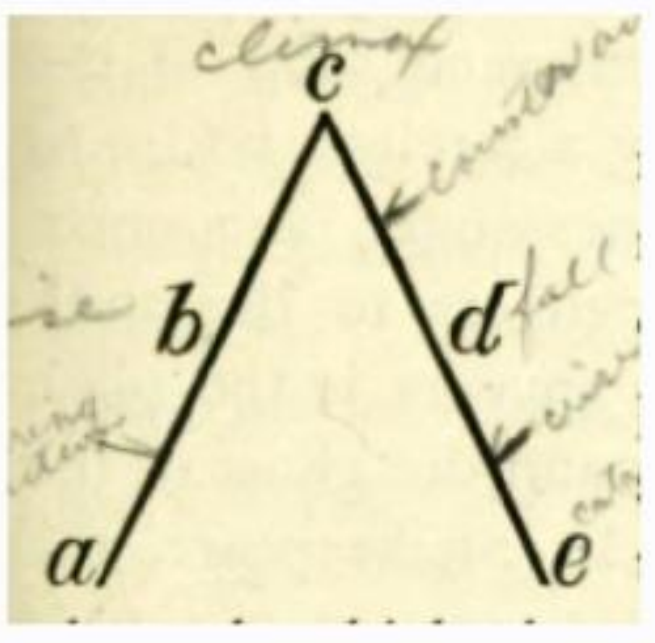

Figure 7.2: Freytag's 'pyramid' paradigm, described in Die Technik des Dramas (1863, The Technique of the Drama, trans. 1900); p. 115

(I)t is almost always the crowning point of a great, amplified scene...

The poet needs to use all the splendour of poetry, all the dramatic skill of his art, in order to make vividly conspicuous this middle point of his artistic creation. (Freytag, p. 128-129)

Most significant in this finding is that the two screenwriters who invoke Aristotle respond either directly or indirectly to a question about the three-act structure — but they do so outside the norms of the subject. In the case of Richard Bruce, the writer defies contemporary dictums on three-act structure to indicate the primacy of the midpoint; this might suggest he has read Aristotle but more importantly Freytag more carefully than have the majority of screenwriting textbook writers, and has absorbed both writers' observations on four-act structure. If Bruce has sufficiently internalized their instructions on the four-act structure, it makes sense that he would not stop to explain his 'deviant' interpretation of Aristotle's structural rules to the interviewer. The same observation may hold true in the 
case of Matt Sparks, who refers to a dramatic truism unrelated to the idea of structure but nonetheless important in Aristotle's Poetics: that is, that the conclusion of best-written tragedies contain an inner logic that surprises its viewers but in hindsight seems inescapable, "inevitable." We may have been discussing structure initially (specifically in reference to the midpoint of the screenplay), but for Sparks, a more compelling Aristotelean lesson relates to plotting of dramatic stories.

These observations lead us back to theories of writing and, in particular, how writers of various genres resist edicts from even the best qualified (or at least best equipped) tutors. Michel de Certeau writes of reading and writing as not merely dialectical forms but activities representing economic disparity, with discrete strategies/tactics deployed by each side to make their ways through the world. While writers are "founders of their own place, heirs of the peasants of earlier ages now working on the soil of language, diggers of well and builders of homes" (Certeau, 1984, p. 174), readers are dispossessed poachers, "travellers; they move across lands belonging to someone else,"

...(L)ike nomads poaching their way across fields they did not write, despoiling the wealth of Egypt to enjoy it themselves. ... Reading takes no measures against the erosion of time (one forgets oneself and also forgets), it does not keep what it acquires, or it does so poorly, and each of the places through which it passes is a repetition of the lost paradise. (Certeau, 1984, p. 174).

Reading for Certeau is, like the act of walking, cooking or any other activity of the disenfranchised, an unconscious compensation that attempts in small ways to level an uneven playing field. Reading and poaching are hasty, happenstance acts, and the 
reader/poacher values only part of what s/he pilfers: only specific information of interest to the reader is perfectly retained during the process, and in fact much is lost or forgotten.

Certeau's observation of the pilfering reader resonates throughout the words of the interviewees discussed here. As we have seen, Sparks, Freiman and Bruce have absorbed various lessons in screenwriting from a variety of instructors, but none are particularly interested in the industry's conventional interpretations of Aristotle: although this topic was not directly discussed, these writers have clearly made their own personal conclusions about the efficacy of such direction. But what's most notable about this series of exchanges is how the writers indicate the usefulness of the midpoint as a personal lodestar: it indicates whether or not the story has enough complexity and is therefore worth developing (Sparks); it provides a more useful tool by which the writer may demarcate key points of the (in this case) four-act structure (Bruce); it provides a guideline that allows the writer to flesh out the rest of his/her story with confidence (Freiman). In each case, the writers reveal that they have developed their own unique approaches to writing from the variety of dictums provided through either the usual education pathways or through their own reading and writing.

\subsection{Closure in the Screenplay}

Most screenwriting pedagogues are circumspect, even cagey, when making recommendations on the matter of closure — by which I mean a decisive, unambiguous ending to a narrative. Syd Field advocates for "an ending that works, that fits your story," although he is also clear that for Hollywood conclusions, "(i)n the long run, good always triumphs over evil” (Field, 1984, p. 180, 179). Robert McKee is similarly wary, avoiding an easy answer with his interpretation of endings/story climaxes as either "OPEN" or 
"CLOSED" (the former defined as a note of "absolute, irreversible change that answers all questions... and satisfies all audience emotion" while the open ending "leaves a question or two unanswered and some emotion unfulfilled" (McKee, 1997, p. 48)). Like Field, however, McKee assumes a more decisive position when describing closure in classical story design, which he says demands "a closed ending of absolute, irreversible change" (McKee, p. 45).

David Bordwell, whose important work in cinematic narrative analysis has received to this point little attention in this dissertation, ${ }^{5}$ offers a curt observation of 'closure' in classical Hollywood cinema: it is "the crowning of the structure, the logical conclusion of the string of events, the final effect of the initial cause, the revelation of the truth":

Rule books tirelessly bemoan the pressures for a happy ending and emphasize the need for a logical wrap-up... It is significant that of one hundred randomly selected Hollywood films, over sixty ended with a display of the united romantic couple — the cliché happy ending, often with a "clinch" — and many more could be said to end happily. (Bordwell, 1985, p. 159).

Quoting Brecht, whose Three Penny Opera features a deus ex machina ending when a mounted messenger delivers a queen's pardon to a man who is being led to the gallows, Bordwell notes that film, like bourgeois literature, relies entirely upon either the mounted messenger or "a skillful tying up of all loose ends":

The mounted messenger guarantees you a truly undisturbed appreciation of even the most intolerable conditions, so it is a sine qua non for a literature whose sine qua non is that it leads nowhere. (Brecht quoted in Bordwell, 1985, p. 150) 
But even the most classic examples of Hollywood cinema may fail to tie up every loose end or culminate in a bourgeois "nowhere" ending. Bordwell points out that while Hawks' His Girl Friday (1940) appears to end with seamless finality as Cary Grant's Walter and Rosalind Russell's Hildy are reconciled, the narrative nonetheless leaves some "comparatively minor issues" dangling — like the matter of the hapless Mollie Malloy, who leaps out of a window rather than to reveal the whereabouts of convicted murderer Earl Williams ("We only know that she was alive after the fall" (Bordwell, p. 159)). These unresolved issues are typically brushed off in a classic film's last scenes, particularly in the epilogue, which restates previously exercised themes and provides the narrative the impression of "strong unity: when such details are so tightly bound together, Molly Malloy's fate is more likely to be overlooked" (p. 159).

William Chopin makes a similar case when discussing the question of closure in his screen narratives, using It's a Wonderful Life (Capra, 1946) as his exemplar. When fully scrutinized, he says, this classic story withholds closure in "tons of ways...although one feels that everything that needs to be achieved for the moment has been":

The decision not to punish Potter, not to have anyone remember about Uncle Billy's money, to have Potter there looming as large as he did at the outset, to have the recognition if you think a little bit about it that George Bailey is going to feel the need to pay back the loan that his friends have given him to get out of a jam, that he's not going to get out of Bedford Falls. And there's a loss involved in not getting out, and that the tension of his struggle throughout the movie is one that cannot and should not be resolved... (W. Chopin, personal communication, October 25, 2013) 
Beyond concurring with Bordwell's assertion that the most classic of films leaves numerous secondary plot threads dangling, Chopin suggests that even primary narratives are problematic - that closure is never complete nor completely satisfactory, despite the fact that many audiences will experience considerable emotional satisfaction at a movie's finale. Indeed, Chopin points out that Wonderful Life puts an additional moral spin on its own conclusion: instead of learning how much the townspeople of Bedford Falls need him, the narrative's protagonist, George Bailey, learns "how much he needs the people of Bedford Falls":

(I)t seems to me that the character cannot learn directly what Clarence has been telling him in Pottersville, that he cannot learn that without becoming a much worse and different person than we take him to be... And all the thinking has to be concentrated there, or (the film's conclusion) becomes proud and complacent. (W. Chopin, personal communication, October 25, 2013)

Chopin's take on closure is unusually analytic (he does note at one point that he has studied Wonderful Life for "many, many an hour over the years...because it's a film that I'm deeply indebted to"), but answers by the other interviewees are equally provocative. Richard Bruce bristles at the idea that a film must work towards absolute, irreversible change: any film "that's any good or that's really going to make you think about it, there's going to be some ambiguity," he notes. "I don't know that 'absolute' is the way to go..." Although he is uncertain as he describes the ending of one of his contract screenplays ("You know, as I said, it's been a long time since it's been in my head, so I apologize if I'm not, ah, super clear on it”6), he notes the various finales for his first screenplay, an 
ensemble narrative, resolve in disparate ways. These are "separate stories that are connected but... burning independent of one another":

The final scene is them (the dead boy's mother and the guilty driver) confronting each other ... he shows up at her doorstep to pour his heart out, to make amends, to apologize, and she gets her chance to release on him... There's also another character in that, who is the son's best friend who was with him in the car at the time when he was killed. His is all about survivor's guilt and how he learns...that it was beyond his control and that...it wasn't his fault. (R. Bruce, personal communication, September 26, 2013)

The writer explains the separate endings as integral to his retelling of a true story ("(o)ne of my best friends was killed by a drunk driver and I was with him at the time"), noting the screenplay's structure was shaped by his personal need to explore the radial qualities of the calamity:

And so I saw the net effects that this tragedy had, and how everybody is connected and everybody is dealing with the same thing, but they're dealing with a different thing. And kind of really saw a textured multicharacter, um, story. (R. Bruce, personal communication, September 26, 2013)

Although there is a certain resolution for each of this film's various narrative threads (at least one the writer describes as "cathartic"), there is certainly no standard ending here certainly not in the usual sense of the Hollywood ending with "(n)o loose ends" and “everything...resolved dramatically, in terms of action and character" (Field, 1984, p. 101). This refusal to neatly tie all narrative threads together is shared by Jane Parsons, who 
considers the directive not just "the marketable thing, that they want audiences to feel satisfied when they go out the door": she further poses the desire to avoid complete closure as an attribute of Canadian filmmakers:

I would say that if Canadians had been given the freedom to pursue who we naturally are as storytellers, our instincts would be absolutely not to do that. It makes me feel uncomfortable to do that... Because life is not like that. Maybe it's our documentary heritage and maybe that we want to provoke people rather than to completely satisfy them at the ending. We want to send them out thinking... (J. Parsons, personal communication, September 24, 2013)

She uses her recent documentary to illustrate this point, the story of a woman who seeks treatment for a disease that proves fatal; it's a "documentary in the old sense that I didn't know where the story was going when I was making it." Further, the film's narrative structure is designed to encourage viewers to re-view it in light of its ending:

And it's very non-conclusive, what the film says. It says something different to everyone, which is I think is its great appeal for me. I didn't take a story and give it a happy ending. You think it's ended one way and then I jump back in time so you can see the whole movie that you just watched from another point of view. (J. Parsons, personal communication, September 24, 2013)

Parsons considers this documentary a "tough film; it's not a happy ending," but suggests that in the spirit of Canadian documentary (which for her is rigorously investigative, objective and cerebral), this short film encourages its viewers not to watch the ending in floods of tears, but to examine their own thoughts in an enlightened way: "(p)eople go 
away really re-examining some of their own feelings and plans about how they think about death and how to handle the last 20 per cent of their life."

Benjamin Philip similarly positions the idea of closure in national terms, although for him, the "logical conclusion" to a film is one that creates "a universality of experience" vs. the American pursuit and seizure of happiness. Open-ended narrative conclusions represent a "small-P political thing":

(I)t's a very Canadian socialist ideal in a way, that we're all in this together, we all have to take care of each other... People need to be tolerant and mindful of each other, responsible for each other. Which is a very different thing -- when you talk about closure, which is the Hollywood ending, the happy ending, where it's a very selfish objective: you want the main character to get everything. (B. Philip, personal communication, January 12, 2012)

Philip's decision to avoid standard closure may come not simply from his take on Canadian ideals of inclusiveness and fairness, but from his self-aware status as a gay filmmaker who honours and welcomes diversity in his movie- and television-making. All his films are "very open ended," he notes, with his screenwriting inviting audiences to the act of contemplation:

(W)hat I want is for the audience to wonder about the future, what the future holds for these characters. We don't know if these people are going to make good decisions or bad decisions, or where they're going to end up, but we are moved by their plight... You know, there is no closure in life and there is no right or wrong in terms of decision making... (B. Philip, personal communication, January 12, 2012) 
Taking cues from similarly open-ended films like the Schnitzler/Ophüls collaboration of $L a$ Ronde (1950) and Altman's Nashville (1975), Philip designs his narrative worlds to prompt audiences to think about characters, but also to relate to and appreciate their differences.

"To me, the biggest thing is if the audience can feel a connection with the character, there is a kind of universal bonding," he says.

It's an issue of empathy where you can feel and understand what the character's going through. ...(N)ot to get too Pollyannish, but if you can create this ring of empathy — sympathy/empathy — then it's hard for you to distance yourself from other people in real life, because you realize we are all the same, we all go through the same things, we all suffer the same way, we all find joy in similar ways. (B. Philip, personal communication, January 12, 2012)

Other interviewees are more ambivalent on the topic of closure. Henry Talbot, for instance, allows that closure does not demand irreversible change, "but I think people like closure...I think it's a contract you have with an audience that if you start telling them a story, they need an end to it":

My latest film, we have a slightly open-ended — not open-ended but it's a film about a couple coming together and bonding, and the last scene is of them together... But what we found is that people really wanted to know what happened to them. Like do they get married, do they stay together. So yeah, I think people need a little bit of closure although does it have to be irreversible? I don't think so. (H. Talbot, personal communication, September 20, 2013) 
Joseph Freiman, who says he "loves" movies because "movies have an ending" (vs. television, which traditionally defers endings) interprets the question on narrative closure in similarly ambiguous terms. Speaking in technical terms, he considers the crafting of an appropriate ending a matter of professionalism: "in the end, you (as a writer) have to make a choice; you have to decide, this is what I think happens... and that's hard." Despite that drive to a relevant ending, he does not deny uncertainty as a narrative factor:

You can still make a choice but have it be open-ended or ambiguous or have questions remain. You can resist closure because you believe in that specific situation and that with these specific characters that closure would be elusive. But I have to feel that it's not that you just didn't know what you were saying, or that you just couldn't make a decision. (J. Freiman, personal communication, January 21, 2012)

Both Talbot and Freiman take a pragmatic approach to the topic of narrative closure, which narrows their focus: in these answers, they prove themselves more likely to regard screenwriting as a fit-for-purpose plan than an elastic narrative form.

Ron Booth by contrast responds to the idea of irreversible closure with explosive displeasure: "I think that's bullshit."

(T)he hair on the back of my neck goes up as soon as I hear someone say, Something has to happen for a movie to work, any movie. I think that's totally absurd and it's also totally limiting to our idea of what movies and more largely, what any kind of narrative is. ...I don't really recall The Iliad having a super-satisfying bit of closure. And yet, here we are, still reading the fucking thing. (R. Booth, personal communication, November 6, 2013) 
Like Parsons, Booth equates the notion of the closed Hollywood ending with commerce. He recalls an "old Hollywood story" about the 2001 Merchant-Ivory production of Remains of the Day: "Emma Thompson gets on the bus, he (Anthony Hopkins' character) watches her go and that's the end of the movie: 40 million dollars. He runs after the bus: 60 million dollars. The bus stops halfway down the block, she gets off, they run and make out, 100 million dollars." According to this writer, such "rules" about film endings are made to be subverted, if for no other reason that the makers of the film must be true to themselves:

Because we're not inventing the wheel with movies here, they've been around for long enough that they have a language and they have a structure and they do have a series of ideas that come with them. And the more you can kind of educate yourself as to what they are as a writer, um, the better chance you have of writing something interesting. (R. Booth, personal communication, November 6, 2013)

\subsection{The Character Arc in the Screenplay}

Related to the idea of closure in a screenplay is that of the character arc, described earlier in this dissertation's literature review as transfiguration of the protagonist through external conflict (prompted by the scenario's antagonist(s)) and internal turmoil, resulting in permanent change to the protagonist's character. ${ }^{7}$ As might be expected, there was no consensus on the value of the character arc amongst the interviewees, although every writer had a strong opinion on the subject.

Jane Parsons accepts the primacy of the character arc for the most part, relating the plotting of arcs throughout a screenplay to a "huge puzzle" of interconnected transitions. 
The computative nature of this plotting she considers due to her "mathematical logical mind":

...I go through the story in every character, and in a sort of stream-ofconsciousness state write the story out from that perspective of that character... It becomes a huge puzzle of how the different arcs crisscross each other and act upon each other and land in the end. So I basically write a short story from the lead character's point of view and then I sometimes will go on to do another short story from the two main characters' point of view crisscrossing each other. And then the weaving gets tighter and tighter with more characters coming in and working themselves into the warp. (J. Parsons, personal communication, September 24, 2013)

This metaphor of logic-based braiding relates more to plot construction than to character arcs; however, Parsons shifts gears as she relates the storyline of one of her best-known films, saying what interests her most in characterization is what they learn in what they go through, "and how that can be passed on to the audience. What did I learn from this experience, how did it change me?" (J. Parsons, personal communication, September 24, 2013). Henry Talbot echoes her conviction, emphasizing that "the character has to go through change, or you're (the audience) not invested or you don't care." At the same time, he concedes that characters do not always have to be likeable (in that "he doesn't necessarily have to save a bus of orphans to establish that"): the protagonist of Woody Allen's 1999 Sweet and Lowdown for example is lovable "because of how uniquely" he is “an asshole” (H. Talbot, personal communication, September 20, 2013). 
Both Talbot and Parsons accept the idea that character change is essential, and neither challenge conventional thinking or definitions of the concept of the character arc. The remainder of the interviewees consider the idea problematic and note they have analyzed films that defy normative standards and/or tested modifications in their own screenplays. Matt Sparks, for example, recalls one of his own films, a story with a surprise ending designed to force the viewer to "think back to what (the protagonist) was being taught": And that was part of my attraction to the material is that you would see the whole movie in a different way, seeing the ending. It's not the movie you thought were watching necessarily. But yeah, (the protagonist is) a lowlife and thinks he's been unlucky (and) someone who is frustrated with him is showing him the error of his ways... (M. Sparks, personal communication, September 27, 2013)

However, Sparks immediately undermines what may seem a fairly standard character arc by noting that the viewer may choose not to believe it: "I think we're meant to question somewhat at the end if it one-hundred-per-cent worked or not. Depends on whether you're a cynic or not."

These notions — viz., that audiences may bring cognition (rather than emotion) to a film viewing and that some may disbelieve that a film protagonist has experienced an irreversible and profound change - are not acknowledged in the usual screenwriting texts. Robert McKee, who is a vociferous proponent of the classical character arc, uses the examples of Shakespeare's Hamlet and Sidney Lumet's The Verdict to describe two protagonists who move through change: the former, he notes, experiences a profoundly moving and irreversible change, reaching "a peaceful maturity as his lively intelligence ripens into wisdom: 'The rest is silence"” (McKee, 1997, p. 105). However, McKee writes 
little else about this all-important facet of character development, leaving the acolyte to believe that the process is unproblematic, even straightforward. Joseph Freiman takes this notion to task, saying he believes the arc is important, "but I think it can be overstated because of all these screenwriting gurus who create a sort of, whatever, a chart of how your character's supposed to evolve." At the same time, he identifies the classical character arc as a characteristic of Hollywood film, one that "may be the only true thing in a lot of Hollywood films (in that) people will only change if forced to under extraordinary circumstances. And that's actually true." In the next breath, however, Freiman notes that not every narrative must be "programmatic" in revealing "the biggest moment in this character's life. Sometimes it's just nice to tell a story about $\boldsymbol{a}$ moment in a character's life." Then, again, Freiman flips his argument to note that "that catharsis of change is deep in our bones as storytelling animals,"

(A)nd if you don't at least consider that and deal with it in your movie, then the audience is going to have a vague sense of dissatisfaction... I think if you're going to destabilize the traditional ways people achieve dramatic satisfaction in their stories...I think that's fine, but you have to realize, your story may be dissatisfying. ...Congratulations, you wrote a dissatisfying story! Excellent! (J. Freiman, personal communication, January 21, 2012)

Such equivocation is not unusual amongst these writers. Although Richard Bruce does not speak for long on the topic (he does note that "absolute" change in a character "is certainly not the way I would set out to finish something"), he observes that the protagonist is not always the one to experience the arc: "You know, your main character is often the one who is initiating the change in supporting characters." In fact, in his first screenplay, 
which features an ensemble cast, the protagonist experiences a less profound change than do the people around him: a mother whose son was killed in a car accident finally "deals with what she hasn't been dealing with and kind of gains her freedom in that way." At the same time, the protagonist provides his autistic sibling with guidance "and gives his brother some happiness," which again allows a relatively minor character to arc. The screenplay is "a bit of an anomaly in terms of...arcs" because of its multi-character nature, he suggests: "It's not going to fit into that...traditional structure." (R. Bruce, personal communication, September 26, 2013)

Benjamin Philip, who similarly favours the ensemble screenplay, observes that character arcs in such screenplays are "slightly unconventional...I've always been interested in the prismatic view of the theme,"

...so you see a theme refracted through a number of different characters, and you have an aggregate idea of what the theme is. You have all these characters grappling with an idea or a theme. ...I didn't create that design but it was very appealing to me for a long time, to look at subjects that way. (B. Philip, personal communication, January $12,2012)$

Here, Philip correlates, even replaces the idea of the character arc with that of theme - a literary construct that receives little to no attention in screenwriting pedagogy. To review: theme, very broadly defined as "the dominant idea" of a literary work (Merriam Webster's Encyclopedia of Literature, 1995, n.p.) or more specifically, as a "salient abstract idea that emerges from a literary work's treatment of its subject matter...(and) may be announced specifically but more often emerges indirectly through the recurrence of motifs" (Oxford Dictionary of Literary Terms, 2015, n.p.) invokes the arena of aesthetics and, by extension, 
art. We enter a degree of complexity here that the screenwriting guru crowd would likely renounce as overly sophisticated and unnecessary to understanding the character arc, yet Philip does not hesitate to express himself using such a concept. Given his immersion in literature as a child and young adult, it makes sense that he would express his views on screenwriting in literary terms. Philip defies convention here not only by conflating screenwriting and literary terms, but by challenging the usual Hollywood focus upon one hero or heroine with a more complex ensemble cast. "I've always been interested in the prismatic view of the theme," he notes. "You have all these characters grappling with an idea or a theme. It's kind of the Robert Altman way of doing it." (B. Philip, personal communication, January 12, 2012)

In a similar manner, William Chopin challenges the question of character arc, although first he acknowledges it exists and is important to the success of a film narrative. "(O)kay, there's this overpowering single need and...it drives the whole narrative, and the fulfillment of that need is how you identify that the narrative has come to an end" (although he immediately adds, “you better have a need that isn't basically stock footage from the Need Factory, is all I can say"). Second, he observes that character arcs can both advance and retreat, in that characters can appear to learn important lessons/gain important understanding throughout the course of a narrative, only to lose that understanding by story end. He cites Todd Field's crime drama In the Bedroom ${ }^{8}$ to make his point, noting that in the film's second act, the story's couple decide to kill an individual who had in the first act murdered their son.

(O)n the surface, the arc of the movie is a couple converging finally in a shared purpose that revenge is necessary for the person who kills their son...but the actual structure suggests they had a truer coming 
together and understanding in the midst of their argument in the second act. They almost got it and then they lost it and that whole third act which completes the revenge arc is in fact a destruction of the understanding that they've possessed briefly, hauntingly, movingly at the end of Act 2. (W. Chopin, personal communication, October 25, 2013)

"So what do you do with that?" he asks. "You have to read against the arc that the characters more or less live to (the arc's) dismal consequences,"

...that the revenge accomplishes nothing though it seems at the very least that both husband and wife believe they've exhausted other possibilities, that it's going to do something for them. But they're wrong, but the film doesn't openly, overtly rhetorically declare them wrong: we see it and feel it. (W. Chopin, personal communication, October 25, 2013)

Chopin's reading lifts the idea of the character arc to another level: that two characters may be transfigured through action in a standard arc, yet inevitably sink back to pre-arc levels suggests the lineaments of a Greek tragedy. Such an interpretation acknowledges themes of intensity and complexity that remain undiscussed in the works of our screenwriting gurus.

Ron Booth restates Chopin's complaint when he relates the story of his first and most successful screenplay to date ("the one I won the awards for and stuff"9), which features a protagonist who does not proceed through a normative character arc. This character, who he describes as performing in a "hero-myth structure," is "more like a Forrest Gump character or Peter Sellers' character in Being There, where you are kind of watching a weirdo navigate a world, and the weirdo doesn't change, he makes the world change." The 
decision not to incorporate a routine character arc was a foundational one, Booth notes: he wanted to make a movie "that rewards (the protagonist) for his belief and celebrates him for his tenacity and his single-mindedness.” Inevitably, the problem Booth experienced in bringing his screenplay to fruition (a project he also directed) was in convincing Canadian funding bodies to accept the screenplay's absence of a standard arc.

(U)nquestionably when you're dealing with levels of bureaucracy and not just bureaucracy and not just Telefilm, but the Harold Greenberg Fund and all these other places you get financing from, they have a very — I don't want to say limited, but particular understanding of how a screenplay works. And so they're confused by a script like (this one). Even though they liked it and it got a lot of institutional support, there was always a kind of asterisk: "Hey, shouldn't this guy learn a lesson? Does he really get the girl -- should he not get the girl?" (R. Booth, personal communication, November 6, 2013)

After years of shopping the project and hearing from potential funders that the lack of a character arc damaged its chances of being supported, the writer went back to the screenplay to incorporate the demanded structural change ("Well, fuck, maybe I should try this.") The attempt went nowhere. In the end, however, the project received funding of $\$ 6.4 \mathrm{M} \mathrm{CDN}$ and the resulting film became a cause celebre in national film circles, earning a high ranking in the Canadian Media Production Association's (CMPA) listing of top ten Canadian-produced films presented in the English-language market (CMPA, p. 72).

Booth looks back at the funding process for his immensely successful film with a somewhat jaundiced eye. The problem he identifies is not that the character arc is a problematic idea, nor that his film was entirely without (admittedly subtle) changes in its 
protagonist. The problem is rather that funders have an oversimplified notion of what the character arc is and what it must accomplish in a feature film:

And you know, what I always used to say about (the film) was it's not that (the protagonist) doesn't change, of course he changes but he's right and he wins...(T)he lesson he is going to learn is never going to be, 'I shouldn't have felt that way or I shouldn't be this kind of person.' $(\mathrm{O})$ bviously characters need arcs but...they can come about in different ways than in the very simple sense that a lot of people have about what a character arc should be. (R. Booth, personal communication, November 6, 2013)

This observation leads us to a final section for this chapter, which reflects interviewees' concerns regarding the 'reader's report,' a first hurdle in the funding body's gatekeeping process.

\subsection{On the Reader's Report in the Funding Process}

The reader's report (also known as 'script coverage' or 'notes') provides a number of functions in the film and television industry, but in this context, it may be described as a critical synopsis of a screenplay; the screenplay is one that has been submitted to a funding body (or major producer/production studio) for development purposes. Reader's reports are usually written by a trusted member of a funding body's staff or by an external creative consultant to the organization. The synopsis is one to two pages in length and provides a review of the script's characters, story, visual elements and commercial potential (amongst other elements); reader's reports also provide their clients with either a "Pass," "Consider" (with rewrite conditions) or "Recommend" (also generally with rewrite conditions) on the 
screenplay. This means of course that the reader is imbued with considerable power as a gatekeeper. Finally, for this purposes of this project, the reader's report generally refers to script coverage written for funding bodies, including Telefilm Canada, the Harold Greenberg Fund, Canada Media Fund, the COGECO Program Development Fund, etc. Many writers also use the term 'notes' to refer to comments that are made by producers and directors (that is, internal above-the-line teams working on a film project) after the reader's report has been filed with the producer; notes are often meant to soften or contextualize the critique of the reader's report.

There seems at first glance little commonality amongst the writers when it comes to reader's reports, although all admit that they felt at one level some resistance to both the reports themselves and resulting notes from such reports. Henry Talbot, whose current role is less that of a screenwriter than a producer and/or director, considers reader's reports to be an important part of the funding process: "I think it's important to keep an open mind with notes but also be critical of them." When reader's reports are filed as 'blind' critiques by anonymous writers (as is the case with Telefilm), “it's a very pure process (and) I've had some very good notes from those people." ${ }^{10}$ Asked if the producer feels every point in the reader's report “should be followed," Talbot exclaims, “Oh, God no. Oh no no no no no no,"

...you'd get into real trouble if you tried to please everybody. But you'll find notes that are working, that have the same end-game that you want and maybe even help you in ways you would never have thought of. And I think those are really valuable things, and I think at the end of the day, everybody's trying to help the film. (H. Talbot, personal communication, September 20, 2013) 
On the other side of this continuum is Jane Parsons, who considers a reader's report potentially ruinous to a film and to a filmmaker's career. The basic problem with such critiques, she suggests, is that they are delivered anonymously without an understanding of context, and so are neither dialogic nor supportive of genuine talent. Further, many individuals delivering reader's reports, she suggests, are occupied with protecting their own roles ("I guess...if they come up with more points as to why this shouldn't be made or why this isn't working, then they think they will get more work, they'll save their own job”).

But by far the most detrimental scenario is that in which the reader does not understand or sympathize with the goals of a screenplay. She uses the example of one project that she was asked to direct, a lesbian coming-of-age story: after the producer and writer submitted their screenplay to Telefilm for development, they received in return a strongly negative reader's report:

The film was clearly about gay subjects and the readers were clearly not gay. They (the readers) found the materials not funny, even kind of disgusting: there was a prejudice in it that was so mind-boggling that you went, 'Well, this is not the audience for this film!' ...And they didn't realize the audience that would immediately come to this film would get it. (J. Parsons, personal communication, September 24, 2013)

This and other developments essentially ended the two women's careers in filmmaking ("they basically now both teach at universities because they just couldn't make it happen"; J. Parsons, personal communication, September 24, 2013). The irony of this anecdote is that Parsons herself made a female love story feature film that was enormously successful, 
winning numerous awards at international film festivals and opening in 300 theatres in Germany alone, she notes.

Most other interviewees register feelings somewhere between these two extremes on the subject of the reader's report. Matt Sparks notes rather laconically that one funding body seemed to have produced two diametrically opposed reader's reports for his first screenplay: development funding proceeded on the basis of the first reader's report, which was "very positive," but when his production team applied for a second rounding of funding, they (the team) "didn't get it (funding), so I think we got a different reader." As a writer-director, he considers himself protected from the frontline between producers and readers: reader's reports generally 'get funneled through the producer and they don't necessarily tell you what they don't think is worth telling you." At the same time, notes of any kind are worth examining, he says, if for no other reason than readers may have identified a genuine flaw in the screenplay.

Sometimes you have to reverse-engineer the note, figure out, okay, what's missing for them that causes them to want something here. I usually go by the rule of two or three: if I hear it a few times, it's almost always valid, but if you hear it once, it's just eccentric. Sometimes I hear it once and I go, 'Yeah, I've been thinking that myself.' (M. Sparks, personal communication, September 27, 2013) Sparks insists that the only authentic way to resist inappropriate or random ideas produced in either reader's reports or notes is to actively resist them: “...you tell them they're insane, and that puts an end to it":

They're not going to respect you if you take their dumb ideas... (interviewer laughs) No, seriously, I think that a certain level of 
respect is lost if it's not challenged. ...I think they realize at the end of the day, the director needs to be happy — the writer and the director. That's not to say they won't fight me on something they think is wrong. But you know, bad ideas get tossed out, and sometimes you have to wait until they've passed. Sometimes you just have to make some noise. (M. Sparks, personal communication, September 27, 2013)

Sparks' speculation that funders can produce discrepant reader's reports is echoed by Benjamin Philip, who notes that “(e)ven within a single agency, they'll have many different people reading scripts and writing notes on them,"

... so there is no clear reference point. It's all kind of up for grabs on what kind of response you'll get, aside from the fact that you assume a certain amount of experience with reading scripts. Which is also different from writing scripts. (B. Philip, personal communication, January 12, 2012)

With the reader's report so difficult to quantify — "such a whimsical, quirky thing to base that (funding) judgement on" — the larger question for this writer-director thus becomes, "Should the agency fund your project?" Philip does not claim to have an answer to that query, but he insists the "fickle assessment" that is a reader's report is "where the problems come in."

(O)f course an agency has to base it on something: you can't have a single person whose bias is clear read every single screenplay because it's physically impossible. I know they do make efforts to not have (reader's reports) as the sole criteria - that is, funding or not funding 
— and I...hope if they get to a certain point where they're close to funding certain projects, more than one or two people will read it, so it can be more of a consensus feeling. It's a bit of a charged thing. (B. Philip, personal communication, January 12, 2012)

Joseph Freiman takes what he calls a more "open-minded optimistic" approach to reader's reports and notes: instead of reading them with a "kind of arms-crossed, critical disdain, like 'Prove to me that you're right', just read (the report) assuming they're right," he suggests. After the report is read, then "go back and think about where you disagree." Like the other interviewees surveyed for this dissertation, Freiman assumes any writer will experience disagreement and resistance to funder/producer suggestions: his advice is meant to soften the writer's almost-certain resentment of strong and not always clearly motivated critique. For him, negotiating this painful — or as Philip calls it, "charged" — stage of screenplay development requires conscious management of expectations. Reader's reports and notes are, he says, "always right" because they express the reader's entirely subjective taste or interpretation.

(But) them being right doesn't mean I'm wrong, it just means they're expressing their point of view. That's why it's important to have an actual human-to-human relationship with people you're working with, because the notes are coming from a perspective. And you're trying to understand that perspective. (J. Freiman, personal communication, January 21, 2012)

At the same time, Freiman suggests the criticism offered through the report may not always be coherent: "Okay, they're giving me a note because something is bothering them. And usually, if something is bothering them, they're right." The real issue here, however, is that 
"(i)t (the thing bothering them) just might not be what they think it is...But they're not the doctor," he concludes. "You're (the writer is) the doctor" (J. Freiman, personal communication, January 21, 2012). What seemed like generosity in Freiman's earlier suggestion is undermined by his confidence that no other consultant has the expertise of the writer. Like Matt Sparks and Henry Talbot, Freiman ultimately considers the original writer the final arbiter - the expert who will not accept someone else's 'dumb ideas' merely for the sake of collaboration.

Richard Bruce offers views remarkably similar to Freiman's on this point. “(T)here’s always a certain amount of validity to the note," he says. "They're bumping on something..." And very like Freiman, he notes that the critic, whether funding reader or producer, may not know how to express the real problem they're "bumping" against: "They might be saying A, but they don't actually mean A, because of XYZ that they're thinking a problem is A. If that makes any sense....(T)he problem might not be what they're thinking the problem is." Yet Bruce also expresses the somewhat plaintive hope that notes will inevitably improve the screenplay — and that writers yearn to experience true collaboration that will result in a better product.

For a writer in an ideal world, it's almost that you don't want notes, but every writer wants notes. I don't want to turn something in and have someone say, Oh, this is great, let's go shoot it!...(W)here that's going to hurt it is down the line when you've got a producer and you're going from treatment to first draft, because your treatment isn't going to be the best that it can be. (R. Bruce, personal communication, September 26, 2013) 
Bruce is also the most appreciative of the collaborative work done in television, where "it's all face to face, you're never writing notes to each other." In this case, the directive oneway communication of notes is transfigured into a dialectic that is not only more humane, but considerably more efficient:

(L)et's say somebody types you two pages of notes — well, that's all they are. ... Whereas if you sit down and have a dialogue, all those things can be said, but you can also say, Well, the reason I did that was because of this. And then you can talk it out. You get three or four emails worth of work done in 10 seconds. (R. Bruce, personal communication, September 26, 2013)

This theme of making a good product better reverberates throughout Ron Booth's commentary: he extols the virtues of working directly with a producer and his/her creative team. Like Parsons, Booth has a personal story about a screenplay in which several reader's reports delivered a scathing critique; unlike her situation, however, the reports failed to torpedo the project.

I mean, (the screenplay) got terrible reader's reports, terrible. I mean, they were like, this movie is nowhere near as smart as it thinks it is! this movie is making fun of Canada and making fun of Montreal, it thinks it's better than — oh, like, just tons of — it's incredible, with reviews and reader's reports, what you end up learning about is the person who wrote the report. (analyst's italics) (R. Booth, personal communication, November 6, 2013)

Booth's frustration with the bureaucracy that employs reader's reports is tangible. Although he jokes about the numerous objections different readers had to his script (including what 
they perceived as cheap shots at eastern Canada's cultural scene and perceived inaccuracies about an historic character who figures prominently in the film), he concludes that the most critical commentaries arise from a sort of "anonymous...internet commentator world" in which readers "can take potshots at things." Otherwise, he finds the reports "useless." The best solution in his mind is to exchange creative ideas with members of his own team:

(I)deally you're working with your producer because this is somebody you respect and you believe cannot just get your movie made but can make your movie good and better. Um, then when you're really developing a script, I mean, that's who you want to be developing with, not with a bunch of anonymous nobodies who get to say whatever they want to say and then walk away. (R. Booth, personal communication, November 6, 2013)

We can see here that although opinions on the effectiveness of the genre seem to range from co-operative acceptance to resistance, the consensus on this point amongst the writers is, with analysis, significant: viz., reader's reports are of little use unless they confirm suspicions already in the back of the interviewee's mind. And while anonymity of the reader is for one filmmaker a hope (if not a guarantee) of objectivity, it is for most others a potentially harmful, even ruinous advantage held by the funding body. If the anonymous reader: a) does not understand the market for the screenplay (as per Jane Parson's complaint); b) fixates upon certain details of the screenplay to the detriment of the project itself (as per Ron Booth's complaint); c) seeks to protect his/her role by turning down a screenplay (as per Parson's concern), a potentially worthwhile project may be extinguished before it has had a chance. 
While it is undoubtedly true that resistance to power, conducted either consciously or unconsciously (as per Certeau's observations), reverberates throughout this chapter, it is in this final section that interviewees were most vocal on the subject. It may be that while writers actively resist the dictates of preordained screenplay structures in numerous ways (i.e., ignoring them, subverting them, working through them to create new structures of their own), they have little recourse when it comes to reports written by external consultants who may use these same preordained screenplay structures to censure them. The unstated irony of this situation is expressed in the frustration of most writers during the interview process: while they press for new and original approaches to the screenwriting, they are at once punished for their efforts. Hortense Powdermaker's comment on the same issue is prescient:

(O)f prime importance remains one fact: The product of the dream factory is not one of the same nature as are the material objects turned out on most assembly lines. For them, uniformity is essential; for the motion picture, originality is important. The conflict between the two qualities is a major problem in Hollywood. (Powdermaker, 1951, pp. $52-53)$

\subsection{Summation: On Power and the Screenwriting Process in Canada}

Michel de Certeau relates the story of how Spanish explorers succeeded in pressing their language and culture upon colonized peoples and, more significantly, how the colonized submitted to this imposition but in doing so innocently subverted foreign "representations." The subversion occurred not because colonized people resented or sought to overturn alien authority and its representations, but because they incorrectly 
incorporated such representations within their own cultures. "They were other within the very colonization that outwardly assimilated them" (Certeau, 1988, p. xiii).

It seems profitable to use an idea like this one to describe the irritations and (at times) travails of the Canadian screenwriter working in a largely Hollywood-designed system - a system that is not restricted to its country of origin, but which colonizes its markets on an international scale. The image of the "classical" (or classic) structure of film narrative described by both David Bordwell and Robert McKee imposed upon film writers by wellintentioned funding bodies and/or producers and directors maps neatly to Certeau's metaphor, especially when we consider the vast number of screenplays that flailed and ultimately failed during Telefilm Canada's Screenwriter Assistance Program (SAP) initiative in the early 2000s (as documented in this dissertation's policy chapter). These Canadian writers, who naively but gamely did their best to adopt classic Hollywood structure, ultimately could not conform to such standards; as we may recall, only six (or 1.6 per cent) of 366 new scripts generated by the SAP initiative received Canadian Feature Film Fund (CFFF) funding. How many of those six screenplays made it past the even larger hurdles of production, completion and distribution of the film? The report ${ }^{11}$ does not say.

On the other hand, these professionals who may as individuals seem to flail helplessly against the rules of screenwriting are also unconsciously united in a system of their own: as Luhmann might have predicted, it is a unity devoted to questioning the orders of its normenforcing policymaking masters. The writers who contribute their voices in this project's interviews distinguish themselves not only from the funding bodies that support their projects, but also from the producers and (to a lesser degree) the directors who hire them and who manage their writing. In this way, they constitute their own unique system — one that, like Luhmann's art world, chafes against both related 'scientistic' systems and their 
own histories to produce ever-evolving definitions of beauty and function in the screenwriting discipline. Like Luhmann's Mannerists, the writers exhibit capacity for "dissolution and recombination" of normative writing structures, which they execute both consciously (as per their responses to interview questions) and instinctively (as per their genius in rewiring the regulations of screenwriting in their own screenplays (see Chapter Six's analysis of representative screenplays)).

As practitioners, the screenwriters interviewed for this paper are not Certeau's colonized innocents, nor are they the credulous applicants so dismally failed by the SAP program. They are not even the sly fabricators of la perruque, the employees who pilfer time and material from their masters/writers who work the Hollywood system to their own personal devices. The writers who comprise the intelligence of this project are immensely talented, well connected and, most of them, influential within the field of Canadian film and television: they are well past the point of either innocence or stealth. Generally, these professionals have as much if not more education in the area of screenwriting than do those who adjudicate their screenplays: in all likelihood, they also have more practice reading, writing and shopping the form than those who gate-keep for funding bodies. These writers do not unconsciously or even recreationally resist the strictures of the Canadian funding system: they consciously, but quietly, oppose it. They are Certeau's anti-discipline rebels taken to another extreme — they might be better described as counter-disciplinarians, who have in effect created their own standards and forms of practice against a system that actively works to keep them in line.

If these writers then $d o$ fall to at least some extent within Certeau's line of antidisciplinarians, what are their tactics — both their conscious tricks and their less deliberate subterfuge of the filmmaking system? For many, the first part of their instinctive tactical 
approach comes with the rejection of normative education routes. Of the more conventionally trained screenwriters, even Matt Sparks and Richard Bruce recall their formal education in screenwriting as either close to nil or forgettable. Henry Talbot, who on the other side of the spectrum was not schooled in screenwriting, yet who is one of the more traditional screenwriters of the group (given his adherence to genre conventions), claims he learned more from Lajos Egri's The Art of Dramatic Writing (1942) than from Robert McKee's Story, which “you can learn from anywhere.” And on the subject of reading, Richard Bruce insists that independent reading was his ultimate tactic for screenwriting education: ${ }^{12}$

I read every book I could get my hands on, I went to UBC and bought all their textbooks, I would go to bookstores and I accumulated hundreds and hundreds of books. So that was kinda my film school. And I also read every script I could get my hands on. (R. Bruce, personal communication, September 26, 2013)

Reading for Bruce is not the reading of one or two books produced by screenwriting gurus: it is rather Certeau's act of reading-as-poaching, in which the reader assimilates and transfigures a text:

The reader takes neither the position of the author nor an author's position. He invents in texts something different from what they “intended." He detaches them from their (lost or accessory) origin. He combines their fragments and creates something un-known...

(Certeau, 1988, p. 169) 
Thus, reading de facto trains its students to write: it encourages creation of the "un-known" text through shards of previous readings. It "accumulates, stocks up, resists time...and multiplies its production through the expansionism of reproduction" (Certeau, p. 174).

Other tactics include the understanding of screenwriting via related disciplines: Henry Talbot, for example, cites his work in feature film editing as training him to write only the most essential elements of a screenplay, to avoid "anything superfluous" and "hang everything off of an A plot or a B plot" (H. Talbot, personal communication, September 20, 2013). William Chopin frequently refers to film scholarship as imparting some of the most important lessons in his screenwriting career, while Ron Booth considers his work reading scripts as a child actor formative in his self-education. Jane Parsons's music degree and theatrical experience have been formative, she notes, and her understanding of mathematics foundational in prompting her to create logical, cause-and-effect scenarios; for her, the "huge puzzle" of weaving together plots and characters is a "wonderful exercise to go through" (J. Parsons, personal communication, September 24, 2013). Dodging conventional strategies of screenplay instruction, these writers rely upon whatever it is they have "poached" in their childhood and early careers to give them an understanding of the screenplay as a form.

Then there is the writers' tactic of promulgating atypical film structures, narrative closures and characters arcs (or non-arcs, to be accurate). I have examined these passages at some length here and will not repeat the analysis; however, we might consider how interviewees have expressed their resistance to normative forms of screenplay assessment. Ron Booth will not offer his writing to professionals he doesn't know, preferring to share his work with a few trusted individuals, a "group of smart friends and colleagues who I think of as my readers and who I send my scripts to" (R. Booth, personal communication, 
November 6, 2013). William Chopin confesses his screenwriting is done much of the time to please himself and not to conform to another's specifications: "I'd hate to feel that I was really only doing screenwriting when in fact, it has a wider extension and I'm doing little bits of poetry, little bits of narrative filigree, I'm doing a little of this and a little of that" (W. Chopin, personal communication, October 25, 2013).

But perhaps the most tactical of all acts for these writers is their almost universal decision to reject external influences in favour of their own artistic instincts on the subject of screenwriting. Not everyone comments directly on this transition: the researcher can only point to the confidence, certainty and declarative language of interviewees, evident earlier in this chapter, to assert this claim. Joseph Freiman recalls his breakthrough in writing came when he realized he wanted no other part of the filmmaking industry than to be a screenwriter: at that point, he notes, he began to "just read a lot of screenplays...to understand how they were built" (J. Freiman, personal communication, January 21, 2012). Matt Sparks, one of the younger participants in the sample, offers a bashful observation of his evolution as a screenwriter. He confesses he is not sure how he matured as a writer, but that at some point, he had to "try to be available to ideas,"

.... and you get an idea and after a while you realize it's an idea or not, usually. And then you write it. And sometimes you realize as you're writing it that it's not an idea (laughs). But with experience, that doesn't happen as often... But yeah, I can't even say, necessarily. It's more instinctive now. (M. Sparks, personal communication, September 27, 2013) 
The understanding throughout this project has been that Canada's arts funding bodies, its writers, directors, producers, actors, etc. comprise a system, and that this system uses/shares, amongst other elements: a common business paradigm; a sanctioned route for filmmaking education; a circumscribed funding route; and a shared language. This system is closed in that it does not share its operations in any significant way with other industries or disciplines: it is a hermetic unit, sealed to protect itself against unwanted influences and open only to a select few talents, resources, 'energies.' Most importantly, however, English-Canada's filmmaking system — or at least its screenwriters — represents Luhmann's art system, which evolves in unique ways by voluntarily breaking down and reconstituting the apparently inviolable rules of narrative.

Consider as well that Canada's system of filmmaking has over the past decade been exposed to a series of environmental perturbations: these include developments like the encroachment of 'quality television' products upon film markets, the increasing movement of audiences away from theatrical to home distribution, the evolving lure of gaming, etc. As potential viewers begin to turn not simply from Canadian film but film in general to other entertainment/rhetorical forms, our filmmaking system will increasingly come under stress, or "perturbations." Luhmann would interpret this point in time as one in which a system will respond to such irritations by reproducing, evolving — or dying. But he reminds us that art by its very nature will have constant change - it must have the "new," despite the distress and inconvenience artistic risks inevitably pose to their creators:

'New' means here, as it has since the seventeenth century, not only another example, but rather something that diverges from the foregoing and thus surprises. Genius lies in the accomplishment of discontinuity and it is clear that this temporal discontinuity 
presupposes a social discontinuity, i.e., the differentiation of art from the tutelage of other, above all religious and political interests.

(Luhmann, 1990, p. 195, quoted in Andersen).

The interviewees who participated in this project's research may diverge in their interpretation of Canadian screenwriting challenges and priorities, but they register enough restlessness and discontent with current education and policy models to suggest that our filmmaking system may be in the throes of evolution. My final chapter will offer recommendations to consider regarding screenwriting policy in this country, as well as future research that springs from this project. 


\section{Notes}

1. Richard Bruce says he regrets not completing his degree, but offers no further explanation as to why he feels this way: "I sometimes wish I had that degree, I don't know why, but I sometimes wish I did."

2. The question "Have you then read any of the typical screenwriting books by Syd Field, the Bob McKees?" was asked of six of the eight interviewees.

3. "Groups" and "organizations" do not include in this case unions or lobby groups like the Directors Guild of Canada and/or the Writers Guild of Canada, to which many of the interviewees belong.

4. Except for a very few cases, the tone communicated by the interviewees throughout these comments on screenwriting gurus was generally one of irritation, contempt and impatience. While such a tone is difficult to convey in a scholarly paper, it is an important conveyor of meaning during interviews.

5. Bordwell and his partner Kristin Thompson have each written important scholarly texts on the subject of narrative in cinema, as have a variety of other academics whose work I greatly respect. However, as neoformalists, Bordwell and Thompson are entrenched in a particular theoretical approach to viewing narrative in film, an approach I wanted to avoid. Because this dissertation incorporates primarily a grounded/ethnographic approach (with appeals to Luhmann's Grand theory and Certeau's more modest proposal), I have avoided excessive reference to formalized narrative theory as offered through neoformalism, narratology, semiotics, Levi Strauss's binary theory and other admittedly potentially relevant doctrine.

6. Bruce is a little embarrassed at this stage of the interview as he notes he cannot remember the ending of a film for which he wrote a contract screenplay. This is perhaps not an unusual situation: three different endings were shot for the movie, with a limited (internal) focus group deployed to choose the 'best' final sequence. The writer also notes that he wrote the screenplay for this genre picture within a few months, as the producer was under pressure to replace a potentially litigious script ("What had happened was the production company had a film set to go, ...but there were some legal issues with the script they were set to shoot. So they said, "You know what? We'll just keep everything as it is, the money's in place, we'll just get a new script").

7. The relationship suggested here comes from the idea of "irreversible change" (Robert $\mathrm{McKee}$ ) at the end of a film coupled with the strong wave of transformation required by the traditional character arc. Specifically, if the film's protagonist moves through designed stages of change, a corresponding transformational finale can be expected to accompany that metamorphosis.

8. It should be noted too that In the Bedroom was no arthouse flop but a multi-awardwinning film nominated for five Academy Awards, including Best Picture.

9. This film won a total of five major awards, including Genie Awards for Best Screenplay and Best Achievement in Music, as well as Audience Awards from the Tokyo and Sofia International Film festivals.

10. Talbot contrasts the anonymous reader's reports with reports from actors who have been cast for the film: these notes, he says, are not as valuable "because many times there is a competitiveness there, or a desire to slant the story more towards their character." 
11. Government of Canada (2000). From script to screen: New policy directions for Canadian feature film, Canadian Heritage. Retrieved from http://canada.pch.gc.ca/eng/1454338798386

12. Indeed, this propensity for self-sufficient and perpetual reading seems a constant amongst the interviewees: almost all describe themselves as habitual readers from early childhood. However, it did not occur to me until about a quarter of the way through my interviews that most of the screenwriters I spoke with might be considered constant or habitual readers, not only in adult life but as children. William Chopin, Henry Talbot, Joseph Freiman, Richard Bruce (via a separate email), Benjamin Philip and Ron Booth describes themselves in such terms; I cannot however make similar assumptions for Jane Parsons and Matt Sparks. 


\section{Chapter 8: Concluding Observations and Implications of the Study}

\subsection{Concluding Observations and Implications of the Study}

This project has taken a qualitative research approach to examining the attitudes and opinions of Canadian screenwriters on the matter of screenwriting practice; during the course of its investigations, the project grew to incorporate discussions on screenwriting education and funding policy in English Canada. The results indicate that the interviewees, all of them successful English-Canadian writers/filmmakers with discrete and idiosyncratic approaches to their writing, have serious concerns regarding funding policy and, to a lesser degree, screenwriting education in Canada. The theoretical writings of Niklas Luhmann and Michel de Certeau provide perspective on how screenwriters as a group of professionals are bound by a normalized system of operation in this country, yet at the same time challenge the rules of screenwriting as laid down by Hollywood authorities and reinforced by Canadian policymakers. In particular, screenwriters, typically considered the least powerful of the players in filmmaking's above-the-line team, have found their own ways to assert authority in the creative process. The dissertation has implications for interpreting policy directions in the nation's filmmaking funding bodies, and for analyzing both traditional and novel narrative directions in Canadian filmmaking. Discussion of these implications and other critical observations will follow a preliminary review of the dissertation's primary conclusions.

In the meantime, how is it that a qualitative research project like this one may inform filmmaking policy in English-speaking Canada? Or in other words, why should funding organizations listen to screenwriters, whose positions of authority are as we have seen contested in both the diverse arena of English-Canada cinema and the more normative setting of Hollywood film? 
There are a variety of answers to such a question. The first one pertains to the everevolving status of the Anglo-Canadian screenwriter, viz., her/his almost inevitable move to the status of the auteur. According to this project's interviews, screenwriters who find success in the field usually consider a move into the production and (less often) direction functions of filmmaking: these individuals are in the unique position of learning the abovethe-line 'trade' from the floor up. Because funding executives may or may not (usually not) have experience as practitioners in this continuous flux of learning, they also may not be privy to the tacit information collected during the course of this difficult and often painful education. Listening closely to and respecting the informed opinions of screenwriters as they negotiate the business of screenwriting and production would give funders a unique perspective on screenplay narrative that, to my knowledge, has not been replicated in howto books.

A second argument for this research posits that because they may not understand the importance of literature and literary conventions in informing screenwriting practice in English-Canada, funding executives might find such information both surprising and potentially useful in contextualizing certain motivations and plot developments in screenplays considered for development. Although such executives may not have time as William Chopin forcefully suggests to "read more," they may benefit from listening more closely to those who read and write for a living. Filmmaking narrative does after all spring from earlier genres of narrative, including (as we have seen) novelistic and dramatic literature.

Third, bureaucratic institutions hiring funding executives may regard the information in this project as useful in hiring said executives. Given the primacy of literary conventions in screenwriting, appointing individuals versed in screenwriting and literature (as well, one 
would hope, in the history of Canadian filmmaking) would give these funding bodies a more holistic approach to developing screenplays and ongoing policy.

Fourth, funders may find information provided by screenwriters through research projects like this one casts a new light on their interpretation of Canadian national identity in film. We have seen that national identity is not a conscious consideration for these writers as they design and execute their work: however, it would appear that despite their intentions, these professionals nonetheless write in ways that are anomalous, if not necessarily unique to English-Canadian screenwriting.

Finally, the image of the screenwriter in English-Canada today appears to be in flux, in large part because these individuals are often eager to incorporate their writerly roles into positions of greater authority. This means that funding bodies would be wise to listen and closely question these ambitious auteurs to discover how they regard the writing process: it's entirely possible these executives might learn something they had not previously known.

These and other justifications supporting this project's policy recommendations follow below.

\subsection{Review of Methodological and Theoretical Approaches}

The methodology for this dissertation comprised a qualitative approach, with the first part a series of interviews with eight successful professional screenwriters and the second, textual analysis of eight full-length feature film screenplays (as written by the interviewed screenwriters) with an additional eight identified screenplays by English-Canadian screenwriters. Hour-long telephone interviews were conducted with eight screenwriters: all were asked to choose their own pseudonym (providing at least some measure of 
anonymity), and all were given the chance to view their transcribed interviews or the dissertation's analysis chapter or both, and to sign off on their contribution to the project. Anonymity is of particular importance to these writers, as the filmmaking community in Canada is small and funding difficult to come by; in fact, one individual revealed he had deliberately withheld a critique of Telefilm from the interview so as to ensure he could not in any way be identified with negative commentary on this funding body's policy. Textual analysis of relevant texts (viz., scholarly literature, films, interviews, policy documentation, etc.) provided the writer with a methodology not only for the dissertation's literature review, but for literally all chapters requiring analysis. Most importantly, textual analysis allowed this writer to examine the ways in which films written by each interviewee departs from standardized models: the script analysis chapter supports the dissertation's position that screenwriters avoid or adapt normative laws of screenwriting to create their own idiosyncratic stories and narrative forms.

Theoretical lenses for the dissertation were provided via Michel de Certeau and Niklas Luhmann, the latter providing a systems-level approach to human communications, while the former depicts the 'System' as it is commonly negotiated by subaltern publics. Luhmann's theory describes society as a series of systems-ruled cells of human activity, each with its own language and laws, while Certeau recognizes the system as a socially constructed stronghold that must constantly be defended and protected, even as its 'powerless' subordinates run rampant over it, poach from it and in related ways negotiate it. Adoption of the two theories proved particularly useful through the interview and analysis stages of the dissertation, when interviewees described first their understanding and adherence to the laws of the filmmaking system in English-speaking Canada, and second, the ways in which they consciously and unconsciously subvert the rules set down by 
Telefilm Canada and other English-Canadian funding bodies. The writers articulate their rejection of normative screenwriting models at times with vociferous objections, but at other points, their resistance is passive and more problematic. That is, instead of noting instances in which classic Hollywood narrative influenced their writing, these individuals point to an entirely new body of sources, many of them literary (i.e.: Greek mythology (Booth), folk tales and Canadian literature (Parsons), early $20^{\text {th }}$-century European literature (Philip)), and others from mid-20 $0^{\text {th }}$-century and contemporary filmmaking itself, most of which is non-conventional and/or counter to normative Hollywood narrative models (viz., Pulp Fiction (Freiman), Nashville and L'Avventura (Chopin), Prisoners (Talbot), Dr. Strangelove (Sparks)). One interviewee mentions a traditional Hollywood narrative as influential in his writing career - but even while discussing The Champ (Zefferelli, 1979), he notes it is the film's unique "guy-centered" elements of masculine melodrama that are/were influential vs. the film's generally conventional elements of narrative structure and plotting. Another writer described the structure of one of his feature screenplays as deriving from a real-life incident that had profoundly affected him: his multi-character script attempts to address the drama's trauma in as diplomatic and 'realistic' a manner as possible.

\subsection{Findings on Screenwriting Practice by English-Canadian Screenwriters}

To return to the dissertation's introduction, this project's original research question was two-fold:

How do English-Canadian screenplay narratives differ from American screenplay stories? 


\section{How do English-Canadian screenwriters distinguish their scripts from}

their American counterparts as part of the exercise to define an

\section{English-Canadian national identity?}

The expectation here was that by outlining these critical differences, the scholar could define if not a holistic then at least a generally descriptive model of the contemporary English-Canadian screenplay. At the same time, this writer's personal experiences in screenwriting prompted a secondary exploration: namely, inquiry into the perception that funding bodies in English-speaking Canada demand filmmaking teams produce screenplays based upon the classical Hollywood narrative structure (as discussed, this structure comprises a three-act form that follows its protagonist through a logically contiguous narrative of sustained conflict and profound character development to an unambiguous resolution). Given the unusual narrative forms of many if not most English-Canadian screen stories, it seemed obvious that screenwriters purposely sought an alternate approach for their writing: the question thus became how these professionals crafted their approach against the normative form.

As the project progressed, the focus shifted from examining how interviewed screenwriters conceive their narratives as distinctly English-Canadian to acknowledging that national or even regional identity was not an important issue. Indeed, one of the project's more salient findings was how few of the interviewed professionals seem to consider their English-Canadian status a relevant factor in the writing process. ${ }^{1}$ At the same time, it is important to note that the interview template did not specifically require screenwriters during the interview stage to define their ideas of English-Canadian narrative structure or to discover if they had intended to write screenplays that express a national identity. The strategy was less direct: namely, I asked questions to discover how much 
these individuals aligned their writing strategies and models to the structural forms described by Hollywood screenwriting gurus like Robert McKee and Syd Field. This research thus sought to discern from the accumulated data a generalized pattern of deliberative resistance to normative writing structures.

However, while there were indications of resistance throughout the interviews, there was little indication of premeditated resistance. Writers did not specify ways in which they deliberately avoided or undermined the classical narrative structure, but simply expressed their discontent with many of the form's maxims. A few interviewees suggested alternatives to the classical narrative structure as offered by the German playwright Gustav Freytag, others mentioned Aristotle's Poetics in passing, while one writer expressed her strong opinion that Canadian writing does not follow American pathways, but not one writer described a concrete alternate model to the Hollywood form. This may be because the writers were not specifically asked to describe their own narrative maps, but more likely it is because they no longer consult classical narrative blueprints as they write. As one interviewee said, the work of screenwriting is most laborious in the early stages, when fledgling writers are learning their craft; as the artists mature, however, the form becomes more 'natural,' less forced. At this stage, the writer does not dwell upon structure but simply writes. At the same time, it is important to note that while many of the screenwriters voiced their contempt for formula-based paths to screenwriting, they also expressed regard for what they considered the "organic" element of the form - that is, the screenplay's threeact structure. While some writers advocated for this structure as the only golden rule of screenwriting, others were less dogmatic: for example, one scholarly writer half-heartedly vouched for classical structure in the absence of "genuinely creative rethinking of structure." A number of interviewees then revealed they considered the four-act structure a 
more apt description of their personal story maps: one pointed out that, along with two major act breaks, the mid-point break of the 120-minute screenplay was an essential element in his writing. The result can be interpreted not as a three-act but a four-act narrative structure - a form somewhat outside the usual dictates of classical Hollywood narrative.

Further, when the completed films of these individuals are examined in the dissertation's script analysis chapter for their adherence (or lack thereof) to classical form, it becomes clear the writers have taken liberties - whether they intended to or not. For example: where one screen story may retain adherence to the three-act structure, at the same time it might defy the classical law of the character arc, allowing its protagonist to remain unchanged throughout the narrative. Where another story may exemplify the timeworn conflict of family drama, it avoids the usual dictates by assigning its story not one but two (female) protagonists who each resist character change. And where yet another film may focus upon a traditional theme of promiscuous sexuality punished, it also adopts an ensemble cast (universally frowned upon by screenwriting textbooks) and an entirely anomalous 10 -act structure.

How deliberative are these liberties? Michel de Certeau notes that as "silent discoverers of their own paths in the jungle of functionalist rationality," citizens conduct their acts of resistance unconsciously:

(C)onsumers produce through their signifying practices something that might be considered similar to the "wandering lines"...drawn by the autistic children studied by F. Deligny: "indirect" or "errant" trajectories obeying their own logic. (Certeau, 1984, p. xviii.) 
Following his larger metaphor of citizens who "blindly" walk through a city, taking their usual shortcuts and detours without regard for the right-angle street crossings prescribed by city planners, Certeau sees this unconscious but still purposeful walker as writing her/his own story of the city - and by doing so, taking back the power to create in her/his own image. According to one commentator, "Certeau's urban pedestrian has limited vision":

(B)ut those limits are what make resistance possible, as the walker cannot be contained by a totalizing vision that he does not share/hold.

The walker does not have a panoptic vision and can thus resist panopticism through his or her everyday practices. (Meagher, 2007, p.

These screenwriters may well work within what Niklas Luhmann describes as a prescribed communications system, but at the same time, they constantly negotiate, resist, poach from and ignore this system, sometimes consciously, at other times unconsciously. In sum, there is considerably more instinct in the writing of screenplays than might be expected, if we are to believe the dictates of Hollywood screenwriting gurus.

This dissertation's major findings for screenwriting practice in English Canada thus are as follows:

First, if there is any real commonality amongst the interviewed screenwriters and their writing approaches, it is that their resistance to the Hollywood narrative model as proselytized by gurus Syd Field and Robert McKee takes multitudinous and circuitous forms, and that many of these non-compliant deviations are made because the writer either a) prefers an unconventional approach to structural underpinnings and character development or b) instinctively resists any strong dictates to her/his writing approach. Like the inhabitants of Luhmann's art system, these writers display the genius of dissolution and 
reconstitution - viz., the inherent ability to productively resist the demands of adjacent worlds of commerce, science, and philosophy.

Second, the individual's driving needs a) to pay homage to her/his literary and filmmaking influences, and b) to create a narrative of some originality (whether this means structural, thematic or character-driven originality) are far more important in determining the screenwriting approach than adoption of Hollywood narrative standards.

Third, the much-vaunted three-act structure is considered an acceptable if not organic standard by most interviewees, but it is also considered an elementary concern for the fledgling screenwriter, and of considerably less consequence to the mature writer than other more critical factors like innovative character development or inventive approaches to story closure and plotting.

\subsection{Findings and Implications for Policymakers in English-Canadian Filmmaking}

One of this project's major discoveries is that creative teams, including screenwriters, producers and directors, perceive English-Canadian funding bodies as adopting an often detrimental gatekeeping function that undermines the creative process and cinematic innovation. Although Telefilm was named at several points during the interviews, the observation was usually made by interviewees as a general statement about Canada's various funding organizations (that is, participants did not name specific funders at most points). While a number of interviewees noted that readers occasionally had insights by pointing to missteps in screenplays (which in their opinions made reader's reports helpful at least to some extent), the consensus was also that such insights were valuable only if they confirmed a nagging suspicion in the back of the writer's/producer's mind. In any case, automatic capitulation to all points in a reader's report was not a serious option. 
The overarching theme here appears to be that both screenwriters and funders/sponsors a) have a strong sense of what they regard as a good screenplay, and b) are often at odds with one another. This is not an unusual complaint within the filmmaking system, either in Hollywood or in English-Canadian circles — indeed, numerous American films (i.e., Altman's The Player, the Jonze/Kaufman collaboration of Adaptation, the Coen Brothers' Barton Fink) reflexively express this systems-level vexation. However, it's also clear from a number of the anecdotes related in the previous chapter that Canadian funding organizations have specifically missed opportunities to support important film projects because their readers were insufficiently educated to recognize alternative screenwriting models, and/or that these readers were insufficiently trained or monitored by their employers. Indeed, in many cases, readers appear to have been mismatched to screenplays.

It's worth noting here that Telefilm has apparently revised its approach to screenplay development. One interviewee mentions briefly that the organization recently introduced a process to encourage a project's creative team to work together on a screenplay:

I find that when you're exchanging creative with the people of your own team, which I will say is a marked improvement in Telefilm development strategy, when you're dealing with your producer and you're actually dealing with — and ideally you're working with your producer because this is somebody you respect and you believe cannot just get your movie made but can make your movie good and better. (R. Booth, personal communication, November 6, 2013)

It is unclear whether organized exchanges with creative teams now replace the gatekeeping function of the reader's report, if these exchanges are encouraged in addition to the script analysis process, or if such exchanges are recommended for only some of the film projects 
submitted to Telefilm for development. Clarification of this point is essential for further research into funding policy. In the meantime, based upon the responses arising from other interviewees, it would seem other funding organizations in Canada continue to use the reader's report as the first gate in the development process, perhaps because this traditional approach is still considered the most efficient for determining script quality. There is sufficient evidence in these interviews to warrant policy adjustments to English Canada's feature film development processes in this regard.

\subsection{Critical Observations of Funding Criteria and Practice}

This dissertation set out to examine English-Canadian screenwriting practices, and in the process critically examine funding practices at the screenplay/above-the-line level, and the information it has gathered suggests the need for change at the funding body level. The changes would recognize the role of the writer and the nature of the Canadian screenplay in a more fulsome manner than is currently practiced; these observations are based on the interview material. While there is no guarantee of consensus amongst the interviewees for these suggestions, there has also been a concerted effort to summarize their desire for change in positive and attainable ways. These observations may have the potential to open the door to further scholarship in English-Canadian screenwriting by providing cues to research questions and improved communication interface between production teams and Canadian funders.

\section{- Existing reader's-report and screenplay development processes are opaque and}

possibly obsolete: A number of interviewed screenwriters observed deleterious actions

by funding body readers who may not have understood the intended market for particular screenplays or who may have wielded more power than wisdom in rejecting 
submitted screenplay drafts. Given the considerable gatekeeping power awarded to funding organizations' readers, this point underscores a need for greater transparency amongst all members of the process. Removing the blind (more specifically, the "double blind") factor of the review process so both readers and producers/ screenwriters are apprised of the identities of all parties involved may be helpful. Although traditionally, the blind review process has been meant to protect involved parties from cronyism, gender bias or otherwise unfairly motivated responses to submitted projects, this measure does not guarantee quality nor does it completely eliminate bias. It may be time then to introduce the scholarly precedent of open peer review to English-Canada's screenplay development agencies: this system would place the work of the screenwriter before an identified 'peer' reviewer known as an expert in an appropriate/aligned film genre or market. Such transparency is not an assurance of seamless refereeing (there will inevitably be problems matching screenwriters to reading experts, for example), but this method should contribute to greater accountability and professionalism amongst those working in the development field that is, putting the reader's name to a written review requires her/him to more carefully consider the honesty and consequences of her/his analysis. Further, both reviewers and creative teams might consider discussing in person or by teleconference the results of reader's reports, with screenwriters encouraged to ask questions and readers allowed to offer greater explanation of their reviews. As one interviewee notes, English-Canada's film community could take a page from television teams, within which communication is conducted face to face, and where both writers and readers may negotiate changes in real time to the submitted draft. Such adjustments to the review process may require greater time commitments on the parts of both readers and creative teams, but the 
results would help address grievances and accusations of irresponsibility such as the ones voiced in this project's interviews. It may also educate readers and their employers on the writing processes of screenwriters and their creative teams, a development that could open up new ways of assessing screenplays when they are first submitted.

- Reader expertise is not always aligned to submitted screenplays: If reader's report practices or similar gatekeeping processes continue at English-Canadian funding bodies, these authorities might consider matching more closely organizational readers and their specialized interests (i.e., LGBT, science fiction, horror, etc.) to the genre of incoming screenplays. This will no doubt require funders to search farther afield for their readers or to share from a bank of readers with self-declared expertise/interest in these genres; such sharing may mean funding organizations will need to reach out to other like-minded organizations in other English-speaking countries or in European countries where many films are made in the English language. Given the industry's challenge to diversify, this change in practice might ameliorate mistakes like the one noted by one writer (in which an influential LGBT film was passed over by major funders), or the near-miss reported by another (in which funders were offended by a minor detail of a narrative and recommended a Pass on the screenplay itself).

\section{- Development executives and their readers are not fully apprised of fruitful alternate}

narrative concepts: Interviewees for this project discussed not just differing models of narrative structures and closures, but the function of narrative in other forms, including literature and dramatic literature. Many of these writers consider literary narrative elements (including theme, characterization, plot, tone, conflict, etc.) as paramount, 
both in their holistic explanatory power and in their place in the history of literature. Concerns about factors like the placement of act breaks, controlling ideas and inciting incidents may then be placed in a larger context: while these ideas from the screenwriting paradigm are generally speaking not incorrect, they are also not the only frame of reference for satisfactory narrative development. ${ }^{2}$ Encouraging development authorities to begin with an understanding of texts like Lajos Egri's The Art of Dramatic Writing (1946) and a closer reading of Aristotle's Poetics might be a helpful start. In all ways, development executives and their readers should be educated at the highest and most diverse levels of the form: echoing the terse phrases of one interviewee, Telefilm executives and contractors should read more dramatic literature, see more alternative film and think more broadly about the form rather than default to normative approaches.

\section{- Funding organizations conduct little research into evolving narrative structures for}

feature film: To their great credit, funding bodies like Telefilm Canada are active qualitative/quantitative researchers: this organization alone conducted 13 major studies over the 2016/2015 period. However, such studies are focused almost entirely upon profiling Canadian film audiences/consumers, with occasional forays into economic reports on the media production industry and the state of funding for film and documentaries in this country. Comparatively little is done to examine the attitude of producers, filmmakers or screenwriters, and even less done to scrutinize a rapidly changing storytelling environment. This dissertation has attempted to fill at least one of this country's gaps in feature film research by approaching screenwriters and other above-the-line professionals to discuss traditional feature film narratives; however, 
further research by qualified policymakers like Telefilm and Heritage Canada would be welcomed.

\subsection{Findings and Implications for Post-Secondary Education in Screenwriting}

Screenwriting education has emerged in this dissertation as the heart of this country's screenwriting issues; certainly it is at the very centre of the interviewees' frustration, given its primacy in the creation and gatekeeping of funding policy. Through the course of this project, there has been evidence that screenwriting texts like Robert McKee's Story are foundational in guiding funding organizations to accept, reject and shape submitted screenplays: considering this and other guru-written books' considerable weight as educational tomes, it is appropriate to regard them with a newly critical eye, and to ask if such resources are still applicable or even relevant to English-Canada's screenwriting practices. As mentioned, a number of participants in the interviews suggested their screenwriting education was either self-directed or minimally resourced at the postsecondary institutions they attended. Further, a number of interviewees expressed concern for limited educational resources on screenwriting. One writer in particular lamented the paucity of training resources for writing students, noting there was little academic training in screenwriting offered within his educational sphere. And while the bootstrap approach to filmmaking, especially filmmaking in English-Canada, demands considerable innovative rigour (people who succeed in writing/making not one but two or three and subsequent films know they have accomplished something that entails a great deal of organizational and emotional investment), most of the interviewed writers would welcome refreshed discussion around screenwriting instruction/resources, particularly in the realm of alternative closure, characterization and plotting. 
Another important aspect of screenwriting instruction comes down to the unease many post-secondary instructors seem to feel around the idea of teaching creative writing of any kind. This occasionally heated debate (which essentially boils down to "Yes, it can be taught: vs. "No, it cannot be taught") has been circulating at universities at least since Creative Writing has been offered as a Master's degree program. In 1985, American novelist John Barth and writing instructor offered in a New York Times Book Review editorial the opinion that while only a small percentage of successful writers emerge from the hundreds of students enrolled in creative writing program, it "can be learned, by the able; it can be studied, by everybody and his brother; it can even (you know what I mean) be taught, even in school..." The idea of screenwriting as a learned craft raises similar discussions: one screenwriting instructor suggests that "you have to realize that (there is) a certain level of training to get to a level of excellence, and that means literally hundreds of craft techniques that have to be mastered" (Truby, 2012, n.d.) Even basic screenwriting requires considerably more education, thought, reading, practice and talent than can be provided by a long weekend in a packed auditorium with a Hollywood guru. The Shawshank Redemption's writer/director Frank Darabont dispatches the fantasies of aspiring screenwriters with alacrity:

(U)ltimately, you know what it all boils down to? You're sitting at your desk, all by yourself for years, trying to figure out your craft and applying the effort necessary. And that's what nobody wants to hear. Everybody wants to hear, 'I can teach you a three-act structure, I can give you a formula, and you'll be selling screenplays within six months.' Bullshit. (Darabont, 2012, n.p.) 
This project's finding that screenwriters are avid readers is of primary importance: this attribute may in fact be a requisite habit for writers of the genre. The conceit in Hollywood is that fine screenwriters may emerge from any background - educated in the craft, uneducated in the craft, from unrelated industries, sprung from the forehead of Zeus, etc. and this may or may not be true. However, a key discovery in this dissertation is that screenwriters are first of all readers, although not necessarily readers of the screenplay form per se. Some screenwriters profess to hate reading screenplays and read them only under duress, while others have read hundreds of scripts in their writing and acting careers - but both persuasions have parlayed their understanding of the story form into screenplays and ultimately into produced film projects. The common denominator here is that the writers interviewed for this project have devoted considerable time through their younger lives to maturity to read and understand the art of narrative in its multitudinous forms. When they bring classical, dramatic or literary language/tropes to the discipline of screenwriting, the form is exposed to new worlds of potential, and the seemingly infrangible rules of screenwriting shot through with fractures.

Although this section's notes on screenwriting education could well spark a variety of recommendations for educational institutions, the focus of the dissertation has been upon English-Canadian feature film funding and related recommendations for screenwriting policy. Seguing into a discussion of educational implications would take the project into a largely uninvestigated (although related) realm of screenwriting education for which this study provides no direct evidence or data. At the same time, suggestions for future research in screenwriting education may be of interest to policymakers; these follow below. 


\subsection{Considerations for further research in English-Canadian screenwriting}

Although the discussion of screenwriting education implications is a wide and complex topic outside the scope of this dissertation, a number of smaller research projects to probe educational practices at the post-secondary level are worth considering. These might include projects to:

- Investigate with English-Canadian post-secondary institutions the viability of studying alternate narrative forms for screenwriting. Given the recommendations of several interviewees for broader study of narrative form as it might relate to current screenwriting practice, a study in conjunction with screenwriting educators could be of value in plotting new strategies for teaching such work. The screenwriters named in this project have already related a variety of alternate texts and sources as a primary set of resources; there are likely many more.

- Conduct textual analysis and qualitative study to investigate how other nations teach their students the art of screenwriting and writing for television. Sweden,

Denmark, Finland and Iceland have currently taken a strong lead in the story-driven quality television market; these writers bring uniquely Nordic approaches to story closure, character arcs and narrative structure. Consider for example Scandinavian noir television dramas (also known as 'Midnight Sun' TV), which includes The Bridge (2011-present), The Killing (2007-12), Borgen (2010-present), Case (2015present) and the Swedish version of Wallander (2005-2010), in addition to Swedish feature films such as Let the Right One In (2008) The Girl With the Dragon Tattoo (2011), The Girl Who Played with Fire (2009) and The Girl Who Kicked the Hornets' Nest (2009): how are these narratives structured and written? and what are 
the 'rules' for Scandinavian writers, if any? Qualitative interviews with select screen- and television writers in these and other countries would provide information on screenwriting pedagogy that may prove insightful for EnglishCanadian writers, educators and, in particular, policymakers.

\section{- Introduce curricular dialogue around the idea of normative structures and rules}

for English-language screenwriting: The interviewed screenwriters for this projective raised numerous questions around the adequacy of current educational resources in the field, particularly around the rules and regulations of Hollywood screenwriting gurus and their texts, resources that are used both in the postsecondary educational setting and by individual 'amateur' screenwriters. One of the important findings from this project is that these professionals consider normative ways of writing to be outmoded and increasingly irrelevant. Educators in the classroom might therefore consider introducing new more dialogic ways of studying the art of screenwriting, which could include such ideas as:

○ Partnering with dramaturgists, novelists and even journalists on the concept of narrative structure, and building such dialogues into the formal curriculum; encouraging students to enter into exchanges on these discrete but related forms would provide them with active examples of alternative writing approaches.

○ Partnering with instructors from related faculties to discuss the function and uses of narrative structure in literature, film, journalism, graphic novels, etc. Much of the scholarly research being done on narratives (to a large extent within the field of narratology) sheds new light on how storytelling has evolved through human history: for example, a team of scholars at the 
University of British Columbia has created visual models of authorial narrative design to provide students with alternatives to common visualizations like Freytag's Pyramid, which they suggest is "not always applicable" to evolving narrative forms (Dobson, 2011, p. 170).

o Through seminar-style proceedings in both undergraduate and graduate classes, encouraging regular open discussion of normative and alternative screenplay structures, avoiding rule-making but always observing histories and trends in the form. Instructors might look to fostering student participation in identification of story structures and ways of writing screenplays: how do students themselves perceive the model? Encouraging the inquiry-based model of education in undergraduate classrooms is another possible tactic: rather than presenting models to emulate, pose questions to students that will lead them to their own answers regarding narrative structure. Can alternate structures be visualized (as per Dobson et al)? and if so, what do these visualizations look like, and how are they helpful?

Not all investigations must incorporate educational considerations: other useful approaches may be to closely analyse exiting texts in the genre, specifically to:

- Investigate the narrative foundation of national films that have resonated in some way with English-Canadian audiences. Specifically, what is it about the narratives of this modest body of films that proves meaningful for national audiences? Consider for example, Eric Canuel's Bon Cop, Bad Cop (2006), a bilingual comedy-thriller considered the highest grossing English-Canadian films to date: why does this entirely generic offering appeal so much to both French and English 
audiences? The same question might be asked of other successful CanadianAmerican films like David Cronenberg's A History of Violence (2005) and Nia Vardalos' My Big Fat Greek Wedding (2002), or more recent co-productions like Lenny Abrahamson/Emma Donoghue's Room (2015): how have these films succeeded in reaching the hearts and minds of English-Canadian audiences when other worthy entrants have failed? Textual analysis of these screenplays specifically of their forms as open- or closed, their approach to character arcs, etc. — might provide some clues to better understanding English-Canadian audience unique appeals.

\section{- Conduct textual analysis of screenplays to discern the evolution (as per}

Luhmann) of the classic narrative structure in film: As per observations during this project that classic narrative structure is not an 'organic' but a systemic coconstructed approach developed over decades of screenwriting history, a project to examine key texts/screenplays during the early and classic Hollywood periods, then through the mid-20th century into the 1960s and ' 70 s, would provide a useful overview of the ways in which the three-act structure has evolved during several key periods in filmmaking history. This project indicates the three-act structure is not an a priori form, as suggested by a number of interviewees, but a social construct created over time by an industry that consciously set itself apart from its narrative predecessors, namely, theatre and literature. If the origin of the three-act structure seems to originate with Aristotle, it does so mistakenly, as we have seen, but the conviction that it belongs absolutely to the screenplay appears incontrovertible. 


\subsection{Limitations of the Project}

The dissertation is limited in a number of ways, most obviously in its unequal weighting of male and female screenwriters. The call for screenwriters through the Writers' Guild of Canada (WGC) was made as a unified appeal to both men and women in the field; of the three that responded, one individual was female and the other two male. Another female screenwriter responded initially to the WGC call, but did not follow up or respond to calls to schedule an interview. Following the initial call-out, a colleague worked on the dissertation writer's behalf to recruit five more screenwriters: the writers who responded to this second call were universally male. ${ }^{4}$ If further work on this research question led to a more equal weighting of male and female respondents, a gender-based examination of approaches to screenwriting might provide a new set of data that could prove rewarding for subsequent study. That is, do male and female screenwriters in English-speaking Canada regard the constraints of the Hollywood narrative model with equal dissatisfaction? Do women adopt different strategies to circumnavigate disagreeable circumstances than do their male counterparts? Are female screenwriters in higher or lower demand, given their propensities to co-operate or not co-operate with funding authorities?

Another limitation of the dissertation is its lack of substantiated material on current screenwriting and reader's report practices practiced by Telefilm Canada and other Canadian funders. As noted above by screenwriter Ron Booth, Telefilm has apparently revised its approach to notes and the screenplay revision process; further information on this update would be beneficial. A series of interviews with the numerous feature film funding bodies in Canada would similarly help inform screenwriting scholarship in the matter; exchanges regarding the value of reader's reports and other screening processes to 
funders should identify precedents for these practices, and help clarify why these organizations employ them.

Finally, while the focus of this project has been on the practices of English-Canadian screenwriters and their conscious/unconscious refusal of the Hollywood narrative model, it may well be the case that Americans working successfully in the film industry similarly resist the normative form. Work to discover how these professionals regard their approach to writing could open new avenues of thought about filmic storytelling in that country to break down national narratives that seem to do present-day America little good. 


\section{Notes}

1. One notable exception to this observation can be seen during the interview with producer/director/screenwriter Jane Parsons, who at numerous junctures suggests that Telefilm and the National Film Board have played an enormous role in shaping her sense of national identity and identity as a filmmaker. Note for example her insistence that ending a narrative in the Hollywood fashion would not be the Canadian way (italics mine).

2. I suggest most screenwriting gurus conflate the idea of structure with narrative pacing. Great ado is made over specific times in the screenplay when specific 'turns' and activities must occur: much of this comes down to the idea that every 15 minutes, the screenplay must be revitalized with a jolt of activity, either a significant plot event that puts a new spin on the narrative or an action scene that enlivens the proceedings. Filmmakers have long recognized that without such regular shocks of narrative energy, movie audiences may be overcome with boredom.

3. To be clear, I did not specify that this second wave of interviewees should be equally weighted between male and female respondents; the colleague who worked on my behalf simply approached screenwriters s/he knew to request their participation in the study. 


\section{References}

Acland, C. R. (2003). Screen traffic: Movies, multiplexes, and global culture. Durham, NC: Duke University Press.

Acland, C. (2002). Screen time, screen space, and Canadian film exhibition. In (Eds.) W. Beard \& J. White, North of everything: English-Canadian cinema since 1980. Edmonton, AB: University of Alberta Press.

Ahearne, J. (2004). Between cultural theory and policy: The cultural policy thinking of Pierre Bourdieu, Michel de Certeau and Regis Debray. Centre for Cultural Policy Studies, Research Paper \#7. Warwick: University of Warwick.

Ahearne, J. (1995). Michel de Certeau: Interpretation and its other. Stanford University Press: Stanford, CA.

Alliance of Canadian Cinema, Television and Radio Artists (ACTRA). (2016). ACTRA applauds government's support of Canada's creative industry in 2016 budget [Press release]. Retrieved from https://www.actra.ca/press-releases/2016/03/actra-applaudsgovernments-support-of-canadas-creative-industry-in-2016-budget/

Andersen, P. B. (2000). Genres as self-organising systems. In Andersen, P. B., Emmeche, C., Finnemann, N. O., and Christiansen, P. V. (Eds.), Downward Causation. Minds, Bodies and Matter (pp. 214-260). Aarhus: Aarhus University Press.

Alliance of Canadian Cinema, Television and Radio Artists (ACTRA). (2016). ACTRA applauds government's support of Canada's creative industry in 2016 budget [Press release]. Retrieved from https://www.actra.ca/press-releases/2016/03/actra-applaudsgovernments-support-of-canadas-creative-industry-in-2016-budget/ 
Arnoldi, J. (2001a). Niklas Luhmann. In A. Elliott and B.S. Turner (Eds.), Profiles in contemporary social theory (pp. 249-259). London: Sage.

Arnoldi, J. (2001b). Niklas Luhmann: An introduction. Theory, Culture \& Society, 18(1), 113.

Atkinson, R. (2002). The life story interview. In N.K. Denzin \& Y.S. Lincoln (Eds.), The Sage handbook of qualitative research ( $3^{\text {rd }}$ edition) (pp. 121-140). Thousand Oaks, CA: Sage Publications.

Atkinson, P. \& Silverman, D. (1997). Kundera's immortality: The interview society and the invention of the self. Qualitative Inquiry, 3(3), pp. 304-325.

Atwood, Margaret. (1972). Survival: A thematic guide to Canadian literature. Toronto, ON: House of Anansi Press

Barth, J. (1985, June 16). Writing: Can it be taught? New York Times Review of Books. http://www.nytimes.com/books/98/06/21/specials/barth-writing.html

Beard, W. (2010). Into the past: The cinema of Guy Maddin. Toronto, ON: University of Toronto Press.

Beard, W. (1994). The Canadianness of David Cronenberg. Mosaic 27(2): pp. 113-133.

Beard, W. (2002). Thirty-two paragraphs about David Cronenberg. In W. Beard \& J. White (Eds.), North of everything: English-Canadian cinema since 1980 (pp. 144-159). Edmonton, AB: University of Alberta Press.

Bechmann, G. and Stehr, N. (2002). Profile: The legacy of Niklas Luhmann. Society, 39(2), $67-75$.

Bordwell, David \& Thompson, Kristin. (2010). In David Bordwell \& Kristin Thompson, (Eds.) Film art: An introduction. Don Mills, ON: Addison-Wesley Publishing. 
Bordwell, David. (1985). Narration in the fiction film. Madison, WI: University of Wisconsin Press.

Bourdieu, P. (1990). The logic of practice. (R. Nice, Trans.). London: Polity Press. (Original work published 1980).

Branigan, E. (1992). Narrative Comprehension and Film. London: Routledge.

British Film Institute. (2007). La Zona case study. [Web post]. Retrieved from http://industry.bfi.org.uk/search?articleid=7\&keyword=La+Zona\&continue=+\&search $\underline{\text { method=ANY }}$

Browne, Dennis. (1999). Canada's cultural trade quandary: How do we resolve the impasse? International Journal, 54(3), 363-367.

Buchanan, I. (2001). Introduction: Michel de Certeau — in the plural. The South Atlantic Quarterly, 100(2), 323-329.

Campbell, J. (2008). The hero with a thousand faces (3rd ed.). Novato, CA: New World Library. Retrieved from https://books.google.ca/books?id=I1uFuXlvFgMC\&printsec=frontcover \&dq=hero+wit $\underline{\mathrm{h}+\mathrm{a}+\text { thousand }+ \text { faces }+ \text { Campbell\&hl=en \&sa=X\&ei=nkf7VI- }}$

WH4vkoASwkYCIDw\&ved=0CCYQ6AEwAA\#v=onepage \&q=hero\%20with\%20a\%2 0thousand $\% 20$ faces\%20Campbell \&f=false

Canadian Media Producers Association. (2011). Profile 2011: An economic report on the screen-based production industry in Canada. Gatineau, QC: Department of Canadian Heritage.

Certeau, M. (1997). The capture of speech and other political writings. (T. Conley, Trans.). Minneapolis, Minnesota: University of Minnesota Press.

Certeau, M. \& Porter, C. (1987). The gaze: Nicholas of Cusa. Diacritics, 17(3), 2-38. 
Certeau, M. (2010). Heterologies: Discourse on the other. (B. Massumi, Trans.).

Minneapolis, Minnesota: University of Minnesota Press.

Certeau, M. (1988). The practice of everyday life. (S. Rendall, Trans.). Los Angeles, CA:

University of California Press. (Original work published 1974).

Cicourel, A. (1982). Interviews, surveys, and the problem of ecological validity. American Sociologist, 17(1), pp. 11-20.

Cicourel, A. (1985). Text and discourse. Annual Review of Anthropology, 14, pp. 159-185.

Coates, K. (1995). Canada's Hollywood: The Canadian state and feature films. [Review of the book Canada's Hollywood: The Canadian state and feature films]. Canadian Historical Review 72(2): 308-311.

Coe, R. M. (1988). Anglo-Canadian rhetoric and identity: A preface. College English, $50(8), 849-860$.

Cohen, J. (2006). Audience identification with media characters. In J. Bryant and P. Vorderer (Eds.), Psychology of Entertainment (183-198). New York: Routledge.

Conor, B. (2010). 'Everybody's a writer:' Theorizing screenwriting as creative labour. Journal of Screenwriting, 1(1), 27-43.

Cravetto, M.L. (2003). The emancipation of thought: On the work of Michel de Certeau. Diogenes, 50(3), 115-129.

Crofts, S. (1993). Reconceptualizing national cinema/s. Quarterly Review of Film and Video, 14(3), pp. 49-67.

Czach, L. (2004). Film festivals, programming, and the building of a national cinema. The Moving Image 4(1): pp. 76-88.

Dal, Y. J. (2011). A critical analysis of U.S. cultural policy in the global film market: Nation-states and FTAs. International Communication Gazette 73(8): 651-669 
Darabont, F. (2012) Screenwriting 101: Frank Darabont. In Go Into the Story.com.

Retrieved from https://gointothestory.blcklst.com/screenwriting-101-frank-darabont-

\section{$\underline{1856 f b b d e 804 \# .0 y e 5 p e a a x}$}

Davies, P. \& Mehan, H. (2007). Aaron Cicourel's contributions to language use, theory, method and measurement. Text \& Talk, 5(6), pp. 595-610.

Department of Canadian Heritage. (2000). From script to screen: New policy directions for Canadian feature film. Ottawa, ON: Minister of Public Works and Government Services Canada.

Department of Canadian Heritage. (2005). Scripts, screens and audiences: A new feature film policy for the 21st century. Ottawa, ON: Minister of Public Works and Government Services Canada. Retrieved from http://www.parl.gc.ca/HousePublications/Publication.aspx?DocId=2134619\&Mode $=1 \& \operatorname{Parl}=38 \& \operatorname{Ses}=1$

Dexter, L. (1970). Elite and specialized interviewing. Northwestern University Press; Evanston, IL.

Dobson, T., Michura, P., Ruecker, S., Brown, M. \& Rodriguez, O. (2011). Interactive visualizations of plot in fiction. Visible Language, 45(3), pp. 169-191.

Dorland, M. (1998). So close to the State/s: The emergence of Canadian feature film policy. Toronto, ON: University of Toronto Press.

Drew, D.J. \& Hardman, M.L. (1987). Designing and conducting behavioural research (2nd ed.). New York, N.Y.: Pergamon Press.

Druick, Z. (2007). Projecting Canada: Government policy and documentary film at the National Film Board of Canada. Montreal, PA: McGill-Queen's University Press. 
Dundes, A. (1968). Introduction. In V. Propp, Morphology of the folktale (pp. xi-xvii). Austin, Texas: University of Texas Press.

Ebert, R. (1999). The Red Violin. Roger Ebert.com. Retrieved from http://www.rogerebert.com/reviews/the-red-violin-1999

Elder, B. (1988). The cinema we need. In D. Fetherling (Ed.), Documents in Canadian Film (pp. 260-271). Peterborough, ON: Broadview Press.

Eisenberg, E.M. (1984). Ambiguity as strategy in organizational communication. Communication Monographs, 51(3), 227-242.

Feldman, S. (Ed.). (1984). Take two: A tribute to film in Canada. Toronto, ON: Irwin Press. Ferguson, Marjorie. (1993). Invisible divides: Communication and identity in Canada and the U.S., Journal of Communication, 43(2), 42-57.

Ferriss-Hill, J.L. (2015). Roman satire and the old comic tradition. New York, NY: Cambridge University Press.

Field, S. (1984). Screenplay: The foundations of screenwriting. New York: Bantam Dell. Field, S. (2006). The screenwriter's workbook. New York: Bantam Dell.

Field, S. (1989). Selling a screenplay: The screenwriter's guide to Hollywood. New York: Bantam Dell.

Fleming, M. (2016, May 13). Deadline disruptors: Max Landis is mad as hell \& changing screenwriting landscape. Deadline Hollywood. Retrieved from http://deadline.com/2016/05/max-landis-interview-bright-netflix-cannes-disruptor$\underline{1201752631 /}$ 
Fontana, A. \& Frey, J.H. (2005). The interview: From neutral stance to political involvement. In N.K. Denzin \& Y.S. Lincoln (Eds.), The Sage handbook of qualitative research ( $3^{\text {rd }}$ edition) (pp. 695-728). Thousand Oaks, CA: Sage Publications.

Freytag, G. (1900). Technique of the drama: An exposition of dramatic composition and art. Chicago, IL: Scott, Foresman and Company. Retrieved from https://archive.org/stream/freytagstechniqu00freyuoft\#page/n3/mode/2up

Froug, W. (1972). The screenwriter looks at the screenwriter. Los Angeles, CA: SilmanJames Press.

Frye, N. (1971). The bush garden: Essays on the Canadian imagination. Toronto: House of Anansi Press.

Ganz, A. (2010). Review of Screenwriting: History, Theory, and Practice, by Steven Maras. Journal of Screenwriting, 1(1), 203.

Gauthier, J. (2005). Where is here? Local visions in three Canadian films. Canadian Journal of Film Studies 14(2): pp. 38-53.

Gestrich, A. (2006). The public sphere and the Habermas debate. German History, 24(3), 413-430.

Giard, L. (1991). Michel de Certeau's Heterology and the New World. Representations, $33(1), 212-221$.

Gittings, Christopher E. (2002). Canadian national cinema: Ideology, difference and representation. New York, NY: Routledge.

Glaser, B.G. \& Strauss, A.L. (1967). The discovery of grounded theory: Strategies for qualitative research. Chicago: Aldine Atherton.

Gledhill, C. (1992). Speculations on the relationship between soap opera and melodrama. Quarterly Review of Film and Video, 14(1-2), 103-124. 
Grossberg, L. (1996). Identity and cultural studies: Is that all there is? in S. Hall \& P. du Gay (Eds.) Questions of cultural identity. London: SAGE Publications.

Goldman, W. (1989). Adventures in the screen trade: A personal view of Hollywood and screenwriting. New York: Warner Books.

Government of Canada (2012). Budget 2012. Retrieved from http://www.budget.gc.ca/2012/plan/anx1-eng.html.

Government of Canada (2000). From script to screen: New policy directions for Canadian feature film, Canadian Heritage. Retrieved from

\section{http://canada.pch.gc.ca/eng/1454338798386}

Gubrium, J.F. \& Holstein, J.A. (2002). From the individual interview to the interview society. In J.F. Gubrium \& J.A. Holstein (Eds.), Handbook of interview research: Context \& method (pp. 3-32). Thousand Oaks, CA: Sage Publications.

Hall, S. (1991). The local and the global: Globalization and ethnicity, in A. King (Ed.), Culture, Globalization and the World-System. London: Macmillan (19-39).

Harcourt, Peter. (1977). Movies and mythologies: Toward a national cinema. Toronto, ON: Canadian Broadcasting Corporation.

Harcourt, P. (2004). Speculations on Canadian cinema. Queen's Quarterly 111(2): 236249.

Henderson, B. (1978). Romantic comedy today: Semi-tough or impossible? Film Quarterly, 31(4), 11-23.

Henderson, D. (2011). Made in Canada: Cultural policy, cinema and the (re)ordering of priorities at Telefilm Canada. (Unpublished doctoral dissertation). University of Guelph: Guelph, ON. 
Hertig, S. \& Stein, L. (2007). The evolution of Luhmann's systems theory with focus on the constructivist influence. International Journal of General Systems, 36(1), 1-17.

Highmore, B. (2006). Michel de Certeau: Analyzing culture. London: Continuum.

Holstein, J.A. \& Gubrium, J.F. (1995). The active interview. Thousand Oaks, CA: Sage Publications.

Holt, Amanda. (2010). Using the telephone for narrative interviewing: a research note. Qualitative Research, 10, pp. 113-121.

Hunter, L. (1994). Screenwriting 434. New York: Penguin Group.

James, N. \& Busher, H. (2006). Credibility, authenticity and voice: dilemmas in online interviewing. Qualitative Research, 6, 403-420.

Jenkins, H. (1988). Star Trek rerun, reread, rewritten: Fan writing as textual poaching. Critical Studies in Mass Communication, 5, 85-107.

Jin, D. Y. (2011). A critical analysis of US cultural policy in the global film market: Nation-states and FTAs. International Communication Gazette 73(8): 651-669.

King, S. (2000). On writing. New York, N.Y.: Scribner.

Kmet, M. (2013, August 18). 'Breaking Bad': Product Placement and 'Quality” Television. MediaScape. Retrieved from http://www.tft.ucla.edu/mediascape/blog/?p=2036

Knodt, E. (1995). Foreword. In N. Luhmann, Social systems (pp. ix-xxxvi). Stanford, CA: Stanford University Press.

Knodt, E. (1994). Toward a non-foundationalist epistemology: The Habermas/Luhmann controversy revisited. New German Critique, 61(1), 77-100.

Kracauer, S. (1952-53). The challenge of qualitative content analysis. The Public Opinion Quarterly, 16(4); 631-642. 
Krippendorf, K. \& Bock, M.A. (2009). The content analysis reader. Thousand Oaks, CA: Sage Publications.

Lee, D. (2000). The society of society: The grand finale of Niklas Luhmann. Sociological Theory, 18(2), 320-330.

Leydesdorff, L. (1996). Luhmann's sociological theory: Its operationalization and future perspectives. Social Science Information, 35(2), 283-306

Loiselle, Andrew. (2006). Self portraits: The cinemas of Canada since Telefilm. Ottawa, ON: Canadian Film Institute.

Longfellow, B. (2006). Surfing the Toronto new wave: Policy, paradigm shifts and postnationalism. In A. Loiselle \& T. McSorley (Eds.), Self portraits: The cinemas of Canada since Telefilm (pp. 167-200). Ottawa, ON: Canadian Film Institute.

Lorimer, Rowland \& Duxbury, Nancy. (1994). Of culture, the economy, cultural production and cultural producers: An orientation. Canadian Journal of Communication, 19(3). Retrieved from http://cjconline.ca/index.php/journal/article/viewArticle/821/727

Lourenco, A. (2010). Autopoetic social systems theory: The co-evolution of law and the economy. Working paper No. 409. Cambridge, Centre for Business Research.

Lucey, P. (1996). Story sense: Writing story and script for feature films and television. New York: McGraw-Hill.

Luhmann, N. (2000). Art as a social system. (E. M. Knodt, Trans.). Stanford, CA: Stanford University Press.

Luhmann, N. (2006a). The autopoiesis of social systems. In D. Seidel \& K.H. Becker (Eds.), Niklas Luhmann and organization studies (pp. 64-84). Copenhagen; Copenhagen Business School Press. 
Luhmann, N. (2006). The concept of autopoiesis. In Seidl, D. and Becker, K.H. (Eds), Niklas Luhmann and Organization Studies (pp. 54-63). Liber \& Copenhagen Business School Press, Abingdon.

Luhmann, N. (1987). The medium of art. Thesis Eleven, 18/19, 101-113.

Luhmann, N. (1996). The reality of the mass media. Stanford, CA: Stanford University Press.

Luhmann, N. (1995). Social systems. Stanford, CA: Stanford University Press.

Luhmann, N. (2006c). System as difference. Organization, 13(1), 37-57.

Luhmann, N. (1985). The work of art and the self-reproduction of art. Thesis Eleven, 12, 427.

Macdonald, I. W. (2010). '...So it's not surprising I'm neurotic': The screenwriter and the screen idea work group. Journal of Screenwriting, 1(1), 45-58.

Magder, T. (1991). Canadian dreams and American control: The political economy of the Canadian film industry. Canadian Dimension, 25(6): 38.

Maras, S. (2009). Screenwriting: History, Theory and Practice. London: Wallflower.

Maras, S. (2011). Some Attitudes and Trajectories in Screenwriting Research. Journal of Screenwriting, 2(2), 275-286.

Mathijs, E. (2011). Referential acting and the ensemble cast. Screen, 52(1), 89-86.

Mathur, P. (2005). Neither cited nor foundational: Niklas Luhmann's Ecological

Communication; A critical exegesis and some theoretical suggestions for the future of a field. The Communication Review, 8(3), 329-362.

McBride, J. (2012). Writing in pictures: Screenwriting made (mostly) painless. Toronto: Random House. 
McIntosh, D. (2008). Waiting for Hollywood: Canada's maquila film industry. Canadian Dimension 42(6): 21-24.

McKee, R. (1997). Story: Substance, structure, style and the principles of screenwriting. New York: Regan Books.

McSorley, T. (2002). The apprenticeship of Duddy Kravitz, or the anxiety of influence. In G. Walz (Ed.), Canada's best features: Critical essays on 15 Canadian films (pp. 5171). New York: Rodopi.

Meagher, S. (2007). Philosophy in the streets: Walking the city with Engels and de Certeau.

City, 11(1), 7-20. Retrieved from http://dx.doi.org/10.1080/1360481070120072

Melnyk, G. (2014). Film and the city: The urban imaginary in Canadian cinema. Edmonton, AB: AU Press.

Melnyk, G. (2010). The gendered screen: Canadian women filmmakers. Waterloo, ON: Wilfred Laurier University Press.

Melnyk, G. (2004). One hundred years of Canadian cinema. Toronto, ON: University of Toronto Press.

Michaels, O. (2009). Expanded screen writing, expansive cinema. Real Time, 91, 28.

Millard, K. (2010). After the typewriter: the screenplay in a digital era. Journal of Screenwriting, 1(1); 11-25.

Miller, M. (1994). Intersystemic discourse and co-ordinated dissent: A critique of Luhmann's concept of ecological communication. Theory, Culture \& Society, 11(2), 101-121.

Miyamoto, K. (2015, October 15). How much do screenwriters really make? Screencraft: The craft of screenwriting, the business of Hollywood. Retrieved from https://screencraft.org/2015/10/15/how-much-do-screenwriters-really-make/ 
Moeller, H.-G. (2006). What is social systems theory? In H.-G. Moeller, Luhmann explained: From souls to systems. Chicago, IL: Open Court Publishing.

Morris, P. (1978). Embattled shadows: A history of Canadian cinema. Montreal, PA: McGill-Queen's University Press.

Nannicelli, T. (2011). Towards a philosophy of the screenplay (Doctoral dissertation). Retrieved from Proquest, U578448

Neale, S. (1992). The Big romance or Something Wild? Romantic comedy today. Screen, 33(3), 284-299.

Nelmes, J. (2011). Realism and Screenplay Dialogue, in J. Nelmes (ed.), Analysing the Screenplay. London: Routledge, 217-236.

Nelson, J. (1988). The colonized eye: Rethinking the Grierson legend. Toronto, ON: Between the Lines.

Neufeldt, A., Watzke, J., Birch, G. \& Buchner, D. (2007). Engaging the business/industrial sector in accessibility research: Lessons in bridge building. The Information Society, 23(3), 169-181.

Neuman, W.L. (1991). Social research methods. Needham Heights, MA: Simon \& Schuster.

Parker, I. (2003, October 20). The real McKee: Lessons of a screenwriting guru. New Yorker. Retrieved from http://www.newyorker.com/magazine/2003/10/20/the-real$\underline{\text { mckee }}$

Pelo, R. (2010). Tonino Guerra: the screenwriter as a narrative technician or as a poet of images? Authorship and method in the writer-director relationship. Journal of Screenwriting, 1(1), 113-129. 
Pendakur, M. (1990). Canadian dreams and American control: The political economy of the Canadian film industry. Toronto, ON: Broadview Press.

Perlmutter, T. (1989). Trespassed territory. Cinema Canada: April-May 1989, pp. 13-14.

Pike, D. L. (2002). Canadian cinema in the age of globalization. Cineaction 57: 2-10.

Platt, J. (2002). The history of the interview. In J.F. Gubrium \& J.A. Holstein (Eds.), Handbook of interview research: Context \& method (pp. 33-54). Thousand Oaks, CA: Sage Publications.

Podak, K. (1986). Without subject, without reason: Reflections on Niklas Luhmann's Social Systems. Trans. David Roberts. Thesis Eleven, 13(1), 54-66.

Powdermaker, H. (1951). Hollywood: The dream factory. An anthropologist looks at the movie makers. London: Secker \& Warburg.

Price, S. (2010). The screenplay: Authorship, theory and criticism. Basingstoke: Palgrave Macmillan.

Producers Guild of America. (n.d.) Code of Credits — New Media. Producers Guild of America. Retrieved from http://www.producersguild.org/?page=coc_nm\#transmedia

Rabinow, P. (2008). Marking time: On the anthropology of the contemporary. Princeton, N.J.: Princeton University Press.

Ramsay, C. (2002a). Introduction. In G. Walz (Ed.), Canada's best features: Critical essays on 15 Canadian films (pp. xi-xxxv). New York: Rodopi.

Ramsay, C. (2002b). Canadian narrative cinema from the margins: 'The nation' and masculinity in Goin' down the road'. In G. Walz (Ed.), Canada's best features: Critical essays on 15 Canadian films (pp. 3-24). New York: Rodopi.

Rapley, T.J. (2001). The art(fulness) of open-ended interviewing: some considerations on analyzing interviews. Qualitative Research, 1(3), pp. 302-323. 
Rosenkranz, R.H.C. (2011). Designing viable social systems. Kybernetes, 40(3/4), 559-580.

Russell, C. (2002). Role playing and the white male imaginary in Atom Egoyan's Exotica. In G. Walz (Ed.), Canada's best features: Critical essays on 15 Canadian films (pp. 321-339). New York: Rodopi.

Sautter, C. (1992). How to sell your screenplay: The real rules of film and television. Pound Ridge, NY: New Chapter Books.

Schiltz, M. (2007). Space is the place: The laws of form and social systems. Thesis Eleven, $88,8-30$.

Scott, S. (2004). Researching shyness: A contradiction in terms? Qualitative Research, 4(1), pp. 91-105.

Seidl, D. (2004). Luhmann's theory of autopoeitic social systems. Munich: Munich Business Research.

Seidl, D. \& Becker, K.H. (2006). Organizations as distinction generating and processing systems: Niklas Luhmann's contribution to organization studies. Organization, 13(1); 9-35.

Seale, C. (2004). History of qualitative methods. In Clive Seale, (Ed.), Researching society and culture (pp. 100-113). London, Eng.: Sage Publications.

Seale, C. (2004). Quality in qualitative research. In C. Seale, G. Gobo, J.F. Gubrium \& D. Silverman (Eds.), Qualitative research practice (pp. 409-419). Thousand Oaks, CA: Sage Publications.

Seger, L. (2010). Making a good script great. Los Angeles: Silman-James. Seguin, D. (2004, August 16-29). The 5\% problem. Canadian Business, 77, 10. Sheldrake, P. (2001). Unending desire: de Certeau's 'mystics'. Way Supplement, 102; 3848. 
Silverman, D. (2001). Interpreting qualitative data: Methods for analyzing talk, text and interaction ( $2^{\text {nd }}$ edition). Thousand Oaks, CA: Sage Publications.

Staiger, J. (1985). The politics of film canons. Cinema Journal 24(3): 4-23.

Sternberg, C. (1997). Written for the screen: The American motion-picture screenplay as text. Tubingen: Stauffenburg.

Sternberg, C. (2014). Written to be read: A personal reflection on screenwriting research, then and now. Journal of Screenwriting, 5(2), 199-208.

Stichweh, Rudolf. (2011). Niklas Luhmann. In G. Ritzer and J. Stepnisky (Eds.), The Wiley-Blackwell Companion to Major Social Theorists: Classical Social Theorists, Volume 1 (pp. 287-309). Oxford: Wiley-Blackwell.

Straw, W. (2002). Dilemmas of definition. In Nicks and Sloniowski (Eds.) Slippery pastimes: reading the popular in Canadian culture (pp. 95-108). Waterloo, ON: Wilfrid Laurier University Press.

Straw, W. (2002). Reinhabiting lost languages: Guy Maddin's Careful. In G. Walz (Ed.), Canada's best features: Critical essays on 15 Canadian films (pp. 305-317). New York: Rodopi.

Sturges, J.E. \& Hanrahan, K.J. (2004). Comparing telephone and face-to-face qualitative interviews: A research note. Qualitative Research, 4, 107-118.

Taylor, A. (2003). Blood in the maple syrup: Canon, popular genre and the Canuxploitation of Julian Roffman. Cineaction 61, 18-28.

Telefilm Canada. (2011). Fostering cultural success: Telefilm Canada's corporate plan, 2011-2012/2014-2015. Retrieved from http://www.telefilm.ca/document/en/01/17/Telefilm-Canada-corporate-plan-20112014.pdf 
Telefilm Canada. (2015). Inspired by talent. Viewed everywhere: 2015-2018 strategic plan. Retrieved from http://www.telefilm.ca/document/en/01/17/Telefilm_Canada_Strategic_Plan-2015$\underline{18 . p d f}$

Telefilm Canada. (2012). Telefilm Canada announces the launch of a new private donation fund, with support from the Canadian Chamber of Commerce [Press release]. Retrieved from http://www.telefilm.ca/en/news/releases/2012/03/02/telefilm-canada-announceslaunch-new-private-donation-fund-support-canadian

Telefilm Canada. (2002). Telefilm Canada provides funding for Mambo Italiano [Press release]. Retrieved from http://www.telefilm.ca/en/news/releases/2002/07/17/canadafeature-film-fund-telefilm-canada-provides-funding-mambo-italiano-la

Telefilm Canada. (2007). 2006-2007 annual report. Montreal, PQ: Telefilm Canada.

Telefilm Canada. (2007). 2010-2011 annual report. Retrieved from http://www.telefilm.ca/rapport-annuel/2010-2011/en/messages.php

"theme." Merriam Webster's Encyclopedia of Literature, Merriam-Webster, 1995. Academic OneFile, go.galegroup.com/ps/i.do?p=AONE\&sw=w\&u=ucalgary \&v=2.1\&id=GALE\% 7CA148 924034\&it=r\&asid=98f7d627555331623025ad0122f90af8. Accessed 26 Nov. 2016.

“theme." Oxford dictionary of literary terms, (4th ed.), 2015. DOI:

10.1093/acref/9780198715443.001.0001

Trottier, D. (1998). The screenwriter's bible: A complete guide to writing, formatting, and selling your script. Los Angeles: Silman-James Press.

Truby. J. (2007). The anatomy of story: 22 steps to becoming a master storyteller. London, U.K.: Faber and Faber. 
Truby, J. (2012, October 19). Why most people fail at screenwriting. Film Courage.

Retrieved from https://www.youtube.com/watch?v=CDKLuUfKYHQ

UNESCO. (2005). Convention on the protection and promotion of the diversity of cultural expressions. Retrieved from http://portal.unesco.org/en/ev.php$\underline{\text { URL_ID=31038\&URL_DO=DO_TOPIC\&URL_SECTION=201.html }}$

Urquhart, P. (2004). 1979: Reading the tax-shelter boom in Canadian film history. Montreal, PQ: McGill-Queen's University Press.

Urry, J. (2005). The complexity turn. Theory, Culture \& Society, 22(5), 1-14.

Varga, D. (2008). Rain/drizzlelfog: Film and television in Atlantic Canada. Calgary, AB: University of Calgary Press.

Vermeulen, T. \& van den Akke, R. (2010). Notes on metamodernism. Journal of Aesthetics \& Culture, 2. Retrieved November 14, 2012, from http://www.aestheticsandculture.net/index.php/jac/article/view/5677/6306

Viskovatoff, A. (1999). Foundations of Niklas Luhmann's theory of social systems. Philosophy of the Social Sciences, 29(4), 481-516.

Vitali, V., \& Willemen, P. (Eds.). (2006). Theorising national cinema. London: British Film Institute.

Walter, R. (1988). Screenwriting: The art, craft and business of film and television writing. New York: Plume Books.

Whissel, K. (2008). Picturing American modernity: Traffic, technology, and the silent cinema. London: Duke University Press.

Whitcomb, C. (2002). Writer's guide to selling your screenplay. Waukesha, WI: Kalmback Publishing. 
Wiley, D.E. (1991). Test validity and invalidity reconsidered. In R.E. Snow \& D.E. Wiley (Eds.), Improving inquiry in social science: A volume in honour of Lee J. Cronbach (pp. 75-107). Hillsdale, N.J.: Lawrence Erlbaum Associates.

Wood, R. (1989). Hitchcock's Films Revisited. New York: Columbia University Press.

Writers Guild of America. (2010). Screen credits manual. Retrieved from http://www.wga.org/subpage writersresources.aspx $? \mathrm{id}=167$

Zolo, D. (1986). Function, meaning, complexity: The epistemological premises of Niklas Luhmann's 'sociological enlightenment.' Philosophy of the Social Sciences, 16(1), 115127. 


\section{Appendix A: Interview template}

1. How were you educated/did you educate yourself in the ways of screenwriting?

2. What is the importance of the three-act structure in your work?

3. What is the importance of the character arc in your work?

4. How about closure -- do you believe that there has to be irreversible change at the end of a film for it to work (as Robert McKee suggests)?

5. Do you think that screenplays must follow narrative conventional logic (cause and effect)?

6. On Telefilm: how useful have their notes been?

7. On producers: how useful are their notes? 